\title{
TEACHING SOCIAL \\ JUSTICE THROUGH SHAKESPEARE
}

Why Renaissance Literature Matters Now

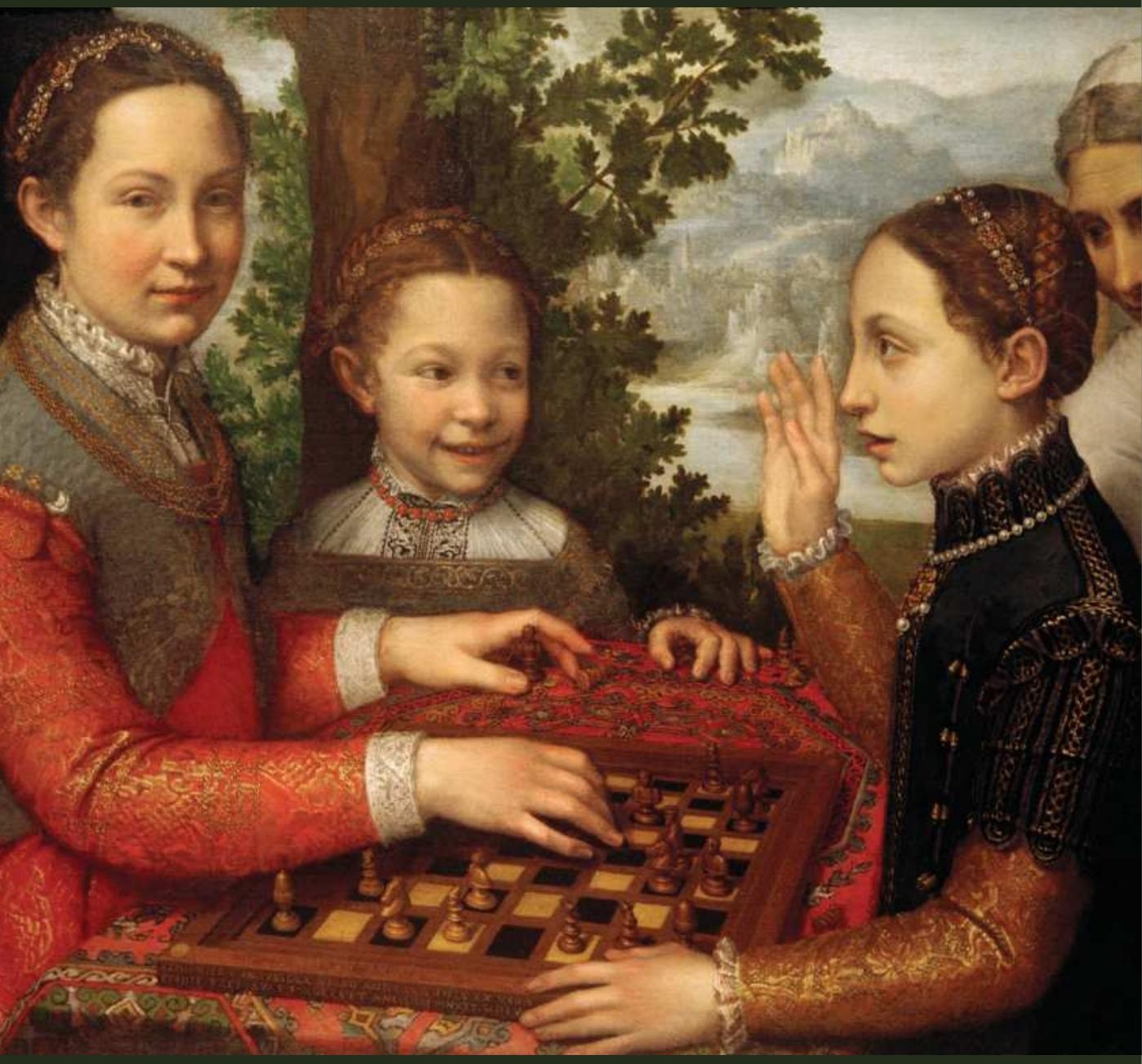

Edited by Hillary Eklund and Wendy Beth Hyman 


\section{Teaching Social Justice Through Shakespeare}





\section{Teaching Social Justice Through Shakespeare}

Why Renaissance Literature Matters Now

Edited by Hillary Eklund and

Wendy Beth Hyman 
Edinburgh University Press is one of the leading university presses in the UK. We publish academic books and journals in our selected subject areas across the humanities and social sciences, combining cutting-edge scholarship with high editorial and production values to produce academic works of lasting importance. For more information visit our website: edinburghuniversitypress.com

(C) editorial matter and organisation Hillary Eklund and Wendy Beth Hyman, 2019

(C) the chapters their several authors, 2019

Edinburgh University Press Ltd

The Tun - Holyrood Road, 12(2f) Jackson's Entry, Edinburgh EH8 8PJ

Typeset in Sabon and Futura by R. J. Fooring Ltd, Derby, UK, and printed and bound in Great Britain.

A CIP record for this book is available from the British Library

ISBN 9781474455589 (hardback)

ISBN 9781474455602 (webready PDF)

ISBN 9781474455619 (epub)

The right of the contributors to be identified as the author of this work has been asserted in accordance with the Copyright, Designs and Patents Act 1988, and the Copyright and Related Rights Regulations 2003 (SI No. 2498). 


\section{Contents}

Acknowledgments

Notes on the Contributors

viii

ix

Introduction: Making Meaning and Doing Justice with Early

Modern Texts

Wendy Beth Hyman and Hillary Eklund

\section{Defamiliarizing Shakespeare}

1. Topical Shakespeare and the Urgency of Ambiguity Adhaar Noor Desai

2. Shakespeare in Transition: Pedagogies of Transgender Justice and Performance

Sawyer Kemp

3. Shakespeare in Japan: Disability and a Pedagogy of

Disorientation

Allison P. Hobgood

4. Global Performance and Local Reception: Teaching Hamlet and More in Singapore

Emily Griffiths Jones

\section{Decolonizing Shakespeare}

5. African-American Shakespeares: Loving Blackness as Political Resistance Jason M. Demeter

6. Chicano Shakespeare: The Bard, the Border, and the Peripheries of Performance 
7. "Intelligently organized resistance": Shakespeare in the Diasporic Politics of John E. Bruce

Kim F. Hall

\section{Ethical Queries and Practices}

8. Sexual Violence, Trigger Warnings, and the Early Modern Classroom Kirsten N. Mendoza

9. Rural Shakespeare and the Tragedy of Education Jeffrey Osborne

10. Shakespearean Tragedy, Ethics, and Social Justice Mary Janell Metzger

11. Teaching Environmental Justice and Early Modern Texts: Collaboration and Connected Classrooms

Rebecca Laroche and Jennifer Munroe

12. Failing with Shakespeare: Political Pedagogy in Trump's America

Steve Mentz

IV. Revitalizing the Archive and Remixing Traditional Approaches

13. Teaching Serial with Shakespeare: Using Rhetoric to Resist Rachel E. Holmes

14. Adjunct Pleasure: Shakespeare's Sonnets and the Writing on the Walls

Matthew Harrison

15. Confronting Bias and Identifying Facts: Teaching Resistance Through Shakespeare

Carla Della Gatta

16. Literary Justice: The Participatory Ethics of Early Modern Possible Worlds Debapriya Sarkar

\section{Shakespeare, Service, and Community}

17. Shakespeare, Service Learning, and the Embattled Humanities 187 Hillary Eklund 
18. Teaching Shakespeare Inside Out: Creating a Dialogue Between Traditional and Incarcerated Students Jayme M. Yeo

19. “'Shakespeare' on his lips": Dreaming of the Shakespeare Center for Radical Thought and Transformative Action Eric L. De Barros

20. From Pansophia to Public Humanities: Connecting Past and Present Through Community-Based Learning

Tania Boster

21. Cultivating Critical Content Knowledge: Early Modern Literature, Pre-service Teachers, and New Methodologies for Social Justice

Todd Butler and Ashley Boyd

An Afterword About Self/Communal Care

Ayanna Thompson

Bibliography

Index 


\section{Acknowledgments}

Our first thanks go to each other and to the contributors, with whom it has been our sincere honor and pleasure to work. Ayanna Thompson has generously supported this project from the start, not only writing the Afterword, but also first putting us in touch with several of our contributors. We would like the thank the Shakespeare Association of America for making room for conversations whose fuller expressions have found their way onto these pages, and the countless colleagues and several editors we chatted with as this project took shape. Carla Mazzio, Jeffrey Cohen, and David Lee Miller provided invaluable feedback, as did two anonymous reviewers. We thank them, and our wonderful editor Michelle Houston, for their time and expertise.

To our students, whose commitment to making the world a more just place has inspired this project, we extend our deepest gratitude. Special thanks to interns Eva Garcia and Leah Shain, who provided indispensable help in assembling the typescript.

Hillary would like to thank Maria Calzada and John Biguenet for supporting this project, Kelly Brotzman, Ashley Howard, and Jennifer Jeanfreau for insightful comments on early drafts, and Greg Larsen for his steady support and replenishing company.

Wendy would like to thank Oberlin College for grant-in-aid support, Sandra Young and Chris Thurman for the Shakespeare and Social Justice Conference in Cape Town, Elizabeth Hamilton for her encouraging feedback on the Introduction, Rian Brown Orso for friendship and inspiration, and Eric Matthew Laferty for everything. 


\section{Notes on the Contributors}

Tania Boster is Executive Director of Integrative and Experiential Learning and Assistant Professor of History at Oberlin College. She teaches courses in which students use traditional historical methods, community-based participatory research, and digital tools to advance community-expressed goals in local, national, and global contexts.

Ashley Boyd is Associate Professor of English Education at Washington State University. Her forthcoming book Survive and Subvert: Social Justice in the Secondary English Classroom (Teachers College Press) analyzes case studies to identify specific pedagogic approaches for advancing equity both inside and outside the classroom. She has published in the Teacher Education Quarterly, Educational Studies, the International Journal of Critical Pedagogy, and the ALAN Review.

Todd Butler is Associate Professor of English and Associate Dean for Faculty in the College of Arts and Sciences at Washington State University. He is the author of two books, the more recent of which is Literature and Political Intellection in Early Stuart England (Oxford University Press, 2019), as well as nearly twenty articles. At Washington State University he serves on the programming committee for the campus Multicultural Center, leads the "Advancing Opportunity and Equity" initiative, and serves on an interdisciplinary research task force on minority health.

Eric L. De Barros is Assistant Professor of English in Early Modern British Literature and Culture at Old Dominion University. His research centers on the politics of embodied subjectivity in early modern literary and educational texts. He has authored several articles, and his main book project, with the working title "Shakespeare and the 
Pedagogy of Sexual Violence," endeavors to rethink Shakespeare as a socially and politically responsive educational theorist with much to teach us about the role of education in combatting sexual violence in present-day society.

Carla Della Gatta is Assistant Professor of English at Florida State University. She specializes in theatrical constructions of race and ethnicity. She serves on the Steering Committee for the Latinx Theatre Commons. In 2016, she received the J. Leeds Barroll Dissertation Prize from the Shakespeare Association of America. She is completing her first monograph, tentatively titled "Shakespeare and Latinidad: The Staging of Intracultural Theatre.”

Jason M. Demeter is Assistant Professor of English at Norfolk State University. He specializes in Shakespeare, early modern race studies, critical race theory, and twentieth-century African-American literature and culture. His current book project considers manifestations of Shakespeare within American civil rights, black power, and black arts discourses of the 1960s and 1970s. He has published essays in the Journal of Narrative Theory and The Shakespearean International Yearbook, and in various edited collections.

Adhaar Noor Desai is Assistant Professor of Literature at Bard College, where he teaches courses on Shakespeare and Renaissance poetry. He is completing his first monograph with the aid of fellowships from the Folger Shakespeare Library and the Huntington Library. The book, tentatively titled "The Poetics of Hesitation," examines how the vagaries and anxieties of the writing process, from composition to transmission, became grounds for poets and playwrights to address the multiple and often contradictory currents of early modern political, religious, and scientific thought. His work has appeared or is forthcoming in Configurations, Philological Quarterly, the Shakespeare Newsletter, and Marginalia: The Los Angeles Review of Books.

Hillary Eklund is Provost Distinguished Professor, Associate Professor of English, and Department Chair at Loyola University New Orleans. Working at a Jesuit university has encouraged her to find ways of linking early modern literary texts to matters of social justice relevant to students' lives now. This work has shaped her approach to curriculum design and led to successful experiments with service learning and other forms of community engagement. She is the author of Literature and Moral Economy in the Early Modern Atlantic: Elegant Sufficiencies 
(Ashgate, 2015) and editor of Ground-Work: English Renaissance Literature and Soil Science (Penn State University Press, 2017). Her current book project is "The Unfast Imagination: Reading Early Modern Wetlands.”

Ruben Espinosa is Associate Professor of English at the University of Texas at El Paso, where he specializes in Shakespeare and early modern literature. $\mathrm{He}$ is the author of Masculinity and Marian Efficacy in Shakespeare's England (Ashgate, 2011) and co-editor of Shakespeare and Immigration (Routledge, 2014), a collection of essays exploring the role of immigrants, exiles, and refugees in Shakespeare's England and work. He has published essays in Shakespeare Quarterly, Explorations in Renaissance Culture, and Literature Compass. He is currently at work on a second monograph, "Shakespeare on the Border: Language, Legitimacy, and La Frontera.”

Kim F. Hall is the Lucyle Hook Professor of English and Professor of Africana Studies at Barnard College. Her research and teaching cover Renaissance/early modern literature and culture, critical race theory, black feminist studies, slavery studies, visual culture, food studies, and digital humanities. She is the author of Things of Darkness: Economies of Race and Gender in Early Modern England (Cornell University Press, 1996) and Othello: Texts and Contexts (Bedford/St. Martin's Press, 2006). She co-edited, with Peter Erickson, a special issue of Shakespeare Quarterly on early modern race studies, and her work has appeared in numerous journals and collections.

Matthew Harrison is the Wendy and Stanley Marsh 3 Assistant Professor of Shakespeare Studies at West Texas A\&M University. His forthcoming book, tentatively titled Tear Him For His Bad Verses, explores the rhetoric of bad poetry in early modern England, along with the self-deprecation, failures, and errors that poets and playwrights use to describe the craft of writing. He has recently published on new media and the tradition of rearranging Shakespeare's Sonnets, on the "layered temporality" of poetic reception, on the "glitch" as a mode of reading poetic failure, and (with Michael Lutz) on video game adaptations of Hamlet.

Allison P. Hobgood is Associate Professor of English and Women's and Gender Studies at Willamette University. She is the author of Passionate Playgoing in Early Modern England (Cambridge University Press, 2014), co-editor of Recovering Disability in Early Modern England (Ohio State University Press, 2013) and "Disabled Shakespeares" (a special section 
of Disability Studies Quarterly, 2009), and editor of a special issue on disability, care work, and teaching in the journal Pedagogy (2015). Her other essays have appeared in venues such as Shakespeare Bulletin, Textual Practice, Shakespearean Sensations, Disability, Health, and Happiness in the Shakespearean Body, and The Cambridge Companion to Literature and Disability. She is currently completing a second monograph, "Beholding Disability in the English Renaissance."

Rachel E. Holmes is currently a Teaching Fellow in Shakespeare and Renaissance Literature at University College London. Between 2015 and 2018, she was a Research Associate at CRASSH and the Faculty of English at the University of Cambridge and a Junior Research Fellow at Wolfson College. She co-edited In Pursuit of Truth: Law and Emotion in Early Modern Europe, a special issue of Forum for Modern Language Studies (January 2018). She is series co-editor of Crossroads of Knowledge in Early Modern Literature (Palgrave). Her work appears in Studies in Philology, Forum for Modern Language Studies, and various edited collections. She is currently revising for publication a monograph on clandestine contracts in early modern European law and literature.

Wendy Beth Hyman is Associate Professor of English and Comparative Literature at Oberlin College. She received her M.A. and Ph.D. from Harvard University, and her B.A. at Smith College. She is the author of Impossible Desire and the Limits of Knowledge in Renaissance Poetry (Oxford University Press, 2019), and editor of The Automaton in English Renaissance Literature (Ashgate, 2011). She has published on early modern mechanical birds, Spenser's The Faerie Queene, the influence of insect poetry on early microscopy, physics and metaphysics in early modern lyric, jacquemarts and Shakespeare's Jack Falstaff, Nashe's Unfortunate Traveller, metaphors in early modern science, and book history in liberal arts colleges.

Emily Griffiths Jones is Assistant Professor of English at the University of South Florida, where she teaches Milton, Shakespeare, and women Renaissance writers. As a postdoctoral associate at MIT, she helped create an online teaching module on Hamlet for the MIT Global Shakespeares project, and piloted the module at MIT's sister institution, the Singapore University of Technology and Design. She has published articles in SEL, Shakespeare Studies, Studies in Philology, and Huntington Library Quarterly. She is working on a book manuscript about romance, religion, and politics in seventeenth-century England; and developing a digital tool for visualizing the romance 
landscape of Spenser's Faerie Queene. Her first book, provisionally titled "Right Romance: Heroic Subjectivity and Elect Community in Seventeenth-Century England," is under contract with Penn State University Press.

Sawyer Kemp is a doctoral candidate in English at the University of California, Davis, where they study early modern drama and performance. Their dissertation investigates the rhetoric and practices that construct "accessibility" in contemporary Shakespeare performance. Their first article, co-authored with mentor Gina Bloom, appeared in Shakespeare Quarterly, and their work on transgender representation in Shakespeare is forthcoming in Shakespeare Studies and the Journal of Early Modern Cultural Studies. They are also the co-founder of Skip Theory, a theater company in Sacramento with a commitment to diverse and gender-inclusive casting and storytelling practices.

Rebecca Laroche is Professor of English at the University of Colorado, Colorado Springs. She has published on Shakespeare, early modern women's writing, medical history, and ecofeminism. She is the author of Medical Authority and Englishwomen's Herbal Texts, 1550-1650 (CRC Press, 2016) and co-editor (with Jennifer Munroe) of Ecofeminist Approaches to Early Modernity (Palgrave Macmillan, 2011). In 2011, she was the guest curator of the exhibition "Beyond Home Remedy: Women, Medicine, and Science" at the Folger Shakespeare Library. Most recently, her book Shakespeare and Ecofeminist Theory (co-authored with Jennifer Munroe; Bloomsbury, 2017) has appeared in the Arden Shakespeare and Theory series. She is a founding and present member of the Early Modern Recipes Online Collective (EMROC), an international digital humanities project.

Kirsten N. Mendoza is Assistant Professor of English and Human Rights at the University of Dayton. Her work, which focuses on English early modern drama and literature, race studies in a global early modernity, gender, sexuality, and contract theory, has been supported with grants from the Huntington Library, Folger Shakespeare Library, and the American Council of Learned Societies. She is currently working on a book that interrogates Renaissance paradigms of race in theatrical scenes of coercion and consent. She is also co-editor of a digital edition of the John Ward Diary, owned by the Folger Shakespeare Library. She is passionate about connecting early modern works to our contemporary moment through courses such as "Shakespeare and the Construction of Difference" and "The Politics of Rape in Early Modern England." 
Steve Mentz teaches Shakespeare, literary theory, and maritime literature and culture with a focus on the environmental humanities at St. John's University. He is author of three books, Shipwreck Modernity: Ecologies of Globalization 1550-1719 (University of Minnesota Press, 2015), At the Bottom of Shakespeare's Ocean (Bloomsbury, 2009), and Romance for Sale in Early Modern England: The Rise of Prose Fiction (Ashgate, 2006), and editor or co-editor of four collections, The Sea in Nineteenth-Century Anglophone Literary Culture (Routledge, 2017), Oceanic New York (Punctum, 2015), The Age of Thomas Nashe (Ashgate, 2014), and Rogues and Early Modern English Culture (University of Michigan Press, 2004). He has published numerous articles on Shakespeare, ecological criticism, maritime culture, the history of the book, and related topics.

Mary Janell Metzger is Professor of English at Western Washington University. There she teaches and writes about early modern and contemporary literature, pedagogy, and feminist and queer issues. She is the author of Shakespeare Without Fear: Teaching for Understanding (Heinemann, 2004) and numerous essays on literature and pedagogy. Her most recent works include "Epistemic Injustice and The Rape of Lucrece" (Mosaic, 2016) and "It is a reeling world indeed': Teaching Richard III as a Skeptical Text Through Montaigne" in Approaches to Teaching Shakespeare's English History Plays (MLA, 2017).

Jennifer Munroe is Professor of English at the University of North Carolina at Charlotte. She is co-author (with Rebecca Laroche) of Shakespeare and Ecofeminist Theory (Bloomsbury/Arden, 2017), author of Gender and the Garden in Early Modern English Literature (Ashgate, 2008), and editor of Making Gardens of Their Own (Ashgate, 2007). She is co-editor (with Rebecca Laroche) of Ecofeminist Approaches to Early Modernity (Palgrave Macmillan, 2011); and with Lynne Bruckner and Edward J. Geisweidt of Ecological Approaches to Early Modern Texts: A Field Guide to Reading and Teaching (Ashgate, 2015). Her current project is an ecofeminist literary history of science that examines the relationship between knowledge-making practices, nature, and writing in seventeenth-century England.

Jeffrey Osborne is Professor of English at Murray State University. His work on early American literature and culture has appeared in Early American Literature, Literature and History, Orbis Litterarum, and American Studies Journal. 
Debapriya Sarkar is Assistant Professor of English and Maritime Studies at the University of Connecticut. She is writing a book entitled "Possible Knowledge: The Literary Forms of Early Modern Science" and co-editing, with Jenny C. Mann, a special issue of Philological Quarterly called "Imagining Early Modern Scientific Forms." Her work appears or is forthcoming in A Cultural History of the Sea in the Renaissance, Shakespeare Studies, Spenser Studies, Exemplaria: A Journal of Theory in Medieval and Renaissance Studies, Macbeth: The State of Play (Arden), and Object-Oriented Environs. Her work has been supported by an NEH/ Folger Shakespeare Library Long-Term Fellowship (2016-17), and she received the J. Leeds Barroll Dissertation Prize from the Shakespeare Association of America in 2015.

Ayanna Thompson is Director of the Arizona Center for Medieval and Renaissance Studies (ACMRS) at Arizona State University. She is the author of Shakespeare in the Theatre: Peter Sellars (Arden Bloomsbury, 2018), Teaching Shakespeare with Purpose: A Student-Centred Approac" (Arden Bloomsbury, 2016), Passing Strange: Shakespeare, Race, and Contemporary America (Oxford University Press, 2011), and Performing Race and Torture on the Early Modern Stage (Routledge, 2008). She wrote the new introduction for the revised Arden3 Othello (Arden, 2016), and is the editor of Weyward Macbeth: Intersections of Race and Performance (Palgrave, 2010) and Colorblind Shakespeare: New Perspectives on Race and Performance (Routledge, 2006). She is currently working on a collection of essays for Cambridge University Press on Shakespeare and race, and is collaborating with Curtis Perry for a new edition of Titus Andronicus. Professor Thompson is the 2018-19 President of the Shakespeare Association of America, and has served as a member of the board of directors for the Association of Marshall Scholars. She was one of Phi Beta Kappa's Visiting Scholars for 2017-18.

Jayme M. Yeo is Associate Professor at Belmont University in Nashville, Tennessee. Her work centers on affective reading communities and early modern literature, as well as Shakespeare and community-based learning. Her articles have appeared in Intersections: Yearbook for Early Modern Studies, Literature and Theology, Exemplaria, and Teaching Theology and Religion. Her current manuscript, "Imagining Unity: The Politics of Transcendence in Donne, Lanyer, Crashaw, and Milton," investigates religious affect in seventeenth-century poetry. 



\section{Introduction: Making Meaning and Doing Justice with Early Modern Texts}

Wendy Beth Hyman and Hillary Eklund

[Poetry's end is] well-doing and not . . well-knowing only. ${ }^{1}$

Formal innovation (of the sort that matters in literature) is a testing of the operations of meaning, and is therefore a kind of ethical experimentation. To respond to the demand of the literary work as the demand of the other is to attend to it as a unique event whose happening is a call, a challenge, an obligation: understand how little you understand me, translate my untranslatability, learn me by heart and thus learn the otherness that inhabits the heart. ${ }^{2}$

On January 22, 2017, in a "Meet the Press" interview that soon became infamous, Donald Trump's advisor Kellyanne Conway defended the exaggerated claims made by White House Press Secretary Sean Spicer about attendance numbers at Trump's presidential inauguration. According to Spicer, "This was the largest audience to ever witness an inauguration-period-both in person and around the globe." ${ }^{3}$ Given the chance to correct Spicer's exaggeration or supplant it with a less blatantly fraudulent form of presidential praise, Conway made the curious choice to double down on error, positing Spicer's claim as an "alternative fact." What universe was this? As citizens and journalists alike struggled to make sense of the prevarication, an answer soon emerged: it was a universe composed, to alarming degree, of these and other "alternative facts." 4 A new Orwellian era dawned, one poised to distort not only interpretation, but also memory-one in which history risked being not only difficult to understand but also increasingly difficult to recover.

The political lie, of course, is nothing new, even if it was never before delivered by such an unblinking propagandist. Conway's and Spicer's staggering adherence to information so demonstrably falsifiable, however, is new, and it bespeaks the emergence of a still-darker corollary 
trend-a corrosive distrust of the sectors of our society devoted to the pursuit of knowledge. Where a class-conscious earlier generation might have identified "bosses" as antagonistic to their freedom and self-determination, that reviled position seems now to be occupied by "experts," including researchers and educators. Informed dialogue in the United States is increasingly imperiled: replaced by ideological extremism, motivated reasoning, and vitriol. Increasingly, these trends are emerging with equal force in Europe, South America, and beyond.

This political climate has newly mobilized many within academia, both in the United States, where we reside, and among our colleagues around the globe. Beyond merely learning to identify quality refereed journals, students must now learn how to distinguish real from "fake news," facts from "alternative facts," legitimate experts from charismatic ideologues, diploma mills from reputable institutions. College campuses, like abortion clinics or political organizations, have been subject to new forms of subterfuge, secret recordings, and professor watch lists. Marching for science has become a radical act. In this cultural climate, helping our students evaluate evidence, parse rhetoric, and engage in a thoughtful contest of ideas forms a crucial bulwark against the forces of political expediency and anti-intellectualism.

Still, it is not enough. This collection has grown from the conviction that each of us must also use our expertise to promote justice in more direct ways. Just as we count on our colleagues in climate science to speak up against the voices that deny global warming, we humanists must counter the forces that denigrate knowledge-based discourses, threaten humane values, and whitewash historical events. Those of us who teach Renaissance literature specifically must refuse the appropriation of canonical figures or cultural formations to bolster nefarious ends. Shakespeare, perhaps more than any other literary figure, has been trotted out as a symbol of white cultural supremacy. It is incumbent upon us to call out and correct this dangerous lie. In a similar way, white power groups attempting to reconfigure European culture as a white monolith have availed themselves of medieval and Celtic symbols that, they believe, emblematize that idealized past. We need to help our students recognize such false associations. Countless examples illustrate the stakes of unresisted historical erasures: fatal encounters between unarmed black people and police officers, white supremacist rallies on college campuses, anti-immigrant and anti-Muslim sentiment, anti-Semitism, the re-emergence of hate groups, and even explicit Nazism. It is a grim era for American and European democracy, and, for that reason, there has never been a more crucial time to articulate the ethical value of study, reflection, and engagement. 
Yet at precisely the moment when expert knowledge and careful thinking are needed most, many of us find ourselves pressured to instrumentalize and monetize our work in the classroom. Burgeoning student debt and concerns about employment prospects have understandably prompted college-bound students and their families to seek the reassurances of pre-professional, skills-based instruction; institutions eager to attract new students roll out increasingly specialized programs deemed more practical than an expansively formulated liberal arts education. As a statement by faculty, students, and alumni from the University of Aberdeen argued in 2016, institutions of higher education find themselves at a juncture that offers two ways forward:

One is to follow the business model of higher education to its logical conclusion, in a competition for students, research funding and ratings that values constant change as an end in itself. The other is to rediscover the civic purpose of the university as a necessary component of the constitution of a democratic society, with the responsibility for educating its citizens and furnishing them with the wisdom and understanding that will enable them to fashion a world fit for future generations to live in. ${ }^{5}$

If the logic of the first path casts the study of literature as an unaffordable luxury-one at best ancillary to imperatives to train the workforce of the future - the logic of the second path insists instead on the centrality of literary and humanistic studies to fostering the prudent discernment required for civic participation.

A spate of recent work has attempted to reimagine humanist-and in particular literary critical - thought amidst the rising cost and increasingly vocational emphasis of higher education. In The Work of Literature in an Age of Post-Truth, Christopher Schaberg contemplates the study and teaching of literature as an antidote to cultural forces that, in prizing speed, efficiency, and the superficial assimilation of information, dangerously elide the value of slow, careful reading. Schaberg views the classroom as a "resilient" space where students' confounding experience of a changing world-including institutional pressures to adorn the "student experience" with newfangled innovations-can be thoughtfully considered. The aim, he writes, is for students to develop a critical habit of mind, "a comportment toward the world as it is, with a mind to changing it for the better." "If Schaberg paints the classroom as a site of utopian reflection, he does not discount its potential as a site of revolutionary action. Indeed, as Derek R. Ford proposes in Politics and Pedagogy in the "Post-Truth" Era, the mantle of "post-truth" can be appropriated "to agitate the political nature of truth and, more importantly, the pedagogy of truth," enabling teachers and students 
not just to understand "the power relations that compose truths" but also to explore how "we engage ourselves, each other, and the world in transformative processes as we formulate and realize these truths."

As much as this book has been spurred by recent conversations, it is also deeply informed by a longer history of critical pedagogy. Paolo Freire outlines a model for learning and teaching that is oriented toward developing "critically transitive consciousness": a more sophisticated interpretive framework for grappling with complexity, increased critical flexibility, heightened receptivity to new information and methods, and improved reasoning. ${ }^{8}$ Central to Freire's model is dialogue, through which learners reflect on the problems that arise in their relation to the objects of study and the world. ${ }^{9}$ By leading students to see how they can change their relationship to the external world, Freire's "pedagogy of the oppressed" offers a model of both individual and social transformation. Similarly, what bell hooks terms the "pedagogy of hope" describes modes of teaching and learning that do "not reinforce systems of domination, of imperialism, racism, sexism or class elitism." 10 Teaching, hooks posits, is "rooted in hopefulness," as teachers believe not only that learning is possible, but also that an open mind will tenaciously pursue knowledge that is liberating. It is this same transference of individual skill to social practice that education theorists have framed more recently as "social justice education" (for more on SJE, see Chapter 21 in this volume, by Todd Butler and Ashley Boyd), which aims, as Maurianne Adams puts it, "to generate active engagement with social justice content through learning processes that are consistent with the goals of social justice." Accordingly, social justice educators cultivate equitable learning environments whose structures can be replicated in wider social contexts. ${ }^{11}$ These methods do not belong to any one discipline, and can be pursued across the curriculum.

Although these conversations have been ongoing for some time, for many of us who work with historical literatures the integration of teaching and justice is a newer undertaking. One reason may be a widespread perception that the material we teach does not contribute to current conversations about justice, at least not in the same way that contemporary texts or literary works emerging from underrepresented communities do. Another factor may be a tacit attribution of conservatism (academic or political) to those teaching in historical fields, which can further isolate early modernists from important conversations in which we have a vested stake. As a corollary, in many conversations about curriculum, historical requirements are singled out as most in need of overhaul or cutting. Without questioning the imperative to expand offerings in emergent fields or the need to appeal to diverse 
student populations, we assert that historical literatures can speak to the demands of our current moment, and that, as specialists in older fields, we share responsibility with our colleagues in newer fields for doing that work.

The moment seems right for early modern studies to undertake a new kind of engaged truth-seeking and truth-making. At the 2017 Sixteenth Century Society Conference, a group of scholars convened a forum (the proceedings of which were later published in Sixteenth Century Journal) to exchange ideas about feminist practice in early modern scholarship and teaching. As co-conveners Kathryn Brammall and Whitney Leeson note, the forum appeared at a moment of resurgence for feminism in popular culture-in the wake of the 2016 election of U.S. President Donald Trump, the Women's March on Washington, and the \#metoo movement-and thus affirmed the opportunity those of us working in historical fields have to make our work matter to the prevailing concerns of the day. ${ }^{12}$ And in 2018, Shakespeare's Globe theater hosted the symposium "Shakespeare and Race Across Borders," which drew international attention to how "race is taught at university, discussed in the critical field and represented in performance." 13 Harnessing the London theater as a hub of thinking about Shakespeare's cultural influence, the symposium identified the centrality of race to current conversations about Shakespeare. Even as this book goes to press, we are aware of at least two other collections in the making that resonate with our topic: David Ruiter's Shakespeare and Social Justice and Timothy Francisco and Sharon O'Dair's Shakespeare and the 99 Percent. As Ayanna Thompson and Laura Turchi have demonstrated in Teaching Shakespeare with a Purpose, learning about Shakespeare can be both empowering and relevant to the lives of our students. ${ }^{14}$ Likewise, we see this moment as opportune for rethinking what we do with early modern literature in the classroom, and to use those insights to contribute to an ongoing conversation about doing justice through teaching.

This collection offers a response to a crisis of information whose pernicious and even deadly consequences we now know too well, a situation which urges us to transform our classrooms into places that foster intellectual engagement and learning while also helping students see themselves as shapers of a more just and equitable world. Beyond the exigencies of our lived present, we wish to explore how teachers of historical literature can adapt to what will continue to be the changing needs of our students within the tumultuous and even threatened environment of higher education. As urgent as the political turmoil around us seems, we wish to move forward in a positive direction by resisting the polarization that feeds on that turmoil, especially where 
the formation of our students is concerned. Our focus on preparing students for thoughtful engagement with the world around them is emphatically not about inculcating our own views in the minds of passive students. Nor is it confined to the horizon of those struggles in view from our specific location in space and time. We are seeking, instead, an understanding of justice in action that includes all modes of engagement through which we, and our students, can find meaning in making knowledge regardless of political affiliations.

We see teaching in the humanities as uniquely suited to this work, precisely because humanist thought is not ideological but instead allows for multiple and competing approaches to socially relevant problems. Jennifer Summit articulates a view of humanism not as a philosophy but as a broad set of social and scholarly practices that privilege integrated processes of inquiry, rather than rarified objects of knowledge. These practices fuse speculative knowledge, technical skill, and practical wisdom. ${ }^{15}$ On the one hand, "one value of humanities scholarship derives from its curatorial oversight of its objects": the works of art and literature, performances, and scholarship that we study. But even more saliently, "beyond the intrinsic value of their objects, the humanities exist as a disciplinary matrix because of the questions, methods, and practices that scholars bring to them in order to make those objects legible and meaningful." ${ }^{16}$ Literary learning, specifically, ought not be about the veneration of any particular text or object, but the cultivation of a way of looking at the world (and not least because of the elusive nature of our "objects" of study; as the old quip goes, "if the Mona Lisa is in the Louvre in Paris, where is Hamlet?"). Prioritizing modes of inquiry over the unquestioned veneration of celebrated objects (like Shakespeare, the First Folio, or any other thing) allows humanists across the disciplines to address issues of justice-to confront racism, misogyny, and lack of diversity in the canon, and more broadly to open up the richness of the past as a prod to action in the present.

Within the broader multidisciplinary context of the humanities, we see unique opportunities in the teaching of literature and historical sources like Shakespeare's in particular. Because our interpretive work rests on literary texts that are themselves sites of contested meaning, we can reproduce in our classrooms smaller, less risky versions of the struggles present in other aspects of our institutional and social lives. The literature classroom can function as an ideal laboratory for responding to those struggles experimentally. For example, one of us regularly asks students, "What can you change your mind about today?" The low-stakes testing of assumptions and taking of risks in the classroom prepare students for higher-stakes ethical and creative responses to their 
experience of the world. But historical literature offers us something additionally fruitful: the chance to defamiliarize our own lived experience, a topic taken up explicitly by the essays in Part I of this book. As L. P. Hartley famously noted, "The past is a foreign country: they do things differently there." 17 The study of historical literature affords students particular encounters with the far-away, encounters that defamiliarize their modern lives and foster ethical engagement with the strange or remote. The "foreignness" of the historical offers a disruptive estrangement from the present; from the alternate viewpoint of the early modern, after all, it is we who are strange. (One suspects Shakespeare knew this, too, given that nearly all his plays are set at a geographic or temporal remove from early modern England, and, moreover regularly thwart Aristotelian "unities," yoking together heterogeneous localities and temporalities). Even Shakespeare's language detains our modern ears with nuances that forcefully expand our interpretive resources, and etymological surprises that defamiliarize our own English. The past, in other words, teaches us that knowledge- then as now-is contingent and provisional. One of the most valuable elements of studying Shakespeare and Renaissance literature is this constant reminder that things can and do change: from the social structures we take as a given, to the very language that we use.

However alien the early modern may seem to our students today, we are inversely reminded that, as Faulkner wryly puts it, "The past is never dead. It's not even past." ${ }^{18}$ Here, too, we see rich opportunities. The multifarious and extensive performance history of Shakespearean drama in particular transforms the distant past into an ongoing and polychronic now. As Thompson and Turchi argue, Shakespeare's texts only "get more complex over time because of the layering of meaning" through performance. ${ }^{19}$ From the ethereal films of the silent era to the condemned 2017 production of Julius Caesar which figured the doomed monarch as a Trumpian doppelganger, stage and film productions function as interpretations that can, themselves, be interpreted and historicized. Theater historians therefore recognize the liberatory potential of there being multiple Shakespeares, existing across a wide range of temporalities, locations, and idioms. Comparing these instantiations affords us critical distance from our own troubling era. These fluctuating meanings affirm again our capacity to effect change.

While we recognize Shakespeare as multiple, contingent, and evolving, we are also aware of the dangers of overly universalizing "Shakespeare" as a social institution. Too often, Shakespeare's "universality" has meant white/European cultural supremacy. As Michael Witmore, Director of the Folger Shakespeare Library, observed at the Shakespeare Association 
of America's 2017 "Color of Membership" panel, that great library was founded in part to shore up an anti-immigrant agenda by augmenting an ideology of European superiority. ${ }^{20}$ Similarly, in Chapter 5 of the present volume, Jason Demeter delineates how the American educational system trumpeted Shakespeare "as a common cultural and linguistic touchstone ... under the banner of a homogenized whiteness, all while excluding non-whites from Shakespeare." ${ }^{21}$ To the best of our ability we have sought to avoid replicating these constructs in this book by recovering and expanding upon this fact: Shakespeare has long been many people's Shakespeare-indeed many Shakespeares.

Even as the contributors to this volume problematize the notion of a timeless, universal Shakespeare, they demonstrate confidence that Shakespeare's works can speak to a wide range of issues related to justice, partly but not only because he thematizes justice so often in his plays. While Shakespeare's enduring status as a shared cultural text should not be a bludgeon for fashioning whiteness or privilege, it does create common discourses that themselves yield opportunities for exchange. ${ }^{22}$ As legal scholar Kenji Yoshino writes, "one reason current discussions of justice are so impoverished is that our heterogeneous society does not have many shared texts. Shakespeare's plays are among the few secular texts that remain common enough and complex enough to sustain these conversations." ${ }^{23}$ The essays that comprise this volume bear this out, as they bring a range of pedagogies and perspectives into conversation around this literary material that we collectively own. And although the early modern texts discussed in this volume are not limited to Shakespeare or drama, it is worth noting that drama itself has an explicitly social function. As theater scholars Kelly Freebody and Michael Finneran write, social change and pedagogy are baked into dramatic form itself. ${ }^{24}$ The study and teaching of plays, therefore, afford a clear opportunity to engage in conversations about social justice that risk being "relegated to the margins under the burden of current social trends, the restlessness of contemporary political movements and the sheer speed of societal change." ${ }^{25}$ Accordingly, the contributors to this volume recognize the unique potential, as Adhaar Noor Desai puts it, to "make the Shakespeare classroom a site for social engagement and action, rather than a place to understand our world through the veils of aesthetic and historical distance." ${ }^{26}$ In this way, we aim to treat Shakespeare's texts not as monoliths but as "living documents," to borrow Thompson's and Turchi's phrasing, whose meanings are "always in flux," and thus invite ever-new modes of critical, imaginative, and ethical engagement. ${ }^{27}$

In thinking about practical pathways ahead, we acknowledge the cautionary admonitions of scholars who have identified the disenfranchising 
effects of malign — and seemingly infinitely replicating - power structures. A Foucauldian critique of power, for example, identifies the forces that impede justice as ubiquitous and hegemonic. It is a society's institutions, including those where we work, that realize both justice and injustice, and that control access to power. Effecting a more just world requires operating from within those institutions to promote critical analysis of power, and to expand access to that analysis. Critical pedagogy must therefore be "grounded in critique as a mode of analysis that interrogates texts, institutions, social relations, and ideologies as part of the script of official power." ${ }^{28}$ Interrogating these symbolic and material signs of power is already idiomatic to our scholarly generation's critical habitus. But while acknowledging that "every act of unmasking, critique and opposition uses the tools it condemns and risks falling prey to the practice it exposes," ${ }^{29}$ we also want to avoid falling prey to the insidious passivity and even despair that such totalizing paradigms can give rise to. ${ }^{30}$ Even as we acknowledge that we are interpolated within a system, we own that it is interpolated within us. We must therefore recognize our responsibility not just to critique things as they arepotentially a sterile and self-serving practice-but also to transform them. As Henry Giroux maintains, "while it is important to politicize the process of schooling and recognize the gritty sense of limits it faces within a capitalist society, what is also needed to supplement this view is an ennobling, imaginative vision that takes us beyond the given and commonplace." ${ }^{31}$ Teaching Social Justice Through Shakespeare: Why Renaissance Literature Matters Now aims to effect this transcendence on an individual as well as a social level.

This book is thus primarily about praxis: the implementation, through teaching early modern texts, of a set of hopeful ideas about the potential of education, with the aim of making those ideas both better understood and materially significant. ${ }^{32}$ Such a practice of teaching can take aim at structures that cause suffering and social inequality, degrade the nonhuman, and make power and profit the only sources of value. It might explicitly identify the key actors in this grim state of affairs: late capitalism, structural racism, and patriarchal power foremost among them. But we do not assume a singular definition of "justice" that is fixed by a timeless ideal or presentist ideology, nor do we adhere to an exclusively redistributive emphasis for social justice as pertains to "the possession of wealth, commodities, opportunities, and privileges." 33 We prefer an expanded understanding of justice, one that resists the subjection and instrumentalization of learning and intellectual exchange. Instrumentalizing imperatives can undermine even the best-intended responses to our contemporary crisis. In an era increasingly hostile to 
the value of humanities-hostile even to education itself-we do not want to cultivate the belief that the justice-oriented classroom must "produce" anything, including activists. What we do wish to enable, however, is the making of "citizens who are critical, self-reflective, knowledgeable, and willing to make moral judgments and act in a socially responsible way." ${ }^{34}$ Essential to this process is a model of education that inspires students to recognize themselves as agents, to cultivate skills of responsiveness over dogmatism, to have the humility to learn from history and each other, and to feel intellectually prepared to take action against injustice.

Another essential feature of the approaches to teaching described in this book is a regular practice of confronting "who has control over the conditions for the production of knowledge," both within and beyond the classroom. ${ }^{35}$ Critical pedagogy, crucially, brings democratic methods and ideas into the space of the classroom. As several chapters in this volume describe, this comprises activities like service learning, working with incarcerated learners, and other community partnerships that encourage students to make connections between the classroom and the world beyond it - and to examine their assumptions about a range of social, racial, economic, and environmental issues and the people they affect. As chapters in this book point out, critical pedagogy is also about the habits of mind that enable students to be thoughtful consumers and makers of knowledge. Gathering information from multiple sources and through multiple senses, evaluating data without bias, reevaluating previously held beliefs, being asked to teach material to their peers, and recognizing motivated reasoning all help students become aware of how they are processing knowledge. Similarly, communicating precisely and framing ideas as sites of curiosity rather than as possessions help students to be deliberate about the kinds of knowledge they are making and to cultivate a willingness to revise that knowledge. Developing these habits of mind is an essential complement to more traditional modes of developing students' intellectual autonomy, such as training them to make claims and defend their arguments with evidence. ${ }^{36}$

The essays in this volume reflect the scope of these habits of mind, seeking a balance between reflection and action. The volume offers no false choices between intellectual rigor and community engagement, between practical strategies and theoretical questions, or between "traditional" and experimental or multimodal pedagogies. We believe that, if pursued in good faith and responsive to a dynamic classroom, a truly wide array of pedagogical practices can be harnessed toward liberatory ends. Several of our authors address the expansive potential of very traditional classroom practices, such as close reading, rhetorical 
analysis, or unraveling the thought experiments posed by paradox and ambiguity. Other chapters explore emergent practices that productively disrupt teacherly authority, experiment with new media, prioritize collaboration, and reach beyond traditional classroom spaces. This heterogeneity reminds us that although there may be such a thing as "bad" pedagogy_inert, bullying, shaming, misinformed-there are many modalities in a classroom that prioritize justice. Identifying them in a quickly shifting educational landscape requires an adaptable, creative mental framework, rather than a dogmatic model of any kind. Teaching Social Justice Through Shakespeare: Why Renaissance Literature Matters Now begins with the conviction that we can teach Shakespeare and Renaissance literature in ways that are vital to the pursuit of justice, while also doing literary texts themselves justice. As these chapters show, there is great variety in the ways we can "affirm, model, and sustain socially just learning environments for all participants and by so modeling, to offer hope that equitable relations and social structures can be achieved in the broader society." ${ }^{37}$ We offer this book as a vote of confidence for the liberatory potential of debates sparked by these linguistically rich, historically remote, and intellectually complex texts. It is in this spirit that we enthusiastically turn now to the chapters in this volume.

The chapters are grouped in five parts. Understanding that such groupings necessarily impose separations where there is continuity, we do not intend these headings to prescribe how you read this book. Think of them instead as invitations to begin connecting these chapters and the strategies they describe, with room to add improvisational linkages of your own. Part I, "Defamiliarizing Shakespeare," takes as its point of departure the necessity to confront cultural forces that reify the "Bard" into something students may suppose they already know. Often such familiarity may take the form of unthinking adoration, intimidation, or resentment: presuppositions that impede receptivity. The authors of these chapters propose constructive ways to unreify and defamiliarize Shakespeare, and thereby help students to set aside presupposition and embrace challenge. Likewise, they discuss the benefits of creating room for curiosity and learning.

Adhaar Noor Desai addresses these issues head on, asking what we can do to make the Shakespeare classroom a site for social engagement and action, rather than one overly invested in historicizing or aestheticizing Renaissance literature. "Topical Shakespeare and the Urgency of Ambiguity" suggests that one possible answer is letting students themselves decide what Shakespeare's plays can offer them. Taking his inspiration from James Baldwin ("Why I Stopped Hating Shakespeare"), 
Desai describes a classroom that does not exalt Shakespeare but enlists him as a "witness." Desai's strategy is to liberate "close reading" from a results-based search for meaning and focus instead on its potential as a "risky, collaborative, and urgent exercise." He does this by encouraging a process of experimental free association he calls "riffing," which entices students to trust their instincts and the text's volatile ambiguities. Experimental, collaborative, and empowering, its goal is to give students, not Shakespeare, authority in the classroom.

As the rhetoric of gender and trans theory has made its way into Shakespeare studies, critics and practitioners increasingly reach for "trans" as a lens through which to read and produce Shakespeare. Sawyer Kemp's "Shakespeare in Transition: Pedagogies of Transgender Justice and Performance" points out that although both Shakespearean performance and criticism rely fundamentally on the rhetoric of trans people and their bodies, actual trans people and bodies are predominantly absent from discourse and performance. This essay looks to readings of the "transgender" in Shakespeare as a way of grappling with both historicist and presentist methodologies, asking us to look beyond "the pants" of cross-dressed heroines to more subtle signifiers of gender nonconformity. The essay then tracks some ways in which education and outreach departments can engage trans and gender-nonconforming communities at the level of production.

Allison P. Hobgood's essay, "Shakespeare in Japan: Disability and a Pedagogy of Disorientation," describes what happened in her Shakespeare classroom at Tokyo International University in the wake of a deadly stabbing attack at a residential care center for people with disabilities in nearby Sagamihara. Hobgood discovers that the importance of Shakespeare in processing and responding to the Sagamihara attack was, paradoxically, his relative non-importance to her students, as compared with Shakespeare's elevated status among U.S. undergraduates. Her model of a "feminist disability pedagogy of disorientation" decentralizes stoic analysis and mastery in favor of "immersive, deeply affective, real-time experiential learning." By juxtaposing irreverent adaptations and selected close readings from Macbeth with frank discussions of cultural attitudes toward disability, Hobgood and her students carved out a space for Shakespeare to speak to their disorienting present, fashioning in their responses to Shakespeare a framework for more just thought and action.

In "Global Performance and Local Reception: Teaching Hamlet and More in Singapore," Emily Griffiths Jones describes her experience teaching a Shakespeare seminar in Singapore through MIT's Global Shakespeares project. The "entrenched Western interpretive tradition" 
and its assumptions of a "supposedly universalizing psychological realm," are, Jones argues, "ripe for global reconsideration." Her chapter shows how the comparative deployment of digitally archived multicultural performances leads students to engage with Shakespeare's works in a way that "transcend[s] the myth of monolithic textual authority." Through interpreting, comparing, and responding creatively to global Shakespeares (including, as in Espinosa's classes mentioned below, making their own short films), students used Shakespearean performance to address social issues relevant to them, from immigration to LGBTQ rights.

The essays in Part II, "Decolonizing Shakespeare," explore intellectual and artistic movements that either enshrine or challenge traditional associations of Shakespeare with racial and cultural superiority. Will Shakespeare always be marked by a forbidding canonicity and Eurocentrism, or can he be seen as intersectional: perhaps just as aligned with liberatory futures as a figure like Audre Lorde? How can Shakespeare be made accessible to readers who may see his work as belonging to someone else? What can we learn from nineteenth-century pan-Africanist autodidacts who laid claim to Shakespeare as an instrument of aesthetic pleasure, community building, and racial uplift? These chapters explore the troubling past of Shakespeare studies and the potential for transformation that we must aspire to.

In "African-American Shakespeares: Loving Blackness as Political Resistance," Jason M. Demeter reflects on a course designed to historicize and challenge Shakespeare's deployment in U.S. educational contexts "as an instrument of white racial consolidation and non-white marginalization." Demeter offers a concise summary of Shakespeare's positioning as the pinnacle of "universal" white, Western cultural values before detailing a course that combines Richard III, Henry IV Part I, and Othello with responses to Shakespeare's works by black artists such as James Baldwin, August Wilson, Toni Morrison, and Djanet Sears. Though he hoped that placing African-American literature and Shakespeare "on equal footing" would provoke critical interrogations of Shakespeare's privileged place in the literary canon, Demeter finds Shakespeare's whiteness and universality difficult myths to dismantle, and offers his ambivalent experience as a way to frame key questions about the relation between Shakespeare pedagogy and social justice.

Ruben Espinosa's "Chicano Shakespeare: The Bard, the Border, and the Peripheries of Performance" illuminates how questions of race, ethnicity, power, and identity are not "marginal" to the study of early modern texts, but are indeed central to the work of teaching Shakespeare to students living along the U.S.-Mexico border. Lack of 
visibility and access regularly alienates Chicanx, Latinx, and other students who have never been invited to imagine Shakespeare as "theirs." This chapter details an innovative strategy for addressing this problem: student-directed productions (five-minute films) that incorporate original Shakespearean language with dialogue of the students' own, in which students are free to address contemporary social issues. The result is creative projects that help students feel visible, surmount linguistic barriers, and put the issues that matter to them on the "map."

Kim F. Hall's “'Intelligently organized resistance': Shakespeare in the Diasporic Politics of John E. Bruce" describes an outline for the study of Shakespeare propounded by the black journalist and organizer John Edward Bruce in 1916. Hall situates Bruce's inaugural address to "The Friends of Shakespeare," a black organization for the study and performance of Shakespeare, in the wider U.S. context of migration, the rise of white nationalism, and pan-Africanist thought. An autodidact, Bruce advocated for a collaborative approach to studying Shakespeare's works in their historical context and alongside works by black authors. Comparing Bruce's collectivist and historicist strategies for using Shakespeare as a vehicle for racial uplift, with radical pedagogies described more recently by Joyce E. King and others, Hall argues that the study of Shakespeare, then as now, can equip students for "intelligently organized resistance."

Part III, "Ethical Queries and Practices," lays out some of the more polarizing and also the most activating questions in teaching Shakespeare and early modern literature today. Is there a place for trigger warnings in the classroom? How do we defend the humanities without merely instrumentalizing them, and how can we meet students where they are without succumbing to a pedagogy of low expectations? How can we help students who not only feel alienated from early modern literature, but believe that the study of the humanities itself constitutes a kind of cultural betrayal? These chapters explore best practices for approaching difficult topics in the classroom with both rigor and care, and the necessity of making room for complexity and ambiguity.

"Sexual Violence, Trigger Warnings, and the Early Modern Classroom," by Kirsten N. Mendoza, tackles the controversial subject of trigger warnings, which she sees as an ethical practice that, deployed correctly, can augment rather than shut down discussion. As Mendoza explains:

I not only expect but hope for productive contention and discomfort in the classroom. However, I have come to realize that in order to create an environment in which such conversations are possible, a basic ethos of trust 
needs to exist; trigger warnings have not hindered but have helped me to cultivate such an atmosphere.

This chapter takes seriously both depictions of early modern violence and their connection to students' experiences, and it provides strategies for using affective responses to support aesthetic and intellectual analysis.

How do professors connect Shakespeare to "something like social justice and democratic practice" when students see higher education as suspect and "learning as an act of cultural betrayal"? This is the challenge faced by many of those teaching early modern texts to first-generation economically disadvantaged students in rural communities who have been raised to doubt that "the arts and humanities have any positive value at all." In "Rural Shakespeare and the Tragedy of Education," Jeffrey Osborne observes that the first step in engaging such students is helping them see that their disaffection is the result of their having actually been "the objects of an injustice." Osborne describes a general education seminar in literature and philosophy which gives students space to temporarily "suspend and question their values." Here, the tragedies of Shakespeare and other authors enable the kind of productive disorientation (aporia) that enables rediscovery and leads to a hunger for justice.

How can the study of literary form shape students' understanding of ethics, justice, and community? Mary Janell Metzger addresses this question in "Shakespearean Tragedy, Ethics, and Social Justice," which describes a course she developed yoking Shakespearean tragedies to ethical philosophy from Aristotle to Patricia J. Williams. Through these pairings, students compare the benefits of cognitive and affective learning, consider questions of epistemic injustice, reasoning, and belief in historical moments of epistemological crisis, and question the roles of individuals and collectivities in precipitating tragic outcomes. Detailing her approach to teaching Othello alongside Williams' "The Obliging Shell," Metzger illustrates the importance of historicizing the construction of whiteness in order to illuminate the effects of systematized injustice.

In "Teaching Environmental Justice and Early Modern Texts: Collaboration and Connected Classrooms," Rebecca Laroche and Jennifer Munroe offer innovative approaches to teaching the embodied and collective history of human impact on the planet through early modern texts and contemporary ecofeminist theory. Combining Rob Nixon's concept of "slow violence" (a way to understand environmental destruction over long periods of time) with an ecofeminist approach that 
"interrogates mutual forms of subjugation," Laroche and Munroe stress how humans inhabit collective environments with other human and nonhuman entities. Their intersectional teaching strategy reflects this attitude by elevating collaborative scholarship, forging links between distinct classroom communities, and empowering students to historicize environmental problems, from water quality to wildfires. Students collaborate across geographic and institutional differences, and with scholarly efforts like the Early Modern Recipes Online Collective, to develop a heightened sense of both place and global interconnectedness.

What are the perils and rewards of teaching Shakespeare during a U.S. presidential election year, in the midst of political upheaval? Steve Mentz's "Failing with Shakespeare: Political Pedagogy in Trump's America" shows us how good Shakespeare is to think with during times of crisis and failure. This chapter proposes new pedagogical implications for the old story of Shakespeare's dramatic ambivalence: both by connecting the current political situation of the U.S. to critical moments in the past, and by exploring the range of available ethical responses to the experience of uncertainty, failure, and defeat. After all, as Mentz notes, "Politics is always violent and theatrical," making a course structured around analysis of live theatrical productions particularly generative in the current climate. Mentz also unflinchingly addresses an experience so many of us have had of feeling like we are "failing," and guides teacher-scholars toward an adaptive methodology that makes room for our own sense of disorientation and frustration.

Part IV, "Revitalizing the Archive and Remixing Traditional Approaches," posits that we can mobilize early modern literary works to become better thinkers ourselves. The authors in this part consider the potentially progressive role of traditional paradigms like ethical philosophy, classical rhetoric, thought experiments, and close reading to make early modern literature new again. These chapters suggest that early modern literary texts help us think about thinking itself, and they seek to underscore that epistemological savvy may be the most vital of activists' tools in an era of "alternative facts."

Rachel E. Holmes' "Teaching Serial with Shakespeare: Using Rhetoric to Resist" brings the wildly popular 2014 podcast into conversation with Shakespearean tragedy (Romeo and Juliet; Othello) and problem comedy (Measure for Measure) through the unexpected lens of Aristotelian rhetoric. By first introducing the conventions of the classical persuasive arts, Holmes enables students to analyze the legal and interpretive crises that plague Renaissance literature and contemporary court cases alike. This combination empowers students to question the construction of cultural and legal narratives when truth itself seems precarious. 
Matthew Harrison's “Adjunct Pleasure: Shakespeare's Sonnets and the Writing on the Walls" explores how the radical contingencies of Elizabethan sonnets and academic employment can mutually inform pedagogical practice. As he notes of Sidney, "the poems enact a phenomenology of contingency," tracing the "contortions of selfhood when an individualistic idea of value confronts a world operating on other logics." This chapter diagnoses how readily structural shortcomings are masked by fictions of personal exceptionalism or failure, and it proposes several practical strategies that "invite students to ... replace postures designed for obedience with active and bodily engagement with each other's ideas."

Carla Della Gatta's "Confronting Bias and Identifying Facts: Teaching Resistance Through Shakespeare" foregrounds the essential role of critical analysis in an era when facts, feelings, opinions, news, and propaganda have become increasingly hard to disambiguate. Shakespeareans are in an excellent position to help our students navigate this terrain, thanks to our field's "lengthy, cross-cultural, and international history of determining, disputing, and reinterpreting facts," a habit that can be put to especial use in identifying various modes of misinformation and bias. This chapter relates exercises in introductory scholarly editing and comparative theatrical/film analyses that enable students "to be makers of knowledge." Such practices put primary sources directly in students' hands, empowering them as they apply rigorous analysis to solving interpretive problems. Such skills enable them to "gain confidence in their ability to question what was previously perceived as venerated authority or fact," with obvious payoffs for both understanding of Renaissance literature, and also informed encounters with "fake news," biased sources, or unresearched content.

As important as it is to discriminate the factual from the fake, studying Shakespeare and Renaissance literature also provides opportunity to mobilize imagination for its transformative potential. Where early modern writers traffic in imaginative inventions, they often do so with the aim of effecting positive change. Debapriya Sarkar's chapter, "Literary Justice: The Participatory Ethics of Early Modern Possible Worlds," puts pressure on the ethical relation between literature's celebration of possible worlds and the pedagogical value of such imagined realms for the reader-and, by extension, for the student of early modern literature and culture. The chapter exemplifies how we might tap into the ubiquitous presence of imaginary worlds in early modern literature; these "golden" worlds of the imagination, Sarkar argues, simultaneously practice and theorize ways of knowing and being in the actual world. What she calls "participatory readerly ethics" reveals 
"the radical potential of poiesis" to help us transform what is into what might be.

In an educational landscape where proliferating programs and tracks offer an increasingly customizable student experience, and where the humanities are pressed to demonstrate their relevance by preparing students for "useful" employment, it can be difficult for students to situate their individualized trajectories of learning in the context of community. The essays in Part V, "Shakespeare, Service, and Community," describe innovative uses of digital methodologies, community engagement, and students' own experience to enlist students in recasting Shakespeare's cultural significance as a tool for community-based learning and activism.

Hillary Eklund's "Shakespeare, Service Learning, and the Embattled Humanities" provides an evolving model for uniting educational practices often believed to be quite remote: service learning and literary analysis. Although one mode ostensibly attends to utility while the other dwells in academic abstraction, pursuing both in tandem reveals more shared interpretive practices than one might expect. This chapter argues that "when we free ourselves from the burden of proving the relevance of Shakespeare," and instead create frameworks that collate classroom and community learning, we "heighten both the intellectual and civic stakes of our teaching." Key to this model is a process that compares "problem-solving frameworks" as a way to foreground metacognition and self-reflection.

In "Teaching Shakespeare Inside Out: Creating a Dialogue Between Traditional and Incarcerated Students," Jayme M. Yeo explores the possibilities for teaching Shakespeare within and outside of the criminal justice system by putting these communities of learners into substantive dialogue. In contrast to many "prison Shakespeare" programs, a social-justice oriented approach "privileges learning over therapy" and "fosters dialogue and equal participation among both populations." Success in such a program "yields positive social results, including increased activism and decreased stereotyping," but difficulties can be profitable too; as Yeo puts it, an egalitarian reading community "should value not only common understanding but also misunderstanding, through the uncomfortable dissonances that occur when diverse populations interact." This, she argues, is where Shakespeare faculty can best transmit their skills to students, "for multivalence and conflict accurately describe the work of literary interpretation itself."

Rooting his pedagogy in an Orwellian commitment to exploring the relation between writing and the cultural forces that shape it, Eric L. De Barros takes up linguistic complexity itself as a pedagogical model 
in his chapter "'Shakespeare' on his lips: Dreaming of the Shakespeare Center for Radical Thought and Transformative Action.” De Barros sees Shakespeare's texts as a "weapon" to use against a range of lazy habits of mind, from bardolatry to consumerist approaches to higher education. He describes how he invites students to examine their own subject positions and ethical priorities in conversation with Shakespeare's plays; how this engagement spurs conversations about issues from racialized beauty and consent to social mobility and criminality; and finally, how students parlay these insights into practical strategies for addressing related issues in their own lives. Fusing thoughtful intertextual engagements with close reading and autobiographical student writing, De Barros seeks to develop a "personally inflected, politically responsive" Shakespeare capable of combating cultural forces that discourage potentially subversive thought and action.

In "From Pansophia to Public Humanities: Connecting Past and Present Through Community-Based Learning," Tania Boster describes a course that explores the public humanities by combining service learning with historical documentary analysis. Students pair with community partners working to address a range of pressing local, national, and global issues. Through analysis of public and historical records, they develop broad strategies for understanding and contextualizing "competing views of social justice, radicalism, patronage, network analyses, structure and agency, and the practical application of the liberal arts." They then deploy similar strategies in analyzing digitally archived primary sources on seventeenth-century polymath Samuel Hartlib and his pan-European circle of scholars. Comparing the circle's utopian ideals of pansophia - universal wisdom - with its more severe proposals for reform amidst the turbulent contexts of war and social change, students historicize these discrepancies and gain critical purchase on contemporary approaches to solving similar social problems.

Todd Butler and Ashley Boyd, in "Cultivating Critical Content Knowledge: Early Modern Literature, Pre-service Teachers, and New Methodologies for Social Justice," give new reasons for attending to pedagogical training in literary studies classrooms. With so many English majors planning to enter secondary classrooms of their own, Butler and Boyd highlight the potential impact that combining social justice and content knowledge pedagogies can have on generations of classroom learners. At the same time, they claim that including teaching methodologies in undergraduate literature courses builds pedagogy as a habit of mind for all undergraduates, encouraging them to consider issues of social justice in their readings, and how those issues might be effectively conveyed to others. 
If our book demonstrates the intellectual benefits of teaching social justice through Shakespeare, Ayanna Thompson's Afterword meditates on the personal and emotional costs of doing this work. The conversation we have begun here might generate many others. But as we go forward, Thompson reminds us, we must also prioritize self-care. For if we are to sustain and embed social justice in our pedagogical and scholarly practices, we must also care for individuals doing this work. Fortunately, communities of care can transform difficult work into work that is also gratifying, energizing, and buoying.

The conversation we have initiated here is necessarily incomplete; for every topic addressed in these essays, there is another approach we would love to have added. The topics covered here-as broad as they are-in no way exhaust the scope of possibility for the justice-oriented pedagogy we advocate. Indeed, from the start we have been surprised at how this project has expanded in scope. Its growth has challenged us to think more broadly about what it means to teach social justice through Shakespeare. It has revealed how many of our colleagues are already doing and reflecting on this important work. This gives us great hope. At a time when we encounter so much discouraging news about the state of global political affairs, planetary health, and our institutions of higher learning, it has been buoying to think with colleagues who, in collaboration with their students, are making these old texts speak in ways that directly address our most pressing social problems.

The work is not done; the work will never be done. This fact, though humbling, should encourage as we each move our collective venture into the future. We therefore readily admit some caveats to the present volume. For one, this book is not really directed at educators skeptical of social justice as a teaching tool (although we hope some of them find their way here, and are intrigued enough to try out some of its methods!). We aim instead to encourage those already doing this work-or hoping to-with specific, applicable strategies for teaching social justice through Shakespeare. We hope it will provide you, as it has us, a greater awareness of the community of similarly committed scholars. We also know it won't solve the social problems in our sights, that it neglects to address the growing economic challenges to higher education, and that it does not speak to legislative opportunities for change. We very much hope others will take up these charges. What we believe we are contributing to is a slow but steady cultural shift, one that sees that "time's up" for instrumental, exclusionary approaches to higher education, and which reimagines early modern texts as potentially fundamental to collaborative meaning-making and liberatory action. Reading the essays contained here, we have renewed confidence in 
the "infinite variety" of ways that the works of Shakespeare and his contemporaries can be deployed for social justice pedagogy, and great admiration for the tenacity and creativity of our colleagues' engagement with the causes of equity and social change.

\section{Notes}

1. Philip Sidney, "A Defence of Poetry (1595)," in Miscellaneous Prose of Sir Philip Sidney, ed. Katherine Duncan-Jones and Jan van Dorsten (Oxford: Clarendon Press, 1973), 83.

2. Derek Attridge, The Singularity of Literature (New York: Routledge, 2004), 181.

3. "Statement by Press Secretary Sean Spicer," Press Briefings, January 21, $2017<$ https://www.whitehouse.gov/briefings-statements/statement-presssecretary-sean-spicer> (accessed February 15, 2019).

4. "Conway: Press Secretary Gave 'Alternative Facts'," NBC News, January 22, $2017<$ https://www.nbcnews.com/meet-the-press/video/conway-presssecretary-gave-alternative-facts-860142147643> (accessed February 15, 2019).

5. Scholars, students, staff, and alumni of the University of Aberdeen, "Reclaiming Our University” <https://reclaimingouruniversity.wordpress. com> (accessed April 14, 2018).

6. Christopher Schaberg, The Work of Literature in an Age of Post-Truth (New York: Bloomsbury, 2018), 70, 72. Original emphasis.

7. Derek R. Ford, Politics and Pedagogy in the "Post-Truth" Era: Insurgent Philosophy and Praxis (New York: Bloomsbury, 2018), 2. Original emphasis.

8. Paolo Freire, Education for Critical Consciousness (New York: Bloomsbury Academic, 2013), 15.

9. Paulo Freire, Pedagogy of the Oppressed, trans. Myra Bergman Ramos (New York: Continuum, 2000), 60.

10. bell hooks, Teaching Community: A Pedagogy of Hope (New York: Routledge, 2003), xiv.

11. Maurianne Adams, "Pedagogical Frameworks for Social Justice Education," in Teaching for Diversity and Social Justice, 2nd edition, ed. Maurianne Adams, Lee Anne Bell, and Pat Griffin (New York: Routledge, 2007), 27.

12. Kathryn Brammall and Whitney Leeson, "Feminist Forum at the SCSC: Teaching and Activism in a Transformed Landscape," Sixteenth Century Journal 48, no. 4 (winter 2017): 881-2.

13. "Shakespeare and Race Across Borders: A Scholarly Symposium," <http:// www.shakespearesglobe.com/whats-on-2018/shakespeare-and-race> (accessed January 25, 2019). 
14. Ayanna Thompson and Laura Turchi, Teaching Shakespeare with a Purpose: A Student-Centered Approach (London: Bloomsbury Arden Shakespeare, 2016).

15. Jennifer Summit, "Renaissance Humanism and the Future of the Humanities," Literature Compass 9, no. 10 (October 2012): 669-70. See also Anthony Grafton and Lisa Jardine, From Humanism to the Humanities: Education and the Liberal Arts in Fifteenth-and Sixteenth-Century Europe (Cambridge, MA: Harvard University Press, 1986) for a deconstruction of several shibboleths of ideologically motivated misconstruals of the goals of humanism.

16. Summit, "Renaissance Humanism," 674.

17. L. P. Hartley, The Go-Between (London: Hamish Hamilton, 1953).

18. William Faulkner, Requiem for a Nun (New York: Random House, 1951), 73.

19. Thompson and Turchi, Teaching Shakespeare with a Purpose, 49.

20. Michael Witmore, "Opening Remarks for Plenary Panel on 'The Color of Membership'," presented at the annual meeting of the Shakespeare Association of America, Atlanta, April 17, 2017.

21. Jason M. Demeter, personal correspondence, January 28, 2017.

22. In their edited collection For All Time? Critical Issues in Teaching Shakespeare, Paul Skrebels and Sieta van der Hoeven see Shakespeare's enduring yet dynamic importance in secondary and higher education as an opportunity to reconsider the influence of critical theory on Shakespeare pedagogy. Contributors' strategies for integrating theory into the teaching of Shakespeare activate students' awareness of his contested and evolving cultural status and equip them to define for themselves what uses Shakespeare's works have in the present. Paul Skrebels and Sieta van der Hoeven, For All Time? Critical Issues in Teaching Shakespeare (Cambridge, MA: Wakefield Press, 2002).

23. Kenji Yoshino, A Thousand Times More Fair: What Shakespeare's Plays Teach Us About Justice (New York: HarperCollins, 2011), xiii.

24. Kelly Freebody and Michael Finneran, "Introduction," in Drama and Social Justice: Theory, Research and Practice in International Contexts, ed. Kelly Freebody and Michael Finneran (New York: Routledge, 2015), 1-2. However, as Hyman has noted elsewhere, Renaissance poets sometimes "erect spaces as consciously constructed as those of the theater . . . Early moderns well knew that the transgressive could be and sometimes had to be acutely private. Works appearing in manuscript sometimes had audiences of one, yet were still not necessarily partitioned from the experiences of the everyday." Wendy Beth Hyman, Impossible Desire and the Limits of Knowledge in Renaissance Poetry (Oxford: Oxford University Press, 2019), 17.

25. Freebody and Finneran, "Introduction," 5.

26. Adhaar Noor Desai, personal correspondence, January 31, 2017.

27. Thompson and Turchi, Teaching Shakespeare with a Purpose, 52. 
28. Henry A. Giroux, On Critical Pedagogy (New York: Continuum, 2011), 5.

29. Harold Aram Veeser, The New Historicism (New York: Routledge, 1989), 11.

30. Ford offers a rebuke of certain modes of critical pedagogy that limit themselves to the generation of critique without action. Instead, he advocates a model of politically engaged study that prioritizes openness and indeterminacy over mastery of existing knowledge. Politics and Pedagogy in the "Post-Truth" Era, 14.

31. Giroux, On Critical Pedagogy, 4-5.

32. For Freire, praxis is essential to critical consciousness: "being aware of objects as things is merely realization of their existence and does not mean knowledge of them. On the other hand, human beings (who cannot be apprehended without their relations with the world, seeing that they are 'beings-in-a-situation') are also beings who work and transform the world. They are beings of 'praxis': of action and of reflection. Humans find themselves marked by the results of their own actions in their relations with the world, and through their action on it. By acting they transform; by transforming they create a reality which conditions their manner of acting." Freire, Education for Critical Consciousness, 90.

33. Oxford English Dictionary, s.v. "justice, n."

34. Giroux, On Critical Pedagogy, 3.

35. Ibid., 5 .

36. See Arthur L. Costa and Bena Kallick, eds, Learning and Leading With Habits of Mind (Alexandria, VA: Association for Supervision and Curriculum Development, 2009).

37. Adams, "Pedagogical Frameworks," 27. 

Part I

Defamiliarizing Shakespeare 



\title{
Chapter 1
}

\section{Topical Shakespeare and the Urgency of Ambiguity}

\author{
Adhaar Noor Desai
}

In the winter of 2016, in the wake of the U.S. presidential election, I reflected on the privilege of studying Shakespeare in a country wounded by grotesque racism, inequality, and distrust. I found myself cheering as students replaced his portrait at the University of Pennsylvania with a photo of Audre Lorde, and felt dismay when I heard that white supremacists and ideological pundits rallied behind him to mock the students. ${ }^{1}$ I did not resent Shakespeare, but I certainly needed to rekindle my enthusiasm for teaching his works. An essay I had last read as an undergraduate, "Why I Stopped Hating Shakespeare" by James Baldwin, screamed out from my memory — or rather, its title did. "The greatest poet in the English language found his poetry where poetry is found: in the lives of people," Baldwin reminded me. "He could have done this only through love- by knowing, which is not the same thing as understanding, that whatever was happening to anyone was happening to him." The essay concludes by explaining that Shakespeare is "called a poet" because

his responsibility, which is also his joy and his strength and his life, is to defeat all labels and complicate all battles by insisting on the human riddle, to bear witness, as long as breath is in him, to that mighty, unnameable, transfiguring force which lives in the soul of man, and to aspire to do his work so well that when the breath has left him, the people-all people!- who search in the rubble for a sign or a witness will be able to find him there. ${ }^{2}$

I realized, inspired anew, that if was going to teach Shakespeare in 2017, what I wanted most for my students was for them to find what Baldwin found-and what I continue to find-in Shakespeare's work: a "witness." This "learning outcome" had nothing to do with reciting facts or writing essays; it had everything to do with love. It had to 
do with the emphatic "all people!" of Baldwin's final sentence, and I trusted Baldwin's sense that such radical inclusivity required the patient work of defeating all labels and complicating all battles. Of course, I had no idea how to accomplish this goal pedagogically, but one night in January I nevertheless erased my tried-and-true syllabus. In what follows, I recount some of the decisions I made to reconceive my course as "Shakespeare 2017." The challenges of this new approach revealed to me two related approaches for democratizing the Shakespeare classroom: firstly, relinquishing as much authority as possible (both Shakespeare's and my own) to privilege experiences of ambiguity and confrontations with "the human riddle"; and secondly, redefining "close reading" as a risky, collaborative, and urgent exercise rooted in what I took to calling "riffing."

Once, during a conversation he was having with some farmers, Paolo Freire realized that his interlocutors had stopped talking. "Excuse us for talking," one of them apologized, "You're the one who should have been talking, sir. You know things, sir. We don't." In response, Freire played a "knowledge game" in which he and the farmers stated things they each believed they knew that the other party did not. The game inevitably came to a tie, and Freire had created a new platform upon which conversation could proceed with mutual respect and with a sense of communal ownership. ${ }^{3}$ This scene lingered in my mind as I reconceived my approach to teaching Shakespeare. Was it more important to me that my students processed a particular snapshot of Shakespearean literature via documents and passages I had cobbled together, or that they learned to claim Shakespeare for themselves? I could give them techniques for reading, certainly, and they could digest Shakespeare via units on early modern culture addressing theatrical practices, conceptions of race and otherness, gender, and politics. But what would a pedagogy look like that compelled them to bring Shakespeare with them to discussions outside of class? I remembered that, as a freshman, I chose to study Shakespeare because his characters commiserated with my anxieties about belonging and provoked me to joy as I joined in their playfulness and their triumphs. While I know that modeling the intellectual work of our discipline for students is undoubtedly necessary, I decided that drawing students into disciplinary work might be more successful if I retraced my own history and first cultivated more personal attachments. I also felt that such attachments might enable our class at least to acknowledge what was going on in the world outside our envelope of privilege. I made Baldwin's essay the first night's reading of my course, and treated it as a promise that our object of study would not be "Shakespeare" but rather "the lives of people." This would involve 
de-contextualizing Shakespeare's plays, and instead emphasizing the context of students' own lives.

As teachers, we often insist that Shakespeare is "relevant," yet we also reject presentism and simplistic analogies. Rather than shunting associations students might perceive to jokes whispered after class, however, we might cherish their impulse to identify with characters and hold texts up as mirrors. Addressing topical, reductive, or even personal connections does not have to mean class will become a hunt for flimsy correspondences. If we engage them seriously-even by asking a few follow-up questions-we can start to foreground the blurs, smudges, and distortions the Shakespearean mirror can make visible. I presented to the students various writings on Shakespeare for popular audiences, like Stephen Greenblatt's account of the 2016 election, an excerpt from Jillian Keenan's Sex with Shakespeare that relates his plays to the author's spanking fetish, and Caitlin Keefe Moran's essay on Emilia and female silence. ${ }^{4}$ With these texts situating Shakespeare amid current events and cultural norms, I asked the class what they found interesting, challenging, and still hard to think about. Do these seem persuasive? What do we do when we feel strongly about our own response to something, but someone else challenges our ideas with evidence we cannot dismiss? I named such conflicts "experiences of ambiguity." After students read the definition given in the Oxford English Dictionary, we discussed how "ambiguity" can incorporate both subjective experience, that is, "wavering of opinion; hesitation, doubt, uncertainty," and an objective condition: "capability of being understood in two or more ways." I then positioned ambiguity against definitions of "authority": "A book, passage, etc., accepted as a source of reliable information or evidence" or "Power to influence action, opinion, or belief, or a party possessing it." I told the class that we would try to undermine approaches that rely on any one person's authority, and that we would treat texts as avenues for discovering ambiguity.

To enlist Shakespeare as an agent of ambiguity, we must position him to reveal contradictions in ways that students can also affectively experience. For example, consider Othello's final monologue, in which he equates himself as both a servant of the Venetian state and as its enemy, alongside lines from 1978 by Audre Lorde:

Set you down this,

And say, besides, that in Aleppo once, Where a malignant and a turbaned Turk Beat a Venetian and traduced the state, I took by th' throat the circumcisèd dog And smote him thus. (Othello, V, ii, 344-9) ${ }^{7}$ 
Today that 37 year old white man

with 13 years of police forcing

was set free

by eleven white men who said they were satisfied

justice had been done

and one Black Woman who said

"They convinced me" meaning

they had dragged her 4'10' black Woman's frame

over the hot coals

of four centuries of white male approval

until she let go

the first real power she ever had

and lined her own womb with cement

to make a graveyard for our children. ${ }^{8}$

Othello metaphorically taking himself by the throat as dutiful soldier and Lorde's juror letting go of "the first real power she ever had" for "white male approval" spiral together in a trans-historical rumination on racist othering and what it means to belong, to have power, to have civil rights, and to identify with people and places that might reject you. With the Black Lives Matter movement happening on college campuses and public streets around the country, staging such conversations may allow Shakespeare to seep into the world and expose the complexity of its battles.

Seeing from this angle, students gained purchase on the "micro-aggressions" that texture Othello's experience: they saw that hardly anyone calls him by his name, that even he would make casual remarks disparaging his appearance, that the Venetian Duke first inquires after the Italian "Marcus Luccicos" before deciding Othello will go to Cyprus (I, iii, 44), and that even Desdemona claims to see his "visage in his mind" and so consciously overlooks his actual visage (I, iii, 249). What are we to think after we see Othello commit an act of egregious violence and then take his own life, sensing as we do his marginalization and the entanglements of identity, violence, and the state? Lorde's "Power" ends with her imagining herself at a breaking point and committing an act of unspeakable violence against "an 85 year old white woman," prompting society to condemn her but not the police officers and centuries of oppression that led her to it: "a greek chorus will be singing in 3/4 time / 'Poor thing. She never hurt a soul. What beasts they are." We can condemn Othello's murder of Desdemona, we can condemn Iago, misogyny, state violence, racism, and retaliation, and yet our virtuous condemnations may not amount to much more than figs in terms of the advancement of justice. Such problems are bigger than us 
and our critical apparatuses, and denser than any literary text. Lorde's "Power," students marvel, is now some forty years old. Othello's tragedy continues with Iago bleeding but not killed. What we should do with our resentment, with our resignation, and with our rage are questions we need to confront together. We might start in our classrooms.

I staged similar interventions throughout the term by pairing texts with difficult topical questions. Alongside Love's Labor's Lost, we read articles condemning "liberal smugness"-how do you convince someone you are not trying to deceive or dominate them?" With The Merchant of Venice, we watched clips from Gurinder Chadha's 2002 film Bend It Like Beckham and read Sara Ahmed's chapter "Melancholic Migrants"-what are the responsibilities of a state to foreign migrants, and of migrants to states they are entering? ${ }^{30}$ I asked students to pay attention to how women's voices are stifled or circumscribed in The Winter's Tale, and we read Rebecca Solnit's foundational essay on the concept of "mansplaining." 11 Students admired Hermione-nevertheless, she persisted-but had a difficult time with her seeming to forgive Leontes. We dwelled: how do we, and should we, bring ourselves to forgive even the worst crimes? Does forgiveness require sacrificing our sense of justice? All of these conversations were hard, and they did not always stop after class ended. It may sound like our meetings were exceedingly somber, but in them we also learned how to discuss our pleasure in moments of irreverence and find comfort in moments that struck us as earnest: Queen Margaret's lessons on cursing, Moth's and Dull's mockeries of pretentious courtiers of Navarre, the porter's crass commentary on bodily fluids, Florizel's speech on Perdita's dancing, and the reunion of Hermione with her daughter.

Pairing Shakespeare's texts with contemporary issues was a way to make clear to students that our task was to dig in rubble and try to make sense of it together. The real goal of my course was not to fixate on specific issues, however, but to encourage students to start forging their own connections. In midterm reflections, students remarked that they appreciated our class conversations but that many of them were still struggling with how to have insights or discover meaning by a close reading of Shakespeare's plays. I had sensed their lack of confidence, and was admittedly humbled, worried that I had failed in the basic requirement of a literature course. In our subsequent meeting, I opened a conversation about where "meaning" comes from, and why we come to think of it as needing to be "discovered." I think the most important and challenging thing about close reading, and what makes it so difficult to teach, is that close readers have to trust their instincts and articulate what a text has brought to mind. Making the facile, or reductive, or 
topical, or anachronistic connection is a necessary step in the process of having new ideas; in time, we learn to silently reject our misfires, but without them we would never make discoveries. On that day, midway through the course, I revealed what I had done to design the course itself. I confessed that I had simply been "riffing." This riffing involved seeing a moment, or a speech, or even a word in a play and tracking what ideas and moments it raised to the foreground of my attention. Riffing allowed Lorde's "What beasts they are" to snap together with the animalistic characterizations of Othello throughout the play and with Officer Darren Wilson's testimony recounting the death of Michael Brown. ${ }^{12}$ Riffing lives in the present as a process of unraveling and an act of urgent liveness, like the jests of theatrical clowns speaking more than was set down for them. Moreover, riffing has no immediate stakes. You can do it wrong only if you stop doing it, or depart entirely from your prompt. It is a constructive game of "yes, and." I confessed that I did not know at the start of term how well pairing Love's Labor's Lost with discussions of liberal smugness would go, or how much traction a critique of "mansplaining" would give us in reading The Winter's Tale. Close reading similarly begins with riffing, I explained; it does not see plays as storehouses of hidden meanings: it sees them as a musical key within which we are encouraged to improvise.

To practice riffing, we spent the remainder of that class period focusing on the first word of Macbeth - "When." Students had already read the entire play (like all good close reading, riffing demands re-reading). I began by asking them to define "when" and name its associations. I told them to be outlandish, and I wrote all of their comments on the board: about the future and the past, about how we name points in continuous time so we can measure it, about conditionals and hypotheticals, about how in our contemporary idiom we "say when" when we want someone to stop pouring a drink. Once we had a sprawling, ahistorical network of associations, I asked what other parts of Macbeth came to mind. "Tomorrow and tomorrow and tomorrow" (V, v, 19) came up immediately. "That shalt be king hereafter" (I, iii, 51) derailed us into a conversation about "shalt," and how the play's second word is "shall." We noted that the last word Macbeth says in the play is "enough" (V, vii, 64). The play suddenly invited rumination on how individuals relate to time- "here, upon this bank and shoal of time, / We'd jump the life to come" (I, vii, 6-7) —and what the consequences are of owning a point in time by severing it from the others. These were just observations, but they were the fodder, we sensed, for saying something important about Macbeth. This was similar to how I typically teach close reading, but what was palpably different about it was the sense that our conclusions 
did not yet matter and that we were just trying things out. We were inhabiting the play and tuning it to our needs, even as we felt our ideas twisted and augmented with each new observation.

Box 1.1 shows the actual assignment prompt I subsequently used to encourage students to try riffing in their weekly online response posts. The responses could be as inane or as rigorous as students wanted; the idea was that they should try to be both provocative and collaborative. "Go out on a limb!" became our mantra. Other prompts included terms like "briars" (As You Like It, I, iii, 12); the stage direction "with a taper" (Macbeth, V, i, 15); and a single dash (punctuation mark) from Othello (V, ii, 332). Reading the threads at the end of the week was routinely surprising; students found all sorts of unexpected connections that they developed and debated: against Rosalind's "briars" they referenced the way wrestlers entangle one another and Orlando suffering "the thorny

\section{Box 1.1. Assignment prompt}

This thread is organized around a specific word or event from the play, and your task is to "riff" on it (in the same way we riffed on "when" in Macbeth). This entails thinking of all the possible associations you have with this word/event (how you would use the word, what other words it invokes, how you would imagine a scene playing out live-i.e., "awkward"/“slow"/“chaotic," etc.).

Consider this word's /event's meaning in its particular context, and then link it to at least one other passage in the play. As you read (and respond to) one another's posts, do your best to add ANOTHER, new, different passage to the discussion. You will lose half a point if you do not introduce any new passages to the discussion.

The only way to improve your abilities as a close reader is to take risks and go out on a limb. Trust your instincts! Be imaginative! These posts are not graded on quality, only on the objective rules that apply to every week:

1. Post by midnight on Friday

2. At least 200 words, not including quotations

3. Quote from this week's readings

4. Respond directly to at least one of your peers' posts (the first response, obviously, is responding to this prompt)

Your prompt for this thread is "stir" (The Winter's Tale, III, ii, 206) 
point / Of bare distress" (II, vii, 95-6). Lady Macbeth's taper recalled for them how heaven's candles were all out (II, i, 5) and Macbeth's "brief candle" (V, v, 23). They remembered Othello's seeming non sequitur "-Goats and Monkeys!" (IV, i, 250) when thinking about the dash. Sometimes I would pick a passage from a non-Shakespearean text, like the phrase "I'm not holding my breath" from Solnit's essay. I asked them to think about this phrase as an extension of Shakespeare's text, and they remembered Leontes' suspicion of breath escaping Hermione's statue (V, iii, 77-8). When it came time to write essays, students had textual questions - what do thorns have to do with wrestling and the "workaday world"? What do the stars have to do with Lady Macbeth's candle?-but they also knew they had license to range widely and into their own experiences in trying to address them.

I conclude with this assignment not because it is particularly novel, but because it foregrounds how reading Shakespeare-reading literature of any kind-can promote imaginative experimentation and collaboration. We cannot bear witness to the "human riddle" alone; we might confront it by sharing all our individual knowledges and by treating the texts we read as true interlocutors. In truth, "reading" now seems inadequate for describing what we were doing; we were riffing on, manipulating, adapting, and contorting Shakespeare's words. We would go out on precarious limbs, but the important thing was that we would temper or embolden our ideas by entwining them with others posed by our peers. No idea was too silly, and no idea was sacred. Shakespeare himself was no longer sacred. At the end of term, I asked my students whether they had any better answers regarding how to change our world to be more just. They were honest - they did not. But we all understood that the only way to come up with new ideas is to take risks and embrace, rather than foreclose, ambiguity. It would mean resisting unquestioned authorities and treating experience as rubble. As teachers, we can start this process by helping to topple the walls that privilege Shakespeare's face over students' lives.

\section{Notes}

1. Scott Jaschik, "Making a Point by Moving Shakespeare's Portrait," December 14, 2016 <https:/www.insidehighered.com/news/2016/12/14/ students-penn-remove-portrait-shakespeare > (accessed February 20, 2019).

2. James Baldwin, "Why I Stopped Hating Shakespeare," in The Cross of Redemption: Uncollected Writings, ed. Randall Kenan (New York: Vintage International, 2011), 68-9. Original emphasis. 
3. Paulo Freire, Pedagogy of Hope: Reliving Pedagogy of the Oppressed, trans. Robert R. Barr (New York: Bloomsbury Academic, 2014), 37-8.

4. Stephen Greenblatt, "Shakespeare Explains the 2016 Election," New York Times, October 8, 2016 <https://www.nytimes.com/2016/10/09/opinion/ sunday/shakespeare-explains-the-2016-election.html> (accessed February 20, 2019); Jillian Keenan, Sex with Shakespeare (New York: William Morrow, 2016); Caitlyn Keefe Moran, “'Yet I'll Speak': Othello’s Emilia, a Rebuke to Female Silence,” April 13, 2016 <http://the-toast.net/2016/04/13/ yet-ill-speak-othellos-emilia> (accessed February 20, 2019).

5. See "ambiguity, n.," definitions 1 and 2, OED Online (Oxford University Press) < http://www.oed.com/view/Entry/6144> (accessed June 2017).

6. See "authority, n.," definitions 1 and 3, OED Online <https://www.oed. com/view/Entry/13349> (accessed June 2017).

7. All quotations from Shakespeare are from The Norton Shakespeare, 3rd edition, ed. Stephen Greenblatt, Walter Cohen, Jean E. Howard, Katharine Eisaman Maus, Gordon McMullan, and Suzanne Gossett (New York: Norton, 2016).

8. Audre Lorde, "Power," in The Collected Poems of Audre Lorde (New York: W. W. Norton \& Company, Inc., 1997), 215-16. Copyright (C) 1978 by Audre Lorde, used by permission of W. W. Norton \& Company, Inc.

9. Emmett Rensin, "The Smug Style in American Liberalism," Vox, April 21, $2016<$ https://www.vox.com/2016/4/21/11451378/smug-americanliberalism $>$ (accessed February 20, 2019).

10. Sara Ahmed, "Melancholic Migrants," in The Promise of Happiness (Durham, NC: Duke University Press, 2010), 121-59.

11. Rebecca Solnit, "Men Explain Things To Me," in Men Explain Things To Me (Chicago: Haymarket Books, 2014), 1-19.

12. Damien Cave, "Officer Darren Wilson's Grand Jury Testimony in Ferguson, Mo., Shooting," New York Times, November 25, 2014, U.S. section <https://www.nytimes.com/interactive/2014/11/25/us/darren-wilsontestimony-ferguson-shooting.html> (accessed February 20, 2019). 


\title{
Shakespeare in Transition: Pedagogies of Transgender Justice and Performance
}

\author{
Sawyer Kemp
}

In May 2017, the Globe theater released a short blog post promoting its summer production of Twelfth Night. In the blog, scholar Will Tosh compared Viola's disguise as Cesario to the experience of contemporary transgender and gender-nonconforming youth. He wrote:

Shakespeare's vision of a gender identity that can slip along the scale from female to male and back seems, in 2017, intriguingly familiar. [. . .] But if the number of transgender people seems greater today than in the past [...] it's worth remembering that gender fluidity is no 21 st-century invention: Shakespeare's comedies show that when it comes to gender, it's all a matter of performance. ${ }^{1}$

Tosh suggests that one can use Shakespeare as historical documentation of gender fluidity in order to validate the legitimacy of transgender youth. In exchange, the implicit payoff for the Globe is that Shakespeare is rendered both socially/politically relevant and (given that Tosh specifically cites GLAAD's statistic that "more than one in ten young people identified as gender non-conforming, compared to $3 \%$ of the over-50s") more accessible to younger audiences by the inclusion of gender-fluid characters.

As the rhetoric of trans theory has made its way into Shakespeare studies, critics and practitioners increasingly reach for "trans" as a lens through which to read and produce Shakespeare. Obviously, gender and cross-dressing have a long history in Shakespeare criticism, perhaps as long as the history of that criticism itself, but as critics shift their rhetorical maneuvers from the "transvestite" or "hermaphrodite" toward the contemporary label "transgender," it is worth pausing as we try to sort out exactly what the connection is between Shakespeare and contemporary social justice movements. The preponderance of scholarship on cross-dressed characters like Viola or Rosalind unraveling 
the gender binary would seem to suggest that transgender identity is indeed integral to Shakespearean performance. However, because of both structural and social inequalities in casting practices, very few transgender actors appear in these or any roles in Shakespeare. ${ }^{2}$ Living, nonfictional, self-identified trans people thus have both a privileged and a completely disposable relationship to the bard. Because we persist in reading androgyny or genderqueerness in the performance of a cis actor, we participate directly in constructing the image of androgyny and genderqueerness from the performance of a cisgendered body. ${ }^{3}$ Dependence on the cis body for these readings then produces a fictional "trans" body continually defined by the same cisgendered norms-a performative fiction of androgyny and genderqueerness that is uninterested in the varied branches of androgyny that medical and social transition have actualized.

By inviting the contemporary and material realities of transgender identity into literary and historical scholarship, we begin to read gender presentation as a function, process, or point of rupture with phenomenological resonance across time. ${ }^{4}$ In our search for more expansive and inclusive modes of reading, teaching, and performing Shakespeare, we must first question how the assumptions that underscore a current critical discussion might replicate transphobic and heteronormative discourse. Not only will this contribute to the inclusive model of Shakespeare that Tosh and others seek, but it can also help us as scholars develop more nuanced work on gender, passing, and the question of trans-historical gender identity. We must reckon not just with the rhetoric of genderqueer bodies and performance, but also with trans people's history with a socially marked body and the community that has developed around self-fashioning. At a critical moment when the boundaries of acceptable gender expression are the subject of political debate, this move signals to our students that there is meaningful continuity between our work and their lives.

\section{Dressing Down the "Dressing Up" Narrative}

The current critical practice, one that contributes to optimistic but distancing sentiments like Tosh's, is a result of a genealogy of scholarship that has long prioritized a study of transvestism, which is to say that it was primarily concerned with clothing rather than identity. It takes little more than a pair of pants to turn Rosalind into Ganymede, Viola into Cesario, or Portia into Balthazar, which is incoherent with the experience of anyone attempting to transition today. Go to any internet 
forum for trans people, and you will find people talking to each other about how to transition-practically, legally, socially — and especially how to pass: that is, to be read as the gender with which you identify. What this suggests is not that passing is mandatory, but rather that it is hard. In Shakespeare, by contrast, the magical transvestism of "the pants" is instant and absolute. Although Orlando has been wandering the woods for days thinking of nothing but Rosalind, when presented with Ganymede-who presumably still looks exactly like Rosalind, the person he has been thinking about continuously-he makes no connection, and addresses the stranger only as "pretty youth." Similarly, when Sebastian encounters Cesario at the end of Twelfth Night, he thinks Cesario looks not like his lost sister, but like himself, as he marvels, "Do I stand there? I never had a brother." Even when Cesario tells him that he had a father named Sebastian, and a brother also named Sebastian, and that he comes from their home of Messaline, Sebastian does not see his sibling in the person standing before him:

Were you a woman, as the rest goes even,

I should my tears let fall upon your cheek,

And say "Thrice-welcome, drowned Viola!"

Sebastian's inability to recognize Viola as Viola is rooted in his inability to believe she is not a man. He sublimates any doubt of gender to a doubt of identity. At the level of cognition, this cedes ontological and intimate knowledge of a person to the knowledge of their gender, seeming to suggest Sebastian knows his own sister less than he imagines he knows this stranger's genitals.

But for many trans people, their families are some of the most difficult people to convince of the legitimacy of their gender identity. Looking at online forums and digital communities, we see thousands of results for searches like "How can I get my parents to use my preferred name?," "How do I get my parents to use my pronouns?," and "My $\mathrm{mom} / \mathrm{dad} / \mathrm{sibling}$ doesn't believe I'm trans." Characters like Viola may present a utopian vision of transition: one of such ease and striking completeness that even your own brother would instinctively use the right pronouns. However, when we take these as uncritical parallels for transness, it obscures much of the anxiety, ambivalence, and danger that this familiar scenario presents for many.

Attending to the precarious lived experiences of transgender people and validating those experiences for our trans students in particular are crucial to rethinking our pedagogy and readings of Shakespeare. That validation might come not from enthusiastic endorsement of a trans reading of Shakespeare's cross-dressers, but by acknowledging 
the limitations of these representations. To that end, good texts to pair with Shakespeare in the classroom could include Leslie Feinberg's novel Stone Butch Blues (1993), Kate Bornstein's semi-autobiographical play Hidden: A Gender (1994), or Janet Mock's memoir Redefining Realness (2014), all of which detail gender and transition as a process of misrecognition, misgendering, and community context. One might, for instance, close read this Cesario/Sebastian scene from Twelfth Night with Act II, scene iii of Bornstein's Hidden, in which the transfeminine character details her coming out:

I'm a transsexual, I said to my wife.

I'm not a lesbian, she said, goodbye.

I'm a transsexual, I said to my friends.

We don't know you, they said, goodbye.

I'm a transsexual, I said to my mother.

You're my child, she said, but for now goodbye.

In this scene Bornstein shows the precarity of relationships during transition-seen here with the repetition of the "goodbye." What we see in Bornstein that differs importantly from the Cesario/Sebastian confrontation is how gender exists as a component of social relationships as well as a facet of interiority, to the extent that a shift or transition on one end of the relationship changes the nature of the relationship itself. Bornstein's refrain of loss and abandonment highlights the failure of the relationships to evolve with their constituents. Compared with our scene in Twelfth Night, Sebastian's use of the past tense for "I never had a brother" suggests an unspoken "before"; he entertains the relationship as possible, if puzzling, in a way that the declaratives "I'm not a lesbian" and "We don't know you" actively reject.

Bornstein's play also contains several scenes of the character interacting with an extradiegetic narrator who repeatedly misgenders her and critiques her appearance, movement, and behavior. The stakes and rules of passing are rendered visible and can also be paired with a number of instructional scenes in Shakespearean text. Indeed, Shakespeare gives what might now be considered very bad advice for passing. In Cymbeline, when Pisanio instructs Imogen on how to pass for a man, he tells her to turn "fear and niceness ... into a waggish courage: / Ready in gibes, quick-answer'd, saucy and / As quarrelous as the weasel" (III, iv, 155-9). Equally pugnacious, As You Like It's Rosalind promises Celia that they will "have a swashing and a martial outside" (I, iii, 117). Portia makes a similar brag in Merchant of Venice when she says she'll "speak of frays / Like a fine bragging youth, and tell quaint lies" (III, iv, 68-9). Waggish, saucy, quarrelous, swashing, bragging-across the 
comedies, all parties agree that affecting the personality of a young, bravado-filled boy is the formula for passing. This spectacle of waggish masculinity seems particularly out of step in the contemporary cultural landscape, where discovery is fatal and stealth is a virtue. Leaning in to this discrepancy could facilitate an introduction to the queer historicist debates in upper-division classes. Pairing transgender style guides with any of Shakespeare's instructional scenes shows us immediately why we can't simply transpose one identity onto another. The popular blog the Art of Transliness (a FTM-s, or female to male, style blog) suggests that "Dressing like a generic guy can often (though not always) increase your chances of being read as male." $\mathrm{Or}$, as vice chair of the Trans United Fund, Allison Gill, said in a 2016 NPR interview: "The last thing you as a trans person would want to do is draw attention to yourself." But by ignoring this contemporary conversation, we lose the voices of transgender people and thus their authoritative perspective on the semiotic efficacy of clothing and behavior, which counters that dressing up is not a hall pass so much as a liability.

However, this does point us toward a larger epistemological bias in Shakespeare criticism. The issue is more than that Shakespeare fails to adequately prefigure the American transgender experience, more than a cautionary tale against looking for transgender resonance in the past. Instead, we must examine how collapsing trans with cross-dressing places undue emphasis on the garment and thus problematically blurs trans identity with the language of disguise. Becoming a man is as simple, per Pisanio, as "forgetting" to be a woman and as remembering to wear the clothes of a man. "First, make yourself but like one," he suggests, and pulls "doublet, hat, hose, all / That answer to them" (III, iv, 168, 170-1) from his bag. Unmaking a man is just as simple-after Sebastian and Cesario/Viola embrace, Orsino continues to call Cesario "Boy," and requests to see him "in thy woman's weeds" (V, i, 269). The superman-like gender costume is fully dependent on the presence or absence of masculine clothing-which always fits perfectly and always looks good.

Ironically, this mutable form cloaked in gender suggests a gender-neutral body that develops gender from the clothes that hang off it. ${ }^{8}$ This mutable body within the gendered cocoon of clothing may lend a supportive example to Laqueur's "one sex" model of the pre-Enlightenment, but it again elides much of the labor and anxiety of passing that surely would have been as true for those evading sumptuary laws as for those avoiding bathroom bills like North Carolina's HB2. ${ }^{9}$ The characters' ease in the clothing/gender and the way they are immediately gendered by other characters may be because, as Bridget 
Escolme writes, "Most disguises in the early modern theatres simply work" ${ }^{10}$ as a plot device, but reading clothing and disguise as markers of transness risks creating a binary between the body-which is "true" and essential—and the clothing — which is "trans" but also deceptive. ${ }^{11}$

In this anxiety about exterior shows, we see shades of early modern ambivalence with respect to interiority. Katharine Eisaman Maus introduces this with Hamlet's devaluation of the "trappings and suits" of mourning (as opposed to the true, but unknowable, ontology of grief) but also explores the unreliability and unwieldiness of visual, external proof more broadly. ${ }^{12}$ By only looking to transvestite characters as the locus of trans in Shakespeare, we reify this internal/external divide, and uphold tired and damaging beliefs about the ontology of the body that antagonize the ongoing political and legal battles faced by trans people today. Early modern anxieties about false outward appearances are all too familiar to current bathroom debates, which suggest that if trans people were allowed to use the bathroom that coheres with their gender identity, men would dress as women in order to infiltrate the bathroom. There are a number of wild assumptions here, including the very early modern concern about the inability to tell the difference between a trans person and a cross-dressing assailant-indeed, a conflation of the two that suggests they may be one and the same. It has therefore become a necessary theorem for contemporary gender activism that gender identity supersedes the physical body - the body is the self-identified gender of the person-regardless of how it is clothed or whether it has undergone medical intervention. Locating gender within self-identification, regardless of the body's exterior, is significant not only to the ongoing argument which questions whether transwomen have male privilege before they transition but also to the act of validating the identities of people who are pre-transition, who choose not to transition medically, or who may not be able to safely transition for any number of reasons. ${ }^{13}$

In situations where adding a full-length text (like Bornstein's or Mock's) would not be appropriate, these sites of popular debate may be useful as preliminary guided discussion material. There are a number of online resources from queer-savvy institutions that unpack "myths" or misunderstandings about trans people. ${ }^{14}$ Use guided questions like "How do Shakespeare's characters fit into, or upset, the myth cycle?" If, for instance, common myths are that trans people are seeking attention, and/or that they are trying to trick people, how does that intersect with Shakespeare's heroines-who are trying to trick people, but hope not to attract attention? Do the nuances of the text perpetuate the myth or destabilize it somehow? In addition to moving beyond stereotypes, we must also cultivate awareness of the material realities of transgender 
people in our contemporary moment, which means including primary sources and taking those experiences seriously. Bringing transgender theory to Shakespeare means becoming literate in transgender sociopolitical issues. It means becoming, on some level, an invested and educated ally.

\section{Justice-Oriented Pedagogy in Praxis; or, Going Pantsless}

Including these sources and issues in our work and classroom need not be viewed as a limiting factor, but rather as an opportunity for more expansive analysis. What characters in Shakespeare might participate in discussions of body dysphoria, a major mental health issue for trans people? What characters experience harassment by law-enforcement figures, as do over one in three trans people? What characters experience homelessness, a situation that affects one in five transgender people? ${ }^{15}$ What characters experience sexual violence, something that over 50 percent of trans people report experiencing? ${ }^{16}$

We can use these questions even as quick asides in lecture to build a more rigorous lens for our critique of cross-dressed characters-we might introduce trans or genderqueer readings of Rosalind by discussing with students the scene where she is kicked out of her home by Duke Frederick. We might model a close reading of Joan la Pucelle's madness through the lens of body dysphoria. We might make a point of noting that in Merry Wives, it is while Falstaff is dressed as Old Woman of Brentford that he is subject to Ford's harshest verbal and physical abuse. When we take care to make these observations, even briefly, it signals to our students that we have more than a passing self-interest in our readings of gender-nonconforming characters.

With these issues in our critical consciousness, we can even decenter clothing entirely. Hamlet makes a nice touchstone here, because he does act out a range of scenarios we can associate with contemporary transgender struggle. Hamlet is disallowed from inheriting his military position, prevented from attending his school, deeply depressed, considering suicide, ejected from his home, and filled with anxiety about the task that generations of scholars have insisted is the ur-quest of masculinity and patrilineage. This might make him a good candidate for an essay or classroom assignment that invites contemporary comparison and analysis-perhaps one that pairs Hamlet scenes with primary documents about the trans military ban, or student Gavin Grimm's 2017 court case. ${ }^{17}$ Rather than a simple compare and contrast between past and present, assignments should discuss the impact of 
potential trans readings on other events and themes in the play. Does this generate a more sympathetic rationale for Hamlet's misogyny? How might a culture of transphobia affect the usurping Claudius's ability to take the throne in place of the king's heir? In the way that the act of performance opens up new potential meanings in the text, readings of Hamlet-as-trans might help us posit potential answers to lingering "problems" in the text, and the benefits for trans students (and trans people, more broadly) are innumerable. By centering the assignment on a text that doesn't have a cross-dressed character and isn't traditionally seen as gender-nonconforming, we reject the myths that you can tell who is trans just by looking and also that you need to dress a certain way to be "really" trans; by using a character as canonical as Hamlet, gender, and transgender identity specifically, is taken in context with the character's life and isn't their only defining characteristic; by framing the assignment in the context of ongoing political advocacy, trans students see their experience validated instead of fetishized by a remote literary discourse.

Shifting away from the interior/exterior rhetoric of truth and disguise, and toward a model developed with a perspective of experience and the self-in-context (which is to say, often either in community or in danger) can help us put Shakespeare to work for justice by training us to see and witness the broad range of experiences of trans people. If we as scholars are going to engage in a practice that believes trans people are integral to Shakespeare, it is important at every phase to make scholarship that is rooted in experience, not abstraction. If we're going to visit the past to serve the present, it should actually and meaningfully serve those populations whose language, identities, and communities we are borrowing.

\section{Notes}

Portions of this chapter were presented as "In That Dimension Grossly Clad: Transgender Rhetoric and Representation in Shakespeare" for the Next Generation Plenary (NGP) at the Shakespeare Association of America in April 2018. The full texts of the NGP papers were published as a feature in the fall 2019 issue of Shakespeare Studies, and the shared sections are used here with permission of the editors of that journal.

1. Will Tosh, "What You Will," Tumblr post, May 11, $2017<$ https://blog. shakespearesglobe.com/post/160546033578/gender-in-twelfth-night> (accessed February 21, 2019).

2. We see this played out even here in the Twelfth Night that Tosh 
describes-despite Tosh's remarks, Viola was played by cisgender actor Anita-Joy Uwajeh. The role of Feste, the fool, was played by drag performer Le Gateau Chocolat, but this habit of lumping "trans" in with drag perhaps only underscores the lack of distinction and sensitivity surrounding trans people and their identities.

3. The stability of a legibly cisgendered body may be a fictional ontology, visà-vis Judith Butler, Bodies That Matter: On the Discursive Limits of "Sex" (New York: Routledge, 1993).

4. See Heather Love, Feeling Backward: Loss and the Politics of Queer History (Cambridge, MA: Harvard University Press, 2009).

5. Shakespeare quotations here (Twelfth Night, V, I, 235) and below are from The Arden Shakespeare Complete Works, 2nd edition, ed. Ann Thompson, David Scott Kastan, and Richard Proudfoot (London: Arden Shakespeare, 2011).

6. "The Art of Transliness Guide to Being Read as Male," The Art of Transliness <http://theartoftransliness.com/post/19575647114/the-art-oftransliness-guide-to-being-read-as-male> (accessed January 26, 2019). Emphasis mine. See also "The FTM's Complete Illustrated Guide to Looking Like a (Hot) Dude" < http:/ftmguide.rassaku.net> (accessed January 26, 2019). Here, even a simple choice between boots or no boots is considered a make-or-break: "Boots are going to be eye-catching. Boots are not a 'safe' or fashion-neutral choice; on men, they make a statement, so if you are trying to sneak below the radar and pass for male without drawing attention to yourself, boots are not your best option." Similarly, see "Why You Don't Pass. Part I," Man 101: The Brutally Honest FTM Guide <http://man101.tumblr.com/post/4634418160/why-you-dont-passpart-i> (accessed January 26, 2019), which rules out buzzcuts, fauxhawks, and tank-tops for similar reasons

7. Jeff Brady, "When a Transgender Person Uses a Public Bathroom, Who Is At Risk?” NPR.org, May 15, 2016 <https:/www.npr. org/2016/05/15/477954537/when-a-transgender-person-uses-a-publicbathroom-who-is-at-risk> (accessed February 21, 2019).

8. See Ann Rosalind Jones and Peter Stallybrass, "Transvestism and the 'Body Beneath': Speculating on the Boy Actor," in Renaissance Clothing and the Materials of Memory (Cambridge: Cambridge University Press, 2000), 207-19.

9. See Thomas Laqueur, Making Sex: Body and Gender from the Greeks to Freud (Cambridge, MA: Harvard University Press, 1990); Helen King, The One-Sex Body on Trial: The Classical and Early Modern Evidence (New York: Routledge, 2013).

10. Bridget Escolme, "Costume, Disguise and Self-Display," in Shakespeare's Theatres and the Effects of Performance, ed. Farah Karim-Cooper and Tiffany Stern (London: Bloomsbury, 2013), 118-40.

11. See also Jack Halberstam, In a Queer Time and Place: Transgender Bodies, Subcultural Lives (New York: New York University Press, 2005). 
12. Katharine Eisaman Maus, Inwardness and Theatre in the English Renaissance (Chicago: University of Chicago Press, 1995).

13. In spring 2017 there was a high-profile debate between feminist author Chimamanda Ngozi Adichie and transgender actor/icon Laverne Cox after Adichie suggested that transwomen benefited from male privilege before transition. Cox's response is detailed by Daisy Murray, "Laverne Cox On Why Not All Trans Women Experienced Male Privilege Pre-transition,” Elle, March 13, 2017 <https://www.elleuk.com/life-and-culture/culture/ news/a34593/laverne-cox-writes-about-why-not-all-trans-womenexperienced-male-privilege-pre-transition $>$ (accessed February 21, 2019).

14. Many universities with LGBT centers develop such a document or website for the campus, and it would be worth checking in with your institution to see what resources are available. These can easily become a tool that both educates your students about how to respect their transgender peers, and facilitates a discussion about Rosalind or Viola. I include here three listicle-style articles that take up the "myth"-busting model (all accessed February 21, 2019): "Frequently Asked Questions About Transgender People,” National Center for Transgender Equality, July 9, $2016<$ https:// transequality.org/issues/resources/frequently-asked-questions-abouttransgender-people>; “Transgender People: 10 Common Myths," Vox, March 21, 2017 <https:/www.vox.com/identities/2016/5/13/17938088/ transgender-people-rights-myths>; Jessica Migala, "5 Things Everyone Gets Wrong About Transgender People,” Health, May 1, $2017<$ https:// www.health.com/mind-body/transgender-myths $>$.

15. "Issues: Housing and Homelessness," National Center for Transgender Equality, 2015 <http://www.transequality.org/issues/housing-homelessness> (accessed February 21, 2019).

16. "Transgender Rates of Violence: Victim Service Provider's Fact Sheet 6," FORGE, October 2012 <http://forge-forward.org/wp-content/docs/FAQ10-2012-rates-of-violence.pdf $>$ (accessed February 21, 2019).

17. See: “G.G. v. Gloucester County School Board,” American Civil Liberties Union, March 6, 2017 <https://www.aclu.org/cases/gg-v-gloucester-countyschool-board> (accessed February 21, 2019); Joshua Block, "A Court Ruling in Gavin Grimm's Case Is A Very Big Deal,” American Civil Liberties Union, May 23, 2018 <https://www.aclu.org/blog/lgbt-rights/transgenderrights/court-ruling-gavin-grimms-case-very-big-deal> (accessed February 21, 2019). 


\title{
Shakespeare in Japan: Disability and a Pedagogy of Disorientation
}

\author{
Allison P. Hobgood
}

On Wednesday, July 27, 2016, I woke to a CNN live news report that Satoshi Uematsu had broken into Tsukui Yamayuri-en, a residential care center for people with mental and physical disabilities in Sagamihara, Japan, and perpetrated the worst mass killing in the country in eighty years. The facility housed approximately 140 residents between the ages of nineteen and seventy-five. In the early morning hours, Uematsu, a former employee of the facility, entered Tsukui Yamayuri-en and stabbed to death nineteen people and injured twenty-six others, some quite severely. The Japan Times described Uematsu as "methodically cutting the throats of his victims in what appeared to be a frenzied mission of mercy" premised upon the belief that he was "trying to 'save' people with multiple disabilities and had 'no remorse' for what he did."1 In the wake of the atrocity, a number of Japanese news outlets deemed Uematsu's murder spree a hate crime motivated by the eugenic logic that, as the killer proclaimed afterward when he turned himself in, "It is better that disabled people disappear."2

Although I am a teacher-scholar located in the U.S., that summer I was living about forty miles north of Sagamihara, teaching Shakespeare and disability studies to (predominantly) Japanese students studying at Tokyo International University (TIU) in Kawagoeshi. This meant I was privy to what The Guardian called "the deadliest postwar attack committed on Japanese soil." 3 I work in early modern disability studies and have been for years making the case that Shakespeare enables us to think about disability — both historically and contemporarily-in new, more ethical ways. My broad aim that summer was to tease out the intersections of global Shakespeare, cross-cultural teaching and learning, and disability social justice. This chapter discusses what happened in my classroom when Shakespeare and the real-life event of the Sagamihara stabbings unexpectedly collided, provoking dialogue about disability 
constructions across time and space, and in the unique context of disabled lives and disability rights in contemporary Japan. While I realize not everyone can or will teach in Japan (or abroad in general), I am hopeful that my experiences nonetheless offer readers portable ideas about radical feminist disability pedagogy and tools for making direct, material connections between Shakespeare and social justice work.

Critical disability studies has established disability as a defining social category, comparable to race, class, and gender, and has mobilized academic theory into civil rights activism. The field has helped define "disability" in usefully capacious terms that name congenital and acquired bodily variations that inevitably occur as people move through culture and time. More than just defining disability, though, disability studies has reimagined disability as a social category, not an individual characteristic; a discursive construction, not a bodily flaw; and a representational system rather than a physiological problem to be "cured" by the medical community. In short, disability studies helps us radically re-envision our world and rethink the ways we understand what it means to be human.

My work uses contemporary disability studies to explore ideas about what constituted humanness in the English Renaissance. How did impaired bodies construct early modern cultural perceptions of normalcy, I ask? Which variant minds were imagined as "less than," and why? From Richard III and the "mad" King Lear in Shakespeare to dwarf narrators in Edmund Spenser's poetry to disability humor in jest books, stigmatized impairment and its representations saturate the landscape of Renaissance literature: when you start paying attention, stuttering servants, melancholy lovers, castrated poets, and limping war heroes appear nearly everywhere on the early modern page and stage. ${ }^{5} \mathrm{My}$ research and teaching think through these representations to uncover a lexicon of early modern impairment, illuminate a cultural imagination of disability in Renaissance England, and grapple with mental and physical variation in a historical period whose ideals and norms often seem so different from our own.

Needless to say, my classes at TIU had to address the event at Sagamihara. But how? I found myself asking questions deeply resonant with the aims of this volume: Where do teachers begin with students in broaching trauma, death, and disability, especially in real time? How best to do so across significant differences in, at minimum, language and in academic and social norms? Could Shakespeare facilitate a fruitful cross-cultural encounter that would enable us to process and comprehend something as complicated, heart-wrenching, and politically fraught as the Sagamihara stabbings? As we approach such circumstances from the vantage 
point of equity and rights, can Shakespeare actually do anything to help us? Does his work really matter when we engage in disability social justice?

In this instance, at least, it turned out the answer was yes. And no. Shakespeare mattered a lot that summer at TIU, in large part because he mattered so little. Reading Shakespeare offered my students social and emotional distance on Sagamihara. While they were wary about discussing disability, their general lack of familiarity with Shakespeare meant they felt unburdened by his status as a Western cultural icon, a burden I often find at play with U.S. students doing early modern studies. In Japan, learners struggled to dialogue about disability, but they felt free around Shakespeare; and that freedom, in the end, gave them the space and language to talk about Sagamihara. Let me explain.

Disability and disability rights in Japan are fraught topics. ${ }^{6}$ Cultural mores and longstanding social taboos can make it difficult for students to talk about mental and physical impairment (their own and others') as well as the politics of disability identity. Hiroe Yōda explains, for example, that Japanese society relegates disabled people to "dependence on their families" and, while generally sympathetic to disability, "shows little concern about the quality of life these disabled persons are actually experiencing." "While the last forty years have seen significant development in Japanese disability activism and reform, built on a U.S. rights-based model of equal access and independent living, Japanese social and cultural values have made less room for an ethics of self-determination and advocacy as political tools. Rights and independence models are often incompatible with political, legal, and social norms in Japan. ${ }^{8}$

Indeed, stigma around mental disability remains particularly palpable. Etsuro Totsuka describes how in the early twentieth century, mental illness, for instance, was imagined as "impossible to understand and dangerous," and people with such diagnoses and experiences thus were "thought to be a disgrace to the family." Even in the face of disability social justice, this attitude still holds sway, so much so that, as Reuters reported three months after the attack at Sagamihara, "almost nothing except [the victims'] genders and ages . . . has been made public." In a statement released to the media, Japanese authorities further noted that they "did not release the victims' names because it was a facility for cognitively disabled people and they needed to protect the families' privacy," and, moreover, that "the victims' families had requested special consideration about how the matter was reported." 10

While many of my students at TIU carried the weight of this disability taboo, they did not suffer from the limitations of obligated 
reverence, anxious admiration, or bored disdain for Shakespeare that (at least in my experiences) lots of U.S. college students bring to that coursework. Especially since World War II, Shakespeare has been a real cultural force in Japan, ${ }^{11}$ but apparently not significantly so for the TIU students I encountered. For example, on the first day of class they interviewed each other and their peers around campus asking: Have you heard of Shakespeare? How? Who is he? What did he do? What did he write? Have you seen his plays? Did you like them? Why or why not? What is his place in Japanese culture ${ }^{32}$ Surprising to me, the majority of my students, as well as the colleagues they surveyed, had little to no experience reading or seeing Shakespeare. Predominantly native speakers of Japanese, it wasn't just that they hadn't read Shakespeare in English: they had not come across his work in Japanese either, not on the page, stage, or even in film. For nearly all of them, Shakespeare never mattered.

That summer, the combination of significant challenges across language (I speak no Japanese; many of my students spoke little English) coupled with the tabooed incomprehensibility of the Sagamihara tragedy and this surprising de-privileging of Shakespeare prompted my total discombobulation. I quickly discerned that tactics I typically use in the classroom to spark interest and conversation about disability, not to mention early modern poetry and drama, were not going to work. I realized I needed a new approach, and so I gave myself over to what I'm calling here a feminist disability pedagogy of disorientation: in short, a pedagogy that encourages everyone, including teachers, away from fear, stoic "empiricism," and the need for mastery toward immersive, deeply affective, real-time experiential learning.

Not incidentally, this pedagogy evolved alongside my own literal, physical disorientation. Just prior to my trip, I was diagnosed with chronic migraine; mine manifested periodically in extreme dizziness, pain, and light-sound sensitivity. This "brain fog," as Mel Chen usefully terms cognitive states of difference, runs against the grain of "the kind of intellectual work we are asked to trade in ... [that] requires a comprehension - a word that suggests both finality but also wholeness of grasp." ${ }^{13}$ Without discounting the real discomfort of chronic physical pain, I want to suggest that my embodied experience of migraine headaches opened up even more space for a pedagogy of disorientation that resists "clean cognition"; this sort of pedagogy invites, per Chen, "partial knowing" and "shared epistemologies that can be developed together among differently cognating beings." ${ }^{14}$ Mine and my students' constructive bewilderment around language, affect, and cultural differences coincided with my own aggravated mental "confusion," and the 
convergence made so obvious to me the necessity and utility of cripistemology ${ }^{15}$ in practice. I want my classrooms, both at TIU and here at home, to be learning spaces that revel in the "displacement not only of conventional ways of knowing and organizing knowledge, but also of the mandate of knowing itself, of the consolidation of knowledge."16

One practical example of the power of this disoriented, partial knowing - what we might also understand as pedagogical "letting go"came in my TIU classes' screening of Akira Kurosawa's 1957 Throne of Blood. The film sets Shakespeare's Macbeth in feudal Japan and employs stylistic elements drawn from Noh, a form of classical Japanese musical drama performed since the fourteenth century. The version of the film we watched offered no English translation, and I assumed I was the only viewer experiencing the film as a kind aesthetic and linguistic outsider. My students informed me, however, that both Noh, which was new to most of them, and the archaic Japanese language Kurosawa employs in the film gave them only partial knowledge. As it turned out, they were pretty disoriented too.

Our joint disorientation prompted productive class conversation about the feeling of the film, as opposed to, for instance, its affinity with the original Shakespeare (something these students unfamiliar with Macbeth were far less interested in anyway). Instead, we found ourselves talking about how frightening Lady Macbeth's exaggerated geisha character was as she began to unravel over the course of the movie. We drew pictures on the board that unpacked Kurosawa's representation of the Macbeth's descent into "madness," and students close read in low-stakes small groups select excerpts from the play: "Is this a dagger which I see before me, / The handle toward my hand? . . . Or art thou but / A dagger of the mind, a false creation / Proceeding from the heat-oppressed brain?” (II, i, 33-9). As we analyzed lines from Lady Macbeth's sleepwalking scene $(\mathrm{V}, \mathrm{i})$, we dialogued about how these various representations might make one fearful of mental disability. I introduced students to the term "stigma" and slowly guided our conversation toward the attack at Sagamihara. In the warm-up context of Shakespeare and the (sometimes hilarious) disorientation it provoked, everyone came to that contemporary event more candidly. What scared Satoshi Uematsu so deeply about disability that it seemingly legitimated his heinous actions, we probed? Why are people with mental and physical disabilities marginalized in Japanese and U.S. cultures, respectively? What kinds of social justice initiatives around disability rights might upend unjust norms and cultural resistances?

In other class sessions, we explored Macbeth via the Manga Shakespeare series and Courtney Carbone's Macbeth \#killingit from 
the OMG Shakespeare series. ${ }^{17}$ These innovative adaptations, lambasted by some scholars as the "dumbing down" of early modern literature, contrastingly provided me and my students with unique points of access to Shakespeare. Recalling Mel Chen, the texts enabled our continued displacement of conventional ways of knowing both drama and disability. Manga Macbeth is an experiment in comic form that, playing on a style developed in Japan in the late nineteenth century, situates Macbeth "in a future world of post-nuclear mutation." ${ }^{18}$ De-emphasizing the written word in favor of graphic illustration, the pictorial elements of manga presented Shakespeare to non-English-speaking students in a visual form that made the play's plot much more discernable. Macbeth \#killingit invited students to use their translation skills in re-reading that plot in English text-speak. Carbone's hilarious imagination of Macbeth via Foursquare, unsent "aside" texts, chatroom dialogues, and emojis revels in a sassy, unserious Shakespeare that resonated with my TIU students as it poked fun at the supposed erudition of the Renaissance literary canon.

Inside Carbone's irreverent text, where Shakespeare's prowess seems not to matter, however, lies fodder for serious discussion of disability. For example, the \#Kingsgiving Chat Room (the infamous banquet scene of III, iv) and its facing-page texts were an opportunity for my class to talk further about representations of mental disability. "Yeah, Macbeth," mocks Banquo's ghostly apparition, "You're just hallucinating. None of this is real [ghost emoji with tongue out]." ${ }^{19}$ Affronted by Macbeth's atypical behavior, Ross suggests "Do you guys wanna reschedule? [July 17 calendar emoji] It seems Macbeth is a little under the weather [rainy umbrella emoji] . . or something ...." " ${ }^{20}$ Lady Macbeth, equally puzzled and exasperated, chides Macbeth: "No idea what ur talking about. Restore ur [phone emoji] to factory settings. AND ACT NORMAL! [angry emoji] . . Stop it! Macbeth, ur acting crazy"; and then later, "Oh, lol. Here we go again! Someone cut him off! [beer emoji] [woman miming an X over her chest signaling cut off emoji]. ${ }^{21}$

Together my classes explored the ways Shakespeare's play struggles to make sense of Macbeth's mental state, deeming it "craziness," drunkenness, and/or illness. In other words, students considered not only whether and why Macbeth "loses his mind" over the course of the drama but also how we are encouraged, through stigmatizing cultural narratives and biases, to understand atypical mental functioning and behavior as "abnormal." We took a broadly comparative approach and talked about an early modern moral model of disability that understood impairment as punishment from God; I said a bit about the Mad Pride Movement in the United States; ${ }^{22}$ and we discussed, as anthropologist 
and disability scholar Karen Nakamura notes, the "incredible amount of shame surrounding mental illness in Japan, [which] has some of the longest hospitalization/institutionalization rates in the developed world as well as the highest rates of pharmaceutical use." ${ }^{23}$ We also viewed Nakamura's documentary film about a radical disability community and residential treatment center for people with severe mental illnesses located in northern Japan. ${ }^{24}$ As one can see, Macbeth in manga and text-speak facilitated not just learning about Shakespeare, but learning about how old cultural narratives can help us write new, more just ones. Shakespeare was the often amusing, always ambivalent fulcrum for good, challenging conversations about disability and equity in modern Japan.

Revenge, justice, fear, violence, and disability were at the heart of the Sagamihara tragedy. They likewise sit at the heart of much of Shakespeare. While I was in Japan, the devastating but potent confluence of these two seemingly disparate domains changed my students; even more so, it changed me. It immersed me in a feminist disability pedagogy that changed my teaching. I became-and have stayed - unmoored. I work hard not to be distraught by this risky uncertainty, but instead inspired by it. Through dynamic disorientation, I find I can teach - and learn - in more ethically minded ways that embrace the following notions: sometimes not knowing is the best kind of knowing; the partial, local, and incomplete can crystallize the big-picture global; social justice work is always hard intellectual work; Shakespeare can matter by not mattering at all. And yet, thinking through the words and worlds of "old, dead, white dudes," as my students like to call them, can help us reshape our words and worlds in ways that might matter in the end, maybe even a lot.

\section{Notes}

1. "Care Home Massacre Probed as Mercy Killing," Japan Times Online, July 27, $2016<$ https://www.japantimes.co.jp/news/2016/07/27/national/ crime-legal/suspect-saga mihara-care-facility-mass-murder-says-noremorse $>$ (accessed February 21, 2019).

2. Justin McCurry, "Japan Knife Attack: Stabbing at Care Centre Leaves 19 Dead," The Guardian, July 26, 2016 <https://www.theguardian.com/ world/2016/jul/25/tokyo-knife-attack-stabbing-sagamihara> (accessed February 21,2019$)$.

3. Ibid.

4. On early modern disability, see David M. Turner and Kevin Stagg, Social Histories of Disability and Deformity (New York: Routledge, 2006); 
C. F. Goodey, A History of Intelligence and "Intellectual Disability": The Shaping of Psychology in Early Modern Europe (Burlington: Ashgate, 2011); Allison P. Hobgood and David Houston Wood, Recovering Disability in Early Modern England (Columbus: Ohio State University Press, 2013); Allison P. Hobgood and David Houston Wood, "Disabled Shakespeares," Disability Studies Quarterly 29, no. 4 (2009) <http:// dsq-sds.org/article/view/991/1183> (accessed February 21, 2019).

5. See, for example, Katherine Schapp Williams, "Performing Disability and Theorizing Deformity," English Studies 94, no. 7 (2013): 757-72; Katherine Schapp Williams, "More Legs Than Nature Gave Thee': Performing the Cripple in The Fair Maid of the Exchange," ELH 82, no. 2 (summer 2015): 491-519; Allison P. Hobgood, "Teeth Before Eyes: Illness and Invisibility in Shakespeare's Richard III," in Disability, Health, and Happiness in Shakespeare, ed. Sujata Iyengar (New York: Routledge, 2015), 24-38; Elizabeth B. Bearden, "Before Normal, There Was Natural: John Bulwer, Disability, and Natural Singing in Early Modern England and Beyond," PMLA 132, no. 1 (January 2017): 33-50; Lindsey RowHeyveld, "Disability and Masculine Commerce in The Fair Maid of the Exchange," Allegorica: Traditions and Influences in Medieval and Early Modern Literature 29 (2013): 88-105; David Houston Wood, "Shakespeare and Variant Embodiment," in Shakespeare in Our Time: A Shakespeare Association of America Collection, ed. Dympna Callaghan and Suzanne Gossett (London: Bloomsbury Arden Shakespeare, 2016), 189-94; David Houston Wood, "New Directions: 'Some Tardy Cripple: Timing Disability in Richard III," in Richard III: A Critical Reader, ed. Annaliese Connolly (London: Bloomsbury, 2013), 129-54.

6. On the history of disability studies and activism in Japan, see: Carolyn S. Stevens, Disability in Japan (New York: Routledge, 2013); Katharina Heyer, Rights Enabled: The Disability Revolution from the US, to Germany and Japan, to the United Nations (Ann Arbor: University of Michigan Press, 2015).

7. Hiroe Yōda, "New Views on Disabilities and the Challenge to Social Welfare in Japan," Social Science Japan Journal 5, no. 1 (2002): 7-8.

8. See Heyer, Rights Enabled, ch. 4.

9. Quoted in Karen Nakamura, A Disability of the Soul: An Ethnography of Schizophrenia and Mental Illness in Contemporary Japan (Ithaca: Cornell University Press, 2013), 44.

10. Linda Sieg and Kwiyeon Ha, "Japan Confronts Disability Stigma After Silence Over Murder Victims’ Names,” Reuters, September 16, 2016 $<$ https://www.reuters.com/article/us-japan-disabled/japan-confrontsdisability-stigma-after-silence-over-murder-victims-names-idUSKCN11M0AM> (accessed February 21, 2019).

11. London Shakespeare touring companies established routes through Japan in the 1860s, peaking around 1913. The first performance of Shakespeare in Japan by Asians in Asian languages was in 1885. While certainly British 
imperialism and Japan's desire for so-called Westernization propelled Shakespeare's appearance there, Bi-qi Beatrice Lei counters that "British colonialism and theory derived thence fall short to account for the origins and meanings of the diverse Shakespearean landscape in Asia": Bi-qi Beatrice Lei, Judy Celine A. Ick, and Poonam Trivedi, Shakespeare's Asian Journeys: Critical Encounters, Cultural Geographies, and the Politics of Travel (New York: Routledge, 2017), 2. For the history of Shakespeare's use and reception in Japan, see: Dennis Kennedy and Li Lan Yong, Shakespeare in Asia: Contemporary Performance (Cambridge: Cambridge University Press, 2010); Tetsuo Kishi and Graham Bradshaw, Shakespeare in Japan (London: Continuum International, 2005); Ryita Minami, Ian Carruthes, and John Gillies, Performing Shakespeare in Japan (Cambridge: Cambridge University Press, 2001). For theoretical and historical perspectives on contemporary Shakespeare performance in Asia, again see Kennedy and Yong, Shakespeare in Asia. On Asian adaptation and acculturation of Shakespeare, see Poonam Trivedi and Ryuta Minami, Re-playing Shakespeare in Asia (New York: Routledge, 2010).

12. There are two "official" Shakespeare theaters located in Tokyo: the Waseda Theater Museum, built in 1928 and modeled after The Fortune, and the Panasonic Globe Theater, built in 1988.

13. Mel Chen, "The Race for Cripistemology," Journal of Literary and Cultural Disability Studies 8, no. 2 (January 2014): 172.

14. Ibid.

15. On cripistemology, see Merri Lisa Johnson and Robert McRuer, "Cripistemologies: Introduction," Journal of Literary and Cultural Disability Studies 8, no. 2 (January 2014): 127-48.

16. Chen, "The Race for Cripistemology," 182.

17. Richard Appignanesi, Macbeth, Manga Shakespeare Series (New York: Abrams, 2008); Courtney Carbone, Macbeth \#killingit, OMG Shakespeare Series (New York: Penguin Random House, 2016).

18. Appignanesi, Macbeth, 3.

19. Carbone, Macbeth \#killingit, 49.

20. Ibid., 48.

21. Ibid., 49, 51.

22. See Bradley Lewis, "A Mad Fight: Psychiatry and Disability Activism," in The Disability Studies Reader, 5th edition, ed. Lennard J. Davis (New York: Routledge, 2006), 102-18; Margaret Price and Lennard J. Davis, "Defining Mental Disability," in The Disability Studies Reader, 333-42.

23. Nakamura, A Disability of the Soul, 17.

24. Karen Nakamura, Bethel: Community and Schizophrenia in Northern Japan, DVD (Manic Productions, 2010). 


\title{
Chapter 4
}

\section{Global Performance and Local Reception: Teaching Hamlet and More in Singapore}

\author{
Emily Griffiths Jones
}

Like many of us, I learned Shakespeare as a student almost entirely from reading play texts edited by Anglo-American scholars, and I spent my graduate school years teaching Shakespeare almost entirely from such books. Then, in 2013, I had the great good fortune of being hired as a postdoc affiliated with MIT's Global Shakespeares project. ${ }^{1}$ Over the next few years, I first helped design an online module for teaching global performances of Hamlet - featuring annotated and searchable archives of full videos and video clips of parallel moments from numerous global cinematic and theatrical adaptations - and then spent a semester piloting it in an undergraduate classroom at MIT's sister institution in Singapore, the Singapore University of Technology and Design (SUTD). My own original intention for the Hamlet module was to orient digital Shakespeare scholarship toward small-scale student learning, and I was broadly pleased that I was participating in Global Shakespeares' goals of "demonstrat[ing] the diversity of the world-wide reception and production of Shakespeare's plays" and "promot[ing] cross-cultural understanding," but I started with little notion of what these might mean for practical pedagogy. ${ }^{2}$ Most of my Singaporean students, for their part, started with two things: an ingrained respect for the genius and general importance of Shakespeare, even if they knew little or none of his work, and a hesitancy to call too much attention to themselves and to the various cultural/ethnic/religious differences present within the classroom.

Beloved as Shakespeare is for representing "universal" human experience, students often need reminders to read with an eye toward localized questions of identity, justice, and politics. I focus largely on Hamlet here, alongside a few other texts, partly because it has an entrenched Western interpretive tradition skewed toward the supposedly universalizing psychological realm, and so is ripe for global reconsideration; one of my 
goals for use of the Hamlet module was to overcome any uncritical reverence for the authorial Shakespeare and the "right" (i.e. Western) way of understanding his work. This chapter reflects on, and advocates, a study of Shakespeare through a wealth of multicultural performances in parallel, either after or before reading traditional textual editions, which lets students discover how global Shakespeares transcend the myth of monolithic textual authority/authorship and how these performances participate in specific, still-vital sociopolitical conversations. My Singaporean students-like many of us, Americans included-were living in a state that takes pride in integrating cultures, faiths, and identities yet in reality privileges some over others, a state that straddles liberal and illiberal philosophies and practices. Over the course of three months, we worked together to use global adaptations of Shakespeare as new frameworks for speaking together and educating each other on Singaporean and worldwide issues. Although this chapter begins with considerations of race and class in Hamlet and Othello, fraught topics for some Singaporeans, these led to some revelatory discussions about sex and gender as my students used our materials to open up avenues I had not anticipated. I want to highlight here the value of making room for independent student projects and unexpected student contributions to a study of Shakespeare that seeks to engage with questions of justice, using my experience in Singapore as a case study but also with an eye toward how other instructors might globalize their Shakespeare syllabi. Ultimately, the success of our effort derived from a combination of what I deliberately set out to teach my students and what I discovered along the way that I did not previously know: the unpredictable passions, cultural ways of knowing, and lived experiences that only our students can bring to the table.

To encourage my students to see Shakespeare as more than the heritage of Singapore's colonizers, I chose to feature non-Anglophone and non-Western performances in the Hamlet module's media library, which also introduced them to contextualized examinations of Hamlet's political obligations as a prince and a citizen. For instance, the opening sequence of Grigori Kozintsev's 1964 film production shows the setting of Elsinore as a real castle, inhabited and staffed by real people whose lives and bodies are impacted by regime change. For Kozintsev, Claudius's rise to power coincides with the closing of the gates that connect (or separate) Elsinore to/from the community outside its walls: an opening scene shows the portcullis being lowered by peasants whose backs are bent painfully over a wheel, and students can read Kozintsev's extratextual, material signs that the usurper's oppressive reign sequesters power away from the people and exploits the working 
class. Instead of emphasizing the prince's neuroses, Kozintsev traces his Soviet-era Hamlet's struggle to overcome fear and moral inertia and act against Claudius as a form of civic resistance to fascist domination; this Hamlet becomes a martyr who sacrifices himself in service to a free state and liberates his people from the "prison" that was Claudius's regime. The film's opening can be taught productively against the intensely psychological first scene of Laurence Olivier's 1948 version, as well as alongside the start of Ragnar Lyth's 1984 Swedish production, which also focuses on Elsinore's laborers. Comparing parallel moments across global productions helps students see Hamlet as more than the angry, brooding melancholic many Anglo-Americans assume they know. In Kozintsev's Soviet moment, he rises beyond his own preoccupationspossibly beyond his original creation by Shakespeare-to discover that justice for his family and freedom for himself matter chiefly because they mean freedom and justice for his neighbors.

As I gradually became more familiar with Singaporean culture, I also began making more spontaneous efforts to use global Shakespeares to encourage students to observe their immediate community with fresh eyes. In reading Othello, they lacked centuries of accumulated Western impressions of "blackness," but when we watched Vishal Bhardwaj's 2006 Indian film adaptation of it, Omkara, many could relate to prejudices over South Asian skin color. They also acknowledged-with laughter of mild unease-my suggestion that Othello in the early modern city state of Venice experienced prejudices comparable to those faced by Singapore's many South Asian foreign workers. Members of this underprivileged group were a constant presence on the university's campus-under-construction and throughout Singapore, but were not a common topic of classroom conversation or (as far as I could tell) even polite acknowledgment. Indeed, our conversation about this local application was short-lived, and I wish in hindsight that I had been more willing in that moment to lean into my students' apparent discomfort. But my hope is that Othello, a play inseparable from race for Western audiences, offered them a way to start thinking critically and compassionately about immigration, labor, and ethnic and civic identity, and to "see" people who are normally expected to fade into the infrastructure they work to build.

Later in the semester, once my students had gained experience discussing global films and parallel interpretations as a class, I assigned a project meant to encourage them to become collaborative producers of knowledge: they worked in small groups to prepare a teaching presentation on either a single unfamiliar production of Hamlet or the treatment of a particular ambiguity (e.g. the awareness of Gertrude 
or the role of the Ghost) across several versions. Students used the module's film-editing tool to cut and compile important moments that they then contextualized for their peers. One result that stood out for its contribution to our ongoing conversation about identity and politics was a presentation on Sulayman Al-Bassam's 2004 stage adaptation The Al-Hamlet Summit, set in a fictional Arab state. "The tragedy in Al-Hamlet is inspired by the tensions between the West and the East," wrote one student in a follow-up paper: "the play reflects how Middle Eastern states are politically manipulated by the West in the form of the British Arms Dealer [who replaces the Ghost], together with its new Westernized ruler, Claudius." Meanwhile, Hamlet emerges as an ambiguously admirable "hero who intends to purge his country of corruption and foreign interventions" by turning to traditional Islam and arguably to terrorism. While this student noted how easily one man's freedom fighter might look like another man's terrorist, another suggested that Al-Bassam's play reshapes Shakespeare's interest in existential uncertainty for the contemporary Arab world and compared Hamlet's growing radicalization to Claudius's attempt at confession. In this scene- a parallel with the First Folio's III, iii-Hamlet has been watching Claudius weeping for his sins but also pleading for God to accept his collaboration with "dirty" Western capitalism so that his country can compete with the rest of the modern world. ${ }^{3}$ Hamlet, on the other hand, abhors his uncle's alliances and seems poised to act as God's "infantry on the ground," but ultimately cannot yet bring himself to fire his gun and "change the geography" of the conflict. ${ }^{4}$ As my student noted, both men seek refuge in their Islamic faith, yet also feel alienated from it or paralyzed by it much as Shakespeare's Christian Hamlet is inspired by righteous anger, but demotivated by his religious doubts. Al-Bassam, my student argued, shows how the Shakespearean tension between spiritual devotion, sociopolitical obligation, and violence remains topical in an Islamic context. In keeping with broader Singaporean demographics, a sizable minority of my students were Muslim, and all had Muslim friends and neighbors, but speaking about their religious identities and differences was a source of anxiety; this play gave them a context for speaking openly about Islam, as Bhardwaj's Omkara had encouraged my Hindu students to speak openly about how that adaptation was shaped by Hindu values. I soon learned that a prefatory remark like "I don't want to cause anyone offense, but-" was not a disingenuous red flag that the student was about to say something insensitive, but a polite Singaporean signal that the student was willing to overcome a mild taboo and offer a sensitive religious insight or speculation grounded in personal knowledge and experience. 
While some of the content and editing tools I discuss here are not readily transferrable to other classrooms, ${ }^{5}$ MIT's larger Global Shakespeares archive is open access and offers a growing library that can transform a course on Shakespeare in the singular into a laboratory on Shakespeares in the global plural. Instructors can mobilize the archive of clips and full videos-spanning thirty-five plays, sixty countries, and forty-four languages - to offer their students representations of Shakespeare that run contrary to their preconceptions of his work as a fixture of white Anglophone culture. It may be productive to flip the script by letting students view some of this material even before they read the plays themselves: this strategy allows them to experience Shakespeare first by seeing his work performed while simultaneously disrupting their assumption of his canonical preeminence as an author. For instance, students who begin with a subtitled viewing of the Yohangza Company's Korean Midsummer Night's Dream can use that production's treatments of marriage, magic, and social hierarchy as avenues into the same themes in Shakespeare's English text, rather than seeing the global performance as derivative and evaluating it largely on the basis of its fidelity to the "original." "MIT Global Shakespeares also features an open-access guided classroom study to one of its most stunning productions, Wu Hsing-kuo's 2001 Taiwanese one-man show Lear Is Here, which incorporates an introduction to the play's constitutive art forms, a study plan, and suggestions for several short assignments.

I was satisfied with the results of my own goals for introducing Shakespeare globally and locally to students mostly unfamiliar with Western literature. They learned to read Shakespeare, and through our equal or greater focus on multilingual and multicultural adaptation rather than printed English text, they also learned to de-mythologize Shakespeare. This was what I had wanted from the class-but they, in turn, took their creative community in directions I did not, and perhaps could not, intend. Teaching in a new country defined by histories and cultures I barely knew meant that my students had even more capacity than usual to surprise me, to call on individual and cultural knowledge, concerns, and experiences with which I was unfamiliar. Beyond advocating the study of Shakespeare through global performance, then, I would suggest that individuals and small groups of students be granted the freedom to choose, to an extent, the specifics of their inquiry and the particular productions which they feel most drawn to explore.

When I authorized students to guide the class into discussions of their own questions and concerns, I discovered that they were especially moved by issues of gender and sexual identity, even when I did not emphasize them. I was in Singapore in 2015, the year when Obergefell $v$. 
Hodges determined that Americans have a right to same-sex marriage. My Singaporean students, who did not and do not enjoy that right, were engaged with this news from the other side of the world to an extent I had not anticipated. I assumed that when we studied Othello we would discuss race, ethnicity, class, and nationality, which we did, but my students surprised me by being very eager to use the play to talk about non-normative sexuality. A vocal group wanted to argue that Iago is motivated, and in part humanized, by repressed desire for Othello. ${ }^{8}$ Evaluating their argument gave us the opportunity to turn both back to the text of the play and, again, to global performance. To help students avoid reductive answers to the Iago problem and to the question of trans-historical queer identity, I began by applying critical pressure and urging them to ground their impressionistic interpretation in textual data. We looked together as a class for evidence of "gay Iago," as well as for passages that could be mustered to challenge that interpretation. Next, their suggestion gave us a new opportunity to situate Shakespeare in his own local moment: I gave an impromptu mini-lecture on the distinctions between homosexuality, homoeroticism, and homosociality, focused on the particular norms of early modern England. This, in turn, offered us new perspective on global performances of Othello, from Geoffrey Sax's 2001 British retelling, in which Iago is definitely both sexually aroused and racially repulsed by Othello, and Bhardwaj's Bollywood Omkara, which features intensely physical all-male dance numbers. But when I suggested that maybe we could read those moments from Indian cinema as manifestations of homoeroticism in Shakespeare's play, my students who were more familiar with Bollywood were the ones to push back: no, they said, Indian culture (like Shakespeare's) is so steeped in homosocial norms that full-contact dancing could not be read as evidence of repressed homosexual desire. While my students were learning from me about careful textual and historical argumentation, I was learning more from them about careful cultural critique.

My students further surprised me when it was their turn to take the reins of the Hamlet module by highlighting the play's concern with female agency. In light of Hamlet's claim that he "essentially [is] not in madness / But mad in craft" (III, iv, 185-6), some students raised their own independent line of questioning about the play's other character who performs madness. After viewing the global productions available to them, they did not automatically assume that Ophelia's gender dooms her to mental illness as "a girl who feels too much, who drowns in feeling," a Western Romantic stereotype that Elaine Showalter contrasts with the overthinking male Hamlet. ${ }^{9}$ What if Ophelia's madness 
was her means of navigating a hostile court, they asked? What would it mean for her insanity, like Hamlet's, to be a sign not of powerlessness but of intent and savvy? One group of students, united by their interest in Japanese culture and language, taught their colleagues-and me-a great deal about Ophelia's possible coded control over her speech in a Noh-inspired play directed by Yoshihiro Kurita (2007). To their great credit, in the absence of subtitles, my students translated her "mad" song with its multiple layers of meaning; the translation that follows is theirs. Kurita's Ophelia, like Shakespeare's, sings a lament ostensibly for her father: "Unable to follow into the grave / Stained with tears of love / The face has already been placed on board the coffin [...] / In the grave, tears of rain fall; / Goodbye, dear you." ${ }^{10} \mathrm{Her}$ "you" in her song's final line, my students stressed, is the word anata. This is not the honorific form that a polite Japanese woman would use when addressing her father-instead, it's a respectful but intimate form normally used for an equal, especially a husband or lover. In bidding goodbye to this anata, my students suggested, Ophelia may not simply be mourning either Polonius or her loss of Hamlet; she may also be signaling her choice to end her own life and leave the corrupt court. After all, she too will soon be placed in the grave, where her lover and her brother will be "unable to follow."

The Noh play evokes Scott Trudell's discussion of Ophelia's ability to transform insane song-speech into personal and political meaning; still, Trudell holds that despite her "orphic" authority, "it is difficult to describe her as an author, since [. . .] her madness robs her of conscious design." 11 The fact that this is probably true for Shakespeare's original character can actually point toward the enduring ability of global Ophelias "to make meaning that captures the imaginations of generations of auditors" through a "continuously adaptive process," new meaning that sometimes does break free from madness. ${ }^{12}$ I responded to my students' interest in gendered agency by guiding them toward non-Western variations in which Ophelia shows every indication of "conscious design" in her struggle to overcome her disempowerment. They were already aware that the Ophelia of The Al-Hamlet Summit makes the deliberate choice to end her life as a suicide bomber, and Feng Xiaogang's darkly feminist The Banquet (2006) became an ideal choice for further study, given students' enthusiasm for the potential authority of Hamlet's women and their native familiarity with Chinese epic fantasy. In this retelling, the prince's conniving stepmother (the film's Gertrude) and her lady-in-waiting struggle to outmaneuver each other in an erotic and political power struggle. Qing $\mathrm{Nu}$ (Feng's Ophelia) neither loses her mind nor commits suicide; she uses her gifts 
for music and poetry to communicate with the court in resistance to the empress, and her accidental poisoning exposes the empress's treachery. Twenty-first-century global Ophelias like these remind students, Western or otherwise, that we have not in fact progressed to an age in which women's equality with men and their fitness for political life is presumed; these Ophelias also sometimes make the significant leap of elevating the character's agency above the level of non-rational "orphic" authority by letting her act deliberately for personal and political causes.

Perhaps the most marked result of our seminar was this potentially Ophelian transformation of traditional silence into critical and creative speech. Just as developing their own analyses of Shakespeare's texts encouraged numerous shy students to start sharing their readings in class, conversing meaningfully about global adaptations required them constantly to acknowledge and examine their preconceptions and differences in order to educate each other. Studying Shakespeare through global performance helped them "go there," whether "there" meant their private identities as Hindus, Muslims, or Buddhists; their reflection on their own freedoms and privileges; or their commitment to feminism.

Instead of idealizing a timeless universal icon, my students came to value a multiplicity of timely, locally active Shakespeares. They learned to read film and performance, and they learned to use the module's editing tool to teach film and performance to their colleagues by presenting their own curated collections of scenes to each other. My students ended the semester with a new understanding of global Shakespeares as an artistic and scholarly community, one in which they could and did participate through creativity and debate. For me, their work came to represent what the goal of global Shakespearean pedagogy could be and perhaps should be: not simply pleasure in the proliferation of Shakespeare's afterlives, but respect for the other human lives-ones across the world, and the one in the next desk over-that new treatments of his work constantly make visible.

\section{Notes}

This chapter is dedicated to the students in my 2015 Global Shakespeares seminar at the Singapore University of Technology and Design, with great affection and respect for their warmth and scholarship.

1. For this piece and much more, I am deeply indebted to the supervisors, colleagues, and friends at MIT with whom I worked on this project: Peter Donaldson, Diana Henderson, Shankar Raman, Suzana Lisanti, and Belinda Yung. 
2. Peter S. Donaldson, “About MIT Global Shakespeares," $2010<$ http:// globalshakespeares.mit.edu/about> (accessed February 21, 2019).

3. Sulayman Al-Bassam, The Al-Hamlet Summit: Original Playscript in English and Arabic with an Introduction by Graham Holderness (Hatfield: University of Hertfordshire Press, 2006), 71.

4. Ibid., 72 .

5. The Hamlet module, for instance, is still an active feature of MIT Global Shakespeares, but for copyright reasons special permission and a login are required from MIT Global Shakespeares to gain full access to it.

6. Jung-Un Yang, A Midsummer Night's Dream (Yohangza Company, 2006).

7. "Study Plan for Lear Is Here," MIT Global Shakespeare Learning Module $<$ https://globalshakespeares.mit.edu/modules/module/lear-is-here> (accessed February 21, 2019).

8. Certain Western scholars have advanced various nuanced versions of a queer Iago, including Matz and Saunders, who each see it as important "not 'to identify the "homosexual" in the text' but rather to explicate the cultural forms and circumstances in which same-sex desire could be represented.” Ben Saunders, “Iago's Clyster: Purgation, Anality, and the Civilizing Process," Shakespeare Quarterly 55, no. 2 (2004): 151, partially quoting Robert Matz, "Slander, Renaissance Discourses of Sodomy, and Othello,” English Literary History 66 (1999): 261.

9. Elaine Showalter, "Representing Ophelia: Women, Madness, and the Responsibilities of Female Criticism," in Shakespeare and the Question of Theory, ed. Patricia Barker and Geoffrey Hartman (London: Methuen, 1985), 83, original emphasis.

10. Yoshihiro Kurita, Hamlet (Ryutopia Noh Theatre, Niigata, Japan, 2007).

11. Scott Trudell, "The Meditation of Poesie: Ophelia's Orphic Song," Shakespeare Quarterly 63, no. 1 (2012): 61.

12. Ibid., 61, 76 . 

Part II

Decolonizing Shakespeare 



\title{
African-American Shakespeares: Loving Blackness as Political Resistance
}

\author{
Jason M. Demeter
}

\section{Introduction: An Antiracist Shakespeare?}

What follows is a reflection on my recent experience designing and teaching a Shakespeare course that attempted specifically to push students to interrogate the poet's racially charged signification within contemporary American culture. Prompted by my uneasiness regarding Shakespeare's use within American education as an instrument of white racial consolidation and non-white marginalization, I aimed to create a class that foregrounded the ways that a number of African-American writers recognized and responded to popular perceptions of Shakespeare as the exclusive property of a white majority culture. In addition to the work of exploring Shakespeare's life, times, and literary output, my course-titled "African-American Shakespeares"-sought to shine a light on the often exclusionary use to which the poet has been put within institutional American culture. In this way, I sought to test whether or not Shakespeare might effectively be employed in the classroom to do productive antiracist work.

Yet despite the many fruitful conversations and moments of real insight that occurred throughout the semester, I cannot deem the class an outright success. Indeed, as the term wore on, I became increasingly frustrated in my attempts to construct Shakespeare as a worthy comrade in the struggle against white supremacy. These difficulties are outlined below. In describing them, I aim not to discourage good faith attempts to enlist Shakespeare for progressive pedagogical projects, but rather to highlight the unforeseen pitfalls that I encountered, in the hope that a frank presentation thereof will prove valuable to educators seeking to use the poet as a vehicle for teaching social justice in their classrooms. The chapter begins with a brief look at how Shakespeare came to be thought of by many as the exclusive property of the white 
majority culture in the United States. This short overview, I hope, will clarify the subsequent discussion of the logic and reasoning behind the course design and the rationale guiding our selection of readings by Shakespeare and his African-American interlocutors. I will then describe the reasons why I think the course failed to live up to my aspirations, providing what I hope is a useful cautionary tale for other well meaning Shakespeareans interested in using the object of our study to help create a better and more equitable world.

\section{American Education and Shakespeare's Whiteness}

While a semester-long investigation devoted to Shakespeare, a writer of unparalleled influence within the English tradition, is commonplace within American universities, the poet's seemingly uncontestable position within the Western literary studies curriculum has come to serve for me as a source of significant discomfort. Clearly, as one whose professional training and academic interests center on Shakespearean drama, I see value in exposing students to a selection of works that have continued to influence world literature for more than 400 years. I remain convinced that a working knowledge of Shakespearean poetics, plots, tropes, and characters can help students to appreciate better a global literary tradition rife with intertextual allusions, references to, and revisions of the immortal Bard. I also continue to find tremendous value in asking students to grapple with syntactically demanding passages of Shakespearean verse. It seems clear that if an individual can effectively make meaning out of Shakespeare's dense and often labyrinthine metaphors, constructed as they are in archaic and unfamiliar language, then she should have little trouble unpacking arguments put forth in, say, the opinion pages of tomorrow's edition of the Washington Post.

Yet despite this belief in the broad utility of a Shakespearean education, I have come to approach the class each year with growing trepidation. My hesitancy comes largely from anxieties rooted in the way Shakespeare has traditionally been employed as a vehicle for the transmission and replication of white supremacist ideologies within American scholastic culture, especially since the rise of compulsorily secondary education in the late nineteenth and early twentieth centuries. Though Shakespeare had been a presence in schools to varying degrees since the colonial period, the ideological work he has been made to perform has shifted over time. Specifically, while Shakespeare's literary achievement was commonly framed within early-American schools as evidence of the preeminence of the relatively young nation's putatively 
Anglo-Saxon cultural heritage, ${ }^{1}$ the early twentieth century saw the poet's province gradually extended and reimagined. No longer was Shakespeare simply an avatar of English - and, by proxy, Americanachievement; instead, he is imagined increasingly as an instrument of European ethno-consolidation: a means though which various newly arrived European immigrants might make themselves into proper white Americans.

This ideological shift is perhaps given voice most clearly in Joseph Quincy Adams' 1932 inaugural address as the first officially appointed director of the Folger Shakespeare Library in Washington, D.C. Written as a broad overview of Shakespeare's role in American culture, Adams asserts early in his speech that, like Presidents Washington and Lincoln, Shakespeare is "indisputably American." Outlining what he claims is a "deep personal concern which every Elizabethan felt in America," Adams reasons that Britain's imperial proclivities had ensured that all Elizabethans were, "in a certain sense, Americans." Of course, notions regarding deep and abiding cultural ties between Britain and the United States were widespread throughout the eighteenth and nineteenth centuries, and Adams was tapping into ideas that would have been widely accepted among cultural gatekeepers of the early twentieth century.

Adams' most important revision to longstanding ideas regarding Shakespeare's essential Americanness appears later in the speech, as he comes to imagine the study of the poet's work as a means of imparting American identity to a wider swath of European expatriates. After lamenting the ways that "the solidly Anglo-Saxon character of the people" in the American Midwest had eroded, he goes on to describe with great concern the millions of "Italians, Poles, Slaves, Hungarians, Czechs, Greeks, Lithuanians, Rumanians [sic], [and] Armenians from almost every clime under the sun swarm[ing] into the land like the locust of Egypt." ${ }^{3}$ Despite his obvious alarm at the perceived dilution of the nation's putatively shared culture, Adams sees the American system of compulsory education, and Shakespeare in particular, as a potential bulwark against "the forces of immigration [that had become] a menace to our long-established English civilization." ${ }^{4} \mathrm{He}$ then heralds the ways that Shakespeare is employed in American schools as "the corner stone of cultural discipline," framing "the great English dramatist . . . as the supreme thinker, artist, [and] poet," and as a figure around which European immigrants of all national and ethnic backgrounds could adopt as a common "object of ... study and veneration." 5

While there is much to unpack here, two elements of Adams' address are particularly notable within the context of our discussion. The first involves the implication that the cultural traditions of a wide and 
disparate swath of European immigrants could and should be consolidated under the banner of an undifferentiated, and implicitly white, American culture- a culture that itself comes to look remarkably similar to that of Great Britain. Adams is essentially advocating that European immigrants shed their previously held beliefs, traditions, and stories and instead embrace distinctly English cultural touchstones as an effective means of becoming American. Even more important for our purposes are the populations that Adams' formulation elides, specifically those individuals who are not of European derivation and who are therefore excluded from the assimilationist benefits Shakespeare might provide. While Adams envisions Shakespeare as an excellent means through which previously marginalized immigrant populations might be enculturated, the poet endures as an object of white European province, and it remains unimaginable that non-whites might achieve similar access to the mainstream through a similar familiarity and mastery of Shakespeare.

Though notions of Shakespeare as the exclusive property of a white-majority culture are not generally expressed in so stark and legible terms as in Adams' address, such ideas continue to bubble under the surface within the early twenty-first century. Indeed, I need only to look to the reactions from within my own classrooms when I employ performance clips featuring non-white actors performing the roles of Shakespeare's iconic characters. It is common, for example, for students to react with hesitancy when confronted with nontraditional casting, with some brave soul finally voicing some variation of what many in the room seem to be thinking: "But I'm confused . . Macbeth isn't black." While such occasions generally serve as fodder for productive conversations about casting, diversity, and our expectations as audience members, so too do they reveal that the works of our playwright-who is all too often carelessly characterized as culturally transcendent and universally relatable - might not be so universal after all. It is here where my role as a Shakespearean conflicts with the political underpinnings of my wider pedagogical and scholarly agenda, focused as it is on social justice and based in my belief of the potential of education to assist in toppling longstanding power hierarchies. As a scholar of race, I am sensitive to the ways that American institutional culture, particularly secondary and higher education, has long been used for antithetical ends, serving to prop up systems of racial oppression and, in particular, white supremacy. In my role as a Shakespearean, I am similarly attuned to how myths regarding the poet's transcendent universality have long been used, somewhat counterintuitively, to cordon off access to the poet and whatever social or material benefits that a thorough knowledge of Shakespeare might impart. And herein lies the crux of 
our difficulties: how can teachers with a real commitment to social justice provide students with the benefits of a Shakespearean education without perpetuating the pedagogical inertia that continues to position the poet, through his curricular prominence, as the supreme avatar of white, Western cultural values? How can we continue to privilege the 400-year-old English poet, suggesting implicitly (and often explicitly) that his work has more relevance in the twenty-first century than that of authors whose identities, experiences, and perspectives might better reflect the lived experiences of our increasingly diverse pool of students? In short, how can we continue to insist that a course on Shakespeare has more value than one on, say, Toni Morrison, a writer whose background and perspective more closely parallel the lives of our students, particularly those from historically marginalized communities?

\section{African-American Shakespeares}

The idea of framing a course around African-American instantiations of Shakespeare was sparked by my positive experiences teaching African-American playwright Shelia Rose Bland's provocative essay "How I Would Direct Othello" as a part of my regularly offered Shakespearean drama class. Given my scholarly focus on race, I feel a distinct responsibility to teach Othello each year. In light of its position as one of the earliest and most stubbornly resonant depictions of blackness in early English literature, I think it would be a matter of professional malpractice for me to avoid working through with students one of Shakespeare's most storied and obviously problematic narratives, irrespective of any personal distaste I have for the play. Yet because Othello so thoroughly objectifies blackness while centering the white gaze, it is imperative that I include black voices in our class discussions as a way of helping students think analytically about a writer whose work tends to be venerated by many almost unconditionally. Bland's essay, which proposes a staging of Shakespeare's domestic tragedy as a comedic minstrel show, functions as an ideal paratext for my purposes, highlighting the play's intrinsic racism by drawing attention to the ways that it "encourage[s] the audience to laugh at Othello, and with Iago." 6 In this way, Bland reminds students of the ways that Othello has always been an exercise in objectification. "These characters have always been effigies, [and] they deserve what they get," she writes, concluding that "perhaps [Othello] was never intended to be a tragedy."

Discussing Bland's confrontational revision inevitably brings out the best in my students, and I have come to look forward to seeing each year 
how the essay is received by a new cohort. More often than not, students initially express shock at a proposed staging of the play that works not to conceal or excuse the play's racism, but rather to foreground it, making all of its intrinsic ugliness plain and inescapable. The class conversation that follows tends to be one of the most interesting and productive of the semester, as students gradually begin to question the politics and ideologies underpinning not only Othello but also other works by Shakespeare. Bland's irreverent take gives students license to question Shakespeare more broadly, steering them away from the commonly recited hagiographic platitudes that many students imagine their instructors want to hear. In short: Bland's essay gives students permission to think for themselves.

Given my successes with Bland's essay, I began to wonder what it would be like to design from the outset a class pairing works by Shakespeare with a number of other skeptical, oppositional, and antagonistic voices. As I considered what such a class would look like and what voices should be represented, I quickly realized that many of the works I deemed necessary to include were written by African-American authors. Of course, Shakespeare's institutionally sanctioned whiteness, enforced by American schools and broadly felt within the culture at large, did much to ensure this was the case, and thus it is no accident that black writers working within the Western literary tradition had good reason to reckon with, to revise, and even to attack Shakespeare in their art. And so it seemed obvious that one way to combat the white supremacist subtext that Shakespeare's uncontested position in American education had continued to reinforce was to create a class on the poet that centered and embraced blackness. Spurred in part by bell hooks' important essay "Loving Blackness as Political Resistance," particularly her assertion that "to love blackness is dangerous in a white supremacist culture," I endeavored to create a syllabus that put Shakespeare and African-American literature on an equal footing, questioning whether a Shakespeare class that embraced blackness could prove dangerous to white supremacist culture. ${ }^{8}$ As hooks notes, "Despite civil rights struggle, the 1960s black power movement, and the power of slogans like 'black is beautiful,' masses of black people continue to be socialized via mass media and nonprogressive educational systems to internalize white supremacist thoughts and values." Given how her description gave voice to the very anxieties I had long harbored regarding what Shakespeare's racially charged signification and curricular prominence signaled to students, I deemed it a worthwhile experiment, and thus the course "African-American Shakespeares" was born. 
I drew up a syllabus that included Richard III, Henry IV Part I, and, perhaps inevitably, Othello. In addition to these works by Shakespeare, the class would look at a number of responses to them from black artists. We would read the aforementioned essay by Bland as well as reflections by James Baldwin and August Wilson; ${ }^{10}$ we would look at plays by Carlyle Brown, Toni Morrison, and Djanet Sears; ${ }^{11}$ and we would watch two filmic adaptations of Shakespeare created by African-American artists and performed primarily by actors of color. ${ }^{12}$ I would introduce students to the issues and tensions that we would be exploring by way of an article on a controversy that had erupted at the University of Pennsylvania, wherein a group of students removed a portrait of Shakespeare that had long hung in a prominent location in the English Department, and had replaced it with a photograph of the African-American poet Audre Lorde. ${ }^{13}$ I had imagined that this moment of symbolic resistance-functioning as it did to raise important questions about identity, canonicity, and curricular inclusion-would push my students to think critically about Shakespeare's privileged place within American education. The ominous fact that the vast majority seemed perplexed and slightly irritated reading about the controversy was an early indicator of the challenges and misapprehensions that would repeatedly arise throughout the semester.

\section{Misgivings and Disappointments}

It would be counterproductive to detail each of the numerous moments when reactions to the course ran contrary to what I had expected. This is especially true since my frustrations now seem to have been occasioned by the obviously problematic nature of the course design itself rather than from any failures on the part of my earnest and hardworking students. Suffice it to say that I cannot assert with any confidence that by the end of the semester I had successfully induced most students to think deeply about whether and why Shakespeare and African-American art and culture are dichotomized within the popular imagination. I had sought to make Shakespeare's whiteness visible, particularly to my white students, and while the course seemed to accomplish this at some moments, notions of the poet's universality remained remarkably difficult to dislodge in any real or permanent way. Indeed, even those who claimed vociferously to dislike Shakespeare were often quick to clarify that the problem was their inability to connect rather than to ask the challenging questions regarding his contemporary relevance that I hoped the course would elicit. 
The first and most noticeable problem is the way that the class had been framed from the outset. Rather than placing Shakespeare and African-American literature on an equal footing, the initially surprising juxtaposition of Shakespeare and blackness worked to dichotomize each as a separate and incommensurable sphere in the minds of many students, inadvertently reifying residual notions of Shakespeare as white property. A related problem stems from the fact that many students had come to the class with far more experience with Shakespeare than with African-American literature. Pairing the familiar with material that was less well known made it far too easy for students to privilege that which proved less disruptive to their preconceived ideas. Despite my decision to give the modifier "African-American" prominence in the course title, it seems that Shakespeare's gravitational pull proved irresistible to many, and it was obvious throughout the term that some students were eager for us to return to the "original" texts. The overall effect was that Shakespeare was continually re-centered while the work of black writers was perceived as derivative of, rather than a potent challenge to, Shakespeare. Rather than showcasing a host of prescient ideological critiques of Shakespeare's racial signification, the course instead replicated the tired notion that minority validation comes from a mastery of Western culture. In this way, it inadvertently reinforced Shakespeare's position at the top of a cultural, curricular, and ideological hierarchy while framing oppositional responses thereto as impotent rejoinders.

None of this is to suggest that Shakespeare cannot be marshaled effectively within the classroom for legitimately antiracist ends. It is meant, rather, as a humble reminder to myself and like-minded others that we cannot rely on the diverse oppositional perspectives of various interlocutors - no matter how wise and prescient - to do the interpretive, pedagogical, and political heavy lifting on our behalf. Indeed, what matters most, it seems, are the steps we take to challenge and nurture the diverse (and potentially oppositional) voices of our students themselves. As Ruben Espinosa and Kim F. Hall suggest in the following two chapters of the present volume, we do best as teachers of Shakespeare when we approach his texts as objects of collective study and analysis. In capitalizing, for example, on the dialogic nature of Shakespeare's drama by designing work that pushes our students to inhabit a wide range of possible identities and perspectives, we can effectively harness the humility, vulnerability, and, indeed, intimacy that arises when a group of diverse individuals come together in a classroom and grapple honestly with language, perspectives, and ideas both unfamiliar and provocative. It is here, in the cultivation of the collective, where the real work of social justice can and must begin. 


\section{Notes}

1. Kim C. Sturgess, Shakespeare and the American Nation (Cambridge: Cambridge University Press, 2004).

2. Joseph Quincy Adams, "The Folger Shakespeare Memorial Dedicated April 23, 1932: Shakespeare and American Culture," The Spinning Wheel, July 1932, 212-15, 229-31.

3. Ibid., 230.

4. Ibid.

5. Ibid.

6. Shelia Rose Bland, "How I Would Direct Othello," in Othello: New Essays by Black Writers, ed. Mythili Kaul (Washington, DC: Howard University Press, 1997), 29.

7. Ibid., 37.

8. bell hooks, "Loving Blackness as Political Resistance," in Killing Rage: Ending Racism (New York: Henry Holt, 1995), 146.

9. Ibid., 159.

10. James Baldwin, "Why I Stopped Hating Shakespeare," in The Cross of Redemption: Uncollected Writings, ed. Randall Kenan (New York: Vintage International, 2011), 65-9; August Wilson, The Ground on Which I Stand (New York: Theatre Communications Group, 2000).

11. Carlyle Brown, The African Company Presents Richard III (New York: Dramatists Play Service, 1998); Toni Morrison, Desdemona (London: Oberon Books, 2012); Djanet Sears, Harlem Duet (Winnipeg: J. Gordon Shillingford Publishing, 1998).

12. Aleta Chappelle, Romeo and Juliet in Harlem, DVD (Library Video Company, 2015); Paul Quinn and Dwain A. Perry, H4, Unreleased, 2013.

13. Scott Jaschik, "Making a Point by Moving Shakespeare's Portrait," December 14, 2016 <https://www.insidehighered.com/news/2016/12/14/ students-penn-remove-portrait-shakespeare $>$ (accessed February 20, 2019). 


\title{
Chicano Shakespeare: The Bard, the Border, and the Peripheries of Performance
}

\author{
Ruben Espinosa
}

In 2007, civil rights activist Dolores Huerta spoke to a student assembly at Tucson High School to encourage Chicanx involvement in the democratic process and uttered three words that would ignite a decade-long legal battle in Arizona: "Republicans hate Latinos." With remarkable candor, Huerta took aim at anti-immigrant legislative initiatives that had garnered support from Arizona Republicans. When Superintendent Tom Horne, a Republican who later served as Arizona's attorney general, learned of Huerta's comments, he was infuriated. He deployed his Republican aide, Margaret Garcia Dugan, to follow up with these students and explain that Republicans did not, in fact, hate Latinos. However, when Dugan began to speak, students turned away and "raised their fists in the air." This act of resistance led Horne to initiate the dismantling of Tucson High School's Mexican-American Studies (MAS) program because, as legislators later argued, it fostered resentment against the U.S. government. The truth, a 2011 University of Arizona study confirmed, is that the MAS program led to higher grades, graduation rates, and college enrollment for its students. ${ }^{2}$ Clearly, what legislators found threatening was not the radical overthrow of the U.S. government, but rather the idea that these young Chicanxs would come to know and understand the power of their political voice.

Arizona State House Bill 2281 became law in 2010, and it eliminated Tucson High School's MAS program. ${ }^{3}$ Conspicuously situated amid a list of books that were removed from the curriculum as a result of this legislation was The Tempest. Although the law did not technically ban The Tempest, it influenced the district to steer clear of books that broached the topics of race and oppression. The question of how Shakespeare should be taught came to the fore. Curtis Acosta, an MAS program teacher, details how the subjects of "race, colonization, oppression, class and power that permeate" The Tempest guided his 
approach to teaching the play prior to the passing of legislation that disallowed discussing such subject matter. ${ }^{4}$ Acosta feared that teaching The Tempest would inevitably lead students, on their own, to recognize "the themes [of race and oppression] and decide to write, discuss or ask questions in class," which would be in direct violation of the law. $\mathrm{He}$ was advised to avoid the play, and he agreed to this because the stakes were "far too high since the violation of the law could cost the district millions" and compromise "employment, and personal penalties from the state for breaking the law." One can hardly blame Acosta for his pragmatic decision to avoid The Tempest for fear that a sanitized discussion of its content was unlikely. Given that Shakespeare was positioned alongside other authors who could no longer be taught in Tucson's MAS program—authors like Martín Espada, Gabriel García Márquez, Junot Diaz, Rudolfo Anaya, Rodolfo Acuña, and Gloria Anzaldúa, to name just a few-his cultural relevance for these young Chicanxs warrants closer scrutiny.

This chapter interrogates what Shakespeare affords Chicanx students who are forced to negotiate perceptions of their linguistic and cultural inferiority in the United States. Looking toward the contemporary cultural relevance of Shakespeare through professional and amateur performances and afterlives of his work, it seeks to kindle classroom practices and conversations that speak meaningfully to social justice initiatives striving to advance dignity, legitimacy, and social equity for Chicanxs - and, more broadly, Latinxs - who often struggle to locate their place in American society. Recognizing these concepts in the classroom foregrounds and legitimizes the influence of Chicanx culture on the making of Shakespeare in our day.

By employing pedagogical practices that draw on critical race and ethnic studies to complement readings of Shakespeare, and by designing assignments that call attention to the intersections between Shakespeare and Chicanx culture, we can tap into understandings of his works that generate possibilities for social change. Movement toward the peripheries of performance-that is, not only nontraditional performances and appropriations of Shakespeare through media such as YouTube and original student productions, but also performances that derive from the peripheral space of the U.S.-Mexico borderlandsopens the door to important classroom conversations about race, immigration, assimilation, linguistic diversity, ethics, and the concurrent promise and limits of belonging for Chicanxs in a post-Obama society. As Gloria Anzaldúa suggests, the experience of being on the periphery, or la frontera, compels us to "shift out of habitual formations," which ultimately allows for a "more whole perspective, one that includes 
rather than excludes." Such perspectives yield novel understandings of Shakespeare. Of more significance, this shift in pedagogical practice creates a space for Chicanxs to understand the power of their political voice and influential position in reimagining Shakespeare's cultural valence and in challenging the structures that often render Chicanxs "illegal" or invisible within the dominant culture. Indeed, Shakespeare's role in the political controversy in Arizona illustrates precisely how his works lend themselves to important social justice issues for Chicanxs.

Of particular consequence in the Tucson High School episode, as Peter Holland notes, is that the MAS program held value for both the 60 percent of students who were Chicanx and the 40 percent who were non-Chicanx. ${ }^{7}$ For students not directly affected by legal structures aimed at oppressing non-white Americans, an ethnic studies program like this familiarizes them with the various social inequities that allow for such oppression. Through programs like these, we can ostensibly recognize how informing our teaching of Shakespeare-and early modern literature more broadly - with race and ethnic studies stands to influence our students, in various settings and from diverse backgrounds, in meaningful ways. For my part, teaching at the University of Texas at El Paso (a university with an 80 percent Chicanx student population), it is an imperative I cannot possibly ignore. I turn, then, to teaching practices from the U.S.-Mexico border to explore how encountering Shakespeare stands to offer quite a bit to Chicanx students who find themselves on the literal and figurative margins of American society.

\section{Chicano Shakespeare}

In his novel La Mollie and the King of Tears, Arturo Islas engages Shakespeare's energies brilliantly through the long narrative that his protagonist, Louie Mendoza, unfolds. The title is a play on King Lear, and keen allusions to Shakespeare emerge at various moments. In one episode, Louie reflects on his formative encounters with Shakespeare in high school and remembers how his teacher, Miss Harper, would show students images of Stratford and Shakespeare. Louie says, "She even showed us that Chandos portrait of Shakespeare, which she said probably wasn't what the guy really looked like. Too bad, cause he looks kinda like a Chicano in that painting, man." Islas subtly captures here the classroom experiences that often shape our view of Shakespeare (quite literally, in Louie's case). While Miss Harper likely imagines Shakespeare through preconceived notions about what he must have looked like, Louie's desire is to see a Chicano Shakespeare. 
I begin here because the issue of similitude is such a fraught facet of identity politics for Chicanxs, and it often defines their encounters with literary works. From the vantage point of the border, it is possible to imagine a Chicano Shakespeare. Chicanxs on the margins have been told, for so long-in criticism, on the stage, and on the screen-how to read Shakespeare, what Shakespeare means, and what Shakespeare looks like. Chicanxs have been told what they should sound like, look like, and be like if they want to be true Americans, and that their presence in the country somehow diminishes America's greatness. It is precisely because of these efforts to dictate the parameters of legitimacy that I look to Shakespeare from the peripheries of performance. For me, it is important to interrogate how Shakespeare is constructed and interpreted-how the Miss Harpers of the world seek to define these interpretations, and how the Louie Mendozas of the world want to understand him. ${ }^{9}$ The idea is to challenge the notion that anyone can say, with any kind of certainty, what Shakespeare "really looked like."

On the U.S.-Mexico border, I expect my students to question Shakespeare's relevance to their cultural identities and experiences. They must ask: Why Shakespeare? I recognize that this generic question is applicable in any given classroom, but it is vital that my students grapple with this question in their particular locale and without my intervention. Through reflection papers or small-group discussion assignments, I ask students to articulate their view of Shakespeare's relevance and/or irrelevance within our border community. Students, and this is particularly germane to the Chicanx community, must be encouraged to look at Shakespeare with a critical eye-that is, not just analytically, but also judgmentally. The why, then, becomes a question not just about Shakespeare, but about the power structures that define Shakespeare.

These power structures also define and often oppress Chicanxs, and this interrelation presents an opportunity to incorporate critical race, ethnic, and cultural studies when exploring Shakespeare. For example, I have students consider Pierre Bourdieu's attention to the role of educational markets in "the objective dispossession of the dominated classes" through the delineation of "legitimate language" in the literary field. ${ }^{10}$ As a quintessential figure in literary studies, Shakespeare is central within this paradigm. How should Chicanxs - who are on the periphery when it comes to dominant views of legitimate linguistic identitynegotiate structures that simultaneously elevate Shakespeare and minimize their legitimacy? To arrive at an answer to this question, I have students read Anzaldùa, who interrogates the "linguistic terrorism" on Chicanxs and confidently explores the power behind Chicanx "linguistic 
mestizaje." ${ }^{11}$ Students also read and discuss Leo Chavez's work, which aims to dispel media-fueled narratives that depict Latinxs as inferior "people who will not and cannot become part of U.S. society." 12 These readings, I firmly believe, arm students with the critical wherewithal to scrutinize Shakespeare anew. Indeed, as the semester progresses, I find that my students are more carefully attuned to the many moments in Shakespeare when questions of legitimacy arise, as they often draw on cross-historical connections. Equally important, these readings lend legitimacy to their voices, and this allows them to consider how their view of Shakespeare from la frontera holds a distinct valence.

To centralize race and ethnic studies is to begin the meaningful conversation about power structures from the outset. While The Tempest lends itself to the topics of race and racism-even if Harold Bloom would have us believe that "anyone who arrives at that view is simply not interested in reading the play at all" 13 - these topics are also pervasive in an array of Shakespeare's works. Indeed, we are indebted to the work of scholars like Kim Hall, Arthur Little, Ania Loomba, and Ayanna Thompson, to name a few, whose critical focus on race and Shakespeare has engendered important conversations. ${ }^{14}$ For my students, reading Hall's explanation of the way Shakespeare helped shape the language of white supremacy is invaluable in giving them the confidence to question why and how Shakespeare treats the topics of race, class, and gender oppression in a host of his works. ${ }^{15}$ It also affords them the opportunity to consider how we, in the present moment, are being asked to see him. The white monopoly on Shakespeare on the stage and in film is no secret, and thus it is important that Chicanx students see within these adaptations their invisibility. It is important that they feel, forcefully, this invisibility. ${ }^{16}$ Finally, it is important that they do not abandon Shakespeare because of this invisibility.

Locating the value of Shakespeare on the border rests squarely on Chicanxs believing that they have legitimate access to him, and thus the advantage of pedagogical practices that allow students to make Shakespeare their own cannot be overstated. Inspired by Thompson's sharp attention to the "interpretive opportunities" behind Shakespeare on YouTube, ${ }^{17} \mathrm{I}$ implemented an assignment years ago where students produce a five-minute iMovie adaptation of a scene from Shakespeare, which they are then encouraged to upload onto YouTube. Initially, I asked students to adhere to Shakespeare's original language, but they clearly found this stifling. It was as if their interpretive lenses were clouded by focusing on what they thought Shakespeare should sound like, and this resulted in adaptations wherein Shakespeare was simply not their own. The difficulty of Shakespeare's poetic syntax is 
wholesale, and not something material only to Chicanx students, but, on the border, language is such a profoundly charged dimension of identity politics. As Anzaldúa argues, linguistic identity is "twin skin" to ethnic identity, and, as a result, language often governs perceptions of belonging for Chicanxs. ${ }^{18}$ I adjusted my approach, and I quote here the revised parameters for the assignment:

Students will collaborate to perform and film a rendition of a scene from any of the Shakespeare plays we cover during the semester. These films should not be more than five minutes in length, should employ some of Shakespeare's original dialogue, and should find a way to speak to contemporary/regional social issues. Beyond these guidelines, you have absolute creative license for the production of these films.

Disconnected from the constraints of his thorny syntax, students confidently engaged Shakespeare.

Encouraging students to use these adaptations as a commentary on social issues of consequence is a deliberate move that allows them to explore Shakespeare's currency in our day. Elsewhere, I detail how students have meaningfully negotiated their linguistic identities through this assignment, and here I will briefly note that Shakespeare often serves as a vehicle for students to register apprehensions about the pressures of assimilation and the burdens of hybridity and daily bi-national, cross-cultural experiences. ${ }^{19}$ Hospitality in Hamlet, alienation in As You Like It, inhumanity in Macbeth, assimilation in Othello, white nationalism in Henry $V$, xenophobia in The Merchant of Venice, illegitimacy in King Lear, and, indeed, race in The Tempest are merely a few examples of topics students address through borderland perspectives in these adaptations. More often than not, students do not eschew their cultural and ethnic identities in engaging these works, but instead draw specific attention to them. They choose to make themselves visible.

The success of these productions varies, and not every project results in a strong social commentary via Shakespeare. However, the assignment inevitably results in students discussing, explicitly, important social issues and why Shakespeare compelled them to think about those issues. In these instances, the focus is not on the productions themselves, but instead the conversations that they provoke. In the process of producing their videos, students mine YouTube to look at previous productions, and this creates an opportunity for them to interact with multifarious perspectives on Shakespeare and social issues. When students upload their videos, this YouTube archive grows and affords us all the opportunity to tap into this resource as a means of engaging a broad range of perspectives. As Thompson notes, "The value of Internet interactivity ... 
is the opportunity for dialogue and debate across the borders of nation, race, ethnicity, sexuality, age, class, physical ability, and education-often for long periods of time." ${ }^{20}$ Thompson urges us, rightly, to consider our responsibilities when using these videos in our teaching, especially as "reception cannot be contained." ${ }^{21}$ For my part, I am fully transparent about the unruly nature of reception, but I also stress to my students that it isn't every day that one gets to see a Chicano Shakespeare.

Collectively, we have an opportunity to bring those on the periphery into view by focusing, in earnest, on issues of race and ethnicity in our teaching. Affording dignity to Chicanxs who are in search of their own voice and place in America is a necessary starting point. In the current political climate-one where the U.S. president has no qualms about characterizing Mexican immigrants as drug dealers, criminals, and rapists while unapologetically suggesting that some white supremacists are fine people-it is imperative that we foster an atmosphere where strategies for social justice can be openly discussed. When Chicanx students confidently engage Shakespeare, they lay claim to a legacy that belongs as much to them as it does to anybody else, and this becomes a springboard for apprehending their legitimacy both within and beyond the borders of academe. The fact that this kind of self-confidence has the potential to diffuse and leave a lasting impact on both the local and the global communities in which Chicanxs live is, without question, where the true promise of giving voice to a Chicano Shakespeare resides.

\section{Notes}

1. See Marc Lacey, "Rift in Arizona as Latino Class Is Found Illegal," New York Times, January 7, 2011, U.S. section <https://www.nytimes. com/2011/01/08/us/08ethnic.html> (accessed February 21, 2019).

2. Weston J. Phipen, "How One Law Banning Ethnic Studies Led To Its Rise," The Atlantic, July 19, 2015 <https://www.theatlantic.com/education/ archive/2015/07/how-one-law-banning-ethnic-studies-led-to-rise/398885> (accessed February 21, 2019).

3. On August 22, 2017, this law was ruled unconstitutional because it was "enacted for racial and political reasons." See Michael Kiefer, "Arizona Law Outlawing Mexican-American Studies Ruled Unconstitutional," azcentral, August 23, $2017<$ https://www.azcentral.com/story/news/local/ arizona-education/2017/08/23/arizona-law-outlawing-mexican-americanstudies-tucson-schools-ruled-unconstitutional/592446001> (accessed February 21,2019$)$.

4. Jeff Biggers, "The 'Madness' of the Tucson Book Ban: Interview With Mexican American Studies Teacher Curtis Acosta on The Tempest," 
HuffPost, January 17, $2012<$ https://www.huffingtonpost.com/jeff-biggers/ tucson-ethnic-studies-_b_1210393.html> (accessed February 21, 2019).

5. Ibid.

6. Gloria Anzaldúa, Borderlands/La Frontera: The New Mestiza, 4th edition (San Francisco: Aunt Lute Books, 1987), 101.

7. Peter Holland, "Shakespeare, Humanity Indicators, and the Seven Deadly Sins," Borrowers and Lenders: The Journal of Shakespeare and Appropriation 7, no. 1 (2012) <http://www.borrowers.uga.edu/783091/show> (accessed February 21, 2019).

8. Arturo Islas, La Mollie and the King of Tears (Albuquerque: University of New Mexico Press, 1996), 159.

9. My reference here to the "Miss Harpers of the world" in no way betrays my feminist sensibilities, because my aim is to register Louie's view of her role in his educational growth. As a character who defines Shakespeare along very narrow lines, Harper works as a stand-in for the many educators who, as Paolo Freire argues, seek to justify their own existence by projecting "an absolute ignorance" onto their students. Paulo Freire, Pedagogy of the Oppressed, trans. Myra Bergman Ramos (New York: Penguin Books, 1996), 53.

10. Pierre Bourdieu, Language and Symbolic Power, ed. John Thompson, trans. Gino Raymond and Matthew Adamson (Cambridge, MA: Harvard University Press, 1982), 58-9.

11. Anzaldúa, Borderlands/La Frontera, 80-1.

12. Leo R. Chavez, The Latino Threat: Constructing Citizens, Immigrants, and the Nation, 2nd edition (Stanford: Stanford University Press, 2008), 45.

13. Harold Bloom, Shakespeare: The Invention of the Human (New York: Riverhead Books, 1998), 662.

14. See Kim F. Hall, Things of Darkness: Economies of Race and Gender in Early Modern England (Ithaca: Cornell University Press, 1995); Arthur Little, Shakespeare's Jungle Fever: National-Imperial, Re-visions of Race, Rape, and Sacrifice (Stanford: Stanford University Press, 2000); Ania Loomba, Shakespeare, Race, and Colonialism (Oxford: Oxford University Press, 2002); Ayanna Thompson, Passing Strange: Shakespeare, Race, and Contemporary America (London: Oxford University Press, 2011).

15. Kim F. Hall, "'These Bastard Signs of Fair': Literary Whiteness in Shakespeare's Sonnets," in Post-colonial Shakespeares, ed. Ania Loomba and Martin Orkin (New York: Routledge, 1998), 64-83.

16. While I employ Baz Luhrmann's Romeo + Juliet (1996) to demonstrate how the casting of Latinx actors often perpetuates the white/non-white dichotomy, I also employ other Shakespeare films that do not include Latinx actors. Instead of minimizing this issue, I draw attention to it, and students often offer their opinions on the predominant whiteness of Hollywood.

17. Ayanna Thompson, "Unmooring the Moor: Researching and Teaching on YouTube," Shakespeare Quarterly 61, no. 3 (2010): 338.

18. Anzaldúa, Borderlands/La Frontera, 81. 
84 Ruben Espinosa

19. Ruben Espinosa, "Beyond The Tempest: Language, Legitimacy, and La Frontera," in The Shakespeare User: Critical and Creative Appropriations in a Networked Culture, ed. Valerie M. Fazel and Louise Geddes (New York: Palgrave Macmillan, 2017), 53-7.

20. Thompson, "Unmooring the Moor," 356.

21. Ibid. 


\title{
"Intelligently organized resistance": Shakespeare in the Diasporic Politics of John E. Bruce
}

\author{
Kim F. Hall
}

On June 6, 1916, Manhattan was temperate but overcast: on the streets, cars and double trolleys vied for space with horses, carts, and pedestrians. The latest arrivals from Europe, the West Indies, and the American South marveled with native New Yorkers at the new buildings springing up everywhere. While skyscrapers replaced downtown mansions in America's largest city, eastern European Jews, southern Italians and Chinese traversed their respective enclaves on the east side. Uptown, whites had fled Harlem as blacks moved there in search of better conditions. By 1916 Harlem was a black "city within a city" where both the better off and the striving gathered on the wide sidewalks and streets for almost weekly meetings and parades. ${ }^{1}$

Although it had just entered World War I, the U.S. had been on a war economy for some time. As European immigration slowed, the labor gap was filled by blacks escaping "low wages, bad sanitary conditions, disenfranchisement, mob law and lynchings" in the South. ${ }^{2}$ The release of D. W. Griffith's film The Birth of a Nation a year earlier had provoked a rise of Ku Klux Klan terrorism. On the street and in the black press, many were debating whether and on what terms blacks would join the conflict: should they join “The White Man's War" when the War Department made clear that black participation would continue under the same degraded segregation as usual? Or would demonstrating their valor in the battlefield - doing the state some service-lead to inclusion back home?

John Edward Bruce (1856-1924), the black journalist, self-trained historian, and indefatigable organizer known as "Bruce Grit," wrote his presidential address for the group "The Friends of Shakespeare," based in New York, even as he pondered these larger questions. His speech gives a glimpse of black participation in the thousands of Shakespeare tercentenary celebrations across the country, which ranged from the 
popular Professor George Lyman Kittredge's lecture at Harvard University and poet Percy MacKaye's massive "community masque" Caliban by the Yellow Sands to smaller events. Outlining a program of Shakespeare study specific to his diverse membership, Bruce closed by celebrating the group's potential: "We have in this body the nucleus of a strong and powerful and useful agency for good." But he also warned that this group-like so many black organizations-would face "organized opposition to your efforts for mental and histrionic advancement," which they needed to meet with "intelligently organized resistance." The collective study of Shakespeare, he was convinced, provided the intellectual tools needed for black advancement and resistance.

Bruce's firm race pride and his refusal "to join organizations run or supported by whites" meant that this fiery black nationalist, who mentored Marcus Garvey in forming the largest mass political movement of the twentieth century, largely disappears from dominant histories. ${ }^{4}$ This chapter teases out links between Bruce's interest in Shakespeare and his lifework of social justice struggle. It is part of a larger project exploring links between black study/performance of Shakespeare and black freedom movements. I approach these texts with a fundamental question: how can they help create a Shakespeare that is not an adjunct to white supremacy and settler colonialism? The divide between Shakespeare and radical black politics has become so complete that it feels important to try to recapture a moment when both could exist as projects of racial uplift - projects not dependent on respectability politics and not (at least not entirely) on Shakespeare's social capital. ${ }^{5}$

Not much is documented about "The Friends" other than that the group was formed in 1915 by "young men and women of studious habits and literary ambition" who met in Harlem with the intention to explore black literature as well as Shakespeare. ${ }^{6}$ This was a gathering of the newly arrived, the socially struggling, and the established. Although older than most of the members, Bruce's radical politics, his deep belief in developing black history and "the beauty of black and the particular cultural aesthetic of the Negro" might have made him the perfect choice to lead such a group. ${ }^{7}$ The major themes of the presidential address are cooperation, diasporic connections, race pride, and the importance of performance. Bruce outlines a program of Shakespeare study in which members would teach each other about Shakespeare's plays and their historical context, studying and writing for enjoyment and for future performance. Bruce clearly venerates Shakespeare: "Shakespeare next to Jesus Christ is one of the greatest teachers the world has ever known ... He was a seer and an incomparable genius." "Yet the speech also makes very clear that the group's literary activities are embedded in racial 
uplift and the promotion of black excellence. Key to understanding the link between Shakespeare study and race development is Bruce's pan-Africanism. He emphasizes cooperation and collaboration, claiming The Friends "in the collective sense is greater than any individual or group of individuals." "For Bruce, literary study is a model for the cooperation he hoped to inspire in blacks across the diaspora.

Bruce opens with a promise of impartiality, but makes it clear that this serves a higher goal than just good leadership: "we are equal partners in a great race uplifting enterprise whose objective is moral intellectual and social development and advancement of our race, and the vindication of its ability and genius for sustained effort in the higher reaches of thought." ${ }^{10} \mathrm{By}$ its end, the speech becomes fully about the possibilities of pan-Africanism:

I wish you all to feel as I do in this regard and to cooperate with me in my efforts to promote good fellowship and goodwill among us-a better feeling and a better understanding between those of us who happen to have been born on opposite sides of the Atlantic. We all of us of the Negro race are under the band of Caucasian caste prejudice; its fixed policy is to delimit the opportunities of the ambitious and progressive Negro whose aspirations are beyond those of mere menial service. ${ }^{11}$

In one sense, the course of study Bruce outlines looks surprisingly similar to modern expectations of professional Shakespeare study. Even as he likens Shakespeare to the Bible, this is not an isolated examination of the Shakespearean text, but a thorough study of Shakespeare's life and times:

The study of Shakespeare is closely akin to the study of Theology. It needs interpretation. Not every Layman who reads his Bible is able to give a free and clear interpretation of the meaning or of the thoughts of the writer... the proper study of Shakespeare should be preceded by the study of history of the times in which he wrote, of the customs, habits, the English he spoke and wrote, the characteristics of the people and things about whom he wrote. ${ }^{12}$

The historical study of Shakespeare sharpens one's intellectual tools for the study of other historical matters, for performance, and for activism. Biblical metaphors aside, Bruce's pedagogical model is one of guided instruction and independent study; this is not a handing of knowledge from accomplished scholar to layperson, but an opportunity for the learned and self-taught to come together to produce a usable Shakespeare. His Shakespeare is not an abstract universal genius, but 
a Shakespeare of his times - and a Shakespeare who is in some way a vehicle for black talent and black aspiration. Bruce suggests that the members organize themselves into smaller interpretative communities of five or more who work together to "master" the history and meanings of a play in order to be of use to the larger group, who might wish to produce it.

It is difficult to identify what specific aspects of Shakespeare pedagogy Bruce's speech was contesting or amplifying. He was primarily an autodidact: after escaping slavery, he went to school intermittently, leaving formal education when work was available. ${ }^{13}$ Additionally, Shakespeare tercentenary celebrations show multiple approaches to Shakespeare study and performance circulating in the dominant culture. Caliban by the Yellow Sands, which envisioned Shakespeare performance as "an act of civic involvement," ${ }^{14}$ seems closer in spirit to the communal ethos that drives Bruce. However, Caliban's sense of community is somewhat undercut by a message of assimilation and elevation through obeisance to a powerful teacher. More influential for American pedagogy was Kittredge's tercentenary lecture. Not only was the lecture immediately published, Michael Bristol argues that it informed Kittredge's popular (but much later) edition of Shakespeare's plays. ${ }^{15}$

Like Bruce, Kittredge sees Shakespeare study in religious terms (the critic "professes and he should keep the faith"); however, his relentlessly isolationist depiction of Shakespeare interpretation ("We should recognize it rather, and cherish it, as our private property" ${ }^{16}$ contrasts sharply with Bruce's ethos of collectivity. Bristol notes, "the classic liberal doctrine enshrined here does not acknowledge anything like collective endeavor"; ${ }^{17}$ this is Shakespeare study sequestered from the radical and public social activism of the era. In contrast to Bruce's wide-ranging exhortation that members research all facets of Shakespeare's times, Kittredge asserts that interpretation requires only the text and an understanding of the Elizabethan stage: research is underplayed or dismissed and performance is seen as an entirely different enterprise. ${ }^{18}$ Kittredge assumes that his audience is burdened with an inheritance of Shakespeare criticism; Bruce knows that many in his audience come from a tradition of struggle for mere literacy. For an audience largely unconcerned with civic and intellectual inclusion, Kittredge can afford to exclude "a politically motivated research program." 19 Bruce envisions freedom as the result of collective struggle; thus his agenda for Shakespeare study in both purpose and implementation is inextricably linked to a larger agenda for racial freedom. It is not surprising that he sees coming together in a literary group as having tangible and lasting benefits both for the individual and for society. This process of learning 
together as a group - of nurturing the talents that might arise in that group - suggests that Shakespeare allows groups to organize in study in the way that they might organize in struggle.

The release of Griffiths' cinematic and white supremacist tour de force The Birth of Nation and the movement of millions of Southern blacks to cities in the North in 1916 (known as the Great Migration) show more clearly how Bruce's promotion of Shakespeare study is laced with political urgency. The film provoked sustained black protests bringing attention to its incitement of the second rise of the Klan and increased anti-black violence by the police. ${ }^{20}$ Black leaders criticized Woodrow Wilson for making the first American film screened in the White House be one that "naturalized white supremacy by juxtaposing white competence, dedication, and physical strength with black incompetence, laziness, and physical degeneracy." ${ }^{21}$ It painted Reconstruction and the participation of blacks in electoral politics as a "black reign of terror" (one intertitle proclaims "The helpless white minority") and no doubt accelerated the beginnings of the Great Migration. ${ }^{22}$ Thus, when Bruce dreams "of a great Negro dramatic society to interpret with precision and ability the masterworks of the greatest dramatist and playwright of all the ages ... [Of] the yet undiscovered geniuses who have no language but a sigh!", he is offering an explicitly political dream to a black community externally confronting a newly revived sphere of white supremacist hatred. ${ }^{23}$ So, too, his emphasis on collaboration and cooperation speaks to rapidly diversifying black communities, including Southern blacks and newly arriving West Indians, all dealing with new living conditions. Shakespeare becomes a common ground for learning new forms of cooperation and also for combating the continuing hold of minstrel performance brought vividly to screen by The Birth of Nation.

Bruce's faith that collective Shakespeare study-research, interpretation, and performance - provides the space for both individual uplift and social transformation provides a lens for evaluating Shakespeare study today. For example, how much of institutional Shakespeare study carries vestiges of Kittredge's privatized Shakespeare? A charismatic teacher energizing students with her love of Shakespeare certainly makes for a welcome community of Shakespeare enthusiasts, but models of collaborative study and interpretation might help students develop tools for "intelligently organized resistance" against oppression. On this note, I want to turn to educator Joyce E. King's interviews with a black teacher who achieved notable success with alienated and disenfranchised black students: "Her strategy is to get students motivated and get them more involved in their own learning by invoking an ethic of collective work 
and shared responsibility." ${ }^{24}$ I suggest that we can take from both King's teacher and Bruce an imperative to embed our teaching of Shakespeare within an ethic of collective work and shared responsibility where the responsibility is not to the canon or the European tradition-but to each other within an ethos of love and kindness.

Bruce was a believer in black organizations and political activism in terms inclusive for his day. For him, the way to push back against the brutal power of the racist state was to join forces across differences in groups with collective purpose. In my reading, Bruce's confidence that his audience would find affirmation, meaning, and power in the study of Shakespeare is not rooted in a celebration of Shakespeare as a lone universal genius or in an affirmation of Shakespeare as the monument to white achievement. White supremacy wants to see a static, sterile, and lone Shakespeare. What happens if we counter this narrative of Shakespeare with images of Shakespeare performance in a variety of hues and "languages"? The Friends organized to read both Shakespeare and black literature, a tradition in black performance as well. Ira Aldridge performed Shakespeare along with music, original verse, comic routines, and abolitionist lectures. Shakespeare elocutionists like Bruce's friend Henrietta Vinton Davis performed Shakespeare along with black literature and music. What happens if we offer students a Shakespeare "fractured" and remade for our times?

One step would be to include texts by figures from different critical and intellectual traditions in our study of Shakespeare. I offer some suggestions that have not yet been tested in my classroom. Both Davis and other elocutionists read the poetry of Paul Laurence Dunbar, another poet who turned vernacular into verse. "Little Brown Baby" was a particular favorite. ${ }^{25}$ Educator Ceola Ross Baber documents success pairing Sonnet 130 with The Impressions' song "Woman's Got Soul," 26 but many black writers have taken up the sonnet form. Countee Cullen's "A Song of Praise," Claude McKay's "The Harlem Dancer," Jean Toomer's "Portrait in Georgia," and Harryette Mullen's more playful "Dim Lady" and "Variation on a Theme Park" all interrogate the sonnet's politics of praise. British rapper Akala asks audiences (for example in his online presentations) to think about the relations between Shakespeare's plays and the culture/rhythms of hip hop. Rather than diverting from Shakespeare, these texts demand close study of language and verse and, in the case of hip hop, meter and rhyme. Asking students to bring in songs and texts related to a play's themes offers another level of collaboration.

On a more abstract level, engaging writers of color might offer useful frameworks for decolonizing the Shakespeare classroom. In addition 
to evocatively posing questions of Chicanx identity, Gloria Anzaldúa's concept of the borderlands could prime a class for thinking of reading Shakespeare as a space of contact across differences as well as for being alert to questions of mixture in Shakespeare. ${ }^{27}$ Similarly, Alice Childress's essay "Candle in a Gale Wind" offers a trenchant critique of universality in the theater that can give us tools for understanding universality, like color-blindness, as an alluring ideal with dangerous effects in a white supremacist educational system. ${ }^{28}$

To study Shakespeare is to study power: the power of the state, the power of the mob, the power of institutions. To use Shakespeare as a means of collective effort is to give students the tools for "intelligently organized resistance" in all phases of life. Shakespeare has much to teach about regime change, the manipulation of language for personal, erotic, and political ends, and social power on all registers. A renewed attention to Shakespeare's language in a time of global neoliberalism, escalating social inequality, politically legitimized white supremacy, and an increase in militarization might give students new skills for understanding the slippery wielding of language and power, as well as for collective action.

\section{Notes}

My research on Bruce was made possible by fellowships at the Schomburg Center for Research in Black Culture and the National Humanities Center. Special thanks to Naomi Lorrain at the Schomburg and the NHC library staff.

1. Irvine Garland Penn, The Afro-American Press and Its Editors (Springfield: Willey \& Co., 1891), 341; William Seraile, Bruce Grit: The Black Nationalist Writings of John Edward Bruce (Knoxville: University of Tennessee Press, 2003). My description of 1916 Manhattan is based on the following sources: Jen Carlson, "Flashback: Growing Manhattan, 1916," Gothamist <http://gothamist.com/2011/01/11/flashback_manhattan_1916.php> (accessed July 1, 2017); James Weldon Johnson, Black Manhattan (New York: Arno Press, 1968); William A. Green, "Caliban by the Yellow Sands: Percy MacKaye's Adaptation of The Tempest," Maske und Kothurn 31, no. 1 (1989): 59-66; Seraile, Bruce Grit; and accounts from black newspapers of the era.

2. John Edward Bruce, The Selected Writings of John Edward Bruce: Militant Black Journalist, ed. Peter Gilbert (New York: Arno Press, 1971), 118.

3. John Edward Bruce, "A Speech to Ye Friends of Shakespeare" (1916), 15, John Edward Bruce Papers, Schomburg Center for Black Culture.

4. Bruce, The Selected Writings, 3. 
5. Since the language of racial uplift seems to have become increasingly elided with respectability politics and framed in antithesis to radical politics in contemporary political discourse, I should be clear that Bruce's notion of black uplift is correlated with an ideal of radical social change.

6. "New Literary Society Organized in New York. Known as Friends of Shakespeare-C. M. Moloney Elected President," Afro-American (Baltimore), May 22, 1915, p. 2.

7. Bruce, The Selected Writings, 9.

8. Bruce, "A Speech to Ye Friends of Shakespeare," 6-7.

9. Ibid., 1.

10. Ibid., 2-3.

11. Ibid., 14.

12. Ibid., 4-5.

13. Penn, The Afro-American Press and Its Editors, 341; Seraile, Bruce Grit.

14. Green, "Caliban by the Yellow Sands," 60.

15. Michael D. Bristol, Shakespeare's America, America's Shakespeare (New York: Routledge, 1990), 130.

16. George Lyman Kittredge, Shakspere. An Address. Delivered on April 23, 1916, in Sanders Theatre at the Request of the President and Fellows of Harvard College (Cambridge, MA: Harvard University Press, 1926) <http://hdl.handle.net/2027/uiug.30112113376450> (accessed February 22, 2019). Spelling adheres to the original text.

17. Bristol, Shakespeare's America, America's Shakespeare, 132.

18. Kittredge, Shakspere. An Address, 14.

19. Bristol, Shakespeare's America, America's Shakespeare, 130.

20. Cara Caddoo, "The Birth of a Nation, Police Brutality, and Black Protest," Journal of the Gilded Age and Progressive Era; Normal 14, no. 4 (October 2015): 608-11.

21. Elaine Frantz Parsons, "Revisiting The Birth of a Nation at 100 Years," Journal of the Gilded Age and Progressive Era 14, no. 4 (October 2015): 596-8.

22. Davarian L. Baldwin, Chicago's New Negroes: Modernity, the Great Migration, and Black Urban Life (Chapel Hill: University of North Carolina Press, 2009), 123.

23. Bruce, "A Speech to Ye Friends of Shakespeare," 8.

24. Joyce E. King, "Unfinished Business: Black Student Alienation and Black Teachers' Pedagogy," in Qualitative Investigations into Schools and Schooling: Volume 11, Readings on Equal Education, ed. Michele Foster (New York: AMS Press, 1991), 253. King offers an important reminder that students are no longer being taught with "emancipatory intentions": "the estrangement of black students from education is a relatively recent phenomenon for they had been in the forefront of the ongoing struggle for education" (248, original emphasis).

25. I offer this historical note with some caution. This poem is written in black Southern dialect that has been so degraded in popular discourse. 
26. Ceola R. Baber, "From Liberal Teacher to Liberated Teacher Educator," in Critical Race Theory and Perspectives on the Social Studies: The Profession, Policies, and Curriculum, ed. Gloria Ladson-Billings (Charlotte: Information Age Publishing, 2003), 51-2.

27. Gloria Anzaldúa, "Preface," in Borderlands/La Frontera: The New Mestiza, 4th edition (San Francisco: Aunt Lute Books, 1987), iii-iv.

28. Alice Childress, "A Candle in a Gale Wind," in Black Women Writers (1950-1980): A Critical Evaluation, ed. Mari Evans (New York: Anchor Books, 1984), 111-16. 

Part III

Ethical Queries and Practices 



\title{
Sexual Violence, Trigger Warnings, and the Early Modern Classroom
}

\author{
Kirsten N. Mendoza
}

Over the last decade, a heated controversy over calls for trigger warnings has emerged among students, faculty, administrators, and those outside of academia. Critics often decry these alerts as antithetical to the purpose of education, cautioning students that "a perfectly safe university would not be worth attending." ${ }^{1}$ Not only do trigger warnings and safe spaces purportedly stifle dialogue and censor the contentious but meaningful subjects that professors teach, but it is argued that they even pose a significant threat to free speech. According to a report issued in 2014 by the American Association of University Professors (AAUP), when teachers are expected or required to alert students to assigned material that elicits "difficult emotional responses," this fosters an "anti-intellectual" environment, diminishes the educational experiences of other class participants, and "could potentially expose teachers to all manner of discipline and punishment." Resistance to this pedagogical tool derives in part from the accusation that students abuse trigger warnings to opt out of distressing or complex material. When this suspicion toward disabilities-specifically, invisible disabilities-meets a widespread derogation of "trigger" to mean anything that leads students to experience some uncomfortable emotion, conversations on pedagogy lose sight of the primary purpose of trigger warnings, which is to help individuals with posttraumatic stress disorder (PTSD) manage their mental health and prepare to analyze violent content.

When Shakespeare is brought to the polemical debate, he often surfaces in rhetorical questions: Should Hamlet be given a "red-flag"? Isn't it precisely because Shakespeare's works "trigger" us that his canon is taught in the first place $?^{3}$ I maintain that the Shakespeare corpus does, in fact, deserve trigger warnings. As an instructor who focuses on the early modern period-distanced by time, language, and culture 
from our contemporary moment-it behooves me to remind my students that the scenes of oppression and violence we analyze together reverberate to varying degrees in the lived experiences of those among us. Shakespeare's works not only move people affectively; some even have the capacity to cause audiences to experience intense physiological reactions - such as panic attacks, vomiting, and fainting, which all notoriously occurred during the 2014 revival of Lucy Bailey's gory production of Titus Andronicus at the Globe. Trigger warnings validate the fact that it is emotionally arduous and demanding to bear witness to scenes of trauma, particularly for those who have firsthand experience of violence. When I have students watch Ralph Fiennes' 2012 documentary-style adaptation of Coriolanus, analyze Ophelia's songs before her suicide, or discuss Desdemona's murder at the hands of Othello, I am not concerned with compelling combat veterans, refugees, adults with a history of self-harm, domestic abuse victims, or sexual assault survivors in my classes to disclose their experiences of trauma, nor is it my duty to police their affective responses by authenticating whose reactions truly warrant accommodation. But when, for example, students receive messages containing a "daily lynching" calendar or see Confederate and Nazi symbols paraded on a college campus, I cannot assume that they come to class in a state ready to engage intellectually with Aaron's refusal to murder his black child or the anti-Semitic insults hurled at Shylock. ${ }^{4}$

This chapter is divided into three sections. The first argues that trigger warnings themselves advocate for social justice since they challenge ableist norms about the people who belong in our classrooms and put communal care and responsibility in action. When the trigger warning debate centers on access, then the decision to utilize them itself becomes a political statement that serves as the point where theory meets praxis. ${ }^{5}$ Rather than indulge the rampant misperception that trigger warnings raise student resistance to difficult materials, the second section of this chapter offers viable ways that this pedagogical tool can frame classroom conversations, provide points of entry for discussion of early modern works, and optimize access, learning, equity, and respect in the classroom. The chapter ends with an example of one particular class discussion in which I utilized trigger warnings to facilitate a conversation with students that explicitly used Shakespeare to talk about rape on our college campus. When I teach Shakespeare, I have my students confront misogyny, racist ideologies, and scenes of graphic violence. I not only expect but hope for productive contention and discomfort in the classroom. However, I have come to realize that in order to create an environment in which such conversations are possible, 
a basic ethos of trust needs to exist; trigger warnings have not hindered but have helped me to cultivate such an atmosphere.

\section{Trigger Warnings and Disability Politics}

Terms like "trigger" and "trauma" continue to be sorely misused by those within higher education and without. "In the recent wave of the politics of the aggrieved," Jack Halberstam explains, trigger warnings and safe spaces have been hijacked by a generation of young adults "who have come to think of themselves as communities of naked, shivering, quaking little selves- too vulnerable to take a joke, too damaged to make one." ${ }^{\prime 6}$ Deployed by conservative students who prefer to skip material conflicting with their religious and political values as well as neoliberals who see progress as the prevention of hurt feelings, demands for trigger warnings have been met with the retort that these "delicate flowers" in our classrooms should "put on [their] big-girl panties" because "life is a trigger."

Indeed, life does not come with cautionary signs, but I am deeply disturbed by the implication that re-traumatizing survivors is acceptable because life is a "trigger." One of the first acts of social justice that an instructor can perform is to reclaim trigger warnings as practices that are meant to mitigate harm, especially for students living with PTSD. Placing the onus on individual students to alert teachers in advance for accommodations to be made maintains the ableist assumption that it is aberrant for students and faculty in the classroom to be living with mental illness. Educators who use trigger warnings affirm the differing exposures to violence of each person in the classroom. More importantly, they incorporate pedagogical practices that address the needs of not only those deemed psychologically "fit" and "ready" for an education. When effectively utilized, trigger warnings neither overprotect victims nor standardize people. ${ }^{9}$ They show that we respect our students, who are capable of making decisions for themselves, who can choose whether or not they should receive therapy, take our courses, or disclose to us their needs and histories.

Above all, trigger warnings enable student autonomy by giving students the time and space to discover what they are capable of doing and when they require assistance, rather than forcing them to determine in advance what they can and cannot do, and to "out" their disability to professors, who might not always be receptive to their needs. ${ }^{10}$ When instructors underscore the ubiquity of violence in early modern works without voicing and responding to its continued pervasiveness in our 
contemporary moment, these silences and inaction neglect those in the classroom who are working through the aftermath of trauma, and suggest that the issues raised in analyses of early modern literature are ultimately limited to Shakespeare's time. Trigger warnings acknowledge the existence of survivors in our midst, address the array of emotional and psychological preparedness students inhabit before immersing themselves in the content of the class, and help to cultivate an environment of care and solidarity. ${ }^{11}$

\section{An Evolving Practice}

To increase transparency, I foreground at the beginning of the semester that discomfort-rather than something that should be avoidedindicates that meaningful learning is taking place. Panic attacks and paralyzing anxiety, however, are not conducive to the work that I expect us to perform in an educational environment. Like other pedagogical tools, trigger warnings can be altered to cater to particular classroom dynamics. An approach that might work for one topic could prove entirely ineffective when applied to another. When I first began teaching, I had a rather standard understanding of the capacities of trigger warnings. Since students would have theoretically encountered texts in preparation for class, I assumed that a simple but supportive preamble that validated survivors and encouraged them to do what they needed to care for themselves would suffice. After reflecting on my practices, I realized that despite naming known triggers particular to different content, such as the verbal abuse hurled at Hero during her wedding by her husband-to-be and Lucrece's post-rape perception of her body as "stained," my stock usage of trigger warnings defined only one scenario and student response - that the individual would need to leave the classroom.

If the purpose of trigger warnings is to provide access, then alluding to an ambiguous description of "care" but articulating only one approach seems limiting and even counterproductive. It undermines the varying specificity of structural violence, dismisses how medium influences student responses, and fails to address the unique and complex subject positions of students, all of which shape their reactions to and thinking about the material they study. ${ }^{12}$ Educators can tailor their trigger warnings and respond spontaneously to the atmosphere they perceive in the class that day. ${ }^{13}$ Rather than offer a standard caveat applied to any potentially distressing topic and at any point in the semester, teachers can increase accessibility for students and heighten 
their intellectual engagement by using trigger warnings as introductions, framing the session's lesson plan, and giving students multiple strategies for beginning analysis and entering conversations. ${ }^{14}$

- Reflect and connect. Trigger warnings can situate the day's topic in relation to prior discussions of the text and/or of the course. Keeping a journal of particularly poignant and insightful comments from students can help instructors prepare their introductory statements. Rather than simply ask students to recall a previous conversation, remind them of the ideas that they themselves and their classmates had generated. This seemingly small gesture acknowledges the ideas raised by students, validates their participation, and gets them in the mindset that they are not to be passive consumers of violence but active and critical engagers who share responsibility for the learning produced in the classroom.

- Learn with emotion. It is difficult to bear witness to violence. If students feel viscerally charged by what they enact, read, or watch, encourage them to interrogate their affective responses. What artistic choices did you find particularly evocative and/or noticeable? How did the experiences of reading these lines as you prepared for class differ from watching the film adaptation or live play?

- Self-guided analysis. Have students compose a list of questions or items to observe (e.g. stage and body positions, setting, and costumes) for their personal use when confronting potentially triggering material. This preparation, which can occur prior to or at the beginning of class, gives students a self-directed agenda.

- Navigate physical responses. In addition to validating a student's need to leave the classroom, which some might find difficult to do if they fear attracting the attention of their classmates, there are other ways that instructors can help students navigate their reactions to witnessing trauma. Instructors could remind students before the class to bring water or to wear something that they find comforting. If "think-pair-share" or small-group discussions will occur, then give students something tactile that they can manipulate in their hands (e.g. stress balls of assorted colors) that designates their groups but also, if needed, provides something inconspicuous on which they can focus.

When I start discussions by acknowledging students and instructors in our midst who have experienced trauma, I encourage participants to consider how scenes of violence impact someone other than themselves. If one of the virtues of teaching Shakespeare is that his works seem 
particularly apt for getting students to make connections and feel with an "other," then trigger warnings start that process of thinking beyond the "I."

\section{Vulnerability and Trust}

In spring 2015, I taught a course that fulfilled a requirement for arts and sciences undergraduates at Vanderbilt University. None of my students were English majors; a few were anxious about in-class participation due to their nonliterary backgrounds, and most exuded hesitance rather than enthusiasm when they learned that works by Shakespeare and his contemporaries comprised the bulk of our readings. At the same time as we started on The Rape of Lucrece, a jury convicted two former Vanderbilt football players of the aggravated rape of an unconscious female student in a campus dorm. I felt that it would be remiss of me not to bring up the rape trial but was also hesitant to do so, since I lack training in therapy and crisis care. Despite my reservations, I announced that the trial would be discussed in the next class. Since this would likely be difficult for men and women who have survived sexual assault, I encouraged students to do what they needed to care for themselves and hoped that everyone would be present for our conversation.

On the discussion day, my trigger warning began with a request that we sit facing one another, followed by a statement regarding sexual violence on college campuses. I encouraged students to care for their overall well-being through actions that may include: drinking water, free-writing, and taking deep breaths. Next, I had the class recall previous insightful student comments that exemplified how close readings of Shakespeare's poem enabled us to interrogate the repercussions of a culture that reduced women like Lucretia to "lucre." By prompting students to remember, reflect on, and restate the ideas that were developed in class analyses of key terms like "chastity" and "honor," I provided students with a concrete approach to our conversation on the Vanderbilt trial. Students knew that they could apply the same critical thinking skills we had been practicing to their analyses of the trial defense's argument that a campus culture glorifying "binge-drinking" and "promiscuity" should be blamed. I also opened our conversation to more personal approaches by asking students if they followed this case and the issues it raised for themselves and for their peers. Every student attended and participated in that day's discussion, which set the tone for the remainder of the course. Later, I learned that our discussion of Vanderbilt's rape trial was a turning point for a student who grew up 
with one of the defendants and had been rather ambivalent about the relevance and import of the work we do in a Shakespeare classroom. That discussion heightened her intellectual and emotional investment in the course because it revealed to her that the work we do with early modern texts can be applied to the world she inhabits. The knowledge we produce together is not just about then: it is also about now.

At the very least, trigger warnings help educators build rapport with students. Offering these warnings conveys that teachers are willing to help students navigate the psychosomatic terrain of engaging with known systemic violence, and that we respect their individual histories and life narratives, so that when seemingly unhealthy situations arise, enough trust has been built for us to continue moving forward as a community. ${ }^{15}$ If we seek to foster an environment in which students are willing to make themselves vulnerable, to challenge fellow classmates and their instructors, and to take risks in their writings, we should model openness to the needs of another, humility by learning with and from our students, and a willingness to be vulnerable, too.

\section{Notes}

1. Lexington, "Trigger-unhappy: Student 'safety' has become a real threat to free speech on campus," The Economist, June 13, $2015<$ https://www. economist.com/united-states/2015/06/13/trigger-unhappy> (accessed February 22, 2019).

2. Committee A on Academic Freedom and Tenure, "On Trigger Warnings," AAUP, August $2014<$ http://www.aaup.org/report/trigger-warnings > (accessed February 22, 2019).

3. Doni Wilson, "9 Trigger Warnings for Hamlet," The Federalist, May 27, $2014<$ http://thefederalist.com/2014/05/27/9-trigger-warnings-for-hamlet> (accessed February 22, 2019).

4. Sarah Friedman, "Vanderbilt Students Get Added to Racist GroupMe Chat," Vanderbilt Hustler blog, November 14, $2016<$ http:// vanderbilthustler.com/featured/vanderbilt-students-get-added-to-racistgroupme-chat.html> (accessed February 22, 2019).

5. Angela M. Carter, "Teaching with Trauma: Trigger Warnings, Feminism, and Disability Pedagogy," Disability Studies Quarterly 35, no. 2 (July 2015): 9-19.

6. Jack Halberstam, "You Are Triggering Me! The Neo-liberal Rhetoric of Harm, Danger and Trauma," Bully Bloggers, July 5, $2014<$ https:// bullybloggers.wordpress.com/2014/07/05/you-are-triggering-me-the-neoliberal-rhetoric-of-harm-danger-and-trauma> (accessed February 22, 2019). 
7. Laurie Essig, "Trigger Warnings Trigger Me," Chronicle of Higher Education Blogs: The Conversationblog, March 10, $2014<$ https://www.chronicle. com/blogs/conversation/2014/03/10/trigger-warnings-trigger-me $>$ (accessed February 22, 2019).

8. Rani Neutill, "My Trigger-Warning Disaster: '9 1/2 Weeks,' 'The Wire' and How Coddled Young Radicals Got Discomfort All Wrong," Salon, October 28, $2015<$ https://www.salon.com/2015/10/28/i_wanted_to_ be_a_supporter_of_survivors_on_campus_and_a_good_teacher_i_didnt_ realize_just_how_impossible_this_would_be> (accessed February 22, 2019); Jerry A. Coyne, "Life Is 'Triggering.' The Best Literature Should Be, Too," New Republic, May 14, 2015 < https://newrepublic.com/ article/121790/life-triggering-best-literature-should-be-too $>$ (accessed February 22, 2019).

9. Alison Kafer warns that a "refusal to see disability as tragedy, as traumatic, can be just as restricting on our politics and our theories as the ableist insistence that disability is always and only tragic." Alison Kafer, "Un/Safe Disclosures: Scenes of Disability and Trauma," Journal of Literary and Cultural Disability Studies 10, no. 1 (2016): 1-20, 6.

10. Jami McFarland, "On Privilege, Authority, and Abuses of Professional Power," in Trigger Warnings: History, Theory, Context, ed. Emily J. M. Knox (Lanham: Rowman and Littlefield, 2017), 170; Gail A. Hornstein, "Why I Dread the Accommodations Talk," Chronicle of Higher Education, March 26, 2017 <https://www.chronicle.com/article/Why-IDread-the-Accommodations/239571> (accessed February 22, 2019); Holly Taylor, "Accessibility on Campus: Posttraumatic Stress Disorder, Duty to Accommodate, and Trigger Warnings," in Trigger Warnings, ed. Knox, 28. Hornstein argues that accommodation letters standardize students with learning disabilities, which discourages them from realizing their actual capabilities. Taylor suggests that trigger warnings make classrooms supportive for students with PTSD, allowing class activities to serve as a form of exposure therapy.

11. For Bonnie Washick, trigger warnings serve to make structural violence "known and to make it a broader public's responsibility." Bonnie Washick, "An 'App' for That: The Case Against the 'Equal Access' Argument for Trigger Warnings," in Trigger Warnings, ed. Knox, 103.

12. Corrine C. Bertram and M. Sue Crowley state that sexual violence "crosses the borders of complex, multifaceted social positions with relative impunity. Resistance to it must cross those same borders." Corrine C. Bertram and M. Sue Crowley, "Teaching About Sexual Violence in Higher Education: Moving from Concern to Conscious Resistance," Journal of Women Studies 33, no. 1 (January 2012): 74.

13. Elizabeth Tolman, "Adapting Trigger Warnings in the Introduction to Women's Studies Course: A Case Study," in Trigger Warnings: History, Theory, Context, ed. Emily J. M. Knox (Lanham: Rowman and Littlefield, 2017), 201. 
14. David Perry quips, "Spoilers might be bad for entertainment, but they are good for education." David Perry, "Should Shakespeare Come with a Warning Label?” CNN, May 20, 2014 <http:/www.cnn.com/2014/05/20/ opinion/perry-trigger-warning-label-for-shakespeare/index.html $>$ (accessed February 22, 2019).

15. Emily J. M. Knox, “On Trigger Warnings,” in Trigger Warnings, ed. Knox, xiii-xxi. 


\title{
Rural Shakespeare and the Tragedy of Education
}

\author{
Jeffrey Osborne
}

Over the past five years or so, a spate of books, articles, and columns have appeared with the aim of assessing the value of postsecondary education, but they ultimately reveal not so much the extent to which university learning is beneficial (economically or otherwise), but what the university has become in the cultural imagination. The reduction of education to an economic investment coincides with the once-gradual and now-precipitous decline in state funding of public higher education. What funding remains is in many places tied to performance metrics that often explicitly devalue arts and humanities study. Because these cuts coincide with a cultural attitude already skeptical of the value of the arts and humanities, legislators suffer little political costand, perhaps, even gain some advantage — for making them. Martha Nussbaum described the situation in 2010 as a "silent crisis," and since then things have only become worse. ${ }^{1}$

This crisis is perhaps felt most intensely at colleges and universities that serve the economically disadvantaged, especially in rural parts of the country, where opportunities to experience the arts, for instance, are already few and far between. Reduced access to arts and humanities study for poor rural students is not simply a function of smaller tax bases, but an explicit aim of the right-wing agenda. In January 2016, Kentucky Governor Matt Bevin (B.A. East Asian studies, for what it's worth) publicly announced his plan to implement performance-based funding for higher education, declaring that "There will be more incentives to electrical engineers than French literature majors ... All the people in the world that want to study French literature can do so, they are just not going to be subsidized by the taxpayer." ${ }^{2}$ And, his Lieutenant Governor, Jenean M. Hampton, said if she were a student, "I would be looking for degrees where people are looking for employees ... I would not be studying history." 3 Making matters worse, for many of 
my students, the university and especially the humanities threaten their often unreflected commitment to customs and traditions that inform their perception of learning as an act of cultural betrayal. In such a climate, the struggle to connect literary texts like Shakespeare's to something like social justice and democratic practice must begin at the most basic level, by convincing students that arts and humanities have any positive value at all-personal, social, economic - and by convincing them that they are actually the objects of an injustice, that access to the benefits of art, music, literature, and philosophy will soon be reserved only for those wealthy enough to pay for it themselves.

As an undergraduate student, I could not have imagined that, thirty years later as a professor, I would have to confront the real possibility of the disappearance of humanistic studies in public universities - that I would need to do more than stage the question of justice in my classroom: I would need to fight for the very existence of that space. This is a problem that will matter to anyone who picks up this book. And, it will matter in a variety of ways: we believe in the power of the humanities, including, perhaps especially, Shakespeare, to enrich our lives, to motivate us, to prompt us into inquiry. It matters to me here-at Murray State-where many of the students I teach are, like I was, economically underprivileged first-generation students for whom university-level humanities study provides one of the first among already few opportunities for self-transformation. Although student self-transformation is obviously not something I can evaluate, creating the opportunity for them to suspend and question their values is a central aim of the general-education seminar in literature and philosophy that I teach every semester. At the beginning of the semester, I share my own journey from rural Appalachia into the academy as a first-generation student as a model for them to share throughout the rest of the course their own experiences with the humanities in terms of loss and discovery. I hope that in this way they may begin to embrace the role the humanities play in developing the habits necessary for individual and civic flourishing and, thus, for a more socially just democracy.

Inspired by the Socratic notion that aporia necessarily precedes the desire to learn - that you must first know you are lost to find your way-I have themed and titled this course "Getting Lost," and the very first learning outcome on the syllabus is "As a result of this course, students will get lost." I want my students to understand that a good humanities education should do what Socrates does to Meno: strip us of our self-assured opinions, leaving us feeling lost, perplexed. Only when we experience aporia can we begin to learn how to be lost in a more just and ethical way. Being lost is not a radical disorientation 
but a reorientation toward questions and dialogue rather than mimicked opinions and ignorant shouting. Situating Shakespeare's Othello, Lear, and Romeo and Juliet in a reading list that begins with Homer's Odyssey and runs from there to Plato, Sophocles, and Euripides, and all the way up to Camus, de Beauvoir, James Baldwin, Elizabeth Bishop, and Cormac McCarthy, I aim to reveal to students the many ways by which we might lose our way, miss the mark, dwell in hamartia-and the exceptionally few ways by which we might become aware of this dreadful fact. Although many of the texts I teach are either explicitly tragedies or can be read as such, a lot of them represent getting lost in other ways. I choose to focus on the tragic in this chapter, as it's more closely related to the question of justice, at least for me.

David Foster Wallace writes that the "central Kafka joke" is that "the horrific struggle to establish a human self results in a self whose humanity is inseparable from that horrific struggle. That our endless and impossible journey toward home is in fact our home." ${ }^{4}$ It is the kind of joke that troubles and perplexes, rather than entertains. When you laugh while reading Kafka's Metamorphosis, I tell my students, you are giving voice to the uncanny within you: Gregor is literally at home, but incredibly not-at-home. Gregor frightens not because he is so other, but because reflected in him we see our own otherness. Why would anyone pursue this experience or try to convince students that getting lost and never returning home is an essential aspect of learning to become, for instance, a more just person? Teaching Plato's Apology and Meno early in the semester lays the foundation for students to understand that the person who is certain they know, who is certain they are not lost, is a dangerous person, more lost than the lost. Even if Meno ends aporetically, one thing becomes clear: certainty is the enemy of virtue. In the Platonic corpus, thinking you know what you do not know is the mental state that corresponds to the action in tragedy that Aristotle refers to as hamartia.

This is one of the meanings of a famous passage in Meno. When Meno is angered that Socrates perplexes him, has brought him, step by step, into aporia, he has missed the mark. If Meno is permanently stuck it is because he is unable to learn that honest, good-faith dialogue is the surest way to learn, even if or especially if encountering ideas that challenge one's own results in aporia. ${ }^{5} \mathrm{He}$ desires what Paulo Freire calls a "banking" form of education, in which an expert "deposits" knowledge into his passively receiving consciousness, to be later withdrawn and recirculated. It is not hard to get students to see themselves in Meno; like him, they are often exasperated by Socrates' moves toward aporia. Despite the philosophical distance between Plato's idealism and 
Freire's Marxist phenomenology, revealing Meno's hamartia-first, his certainty causes him to mistake his false idea of virtue for knowledge; second, his discomfort with aporia and being lost causes him to mistake passive memorization for authentic learning-is actually a productive first step in helping students turn away from the "banking concept" toward developing what Freire calls "critical consciousness," that is, "consciousness as consciousness of consciousness." Transforming the world-through acts of social justice, for instance-presupposes transforming consciousness as a passive receptacle into consciousness that is in its reflections on the world also and at the same time self-reflective. For Freire, in fact, cognition itself is a dialogically intersubjective process that meaningfully "unveils reality" to authentically conscious human beings, as opposed to the instrumentalizing processes of the banking concept. ${ }^{6}$ If Plato gets students thinking about the uncomfortable but necessary stage of perplexity in learning, Aristotle and tragedy introduce students to this more complicated notion of consciousness as a process.

Michael Davis's introduction to On Poetics makes the compelling case that Aristotle privileges tragedy because, more so than other forms of poetry, "it reflects the distinction between doing and looking at doing-between acting and reflecting." As characters mirror actions on the stage (or on the pages of a text) these actions are mirrored in the imagination of the audience in a double sense: we see and reflect upon the characters' actions and see and reflect upon these actions as though they are our own. The spectator's depths are opened up by the performance, initiating a process of reflection or consciousness in the Freirean sense, but one that retains the value of being lost, of that "horrific struggle" Wallace sees at the heart of Kafka's humor. It is precisely this uncertainty regarding who you are that I want my students to experience before they begin to seriously consider a question like "what is justice?"

Whereas Kant could not tolerate the tragic and, thus, had to establish his Kingdom of Ends, Aristotle, whose ethical philosophy could arguably be described as fully rooted in the tragic, pragmatically embraces the principle that virtue is necessary for, but insufficient to achieving, eudaimonia, calling attention to the roles played by fortune in living a good and happy life. For Aristotle, virtue is not the embodiment of a Platonic moral ideal; in fact, practicing the particular form of justice Aristotle describes in Book 10 of Nicomachean Ethics, epieikeia (sound judgment), presupposes that one has recognized there is, tragically, no absolute justice in this world, that the law cannot be generalized to apply to every particular. From the point of view of justice-as-equity, economically prohibiting access to the humanities, for instance, is 
entirely unjust. Yet, tragedy teaches us that equity is not a universal law, especially not a law of nature. It is not $a$ law, and it certainly is not the law; in fact, equity and law are frequently incompatible. On what ground do I stand when I claim that there ought to be universal access to humanities studies in higher education, that reserving it only for the already economically privileged is unjust? If limiting access to the humanities is unfair, this must have something to do with encountering material that puts the very concept of fairness or justice in question, so that one ends up with the paradoxical but meaningful statement: "It is not fair that students might be denied an education that would allow them to see that it is often not fair to say something is not fair." Tragedy is dangerous because it puts justice on trial, the outcome of which is uncertain. It is especially dangerous (but, therefore, necessary) for those on the right and on the left whose actions are informed by a totalitarian telos or microfascist desires. When do we, like Lear, in putting others on trial, unknowingly put ourselves on trial instead? And, what violent storms must we endure to realize we "have ta'en too little care" to see beyond our own navels? If we want to encourage our students to fight for social justice, tragedy suggests that we may need to come up with another name for the thing we have been calling "justice."

I announce at the beginning of the first class on tragedy that there is no tragedy without loss and no experience of tragedy without becoming lost. You could, of course, become comically lost, I tell the students, but no chorus would say to you what Medea's says to her: "A god has engulfed you, / . . this wave is now breaking upon you, / there is no way out." And, although there will be plenty to laugh about when we get to Beckett, it is not a simple side-splitter when Vladimir asks Estragon "What are you insinuating? That we've come to the wrong place?" 10 If you know King Lear, I say, then you know that he arrives at a place so utterly without landmarks he cannot be certain who he is- "I will not swear these are my hands" (IV, vii, 55)—or who Cordelia is—-"Methinks I should know you . . . / Yet I am doubtful, for I am mainly ignorant / What place this is . . A Am I in France?” $(66-7,78) .{ }^{11}$ Generally, several students are able to remember from high school that Macbeth is lost in a world where Birnam Wood does come to Dunsinane. They have read Oedipus the King for this first day on tragedy and, with some gentle orienting, can readily explain how Oedipus has no idea where he is, even though he knows he is in Thebes, how leaving Corinth was not taking him away from but toward his fate, and how this corresponds to one of the principles of being lost: before you are aware you are lost, you are, nonetheless, lost. This introduces one of the guiding questions of the unit: at what precise moment do these tragic protagonists become lost? 
When does knowing where you are and who you are become unknowing? Romeo and Juliet, perhaps more than any other tragedy, replays the horrible question at the heart of Oedipus: who are you? In his "Aphorism Countertime," Derrida writes that this play "stages what is not seen, the name; it stages what one calls because one cannot see or because one is not certain of seeing what one calls." ${ }^{12}$ Romeo is and is not Romeo. To whom does Juliet pledge her love? To the Romeo she hates in the question "wherefore art thou Romeo?" (II, ii, 33). To the Romeo who says to her: "I know not how to tell thee who I am?" (II, ii, 54). She wishes to pledge her love to the being who seems accidentally to carry the name Romeo, but their desire to divorce name and being remains unaware of what the play itself makes us all too aware of: the tragic logic of the proper name reveals that who I am is always and necessarily caught up in the accidents attendant upon my name.

By the time we work through Oedipus and Antigone, Medea, and Hippolytus, and get to Romeo and Juliet and Othello, students have an easy time framing Romeo's and Othello's tragic situations in terms of being lost. Romeo loses himself and utterly loses his way at the moment he believes that Juliet has caused him to lose his way, that she has stripped him of his hardened masculinity. Why did Othello doubt? When, really, did he begin to doubt? Was he not doubting Desdemona before they ever met? Was he not, through his existential thrownness into a world in which he is a religious and ethnic outsider, doubting Desdemona before he was born? Like Romeo, he cannot be divorced from the accidental social structures within which he must necessarily find his meaning. Self-conscious agency and its local desires are merely a fold in the larger field of unconscious social desires; the "I" is a fatal misrecognition that can be engulfed by a tragic wave of desire that sweeps us away from ourselves. Who is it that responds - and in what impossible tense- to Lodovico's question "Where is this rash and most unfortunate man?" "That's he that was Othello. Here I am" (V, ii, 283-4; italics mine). As Harold Barker puts it in his "Asides for a Tragic Theatre": "Tragedy ... drags the unconscious into the public place ... After the carnival, after the removal of the masks, you are precisely who you were before. After the tragedy, you are not certain who you are."13

The point of tragedy is not that we cannot know ourselves. Tragedy says to us instead that knowing ourselves is a self-reflective process that must also consider the profound unconscious social forces within which we are embedded and that conspire to produce us. It produces despair only for those who, like Meno, must possess certainty, who cannot tolerate the horizon of unknowing that envelops what we (think we) know. I hope my students learn that tragedy and a tragic attitude 
contain more hope than despair and that they carry this hope with them when they seek to act with justice in the world, not with Creon's absolutist justice nor with Lear's self-righteous justice, but with a humble sense of justice that respects and embraces the uncertainty born out of careful and deliberate self-reflection. They do not need to become lifelong card-carrying members of the existentialism club to understand that living according to the principle that existence precedes essence and the possibility that the universe will perpetually remain silent in the face of our questions means - tragically - that their moral choices cannot be grounded in absolute principles, but that they must be made nonetheless and must be made all the more carefully. They do not need to shoot heroin to hear the pain in Sonny's piano; they just need to accept that, like Sonny's brother, the more self-assured they are in their own value system, the less likely they are to hear it. Each reading reaffirms that getting lost in aporia opens up the possibility of avoiding truly losing our way. Each reading reaffirms, too, that the act of reading itself can initiate that Freirean critical consciousness that must remain an open process. By the end of the semester, I hope that my students feel in John Barth's short story "Lost in the Funhouse" what I felt as a college freshman: I would be Ambrose, lost forever. And, I would never be able to see my home again, save through the distorting funhouse looking glass. Barth is about as far from Tazewell County, Virginia, or Murray, Kentucky, as you can get. While he helped me configure in my own mind the experience of losing my home, he did so as a part of an intellectual development that would only make it further lost to me. An education is its own form of getting lost, an only partly conscious act of self-murder. But it is also, luckily, its own form of mourning.

\section{Course Material}

Some material I have taught for the "Getting Lost" seminar in literature and philosophy is listed below. I do not teach all of these every time I teach the class.

- Homer, The Odyssey

- Selections from Job

- Plato, Apology and Meno

- Aristotle, selections from Poetics and Nicomachean Ethics

- Seneca, selections from Letters to Lucilius

- Sophocles, Oedipus the King and Antigone

- Euripedes, Medea and Hippolytus 
- Selection from Matthew: "The Sermon on the Mount"

- Dante, selections from Inferno

- Petrarch, selections from Il Canzoniere

- Boccaccio, selections from The Decameron (Rustico and Alibech; Tancred and Ghismonda)

- Geoffrey Chaucer, "Wife of Bath's Tale"

- William Shakespeare, Romeo and Juliet, Othello, King Lear

- Harriet Jacobs, selections from Incidents in the Life

- Friedrich Nietzsche, selections from Gay Science

- Emily Dickinson, selections

- Joseph Conrad, Heart of Darkness

- Franz Kafka, The Metamorphosis

- Virginia Woolf, selections from A Room of One's Own

- T. S. Eliot, The Love Song of J. Alfred Prufrock (paired with several poems from the carpe diem tradition)

- Various murder ballads

- Richard Wright, "The Ethics of Living Jim Crow"

- Eugene O’Neill, Long Day's Journey Into Night

- Samuel Beckett, Waiting for Godot

- Jean-Paul Sartre, "Existentialism Is a Humanism"

- Albert Camus, selections from The Myth of Sisyphus

- Simone de Beauvoir, selections from The Second Sex

- Flannery O’Connor, "Good Country People" and "A Good Man Is Hard to Find"

- Elizabeth Bishop, "Crusoe in England" and "The Art of Losing"

- James Baldwin, "Sonny's Blues" and selections from Notes of a Native Son

- John Barth, "Lost in the Funhouse"

- Toni Morrison, "Recitatif"

- Cormac McCarthy, The Road and Outer Dark

\section{Notes}

1. Martha Nussbaum, Not for Profit: Why Democracy Needs the Humanities (Princeton: Princeton University Press, 2010).

2. Scott Jaschik, "Kentucky's Governor vs. French Literature," Inside Higher Ed, February 1, 2016 <https://www.insidehighered.com/quick takes/2016/02/01/kentuckys-governor-vs-french-literature> (accessed February 22, 2019). More recently, Bevin's continuing aim to vocationalize higher education resurfaced as he reacted to news of a University of Tennessee Promise program which guarantees free attendance to highachieving students who come from low-income families: "The taxpayers, if 
they're going to subsidize an education, should be doing it in areas where there are jobs. Where we need those jobs to be filled. That's the whole reason why we use taxpayer money for it in the first place." Notice that, for Bevin, the "whole reason" the state supports education is to fill jobs. Quote taken from WKMS, “Governor Bevin on Higher Ed Funding,” March 20, $2019<$ https://wkms.org > (accessed February 22, 2019).

3. "Update to April 8, 2016 article, 'Don't major in history, Lt. Gov. tells students,'” Louisville Courier Journal, April 11, 2016.

4. David F. Wallace, "Some Remarks on Kafka's Funniness," in Consider the Lobster and Other Essays (Boston: Little, Brown, 2006), 64-5.

5. Meno's name can be understood to mean something like "stuck" or "unmoving."

6. Paulo Freire, Pedagogy of the Oppressed, trans. Myra Bergman Ramos (New York: Continuum, 2000), 79 and 83.

7. Aristotle, On Poetics, trans. Seth Benardete and Michael Davis (South Bend: St. Augustine's Press, 2002), xvii-xviii.

8. In addition to epieikeia, another candidate for such a name is kairos, the art of deciding according to the moment with all its uncertainties.

9. Medea 369-71. Euripedes, Alcestis, Medea, Hippolytus, ed. Diane Arnson Svelien (Indianapolis: Hackett, 2007).

10. Samuel Beckett, Waiting for Godot: A Tragicomedy in Two Acts (New York: Grove Atlantic, 2011), 8.

11. Quotations from Shakespeare here and below are from The Norton Shakespeare, ed. Stephen Greenblatt (New York: Norton, 1997).

12. Jacques Derrida, "Aphorism Countertime," in Acts of Literature, ed. Derek Attridge, trans. Nicholas Royle (New York: Routledge, 1992), 425.

13. Howard Barker, Arguments for a Theatre (London: John Caldor Press, 1989), 13. 


\title{
Shakespearean Tragedy, Ethics, and Social Justice
}

\author{
Mary Janell Metzger
}

In the wake of $9 / 11$ and the anti-Muslim fervor that followed, I set out to create a Shakespeare course relevant to my students' lives beyond the classroom. The upshot is a course rooted in ethical theory and the transformational power of Shakespeare's tragic forms as representations of human vulnerability, individual and collective needs for community, and the long history of social injustice in which these take shape. By heightening students' sense of literary form, historical violence, and forms of ethical resistance offered in philosophical discourse, I develop their understanding of Shakespeare, theories of virtue and social justice, and the potential collective that is classroom community.

Specifically, we consider the relationship between two forms of knowledge: ethics and tragedy. The first is prosaic, propositional, and declarative, the latter figurative, dramatic, and contradictory. Yet both powerfully shape our sense of the possible. Here I describe how I introduce students to their disciplinary contexts and essential questions, outline the readings and their interpretive challenges, and offer a sample of how I weave ethical theory with Shakespeare's grimmest genre to develop understanding of the value of his work for considering the nature of social justice.

\section{Disciplinary Contexts}

To prepare students to read philosophy and Shakespeare's tragedies we begin with the argument put forward by philosopher of art J. M. Bernstein for the opposition between philosophy and tragedy born of Plato's fear of human and civic vulnerability. ${ }^{1}$ Establishing the historical diminution of tragic art as sensible and deceptive in favor of propositional logic, Bernstein presents philosophy as the thetic ground of true or 
false statements which, unlike the aesthetic realm of art, determines the credible. Rather than denigrating art and specifically tragedy, however, Bernstein elevates it for its power to reveal human life as "bound to opposing goods and impossible differences, [and] irredeemable loss." Tragic knowledge, Bernstein asserts following Aristotle, is a matter of physical rather than cognitive understanding, the product of feeling, "and finally grief."

Bernstein's brief history of ideas about philosophy and art provides students with an introduction to philosophy and an invitation to explore their own beliefs about and experiences of "knowing" suffering and loss-and the effects of art on those views. Questions follow, which students hash out: Is he right that propositional logic alone determines what is true? If not, what are the grounds of our judgments and beliefs? What does he mean when he declares that human life is "bound to opposing goods and impossible differences, [and] irredeemable loss"? ${ }^{3}$ Students' varied trust in logic and mistrust of Bernstein's platonic divide between reason and feeling, especially where suffering and loss are concerned, foregrounds issues of social justice by acknowledging the value of cognitive and affective responses to life and art, and the significance of the social constructs that shape our sense of each. This exchange generates crucial questions about the relation between literary tragedy and actual human loss. Consequently, students share how they define tragic literature, which I record on the board. As they articulate their preconceptions of formal tragedy, someone inevitably asserts that literary tragedies explore the "fate" of tragic heroes determined by their "fatal flaw." A crucial offering, this view allows students to consider its consequences for their sense of the power of the literary imagination as tragic form and the relation between self and other at the heart of ethical theory. I come prepared to help us navigate it.

Via display of Aristotle's description of the essential components of tragic drama in Book XIII of The Poetics, ${ }^{4}$ we explore the possibility and nature of free will and the problem of over-determination that Shakespeare's tragedies and the study of ethical theory entail. How do we imagine our relation to our own or others' suffering? And our responsibility for unjust acts or systems that produce it? Are our views rooted in unconditional ideals or are they the product of complex forms of identity and historical systems? My aims in this discussion are to let students hear each other's views, and to introduce three Aristotelian criteria that we return to throughout the course. First, Aristotle emphasizes action - not character or speech-as the ground of tragedy. Second, the measures of tragedy's effects are imaginative and affective. Only insofar as we feel for others' misjudgment and pain, and fear being 
subject to a similar vulnerability, is the tragedian successful in effecting in us tragic knowledge as compassion for those who err and those who suffer. Last, Aristotle argues the necessity of the artist's representation of a recognizably human and hence vulnerable tragic hero.

The first criterion is relatively accessible to students of literature and film but the last two require careful consideration of the following line: "pity is aroused by unmerited misfortune, fear by the misfortune of a [person] like ourselves ... a [person] who is not eminently good and just-yet whose misfortune is brought about not by vice or depravity, but by some error or frailty." Focusing on the term "unmerited" and the phrase "brought about not by vice or depravity, but by some error or frailty," we explore what such requirements mean for our understanding of the art of tragedy and our sense of human beings in a world of social injustice-especially those whose lives are radically different from our own. Not only does this consideration establish the formal ground of Shakespeare's tragedies in Aristotle's work, but it also unsettles a diagnostic approach to human vulnerability and its literary mode which argues that some are psychologically predestined for terrible ends. Eventually I ask how pity and fear are possible if we treat suffering and loss as a foregone conclusion for certain people or a simple plot device. How and where do we recognize or experience those views and their effects? The conversation thus navigates, by making explicit, assumptions of difference, of social hierarchy, and culture, that suggest that some are by nature or unavoidable circumstance weaker than others, and thus primed for vulnerability and suffering. Revealed as well: we often view the suffering of others, fictive and real, without feeling. If we believe in such indelible or intractable states of being, how can the representation of others' vulnerability to suffering and death be compelling to us, as Aristotle insists it must?

This analysis generates organic and shared essential questions. ${ }^{6}$ If, as Aristotelian tragedy requires, being human entails our vulnerability and necessary interdependence, how do we conceive of the ground of right action? How is the recognition of such shared vulnerability-or its denial - a force for social justice or injustice? How, ultimately, do Shakespeare's tragedies challenge us to conceive of ethical action and justice within the long history of social injustice, its violent enforcement, and the consequent human suffering and unnatural death?

As we head into the heart of the course, reading Shakespeare's tragedies in light of specific ethical theories, I celebrate the honesty and critical acuity of the students. I explain how, given the variety of our lived experiences, our shared objectives, and my practice of facilitating rather than determining student learning, norms are helpful in 
establishing our work going forward. Students, I note, may already sense the risk and opportunity that sharing our beliefs and experience of loss and injustice entails. Building a classroom community that allows us to move from critical parsing to transformational learning is nurtured by acknowledging the difficulty of the work and habits that support it. Our first Shakespeare text, The Rape of Lucrece, explores the motives and effects of rape, likely a violation that a handful of our classmates have survived. Thus, I assert, here's what we should expect from each other: stay engaged (develop awareness of your own engagement and develop strategies for staying with the work); take risks (the more you risk, the more you'll learn); read and listen for understanding (read to learn and beware of listening solely to respond or compare yourself to the speaker; value the opportunity to learn about other points of view); speak your truth (speak from your "I" and share your experience; avoid universalizing or personalizing); experience discomfort (learning is change and change is never comfortable, even when desired; safety and discomfort are not opposed); expect and accept non-closure (learning is a process, the opportunity for which ends only with our own demise; there will be takeaways but my aim is to develop your understanding of the nature and effects of Shakespeare's art and the work of social justice on our lives in and beyond our classroom). ${ }^{7}$

Establishing and practicing these norms in the first few weeks of the class cannot be rushed. So much depends on the way in which I make room for confusion and questioning from the start.

\section{Tragedy and Ethics: Text Pairings and Interpretive Problems ${ }^{8}$}

As suggested above, the crux of this course involves interpreting Shakespeare's tragedies in light of specific ethical theories. Below, for easy reference, I list the pairings of the course and their specific interpretive problems. These pairs build student facility with Shakespeare's language and form, and the nature of philosophical writing. More importantly, as suggested by the brief narrative of our analysis of Othello that follows, they allow students to engage questions of human vulnerability and the complexity of virtue and justice in concrete terms. This specificity enhances their grasp of the transformational power and significance of both Shakespeare and ethics for their lives.

- Aristotle's Nichomachean Ethics (on virtue and justice) and The Rape of Lucrece. Interpretive problem: How do the diverging 
testimonies of the narrator, the rapist Tarquin, and Lucrece challenge us to consider how cultural experience, point of view, and systemic power create or negate the possibility of virtuous auditors and justice as action or equity?

- Kant's "Transition from the Ordinary Rational Knowledge of Morality to the Philosophical" and Coriolanus. Interpretive problem: How does Shakespeare's representation of Roman society ask us to consider the effects of ideal, universal notions of "duty" in the context of the particular, historical suffering of individuals and groups?

- Hume's "Of the Influencing Motives of the Will" and King Lear. Interpretive problem: How does Shakespeare's drama of political and familial devolution explore the role of emotion as human "sympathy" in the construction of virtuous action and social justice in an unjust world?

- Martha Nussbaum's "Rational Emotions" and Romeo and Juliet. Interpretive problem: How do judgments that consider both individual and collective interests in justice as equitable treatment aid us in negotiating the world of Romeo and Juliet, in which historical forms of social hierarchy such as gender, age and rank determine one's relation to others?

- Patricia J. Williams' "The Obliging Shell” and Othello. Interpretive problem: How does Shakespeare represent the challenges of social justice in a world of historical oppression established by categorical fantasies of racial purity and pollution?

\section{Sample Analysis: Williams' "The Obliging Shell" and Othello}

The cumulative effects of our analyses of The Rape of Lucrece, Coriolanus, King Lear, and Romeo and Juliet and the ethical arguments are several. Students wrestle with the idealist versus materialist divide in ethical theory and life, articulate their own ethical commitments, and apply them to Shakespeare's work. They grasp Shakespeare's use of speech, action, and social identity as forms of evidence, the meanings of which rely on juxtapositions that demand critical and aesthetic attention. Increased comfort with the ambiguity of Shakespeare's work emerges as divergent views of specific representations arise in the classroom. Lastly, awareness of abstract argument rooted in a history of ideas about individual and collective human nature, at once useful and suspect given its frequent exclusions, heightens their ability to read with acuity and write with purpose. 
Grappling with ethical arguments, and their application to Shakespeare's work as matters of individual and collective interest in justice as equitable treatment, anchors our reading of Othello. Teaching and performing Othello have long been a means of displaying, if not reckoning with, the history of racial oppression in the West. Some might question teaching it, given its iteration of racist stereotypes and/or its representation of the exploitation of a black Muslim Moor by and for the European project of white, Christian supremacy. But studied in light of Williams' theory, Othello illuminates the moral complexity of Shakespeare's work and its potential for increasing our sense of what social justice might require. ${ }^{9}$

Williams' essay “The Obliging Shell," like The Alchemy of Race and Rights (from which it derives) as a whole, weds meditations on American law with personal reflections on her experience as an African-American woman, practicing contracts lawyer, and law professor. Williams explores the nature and effects of a legal system built on the exclusion of blacks and women, and the impact of this history on our understanding of equal opportunity as fairness. Williams explains how, in the U.S., "Blacks and women are the objects of a constitutional omission that has been incorporated into the theory of [legal] neutrality." Simply put, their historical exclusion from the constitutional establishment of civic liberty (and its consequences) is obscured today in contracts law via a theory of neutrality called the parol evidence rule. This rule obscures the past in favor of a present dream of human sameness that privileges whiteness by default, Williams argues. Specifically, the rule "limits the meaning of documents or words by placing them beyond the bounds of reference [to] anything that is inconsistent with or even supplementary to the written agreement." 11 Williams clarifies the impossibility of fairness as equity when history is made mute by such fantasies of categorical purity. How can definitions be at once fixed-such as goodness, fairness, justice, or citizen - and at the same time be the drivers of their antitheses, making many ever susceptible to another's "paradigm of goodness"? ${ }^{12}$

In this way, Williams makes explicit the work of reading Shakespeare's tragic play in light of an ethical commitment to the varieties of human suffering and our historical interdependence. We are all implicated in our history of racism and misogyny. Unlikely though it may be at this point in the course, idealizing Shakespeare as a writer "not of an age but for all time" withers when Williams asks us "whether [a canonical text] can truly exist apart from the color conscious society in which it exists, as a skeleton devoid of flesh; or whether [it] is an embodiment of society, the reflection of a particular citizenry's arranged complexity 
of relations[?]"13 Given the explicit articulation of white, Christian, male supremacy in Othello and its culminating action in the deaths of Desdemona, Emilia, and Othello, Williams' analysis challenges us to read not solely for the representation of blackness or women's weakness or defiance, but for the play's construction of white, Christian purity as the "obliging shell" of Iago's revenge and Desdemona's ambition, which make of Othello in the end a tragic figure of self-betrayal to a society whose interest in him is revealed as coldly utilitarian.

Focusing not on Othello but on the play's white characters-Iago, Cassio, Roderigo, Brabanzio, Desdemona, Emilia, and the Dukereveals the persistence of their belief in Othello's blackness as an animal pollution which establishes the power of figurative or literal whiteness as human goodness. All these characters, students discover, whether defending Othello, as Desdemona and the Duke do, establishing him as untrustworthy, as Iago and Roderigo aim to do, or both, as Brabanzio and Emilia do, use Othello to establish their own justifications and aims, rejecting the possibility of his own integral human difference. Iago's motive is revenge but the system of "preferment . . . by letter and affection" (I, i, 35) is the cause, and Othello the means of disproving its efficacy and doing violence to those, like Cassio, who benefit unwittingly. Roderigo, who gives voice and cover to the most virulent depictions of blackness in the play in rousing Brabanzio to his daughter's elopement, considers Othello a "lascivious Moor" for whom he would "have been his hangman" (I, i, 126, 33) but is easily made the tool of Iago's resentment by his own weakness. Hating Othello is but the means of justifying his own right to Desdemona's racialized "beauty, wit and fortunes" (I, i, 136).

Indeed, the Duke articulates the play's general assessment of Othello and its explicitly racial terms in trying to offer Brabanzio comfort in his loss; "If virtue no delighted beauty lack, / [Othello] is far more fair than black" (I, iii, 288-9). This hypothetical syllogism relies on the audience's knowledge that, in the world the play represents, blackness and virtue are as forcefully opposed as goodness is to malevolence and power to justice. Desdemona defends her marriage, as Othello earlier explains, as the product of her desire for Othello's "story," the "honours" and "valiant parts" that she associates with his difficult and unconventional life (I, iii, 128, 252). Her willingness to share in such a life, she declares, "[her] downright violence and storm of fortunes / May trumpet to the world," suggesting that the "rites for why [she] love[s] him" are more spatial than personal (I, iii, 248-9, 256). The access to a life of heroic action provided by her marriage to Othello and her need to overlook rather than love Othello's physical beauty- “my heart's subdued / even 
to the very quality of my lord. I saw Othello's visage in his mind" (I, iii, 249-51) — explain her impatient advocacy for Cassio and her later stark turn to radical passivity in the face of Othello's rage. She both treats her husband as a means and fears him as unknowable. As Williams' critique of purportedly race-blind ideals suggests, in the scheme of the play, blackness, and its embodiment in Othello's torment and consequent violence, represents the specific cost of establishing whiteness as a standard of humanity.

Ultimately, as in previous pairings of Shakespeare and ethical texts, reading Othello in light of Williams' critique of parol arguments that elide understanding of a text's connection to historical experience enhances the significance of Shakespeare's work. Analyzing the white characters' use of Othello to establish their own identities and purposes clarifies the ways in which Shakespeare illuminates the sickening effects of systematized injustice. Othello's powerful loneliness in the state of marriage, adrift from the ordering forces of martial life, and his terror at the thought of never securing his wife's sexual fidelity and hence the grounding love it represents, evinces a danger far removed from the comic anxiety of cuckoldry in much of Shakespeare's work. Horror at his manipulation by Iago and sympathy for him as he defends himself as "one who loved not wisely but too well" (V, ii, 349) sound a far less racially neutral note in the wake of Williams' meditations on the historical omission of the humanity of blacks - and women-in Shakespeare's day and our own.

\section{Notes}

1. We read only the first section, "Plato's Complaint." J. M. Bernstein, "Tragedy," in The Oxford Handbook of Philosophy and Literature, ed. Richard Eldridge (New York: Oxford University Press, 2009), 71-3.

2. Ibid., 72 .

3. Ibid.

4. Aristotle, The Poetics, in Critical Theory Since Plato, ed. Hazard Adams and Leroy Searle (Boston: Wadsworth, 2005), 52-68.

5. Ibid., 55 .

6. Essential questions are sustaining forms of inquiry that shape a discipline or a specific approach to a text. See Mary Janell Metzger, Shakespeare Without Fear: Teaching for Understanding (Portsmouth, NH: Heinemann, 2004), 108.

7. Norms are crucial in establishing the practices and expectations that facilitate high-stakes conversation and forestall its derailment. See Caprice Hollins and Ilsa Govan, Diversity, Equity, and Inclusion: Strategies for 
Facilitating Conversations on Race (New York: Rowman and Littlefield, 2015).

8. William Shakespeare, The Norton Shakespeare, ed. Stephen Greenblatt et al. (New York: Norton, 2015). All philosophical works included in bibliography.

9. My teaching of Othello in terms of its construction of whiteness is deeply indebted to many early modern scholars of color, including Kim F. Hall, Arthur L. Little, David Sterling Brown, and Ayanna Thompson.

10. Patricia J. Williams, "The Obliging Shell," in The Alchemy of Race and Rights (Boston: Harvard University Press, 1991), 120.

11. Ibid., 107.

12. Ibid., 116.

13. Ibid., 120. 


\title{
Teaching Environmental Justice and Early Modern Texts: Collaboration and Connected Classrooms
}

\author{
Rebecca Laroche and Jennifer Munroe
}

Human-precipitated climate change promises to be an issue of great import, perhaps the single greatest issue, in this century. Exploring its relationship to social justice - the refugee crises, war, food and water shortages, species extinction, and other problems already underway, as well as the countless more that will inevitably follow as a result of resource scarcity and habitat depletion-will only become more urgent as the planet continues to warm, perhaps irreversibly. Human animals need, have always needed, food, shelter, water, and clothing, and in those needs lie the continuities and gaps - both temporal and geographic - of production and consumption that have culminated in our current times. If nothing more, our current crisis and its forecast for the future should at least remind us that we are all in this together.

As we are forced to face the potential for planetary peril, it is especially important that we ask students to consider how such issues bear out not only today, but also in the past, and how literature might be an ideal medium for understanding them. It is important because, as Simon Irving and Jenny Helin write about examining the current sustainability discourse of development agencies, "we see the need for education where it is possible to develop capabilities to engage in critical reflections on taken for granted assumptions." ${ }^{1}$ Taking this opportunity for historical reflection is essential, as ours might be an embodied and collective present, but it is also an embodied and collective history, one that is shared across time as well as across our blue planet, in the air we breathe and the products we consume. By linking the past to the present, and by teaching early texts, we might identify examples of the sort of "slow violence" described by Rob Nixon, ${ }^{2}$ seeing it at work in past centuries and as something inherited and modified today, and might best seek alternative ways of understanding and living with each 
other that do not simply reproduce the same mistakes and follow the path to further destruction.

While the notion of a collective future that extends from an aggregate past may seem counterintuitive to many (including our students) today, especially in areas of the West that emphasize the primacy of the individual, it might well expose the slow violence Nixon links to "Climate change, the thawing cryosphere, toxic drift, biomagnification, deforestation, the radioactive aftermaths of wars, acidifying oceans, and a host of other slowly unfolding environmental catastrophes [that] present formidable representational obstacles that can hinder our efforts to mobilize and act decisively." That is, we need to make visible the otherwise invisible viciousness associated with such forms of environmental destruction, which are visited most often upon those most vulnerable, a violence "that occurs gradually and out of sight, a violence of delayed destruction that is dispersed across time and space, an attritional violence typically not viewed as violence at all." "While Nixon's call to arms against slow violence is not necessarily "ecofeminist," we turn in this chapter, as we have in our scholarship and our classrooms, to an ecofeminist approach which interrogates the mutual forms of subjugation that Nixon cites: environmental degradation, colonialism, misogyny, racism, and classism. Thinking about multiple collectives in this way has in fact been the subject of extensive ecofeminist documentation and theorization. We might turn here to the work of Stacy Alaimo, Karen Barad, Val Plumwood, and Donna Haraway, ${ }^{4}$ as well as research on subjects ranging from the ecosystem to the microbiome, all of which emphasize how we are/inhabit inherently collective environments, not singular beings with neatly defined boundaries. Our theorizing of ecofeminism in our co-authored Shakespeare and Ecofeminist Theory (2017) takes as its starting place the premise that a devaluing of the nonhuman world is integrally linked to the devaluing of a variety of disenfranchised peoples, and so the ecofeminist approach we use is inherently intersectional. We might answer such slow violence, that is, with what ecofeminist Vandana Shiva calls "Earth Democracy," which emphasizes earth as a planetary commons, where all things are connected, where multiplicity and diversity are valued, are understood as necessary to the collective sustaining of life on this planet. ${ }^{5}$

To this end, our chapter proposes a threefold turn to collectives and connectivity that builds on ecofeminist principles and that yokes alternative avenues of scholarship to alternative approaches in the classroom. First, we discuss the importance of revaluing collaborative scholarship -in particular as it is motivated by a revaluation of relations between plants, humans, and other animals. We do this by 
thinking about the practice of collaborative research, and of scholarly co-authorship in print and digital humanities work. We begin this chapter by extrapolating from our experience of co-authorship and digital humanities endeavors, and the challenge these scholarly practices represent to the dominant model of humanities scholarship as individuated and isolated in its motivation. We then consider how we might adapt a collaborative and (social and ecological) community model of interrelationship to the classroom on our respective campuses. Digital humanities work affords an opportunity for us to reconsider as well the notion of "connected classrooms." It is here that we look to the model provided by the Early Modern Recipes Online Collective (EMROC), ${ }^{6}$ in which two or more campuses working on a shared project communicate and learn from each other's experience. Finally, we turn to our experiment of teaching "Shakespeare and Ecofeminist Theory" as parallel upper-division courses on two geographically distant campuses, University of Colorado, Colorado Springs (UCCS), and University of North Carolina, Charlotte (UNCC). Working and communicating across geographic barriers in these ways, as we discuss, has the double effect of creating the camaraderie of "We're all in this together" at the same time as this work articulates how the "this" is felt differently across local habitats.

While co-authorship is not by any stretch a novelty in literary scholarship, it may be theoretically inflected in unique ways at distinctive moments. As we recently expressed regarding our own co-authorship of Shakespeare and Ecofeminist Theory, true co-authorship reflects the collective and nonhierarchical nature of work for the environment. Within the constructs of co-authorship itself, we were made to confront prescriptive models of hierarchized authorship-particularly within the STEM fields, that represent gradations of commitment and contribution-that in genuinely co-written work is impossible to untangle. In opting for an alphabetical author listing for our monograph, we realized that this may be misread because of convention, and we thus included a reflection upon the co-authoring process in our preface. For us, co-authorship was directly related to our theoretical frame:

From the microbiome in our guts, to the air we breathe, to the food we process and digest, we are linked in ways that exceed our willful selves and that have collateral effects (both negative and positive) for those with whom we share this planet.

The "co-" in our co-authorship, therefore, drew on the general meaning of "'together', 'in company', 'in common', 'joint, -ly', 'equal, -ly', 'reciprocally', 'mutually'," a regular back and forth of idea exchange and 
adjustment, file swapping and text revision, which led to the articulation of concepts not conceivable if either of us was working in isolation. ${ }^{8}$ For us, then, collaborative authorship is modeled after and models our sense of intraconnection among beings, the mutually forming interplay between human and nonhuman things theorized by Karen Barad. ${ }^{9}$ This capacity did not develop overnight, but rather was fostered through an ongoing alliance around the ecofeminist and broader ecological frames founded in our shared love of early modern literature and our concern for the environment.

Such mutual exchange is epitomized as well in the subject of our ongoing research: early household cooking and medicine and the manuscript recipe books that capture its practice. And the fluidity of this exchange has been at the core of our work with EMROC, which has served as a platform for the yoking of research and teaching for ourselves and others. As we have incorporated the collective's mission in our coursework delivery, members of EMROC have created opportunities for students to speak to each other across campuses as they share the work of transcribing a given manuscript. In 2012, students in Amy Tigner's course on food studies at the University of Texas, Arlington, wrote a missive to Rebecca Laroche's women writers course at UCCS, at once articulating shared frustrations and successes as well as the differences of their contexts (in this case, a conventional classroom versus the online environment). Beyond buoying the transcribers against their eyestrain, EMROC has expanded this concept of cross-campus collaboration to include the EMROC blog series, where posts share the findings of individual students within a virtual space of cumulative knowing. For example, a Washington student's independent study on Margaret Baker's "diet drinks," and a Colorado student's final project on the herb "foalefoot" may lead to future understandings of other drinks and other herbs. ${ }^{10}$ Thus, these courses become linked temporally as well as geographically, as students from later semesters read the findings of earlier ones.

As ecofeminists within EMROC's enterprise, we (the authors of this chapter) link this sort of classroom collaboration with a re-examination of the relations between plants, humans, and other animals inherent in domestic work of the period; that is, even as we are connecting classrooms through this shared endeavor we are also asking students to observe the shared qualities of living things-how early modern cookery and medicine express human-nonhuman intra-action ${ }^{11}$ and how our understanding of what constitutes verified "knowledge" is shaped by race, class, and gendered difference. As Munroe has discussed elsewhere, recipes offer particular insights into "an intimacy 
between the woman who gathers, slices, boils the plants-articulated, for instance, in [a] reminder to 'haue care to slitt the ffenell roots and take out the harts stringe which groweth in the middest'-in water, over fire whose temperature she aims to regulate during the process." 12 The cycles of birth, disease, healing, and death are hardly limited to humans alone, as moments in plant lives are highlighted as essential to the success of the recipe, ${ }^{13}$ or veterinary recipes are intermingled among the human-specific eye waters and laxatives. In essence, in working with these texts, students become reoriented to the human subject that otherwise lies at the center of so many literature classes and come to see a broader, less ego-driven context for textual being.

With this pedagogical and scholarly nexus in mind, we decided, in the spring semester of 2015, to "co-teach" the same upper-division course, "Shakespeare and Ecofeminist Theory," on our two campuses. ${ }^{14}$ We each taught our own sections of the course for our respective departments, but we developed and used a shared syllabus, reading list, and set of assignments (including one that, at a significant moment, necessitated our students to communicate across the geographic divide). In the previous year, we had been asked to submit a book proposal for a volume of the same name for the Arden Shakespeare and Theory series. Our students were more than a potential audience for the future book; they were to be co-creators, providing insight, contestation, challenges, and expansions on the ideas that existed yet only in skeleton. To this end, we imagined a course in which students would read the same material, write about the same topics, even compose blogs they would all collectively read (rather than reading only the blogs by other students in their own class). But we knew that students in Colorado would inevitably understand, say, water use or fire, in a way potentially quite different from students in North Carolina. And that, for us, was all the better. Our collaborative pedagogical project in "geo-isolated" classrooms (in Colorado and North Carolina) thus served as an experiment in linking students in time and across space, even if only virtually and for a short duration. By having our students think about similar questions, though embedded in their own local environments, we sought to honor the particulars of their individual experiences while expanding their understanding of others'.

Collaborating as authors can be challenging, but the pursuit of modeling this sort of "connected classroom" approach brought its own set of hurdles, including creating and implementing assignments and readings across different semester templates. Moreover, while we used the same material for our courses, the organic quality of class discussion, and the unique subject positions of our respective students, 
meant that those conversations often led us to explore different aspects of texts and ideas. To this end, though, we wanted to remain open to where those conversations might lead. Many of the assignments we developed while together at the Folger Shakespeare Library over winter break were angled toward the realization of historical difference, in particular in the ways that early moderns related to their environment. Stemming from our work with EMROC, we cordoned off 10 percent of the semester for the discussion, transcription, and exploration of recipes as resources for the kind of questions we would be asking. In particular, we worked on the pages from Mrs. Corlyon's collection at the Folger (MS V.a.388), an accessible hand for beginning transcribers, in which the compiler recorded many recipes for the prevention, treatment, and cure of plague and pestilence.

The first plague preventative recipe, for example, introduces students to many lines of inquiry and objects of research:

\section{An order of dyet to be vsed in tyme of Sicknesse and will preserue the obseruers thereof from the Plauge}

In the morninge, at your vprisinge before you do take the ayre, burne tarre vppon a chafingdishe of coales, and take the ayre thereof, and then drinck a good draughte of beare or ale, where in these hearbes haue stoode all nighte (that is to saye) Sage, Wormewoode, Hearbe grace, and Plantyn, and so soone as you haue dronck out the drincke fill vpp your pott againe. It is not amiss if you drinck thereof againe in the after noones, and shifte your hearbes twice or thrice a weeke. If you do vse this order, and in this sorte, in the tyme of infection, you shalbe free. ${ }^{15}$

In these directions, students confront early modern assumptions and mysteries, from the clearly accessible to the most opaque. The early modern belief that the source of the plague was breathing bad air can lead to a discussion of early modern air quality. These insights in turn might develop into an exploration of how the everyday materials in this recipe might inform our understanding of the intertwining of domestic labor with broader environmental conditions. The stipulation of "beare or ale" unlocks the inquiry into why not water, lack of clean water being a central aspect of early modern existence, and then, perhaps, a discussion of Hillary Nunn's work using the emerging EMROC data set to ask questions about the variety of water sources to be found in these collections. ${ }^{16}$ And finally, the herbal basis of most medicines leads to so many research potentials and upends preconceptions about plants' function in early modern texts as purely symbolic. Three of the plants from 
this recipe have a place in Shakespeare's plays, for instance, and arguably all are invoked in those works for their medicinal, not symbolic, qualities. ${ }^{17}$ Again, this is a radical shift for most literature students, and the presence of "Hearbe grace" (rue) may introduce yet another layer of nuance with the place of prayer and mysticism in material practice.

Students used this classroom close-reading practice as a foundation for their own individual research journeys about the intricate and arduous ways in which early moderns obtained, for instance, bread or furniture or clean water. They would then present their discoveries to their classmates. Through these presentations, they made the classroom a forum for discovery and collective knowledge-making about the past. Presentations were given on such topics as early modern mills, the frequency of house fires, the socioeconomics of coffins, land management, and, yes, water sourcing. They would later develop these findings into researched understandings of Shakespeare's plays, putting the dramatic language in dialogue with other sixteenth- and seventeenth-century texts.

Three-quarters of the way through the course, students made this deep historicity theoretically immediate by investigating how they themselves came to have bread, coffins, or clean water, and they recorded their findings in blog entries they posted on a public site we created. These posts were then shared with students at both campuses, creating a space in which semi-arid Colorado met subtropical North Carolina. These cross-campus readings ultimately revealed how a lived future in climate change will be encountered differently. This sense of students inhabiting an evolving environment was further enhanced by the journals they kept throughout the semester: students were assigned the task of spending at least fifteen minutes outside three times a week or more, and they were asked to reflect on their experience. While some students in our classes were accustomed to being outdoors, were even "outdoorsy" types, we had other students for whom being outside was uncomfortable and unpleasant, especially in the late winter months or on days when it was raining or snowing. To be outside, to experience changing smells and textures in the air, the increasing melodies of insects and bird song, gave students accustomed to climate-controlled surroundings and connected to electronic devices new insight into a time in English history when men and women necessarily experienced these sights, sounds, seasons, and sensations.

Such a shift to the present within the syllabus was central to the course in two ways. Not only did it raise students' awareness of their own relationship to their environments, but it inflected that relationship with what we argue is an especially ecofeminist understanding. ${ }^{18}$ In 
the ecofeminist focus on everyday material practice, in both the early modern period and our own time, students were brought to this current moment with new realizations. The dual confrontation-both by history and by geography — of their "taken for granted assumptions," assumptions rooted in gender, race, and class, repositioned them critically to their own modes of being.

Seeing the radical realizations of students also opened our eyes to the importance of reflections on our current moment to ecofeminist interrogations of texts. While turns to the present were part of our original book proposal, the course made us realize just how central these moves were to the larger rhythms of the project. One Colorado student's presentation on the early modern fear of house fires was deeply felt in a city that had experienced two devastating forest fires within its limits in fewer than five years; the fact that these wildfires were becoming more frequent because of the effects of climate change was not missed on any of us. Shakespeare's linking of the early modern fear with female interiorities, moreover, helped us also to recognize similar linkages in current discourse around wildfires. ${ }^{19}$ And one North Carolina student's presentation on the local Catawba River struck a particular chord in a city where a powerful utility operates a nuclear power station that has routinely dumped coal ash in or near that same river for years. To think about the contamination of a local river, and its importance to trade in the centuries before trains and automobiles, provided students with a different take on the centrality of Shakespeare's own Thames or Avon rivers, and the pollution that resulted from industrial processes long ago. Discoveries made about the connections between modern food waste and Petrarchan discourse, or the devaluing of humanities research and ways of knowing in King Lear all blossomed as well through conversations with individuals differently invested in time and place. ${ }^{20}$

In these ways, cross-campus collaboration breaks down walls. It breaks down the barriers between the professors' intellectual work and lived experiences, and the scholarship and lives of our students. It dissolves the echo chambers of infrequently read publications and of the geo-isolated classroom. And the focus on household cookery and medicine accentuates for students how such work inherently required traversing the walls of the house, of the garden. Most importantly, it challenges the boundary between intellectual and material existence. In asking students to represent where they are and reach across campus entities as parallel but not same, they have to acknowledge that their experiences, however similar, are not universal. The questions we ask, the rabbit holes we enter, are very dependent on what surrounds us. The fact that students in Colorado Springs may be more interested in the 
question of fire than those in Charlotte should not surprise us, but it is easy to lose sight of our own local assumptions. We are indeed, after all, in this together, even if the challenges of the coming years will vary depending on where we live. Connecting our experiences today to those of the past, to Shakespeare, might makes us more mindful of this fact and better prepare us to undertake our uncertain future.

\section{Notes}

1. Simon Irving and Jenny Helin, "A World for Sale? An Ecofeminist Reading of Sustainable Development Discourse," Gender, Work and Organization 25, no. 3 (May 2018): 264.

2. Rob Nixon, Slow Violence and the Environmentalism of the Poor (Cambridge, MA: Harvard University Press, 2011).

3. Ibid., 2.

4. See especially Stacy Alaimo, Bodily Natures: Science, Environment, and the Material Self (Bloomington: Indiana University Press, 2010); Karen Barad, Meeting the Universe Halfway: Quantum Physics and the Entanglement of Matter and Meaning (Durham, NC: Duke University Press, 2007); Val Plumwood, "Nature in the Active Voice," Australian Humanities Review, no. 46 (2009): 113-29; Donna Haraway, When Species Meet (Minneapolis: University of Minneapolis Press, 2008).

5. Vandana Shiva, Earth Democracy: Justice, Sustainability, and Peace (Cambridge, MA: South End Press, 2005).

6. See EMROC's website at <https://emroc.hypotheses.org > (accessed February 22, 2019).

7. Rebecca Laroche and Jennifer Munroe, Shakespeare and Ecofeminist Theory (London: Bloomsbury Academic, 2017), xvii.

8. See "co-," prefix, OED Online (Oxford University Press) <https://www. oed.com> (accessed September 1, 2017).

9. When we use the term "intraconnection" we have in mind the notion of "intra-action" proposed by Karen Barad, which, she writes, "signifies the mutual constitution of entangled agencies" (italics hers). See Barad, Meeting the Universe Halfway, 33.

10. Solveig Roervik, "What Constitutes a Diet Drink?," EMROC: Early Modern Recipes Online Collective blog, May 30, $2017<$ https://emroc. hypotheses.org/1358> (accessed February 22, 2019); Tristan McGuin, "Foalefoote: Defining Ingredients Contextually" EMROC, June 2017 $<$ https://emroc.hypotheses.org/1380> (accessed February 22, 2019).

11. See Barad's use of this term in Meeting the Universe Halfway, 33.

12. Jennifer Munroe, "Harvesting Earth: Where Sustainability and Recipes Meet," The Recipes Project blog <https://recipes.hypotheses.org/6390> (accessed September 8, 2017). 
13. See Rebecca Laroche, "Roses in Winter: Recipe Ecologies and Shakespeare's Sonnets," in Ecological Approaches to Early Modern English Texts, ed. Jennifer Munroe, Edward J. Geisweidt, and Lynne Bruckner (Burlington: Ashgate, 2015), 51-60.

14. We are most thankful for and to our undergraduate collaborators in English 4970 at UCCS and English 4050/5050 at UNCC for contributing their energy and insight to this endeavor.

15. From folio 109. Line breaks are as per the original but a conventional hyphen is used here to denote a word break, rather than the "=" used in the original.

16. Hillary Nunn, "Household Water: Porous Pages and Early Modern Manuscript Recipe Books." Conference Paper for Shakespeare Association of America, April 2017.

17. See Rebecca Laroche, "Ophelia's Plants and the Death of Violets," in Ecocritical Shakespeare, ed. Lynne Bruckner and Daniel Brayton (Burlington: Ashgate, 2011), 211-12.

18. Outside the classroom, Munroe had answered Sharon O'Dair's trenchant question "Is it Shakespearean ecocriticism if it isn't presentist?" with the equally pointed "Is it really ecocritical if it isn't feminist?" Sharon O'Dair, "Is It Shakespearean Ecocriticism If It Isn't Presentist?," in Ecocritical Shakespeare, ed. Bruckner and Brayton, 71-85; Jennifer Munroe, "Is It Really Ecocritical If It Isn't Feminist? The Dangers of 'Speaking for' in Ecological Studies and Shakespeare's Titus Andronicus," in Ecological Approaches to Renaissance Texts: A Field Guide to Reading and Teaching (Burlington: Ashgate, 2015), 37-47.

19. See Laroche and Munroe, Shakespeare and Ecofeminist Theory, 63-75.

20. Ibid., chs. 3 and 4 , respectively. 


\title{
Failing with Shakespeare: Political Pedagogy in Trump's America
}

\author{
Steve Mentz
}

\section{Scene 1: Brooklyn. Kings of War. Toneelgroep Amsterdam. November 4, 2016}

The man who wanted to rule stood apart, downstage left, staring at his body in a full-length mirror. The Dutch actor Hans Kesting, playing Richard III in Brooklyn the weekend before the 2016 U.S. presidential election, projected a sinuous intensity that should have warned us all what was coming. Kesting's Richard was enticing and violent, bare of physical props except a wine-colored stain under one eye. He threatened by standing still, separate, eying his reflection while the other aristocrats pretended they were in control of the kingdom.

Kesting walked as if on springs, unstable and uncomfortable, with his hips slightly forward and arms back, enough to disorient but not tipping into caricature. Only once did he cascade into ridiculousness, wearing the crown he'd not yet claimed, draping a rug over his shoulders, and running around the stage in a parody of the humpbacked king.

All of us in the audience watched that same narcissism triumph in pre-dawn darkness five days later, on November 9. Why did the people choose him? Shakespeare had shown the answer for four mostly anti-democratic centuries. How had I not seen it?

He dominated with unbearable greed and need. Seducing the grieving widow, betraying his brothers, condemning the princes in the tower: every step sang out reckless desperation. When he bared his breast and offered Lady Anne the knife, he revealed urgent but not sexual desire. He must be at the center, he must be the most hated and the most loved, the only one who matters. He-Who-Must-Always-Win. Shakespeare knows this figure, and he's not always the villain.

Before the battle of Bosworth Field, King Richard sat in the chair of power with his back to the audience, staring at his own massive image 
on a video screen. Slowly, the features blurred to superimpose those of his victims: Henry VI, brother Clarence, the young princes, Lady Anne. Their presences maddened the king. As the screen faded to red he galloped around the stage bellowing:

A horse, a horse, my kingdom for a horse!

What he wanted and could not have was a stronger and more animal body, a vehicle for boundless ambition and drive. He never got it. We saw him defeated. He galloped horseless until the video curtain pulled up to reveal the full cast, the nation, dressed as an invading army, with the future King Henry VII at the head. Richard snaked through the crowd and vanished. ${ }^{1}$

Lots of things broke unexpectedly in the fall of 2016 in the United States. Some of those failures occurred in my classroom.

It may be inevitable to find election-year politics in any Shakespeare course, but I have been openly and perhaps (I now feel) recklessly courting such responses since 1992, when as a first-time teacher I asked my students to read Julius Caesar and locate rhetorical parallels in the three-headed television debates that year between Bill Clinton, George H. W. Bush, and Ross Perot. This overtly presentist way of teaching Shakespeare during presidential elections, which I've continued every four years, aims to make Shakespeare into a traveling vocabulary, a set of linguistic and performative tropes for modern students. I've been asking my students to make Shakespeare a mobile political toolkit. I've offered these tools to many different classrooms, from that private high school in Los Angeles in 1992 to the large Catholic university in Queens where I teach now. My consistent belief has been that Shakespeare's perspective on politics-ironic, performative, practical, a little cynical—would be useful, no matter what turns each election took. I have mostly thought these classes worked.

The fall of 2016 tested that belief. We had a wild ride. Perhaps we should have known better than to believe the polls, but all the students and their professor in "Shakespeare and Political Rhetoric" were shocked after November 8, 2016. I don't think that all my students voted for Hillary, but they expected what we all expected, and we didn't get it. As numbness cracked understanding, I found myself thinking that the outcome should not have surprised me as much as it did. Didn't Shakespeare already know?

To clarify: the failure I still feel regarding that semester's class wasn't that my candidate lost, though I certainly feel that. The failure was that 
my pedagogical plan about Shakespeare as a lens through which to read contemporary politics failed to keep up with the swirl of 2016.

A day or two after the election I read a particularly strong undergraduate paper that analyzed Trump's campaign rhetoric in relation to Mark Antony's funeral oration in Julius Caesar. The paper had been written some time before the election, but I didn't read it until a few days after, in the haze. The paper argued that Trump's performative violence, his transgressive urgency and aggression, made great theater, as did Antony's comparable rhetoric. Hillary Clinton, in this analysis, sounded uncomfortably Brutus-like and "honorable." The student pulled back at the verge-when he wrote the paper we did not yet see our Trumpian future-but there was a way in which he was giving voice to what I had been too timid to recognize during the first half of the semester. Maybe Shakespeare, with his keen eye for drama and the secret life of violence, loves Trump? Maybe my hope to build smart, compassionate, informed citizens out of this premodern playwright's ear for ambiguity and conflict was on some basic level misguided? Maybe I'd been doing it all wrong?

I am not sure yet what I will teach in the fall of 2020 .

Whenever I teach Shakespeare, or anything else for that matter, I come to class with a carefully hidden tinge of rose-tinted idealism. I want literary culture that speaks to our world. I walk into class on that first nervous day wanting the aesthetic to speak back to the material and the literary to suffuse the political. Sidney's golden world and all that. As Matthew Harrison observes eloquently in Chapter 14 of this volume, that fantasy of education minimizes the role of structural injustice. Maybe it's my naiveté, or my tenured privilege, that I still crave some taste of that ambivalent idealism, which on some level I still associate with Shakespeare, even though I should know better. A sideways push of poetry against bare reality is what I want from the literary classroom. I don't expect to get it every day or every year, but I am always looking.

Looking back at fall 2016, I'm slowly climbing back from the ledge. Maybe Shakespeare is good to think with not just when things seem to be going in a predictable way, but also in the face of unexpected disorientation. Allison P. Hobgood's exploration of the "pedagogy of disorientation" in Chapter 3 of this volume seems helpful. The ambivalence and restlessness of Shakespeare's dramatic and poetic works-my key texts that fall were the Roman plays and The Rape of Lucrece-may prove good companions in crisis. Shakespeare's dramatic ambivalence, celebrated from Hazlitt and Coleridge into the present, provides insight into political reversals and violent triumphs. In a sense, as Kesting's 
Richard III failed to teach me in a pre-election moment on November 4 , we should have been preparing all semester for the arrival of the unexpected real. Shakespeare's characterization of ambivalence, reversal, and violence in Julius Caesar, Coriolanus, and elsewhere should have prepared us. The lingering takeaway from Shakespeare and politics in the autumn of Trump emphasized the pain of change and the madness change creates. Shakespeare, of course, had already told us as much.

\section{Scene 2: Lower East Side. Rape of Lucrece. New York Shakespeare Exchange. October 16, $2016^{2}$}

I was feeling a bit nervous about this one.

Every semester I bring my Shakespeare classes to live productions so that they can see old texts in dialogue with contemporary concerns. But this new play, commissioned by the New York Shakespeare Exchange and based on Shakespeare's 1594 narrative poem The Rape of Lucrece, seemed too on the nose for October 2016. The company worked for over eighteen months on the production, but they could not have guessed that its opening week would see repeated claims of sexual assault-via the Access Hollywood tape released on October 7-dominate the final turns of a presidential election campaign. Sex, politics, assault, male domination: maybe a bit much, even for students armed with knowledge of Shakespeare's Roman plays and poem.

I was worried, at this painful and unsettled moment in America, about bringing a class of college English majors, mostly women, to a play about politicized sexual assault. In the end I trusted the collective wisdom of theater: the actors, the writers (twenty-first and sixteenth century), Shakespeare's poetry, the ancient Roman story, the audience. I also trusted my amazing students, who, both in class and in the Lower East Side theater that night, faced up to the long and living history of political misogyny to which Lucrece's story responds.

The evening started about ninety minutes before curtain with a pre-show conversation between a half-dozen intrepid students and a trio from the New York Shakespeare Exchange who brought Shakespeare's narrative poem to the modern stage: Cristina Lundy, director; Jessica Cautery, dramaturg; and Kevin Brewer, playwright. Students volunteered their thoughts about the poem's oblique and painful nature, the insufficiency of the rapist's banishment as punishment, and the imaginative consequences of following Tarquin through Shakespeare's words into Lucrece's bedchamber. I didn't know it at the time, but the conversation set up a wrinkle that NYSX added to their rendition of 
the Lucrece story. We talked about the politics of ancient Rome, and the way the eternal city's mythic history builds itself atop stories of sexual violation: the mysterious pregnancy that leads to the birth of Romulus and Remus, which Jessica suggested may have been a way of concealing a rape story; the rape of the Sabine women; the story of Lucrece. As in Ovid's Metamorphoses, the story that must be repeated, survived, and outlived begins with male sexual aggression.

We talked about Trump. How could we not? Cristina noted the play would feature "armed-camp talk," the Roman equivalent of "locker-room talk," the phrase Trump had used that week to explain away his descriptions of sexual assault. We talked about the Mockingjay, and the dehumanizing consequences, for Lucrece in Roman history and Katniss in the third book of the Hunger Games trilogy, of having a woman's wounded body become a political symbol.

In addition to its implicit commentary on national politics, the play Lucrece included almost everything we'd discussed in the first two months of Shakespeare class that semester. A new character in the play was the young Caius Martius, who when he grew up will become the Roman hero Coriolanus, whose play our class had just finished. The production added material about Lucius Junius Brutus, a friend of Lucrece's husband Collatine who used the occasion of Lucrece's rape to banish the Tarquin monarchy and found the Roman Republic. In a gambit that my students recognized from Hamlet, Brutus pretended during the first half of the play to be a drunken fool, only to spring the trap and lead the forces assembled against Tarquin at the end.

The notable addition the play made to Shakespeare's narrative was Mirabelle, Lucrece's servant and confidant, whose story was added by the twenty-first-century playwright. Moving back and forth between the army's camp at Ardea and Lucrece's house at Rome, she served as an emotional register for the audience, suspecting Tarquin before anyone else, concerned about Lucrece, aware that, after the assault, when Lucrece's male allies, including her father and husband, started talking politics, they were likely to forget her.

The action oscillated between presenting Lucrece as an individual and treating her rape as a political symbol. Lucrece's suicide came when Mirabelle was briefly offstage and Lucrece's male allies were distracted by political strategy. Once Lucrece became the symbol of their republic - their Mockingjay_ - she ceased to be present for them as a person. It was shocking to watch her stab herself while half the stage was filled up by men who loved her but were not watching. It was equally shocking - and pruriently gratifying - to watch Mirabelle castrate and execute Tarquin in the play's final non-Shakespearean scene. 
On our way out, one of my male students told me, "This was much better than Shakespeare's version." In a way, the rapist's graphic death provided what today we call "fan service": it added something to the story that indulged our emotional desire to punish Tarquin. Such an ending makes a hash out of tragic necessity, not to mention (masculinist) history, but it articulates a bloody justice. That night in the Lower East Side, it made me happy to think that, even as current events were demonstrating that male sexual assault still brutally punctuated modern politics, young men and women were recognizing that cruel old stories need better and more just endings.

The problem, of course, is that those endings weren't written by Shakespeare. Or is that a problem?

Questions of female power and masculine anxieties were urgent for Shakespeare when he wrote Lucrece in 1594 and also in the United States in 2016. Shakespeare's culture was struggling with the final phase of Elizabeth's solitary reign, and the United States with Hillary's not-to-be coronation as our first female President.

\section{Scene 3: West Village. Coriolanus. Red Bull Theater. November 20, $2016^{3}$}

What would it have been like to have seen Red Bull's blazing production of Coriolanus before our national day of reckoning? Could watching this painful and bloody tragedy of egotism and political betrayal in 2016 have been experienced, before the fateful election, as a muted triumph, in which female resistance managed in the end to save civilization from masculine violence? I'll never know, and neither will my students.

There was a moment near the center of the performance in which the citizens, having more or less willingly given the war hero their voices and their red-colored ballots, realized, with a little help from the smarmy tribunes, that they could change their minds. They rebelled and retracted their support. What an idea!

The set was festooned with ballots and balloons that dropped when Coriolanus was presented to the people and popped loudly when the riots began. These were the last painful set of electoral props I saw in November 2016.

I was left wondering about the tribunes, Brecht's Marxist heroes, enemies of the aristocracy. ${ }^{4}$ Is this play about the failures of democracy in governing a republic? Does that remind us of anything? I'm also left replaying one pure irresponsible stage moment of anti-democratic rage, 
when a nameless citizen jumped up onto center stage and hammered the blunt end of a sledge into a ballot box. It took a few hard blows, but she scattered the red cards of endorsement all over the stage. Votes don't always last.

I don't have a clear lesson to draw from that disorienting semester, in or beyond the classroom. I'm drawn to the idea that disorientation can be a precursor to new knowledge, and I'm tempted to think about the pedagogy of failure in an instrumental sense. But as I think back to those weeks, real disorientation wasn't easy to live in or think with. I'll close with three thoughts on a semester of failing with Shakespeare.

\section{Shakespeare is not a democrat}

We all know this fact, and I always emphasize that it is the leverage of historical distance that allows Shakespeare to cast a revealing light on the twenty-first century. The demos in Shakespeare is the unruly mob, easily manipulated (as in Julius Caesar) and with a frightening wish to consume its heroes (as in Coriolanus). Renaissance humanism has some relation to modern ideas about "human values," but not a straightforward one; humanitas in the Renaissance was primarily about classical texts. As Joseph Campana recalls in his exemplary essay " $H$ is for Humanism," "H, human, humanism . . . are modes of aspiration whose ultimate efficacy and end are still unknown." ${ }^{5}$ Shakespeare's sometimes ambivalent relationship to values such as humanism, against which his tragic vision contends, and equality, against which his desire to dramatize radical singularity struggles, makes him an imperfect vessel for a modern multicultural democracy. In political terms, Shakespeare represents more clog than ideal: his presentation of violence, ambition, and jealousy strain against utopian politics. Juxtaposing such clogs against ideals of harmony enables Shakespeare, like Machiavelli, to present a clear-eyed and realistic vision of political struggle. Sometimes we forget that our contemporary world still resembles that of the Florentine political theorist and English dramatist of regicide and betrayal.

\section{Politics is always violent and theatrical}

The great positive value of thinking politics through Shakespeare is not that he shares our democratic and pluralist values (he does not), but that his artist's eye was always drawn to the performative and melodramatic arc of political narratives. That may not be the best or only way to evaluate political choices in the present, but in historical 
periods of rapid media growth and technological change- by which I mean both the twenty-first century of social media and twitterbots and the sixteenth century of print culture and the public stage-choices of narrative framing and performance weigh heavily. No writer in the Anglophone tradition speaks as clearly about stagecraft as Shakespeare, and politics, he shows us, depends upon stagecraft.

\section{Shakespeare is good at politics-but not inescapable}

We don't have to follow the patterns of charisma, masculinity, and violence that he elucidates on stage. At least I hope not.

\section{Notes}

1. Kings of War mashed together a series of Shakespeare's history plays, from Henry V through all three parts of Henry VI and ending with Richard III. For a different version of this response to the production, see Steve Mentz, "He Must See Ghosts: Richard III, Trump, and the Future," Hypocrite Reader, no. 70 (December 2016) <http://hypocritereader.com/70/must-seeghosts> (accessed February 22, 2019). A longer blog-review appears on my personal blog, The Bookfish: "Kings of War: 11/4/16@ BAM," November 6, 2016 <http://stevementz.com/kings-of-war-11416-bam> (accessed February 22, 2019).

2. See also Steve Mentz, "NYSX's 'Lucrece," The Bookfish Thalassology, Shakespeare, and Swimming blog, October 16, $2016<\mathrm{http}: / /$ stevementz. com/nysxs-lucrece> (accessed February 22, 2019).

3. See also Steve Mentz, "Coriolanus in Trumpland (Red Bull @ Barrow St, 11/17/16)," The Bookfish Thalassology, Shakespeare, and Swimming blog, November 20, $2016<$ http://stevementz.com/coriolanus-in-trumpland-redbull-barrow-st-111716> (accessed February 22, 2019).

4. See Bertolt Brecht, Brecht on Theatre: The Development of an Aesthetic, ed. and trans. John Willet (London: Methuen, 1964), 252-65.

5. Joseph Campana, "Epilogue: H Is for Humanism," in Renaissance Posthumanism, ed. Scott Maisano and Joseph Campana (New York: Fordham University Press, 2016), 313. 

Revitalizing the Archive and Remixing Traditional Approaches 



\title{
Teaching Serial with Shakespeare: Using Rhetoric to Resist
}

\author{
Rachel E. Holmes
}

A few years ago I was teaching a fairly standard undergraduate class on poetics in John Milton's Paradise Lost when a student asked me, point blank, "Why does any of this matter?" The next class, I ditched my lesson plan and instead handed out Francis Bacon's essay "Of Revenge" and a passage from Edward Coke's Institutes of the Lawes of England, and told the students we were going to look at justice and revenge, all to a chorus of semi-audible groans. Then I asked whether they had ever listened to Serial, the record-breaking NPR podcast fronted by Sarah Koenig. They sat forward, attentive nods and eagerness replacing the resignation. So I asked: "Did Adnan kill Hae? Should Adnan be in prison?" Season One of Serial narrates a Baltimore cold case of the 1999 murder of a teen girl, Hae Min Lee, for which her ex-boyfriend, Adnan Syed, was (perhaps wrongly) convicted. Everyone had an opinion, and this led to an in-depth guided and reflective discussion, moving inductively from Adnan's case to a broader conceptual consideration of justice, which, in turn, enabled an easy shift to thinking about Bacon, Coke, and Milton, and how justice and revenge work in the early modern imagination.

My success with Serial in the classroom prompted me to think more about how we might usefully incorporate podcasts and other current media into our pedagogical practice. When listening to Serial, what captured my attention and that of my students was the story itself, but what held it week to week was how the story was told: the competing narratives, the conflicting evidence, the rhetorical strategies. It was that, along with Koenig's allusive description of the case as a "mashup" of Romeo and Juliet ("young lovers from different worlds") and Othello ("the villain not a Moor exactly, but a Muslim all the same"), that made me think of it as Shakespearean. ${ }^{1}$ Their common denominator is rhetoric: how stories are told and to what ends. 
Popular perceptions of rhetoric are now largely negative: either it is the dull partner to composition in a college writing class, or it is empty but elaborate phrasing used in lieu of actual content. But I mean to attend to how people do things with words, to consider the technical notion of rhetoric as the art of effective spoken or written expression. We are generally no longer taught about the prescriptions of classical rhetoricians, even though they continue to shape our narratives, and what we perceive to be true. This growing rhetorical illiteracy limits our ability to recognize rhetoric at work. Thinking critically about the rhetorical construction of narratives-in classic texts such as Shakespeare and multimodal ones such as Serial-helps us to question them, to look beyond words, and to test the veracity of claims. Educators have a responsibility to foster critical thinking that is sensitive to historical and cultural contingency, to rhetoric, and to storytelling, and I suggest here that pairing Serial and Shakespeare is one way to do just that.

My focus for the remainder of this chapter is threefold. First, I explore the pedagogical debates about incorporating podcasts in the classroom and suggest that teaching Serial alongside Shakespeare enhances student engagement with core texts, advances critical thinking, and improves rhetorical literacy. Second, I consider persuasive strategies (both classical and contemporary) in reading the use of evidence in Othello and Serial, thus illuminating their rhetorical similarities. Third, I make a few practical suggestions about how to teach Serial with Shakespeare, a model that helps create a student-led classroom environment in which cultural narratives are questioned, and the power of language appears in a clearer light.

\section{Teaching Serial with Shakespeare}

In 2014, Michael Godsey, an American high school English teacher, gained a great deal of attention for his decision to teach Serial instead of Shakespeare. ${ }^{2}$ He insisted that the "hip" podcast was not only more interesting to his students than Shakespeare, but also better suited to addressing "Common Core" standards, designed to prepare students for college and their future. While this move garnered criticism for its wholesale rejection of Shakespeare, the use of Serial in the classroom also gathered support. Serial was widely credited as the "catalyst" for a kind of podcast revolution when it became the most popular podcast in the history of the form, surpassing 40 million downloads. ${ }^{3}$ This popularity had a pedagogical impact. A number of anecdotal articles sprang up that confessed shifts in teaching philosophy after listening to Serial, 
ranging from one pastor's realization that "messy," "human" elements make stories compelling (influencing his approach to teaching the Bible) to a criminal-justice professor's questioning of the ethics of engagement with an active case. ${ }^{4}$ Added to these responses is a growing body of digital pedagogy scholarship that attests to the merits of incorporating podcasts in class, above all for increasing student engagement and analytical thinking. ${ }^{5}$

Broadly speaking, an approach such as Godsey's might be taken as one of many ways of "flipping the classroom," a pedagogical model concerned with "changing expectations for what happens in class" in order to create a student-led, active learning environment. ${ }^{6}$ Through the use of multimodal podcasts such as Serial in the flipped classroom, Rick Cole and Beth Kramer report a significant increase in student engagement. ${ }^{7}$ Their research speaks to the question asked by Ayanna Thompson and Laura Turchi as to whether we might "combine the pleasure of socially collaborative activities with heightened expectations for individual critical analysis." ${ }^{8}$ Both pairs of researchers, each with distinct disciplinary investments, seek ways to harness the invigoration of the extracurricular in the classroom. Thompson and Turchi are responding to a perceived need for innovation in the teaching of Shakespeare, and insist that "Without a twenty-first century approach, Shakespeare in schools really will cease to matter-it will be a dead subject like Latin — and will be replaced by texts that are 'relevant' and easily accessible." Godsey's decision to ditch Shakespeare for Serial certainly seems to prove their point. But, if taught with rather than instead of Shakespeare, Serial can make Shakespeare relevant and easily accessible.

I am not the first academic to suggest pairing Shakespeare with Serial. Vanessa Corredera argues that this combination challenges the persistent cultural fallacy that modern constructions of race are "stable and emphatically biological" in comparison with undeveloped early modern ones. ${ }^{10}$ She does so by drawing out the indistinctness and "conflation" of identificatory (or social) categories of race, culture, ethnicity, and religion in Serial, exposing the continued "multiplicity" of racial discourses, and thereby enabling students to grapple with both the "complexities of contemporary racial ideology" and those we find in Shakespeare. ${ }^{11}$ This important work implicitly acknowledges what Thompson and Turchi identify as our students" "developing interests in diverse identity politics" as well as the potential to harness those interests to reshape readings of Shakespearean texts. ${ }^{12}$ Serial presents ample opportunities to engage with social justice. It asks, as Corredera discusses, whether racism and discrimination impede justice, 
by exploring the possibility that bias influenced legal process and the outcome of Adnan's trial. ${ }^{13}$ It situates Adnan's relationship with Hae and her murder within broader debates about sexual consent, gender, and domestic violence, asking whether Adnan was a jealous boyfriend and how far that went. ${ }^{14}$ And it raises questions about the prejudicial pervasiveness of Islamophobia. ${ }^{15}$ Underpinning each of these are questions that straddle legal and dramatic storytelling, questions about intention (why did the police focus on Adnan?), about motivation (if Adnan killed Hae, was it because he was jealous?), reputation (were they "good" kids?), and about persuasion (how are people convinced of Adnan's guilt?).

While I share Corredera's investment in reinforcing student engagement with social justice while reading Shakespeare, my focus is distinct. I am concerned with how such literary, legal, and cultural stories are told, and how they become effective, through what rhetorical tropes or figures, and to what end. Thompson and Turchi rightly suggest that, as educators, our ultimate goal is "advancing literacy," and I believe the literacy we seek to advance should be both textual and cultural. We can do this effectively by looking at rhetoric. Cultural narratives, like their literary and legal counterparts, are rhetorically shaped and presented. By pairing Shakespeare with Serial and attending to their rhetorical strategies I seek to improve rhetorical literacy, a skillset which will empower students both in their studies and in the world beyond.

\section{Raising Rhetorical Awareness}

Classical rhetoricians show that how the story is told-its persuasiveness, its believability-determines the outcome of a case more than the evidence presented. The power of storytelling resonates in a play like Othello, where success in a court of law or in courtship is similarly determined by rhetorical performance. In Shakespeare's Europe, as in the classical world, rhetorical skill was what made for a persuasive case. It also helped determine what produced a plausible representation on stage. Sarah Koenig, like Shakespeare, shows just how much rhetoric matters. Teaching Serial with Shakespeare therefore serves a dual purpose: it offers a way into the thorny terrain of classical rhetoric by providing clear and accessible examples of its workings in action; and it illustrates the relevance of rhetorical tools not only to the age of Shakespeare but also to contemporary society. These tools were, and are still, used at law, in literature, and in politics, but while Shakespeare's rhetorical capacity has been treated exhaustively by literary critics, ${ }^{16}$ 
we no longer rigorously learn the strategies that comprise it. Popular awareness of rhetoric has diminished, and the result is that rhetorical mastery of the kinds lauded by the ancients and early moderns often goes unnoticed, rendering it (paradoxically) all the more effective.

According to Aristotle, the strategies of persuasion are threefold: persuasion must be achieved by proving the truth of claims (logos), by establishing the character of the speaker (ethos), or by targeting the emotions of the audience (pathos). By these lights, we might consider the first season of Serial as an exercise in pathos, for Koenig works on her audience's emotions from the start. Take her point of entry to Adnan's story, for instance. We are introduced to him through the lens of Shakespearean tragedy in a move that evokes centuries of empathy: he and Hae are star-crossed lovers, Romeo and Juliet, a maneuver which foregrounds his hapless love for Hae. But Adnan is then framed as Othello, implicitly inviting us, in Koenig's words, to consider "jealousy, suspicion," and to wonder whether he is also "one that loved not wisely, but too well" (Othello, V, ii, 404). ${ }^{17}$ Koenig's rhetorical strategy and its resonances with Shakespearean texts run even deeper than these initial allusions. For the remainder of this section I will draw out some of these resonances by looking at passages from Othello, a common feature of both high school and college curricula, alongside snippets of Serial Season One, Episode 6, "The Case Against Adnan Syed."

On the one hand we have a well known Shakespearean play, and on the other we have a podcast about a modern-day legal trial. They seem disparate, but both rely on the rhetorical construction of pieces of evidence-whether physical or verbal - to represent and to determine guilt. Iago constructs a narrative of Desdemona's infidelity and Cassio's culpability using evidence in much the same way as the prosecution constructed their case against Adnan, or Koenig builds hers in the podcast. Each trades in proof, plausibility, and pathos. ${ }^{18}$ Think of Iago's attempt to convince Othello that his wife is committing adultery with Cassio. "I lay with Cassio lately," Iago tells Othello, and goes on to present a vivid, emotive description (a rhetorical technique that Quintilian might term enargeia) of Cassio's dream about being in bed with "Sweet Desdemona" (III, iii, 470, 475). Neither we in the audience nor Othello are able to contest or verify Iago's report, since there are no witnesses. Cassio's reported speech becomes one proof that Iago insists "may help to thicken other proofs" (III, iii, 488) against Desdemona. To these "other proofs" he adds Desdemona's famous "handkerchief / Spotted with strawberries" and insists he saw "Cassio wipe his beard" (III, iii, 493-4, 499) with the same. He positions himself as an eyewitness, presents a narratio or account of events, and supports it with proofs, as 
the rhetoricians instruct. We know Iago's tale to be fallacious, having witnessed his asides, which more clearly expose his rhetoric.

We can then transfer this awareness to Episode 6 of Serial as Koenig collects pieces of evidence "that look bad for Adnan," and "hang[s] them all up, side-by-side, [to] see what they look like." Obviously, Koenig's journalism is also a narrative, so it is not surprising that the way she presents this information is rhetorical, but, crucially, so is the information itself and the way it was presented during Adnan's trial. One of the proofs she enumerates is a palm print found "On a map" in "the backseat of Hae's car." Although the defense argued that "you can't put a timestamp on fingerprints," the prosecution made a convincing argument that they could, despite there being "thirteen other, unidentified prints" on the same book. As Othello is convinced by the handkerchief even though there are other plausible explanations, the jury was convinced by the prosecution's framing of events. Using Serial in dialogue with Shakespeare, attending in particular to rhetoric, opens up new perspectives sensitive to historical and cultural contingency, and increases rhetorical literacy within and beyond the classroom. I would like to turn now to a couple of examples of this expansive pedagogy, each of which could be adapted for either high school or college classrooms.

\section{Using Rhetoric to Resist}

I have always taught Measure for Measure - a play that tracks the ethical dilemma of Isabella when she is faced with the choice of protecting her chastity or saving her brother's life-by conducting a mock trial, where I preside as judge. I use it as an exercise in textual evidence gathering: Isabella is the plaintiff, for whom students must build a case, knowing only what Isabella can tell them, and students work in groups to gather and present proofs to support Isabella's accusation that Angelo demanded the "gift of [her] chaste body" (V, i, 116) in payment for the release of her brother. This, they discover, is harder than it seems, because they cannot draw on the privileged omniscience of the audience and are bound by Isabella's perspective. They end up with a case of her word versus his, which is the ideal segue into thinking about gender and belief, for, as Angelo scoffs, "who will believe thee, Isabel?" (II, iv, 168). Replace Isabel with Adnan, and you have a question that resounds throughout Serial. Listening to Serial made me think about the rhetorical construction of guilt-about what mitigates and what compounds it - and how that is never straightforward. Serial explores 
often-contradictory testimony about Adnan's character or behavior: he did drugs, he lied to his parents, he was "the community's golden child," he "went to the library," he "led prayers at the mosque." 19 So now I teach Serial (usually Episode 11, "Rumors") alongside Measure for Measure and introduce Aristotle's ideas about legal and rhetorical proofs because, despite initial appearances, guilt is equally murky in Shakespeare's play.

In Measure everyone is guilty of something. I ask students to think in advance about the following questions: How do we decide whom and what to believe? What factors are most influential in forming our opinion? In class, we then use Serial as our starting point, discussing how belief is produced and witnesses are discredited in the podcast and in court during Adnan's trial. Then I use the mock trial to put that into practice. I split the class into small groups, allocating each a character to defend (Isabella, Angelo, the Duke, Mariana). Their speeches for either the prosecution or the defense must use proofs (in the form of textual evidence) and attend to rhetorical tropes. I follow this up with a two-part written assignment: the first part weighs the merits of the competing accounts (what evidence was given, whether it was persuasive, and, if so, why), and the second asks them to choose a contemporary case and to apply what they have learned by researching media reports presenting evidence in defense of a particular party to their chosen case.

The lovers of Verona also have a critical history of competing interpretations of their story. Were they star-crossed lovers who fell victim to familial pressures? Or were they headstrong teenagers who disregarded the wisdom of their elders and wound up dead? This ambiguity has long been overridden in popular culture by portrayals of the story of Romeo and Juliet as the greatest love story of all time, perhaps because of the emphasis placed in contemporary Western culture on free choice in marriage. Parents like the Capulets are now dismissed as controlling and outdated. However, Sarah Koenig explicitly compares Adnan and Hae to Romeo and Juliet in the opening episodes of Serial, not only romanticizing them as the star-crossed lovers of Woodlawn High, but also making a great deal of the disapproval Adnan faced from his Pakistani-American, Muslim family. I use Serial and Koenig's rhetorical depiction of Adnan's relationship with Hae-which draws out tensions between familial expectations and cultural norms - to do three things: to historicize ideas about marriage, to increase cultural awareness and sensitivity, and to think about how narratives of "traditional marriage" are presented and enforced. I set an episode alongside the play (usually Episode 2, "The Break-up") and a selection of secondary reading about marriage in early modern England and in contemporary society, and ask 
students to think about similarities and differences between them. In class, I start out by asking whether the two sets of teens were wrong to date against their parents' wishes. I then divide the class in two: one side must convince me that Romeo and Juliet were justified in their actions, and the other that they should have heeded their parents' wishes. The focus of this exercise is rhetorical persuasion, and students are asked to think about what strategy would best suit their purpose. Do they want to target emotions (pathos), establish the truth of their claims (logos), or demonstrate character (ethos), or is a combination more effective? An assignment could follow that explores the ethical implications of how the rhetoric of cultural expectations interacts with personal desires.

The ultimate goal of this pedagogical practice is to raise rhetorical literacy, empowering students to question cultural narratives and the motives behind those who wield them. With that in mind, I conclude the coursework with a presentation session I call "rhetorical show and tell." Each student presents a contemporary cultural artifact in class-one that would not be typically regarded as a fiction-and unpacks the rhetorical strategies at work: news items, advertisements, political speeches, lawsuits, and so on are all fair game. By challenging their assumptions about the stories we are told on a daily basis, and using the rhetorical literacy we have developed through analyzing Shakespeare and Serial, we can illuminate the artifice of the stories we hear on the public stage, the ones that are so often presented to us as undisguised truth.

\section{Notes}

The research leading to this chapter received funding from the European Research Council (EC) under the European Union's Seventh Framework Programme (FP7/2007-2013)/ERC grant agreement no. 617849. I would also like to thank the editors, and my colleagues Elizabeth L. Swann, and Maria Sequeira Mendes, for their generous and formative comments.

1. Sarah Koenig, "The Alibi," Serial, Season One: Episode 1 (n.d.) <https:// serialpodcast.org/season-one> (accessed February 22, 2019).

2. Michael Godsey, "The Value of Using Podcasts in Class," The Atlantic, March 17, 2016 <https://www.theatlantic.com/education/archive/2016/03/ the-benefits-of-podcasts-in-class/473925> (accessed February 22, 2019); Matt Collette, "To Download or Not to Download," Slate Magazine, November 20, 2014 <http://www.slate.com/blogs/schooled/2014/11/20/ serial_replaces_shakespeare_in_one_california_english_class.html $\quad$ (accessed February 22, 2019).

3. Rick Cole and Beth Kramer, "Podcasts and the Twenty-First 
Century College Classroom," Impact: The Journal of the Center for Interdisciplinary Teaching and Learning, summer $2017<\mathrm{http}: / /$ sites. bu.edu/impact/previous-issues/impact-summer-2017/podcasts-and-thetwenty-first-century-college-classroom > (accessed February 22，2019); Ellen Gamerman, “Serial' Podcast Catches Fire," Wall Street Journal, November 13, $2014<$ https://www.wsj.com/articles/serial-podcast-catchesfire-1415921853> (accessed February 22, 2019).

4. Ricky Alcantar, "What I Learned About Teaching from Listening to Serial," Medium: The Synapse, December 17, $2014<$ https://medium. $\mathrm{com} /$ synapse/what-i-learned-about-teaching-from-listening-to-serialf91a5b4304e1> (accessed February 22, 2019); Julie L. Gafney, "Teaching Serial at the Criminal Justice College: Discomforting Ethics and Interdisciplinary Methods for Critical Thinking," Impact: The Journal of the Center for Interdisciplinary Teaching and Learning, summer 2017 $<$ http://sites.bu.edu/impact/previous-issues/impact-summer-2017/ teaching-serial-at-the-criminal-justice-college-discomforting-ethics-andinterdisciplinary-methods-for-critical-thinking $>$ (accessed February 22, 2019).

5. Linda Flanagan, "What Teens Are Learning From 'Serial' and Other Podcasts," KQED: News, March 11, 2015 <https://www.kqed.org/ mindshift/39461/what-teens-are-learning-from-serial-and-other-podcasts > (accessed February 22, 2019); Godsey, "The Value of Using Podcasts in Class."

6. Cynthia J. Brame, "Flipping the Classroom," Vanderbilt University: Center for Teaching, 2013 <https://cft.vanderbilt.edu/guides-sub-pages/flippingthe-classroom $>$ (accessed February 22, 2019).

7. Cole and Kramer, "Podcasts and the Twenty-First Century College Classroom."

8. Ayanna Thompson and Laura Turchi, Teaching Shakespeare with a Purpose: A Student-Centered Approach (London: Bloomsbury Arden Shakespeare, 2016), 1.

9. Ibid., 7.

10. Vanessa Corredera, “'Not a Moor Exactly': Shakespeare, Serial, and Modern Constructions of Race," Shakespeare Quarterly 67, no. 1 (2016): 32.

11. Ibid., 33.

12. Thompson and Turchi, Teaching Shakespeare with a Purpose, 1.

13. Sarah Koenig, "The Best Defense Is a Good Defense," Serial, Season One: Episode 10 (n.d.) <https://serialpodcast.org/season-one> (accessed February 22, 2019).

14. Sarah Koenig, "The Breakup," Serial, Season One: Episode 2 (n.d.) $<$ https://serialpodcast.org/season-one> (accessed February 22, 2019).

15. Koenig, "The Best Defense"; Sarah Koenig, "Rumors," Serial, Season One: Episode 11 (n.d.) <https://serialpodcast.org/season-one> (accessed February 22,2019$)$. 
16. Michael J. MacDonald, The Oxford Handbook of Rhetorical Studies (Oxford: Oxford University Press, 2017), chs. 30, 35, 36, 39; Lynn Enterline, Shakespeare's Schoolroom: Rhetoric, Discipline, Emotion (Philadelphia: University of Pennsylvania Press, 2012).

17. All references to Shakespeare's plays comes from Shakespeare's Plays, ed. Barbara Mowat et al., Folger Digital Texts (Washington: Folger Shakespeare Library) <https://www.folgerdigitaltexts.org> (accessed December 4, 2017) and will be cited by act, scene, and line.

18. The rhetoric of Othello has been convincingly treated by Lorna Hutson, The Invention of Suspicion: Law and Mimesis in Shakespeare and Renaissance Drama (Oxford: Oxford University Press, 2007), 1-63.

19. Koenig, "Rumors." 


\title{
Adjunct Pleasure: Shakespeare's Sonnets and the Writing on the Walls
}

\author{
Matthew Harrison
}

Bouncing from teaching job to teaching job, I learned to read sonnets differently. In my portable academic life-graduate student, writing consultant, visiting assistant professor, adjunct—sonnets spoke to me in their contingency, their disarray, and the painful realization that no amount of skill (of craft, of mastery) can merit love.

More than 1,000 English Ph.D.s graduate each year and fight for fewer than 200 tenure-track jobs. ${ }^{1}$ The number of degrees granted continues to rise. The number of jobs continues to fall. The effect of this reserve army of labor is a wholesale transformation of the economy of higher education: where 45 percent of faculty were tenured or tenure-track in 1975 , today around 21 percent are. $^{2}$ I need not recount the deleterious effects of such contingent employment: not only low salaries, but unpredictable schedules and incomes that fluctuate with it; heavy course loads with large enrollments; time lost to commuting, often to multiple campuses; lack of physical space; and lack of representation and health benefits. In an era of tightening budgets, adjuncts, along with graduate students and other contingent employees, subsidize the whole enterprise of scholarship with their bodies, with their passion, and with their futures.

I am not alone, I know, in experiencing this structural shift as a series of personal failures. From job letter to campus visit, the academic job market demands a series of ever more brilliant performances, even as the odds grow increasingly slim. Even well intentioned reassurances imagine the challenge in individual terms: keep at it, you deserve this, the good people get jobs. Lurching from each attempt to display my value to each new rejection, I wrote ever more beautifully as I felt ever more worthless.

I can't say I recognized myself in the stylized despair of the sonneteers, but in trying to describe their predicament I found my own. 
As a genre, the English sonnet sequence desperately strives to avoid its own conclusions. If what is hoped for in their sketchy narratives is seduction, in almost every case the end is, rather, rejection, failure, repentance, or at best a kind of agonized stasis. Even the Amoretti, with the Epithalamion lingering a few pages ahead, ends "disconsolate" and "desolate." ${ }^{3}$ Unlike comedies, sonnets don't recuperate ugly feelings with the balm of heterosexual marriage. Unlike tragedies, they don't offer catharsis, revenge, or a blank stage, either. Rather, they are a series of short contracts, brief pleasures wrapped up in brief obligations, extending indefinitely into a fruitless future.

Lurking behind the failure of romance in the sonnet sequence, then, is a more complicated psychological reckoning. Historicist critics have mapped out how the frustrated stasis of Astrophil and Stella, for instance, negotiates Sidney's own contingency: his sense of himself as supremely talented but without the position to which he felt his gifts and birth entitled him. ${ }^{4}$ From his inevitable disappointment flow forth both virtuosic wit and a variety of ugly feelings: self-doubt, anger, guilt, despair. Whether biographical or not, the poems enact a phenomenology of contingency, dramatizing the contortions of selfhood when an individualistic idea of value confronts a world operating on other logics. Sidney is among the most privileged writers of the Elizabethan sonnet sequence, a genre itself often considered "courtly" or "aristocratic." But he reminds us that the whole English sonnet tradition is deeply invested in the relation between individual effort and structural contingency, in the emotional horrors and generative potential of a mismatch between aspiration and opportunity, skill and desire.

Educated to view careful thinking and stylish writing as paths to influence and stability, Elizabethan writers soon learned that positions were scarce and influence rare. Accounts of this shock show up in many genres, from the disaffected bitterness of the satirists to the scrambling scholars of the Parnassus plays. Sonnet sequences don't diagnose this problem. Rather, ever-more ingenious, ever-more contorted performances of self bash against the reality that it is never enough, that even if love might spur our best, our best may not produce love. There is no necessary match - in love or in life-between our efforts and our results. And so we thrash on, trying harder still. I don't want to lose sight of the material here: the economic challenges of adjuncting, its financial, physical, and psychological costs, and the perverse ways in which institutions capture the value of unpaid and underpaid labor. But sonnet sequences resist insights into broader conditions, preferring rather to turn the structural personal, to register ideology as a carefully articulated movement of feelings. In their supreme narcissism, sonnets 
confront the limits of selfhood, the agonizing failure of the project of shaping life with art.

Central to this project is reconsidering an idealistic view of humanist education with its promise that skills of analysis, persuasion, and expression might translate easily into influence and success. The first poem of Astrophil and Stella imagines an educational poetics that moves smoothly from reading to knowledge and on to grace:

Loving in truth, and faine in verse my love to show,

That the dear she might take some pleasure of my paine,

Pleasure might cause her reade, reading might make her know,

Knowledge might pitie winne, and pity grace obtaine,

I sought fit words to paint the blackest face of woe $\ldots{ }^{5}$

These lines plot a course to seduction, but the route they propose is educational theory. Careful study, the octave proposes, enables a masterful poet to construct a compelling representation that demands consent. Unsurprisingly, it won't work. The other sonnets show us the failures of this circuit: knowledge doesn't produce pity; pity doesn't produce grace; the grip of literature on our minds isn't strong enough to overwhelm our values, our relationships, and our plans. Education is Sidney's first figure for the failed hope that a graceful performance of self might overwhelm circumstances, converting desire and desert into success. Astrophil and Stella diverges from the Defence of Poesie in reckoning not with poetry's power to create a golden world but with the limits of its impact in this brazen one.

Emerging from another cultural moment in which a humanist rhetoric of individual capability collided with a generational lack of employment possibilities, sonnet sequences let me bring my analytical skills and training to bear on a dialectic students are all too familiar with: individualistic narratives of value that sit uneasily with structural forces and blockages. But in so doing, as I will show in my next section, they also demand reflection on the transformative hopes of the humanities classroom and the larger university. Finally, I want to ask, if what sonnets do is to limn the false promise of mastery, the painful collision between a carefully fashioned self and a refusing world, how do we teach them? One might counter this futility with a different recuperative narrative: emphasizing the mastery of their making, their intricate structures of imagery and precisely calculated ambiguities. But doing so charges the classroom air with triumphalism, resolving frustration and envy into occasions for still more skillful displays. In my closing section, therefore, I offer a few ideas, borrowed from mentors and friends in 
my many-campused life, for reconceptualizing pedagogical engagement with these poems.

\section{Sonnet Education: Skill and Value}

In many ways, the academic job market has come to resemble the world faced by our students, who negotiate increasing precarity, structural underemployment, and unclear prospects. Like yours, my students work multiple jobs, commute long distances, incur large debts, and make countless other sacrifices for an education that may or may not open up new opportunities. Under such circumstances, it seems particularly pressing to think through the value of literature with our students, to reflect on why it is we teach what we do, in the way we do.

Sonnets foreground this question. Among the most demanding texts that we teach, they require knowledge of literary tradition, an ear for meter and metrical deviation, and careful attention to ambiguity and structure. They reward technical skill, unfolding outward in ever more complex patterns. Yet they expose all too keenly the limits of skill, too, as their pained repetitions reveal wit's futility. In the meantime, competing justifications for literature jangle up against each other: poems as persuasion, expression, advice, lasting monument, meaningless pleasure, tragic warning. However unconvincing, venial, or glib, these jangling juxtapositions insist that literary skill—craft, style, expression- has value beyond what it might produce in the world.

Nearly everyone in a literature classroom regularly says this and believes it, even sometimes simultaneously. But historically, this sense of value has been backed by a machinery of cultural distinction which now seems to be breaking down. To discuss this, I read Stephen Greenblatt's "What Is the History of Literature?" with my students. For Greenblatt, literature serves as part of a "mobile and flexible apparatus of social ... distinction." Its method, he proposes, is always educative. What relates medieval literacy, humanist reading, Victorian aestheticism, and twentieth-century close reading is the ability of these skills, in their various cultural moments, to "formalize and justify" the presence of their practitioners on the privileged side of social boundaries. The boundaries of the literary have moved, he proposes, to allow teachers of literature to continue to impart those skills that mark and enable social discrimination.

Students can identify many ways in which literary study still offers skills that transform into status. We discuss the cultural heft of Shakespeare, conventions of Standard American English grammar, and 
expectations of address and argument. But these seem largely tangential to the work we do together. Why learn to wrestle with meter, to analyze poetic structure, to muddle one's way through a tangled simile? One response, from many sites within the university, is a rhetoric of professionalization that works alongside our disciplinary activities, at résumé workshops and job fairs, networking events, and job-trainings. Well meant, this rhetoric nonetheless works to replace structural explanations with individual ones, to psychologize economic risk as individual failure. As the Precarious Workers Brigade notes:

Risk is internalised within the emotional and fiscal life of the student or worker, rather than the employer. This process of hedging against the material and perceived risk of failure creates a burden that affects people psychologically and physically ... Of course this is not limited to students, it continues throughout our working lives. We all recognise how our own stress levels have increased as we ourselves re-create our employability, constantly. ${ }^{7}$

The sleight of hand undertaken by the notion of "employability" is to convert an economic situation-what jobs are available, at what wage, for whom-into a personal attribute, the "ability" to be chosen as an employee. It simultaneously enrolls students in a relationship with capital $^{8}$ and casts this relationship as outside the disciplinary methodologies, only vaguely connected to the study of literature or history.

A more specific argument might articulate what students gain from literary education. Yet however much I believe that the literature classroom does inculcate skills of critical thinking, careful reading, argument, and empathy, such arguments reproduce the logic Greenblatt describes, whether these skills are imagined as contributing to an ideal of well rounded citizenship or, more crassly, to notions of "employability" or "marketability." Teaching leads students to read, reading leads them to skills, skills lead (haphazardly and unevenly) to worldly grace.

Sonnets remind us - and life confirms - that often they don't. Late capitalism, like academia, like love, does not guarantee prizes to the meritorious, does not necessarily reward skill or effort or passion. My point is not that departments of literature make false promises to our students: the majority of us would separate the value of the skills we teach from their social effects. Rather, an individual and ethical function cohabits uneasily here with a structural and sociological one. Further, an ethical logic that insists that these skills are transformative exists alongside a socioeconomic one in which they are essentially conventional, already in a predictable relation to capital. One reason for the popularity of the adjective of "critical" in learning outcomes 
and mission statements is its blurring of these boundaries, shifting in meaning from "oppositional and analytical" to "crucial and valuable," depending on its audience.

We inherit this conceptual blurriness honestly. It dates back at least to Sidney's Defence of Poesie, which offers an ideal of literature's transformative force that it can only partially reconcile with its tawdry worldly practice. In arguing that poetry educates, moving readers inexorably to virtue, Sidney simultaneously redefines poetry (excluding much) and glosses faint, familiar effects as educative. The Elizabethan sonnet sequence arises at the same historical moment as Sidney's Defense and takes on many of the same concerns. Authors as different as Sidney and Shakespeare question the value of poetry: as Astrophil exclaims, "Come, let me write. And to what end?" Unlike the Defense, however, sonnet sequences don't answer. If the ongoing project of the individual poems is to persuade or sublimate through the power of wit, their ongoing frustration figures the failure of that project. Monuments to individual skill become commodities, nearly identical cogs in a machine that goes nowhere.

Rather than trying to resolve our predicament, they mirror it back at us.

\section{Teaching Relation}

My students have one additional idiom for literary value, describing those poems they admire as "relatable." To be deemed relatable remains their highest praise: it remarks on the unpredictable tendrils of empathy by which we find our ways into poems. With sonnets, it captures both emotional intensity and a partial and incomplete recognition of self. As a teacher, I'm often frustrated by the way relatability resists analysis, privileging loose affective connections over the careful working out of poetic detail.

Yet, as Sidney's first sonnet suggests, the genre is deeply invested in relation, witnessed by direct appeals to emotion and in a speaker who asks for sympathetic identification. The account of rhetoric that underlies poetic theory in the 1590s imagined poetic persuasion working by contagion: skilled writing induces in the reader the emotions felt by the poet. ${ }^{10}$ Highly stylized, highly generic, highly literary, sonnets nonetheless represent themselves as immediate and particular claims on emotion. More: sonnet sequences weaponize relatability, implicating readers in a frustrated desire that curdles into entitlement, self-loathing, despair, and misogyny. 
Sonnets dramatize the painful contradiction between individualistic ideas of value and structural blockages. They immerse us in the contradictions of thinking with literature, our struggles to articulate the worth of what we do. How, at last, do we teach such things? We must start by understanding their craftsmanship, yet this alone sidesteps the challenge of these poems: their conviction that literary mastery is both of the utmost importance and ineffectual. A second method is to unpack the circuits of feelings that these poems trace: how is it that male desire sours into anger, scorn, and even violence? How might thwarted privilege produce misogyny? In my classrooms, such discussions have been powerful and deeply productive, even as they threaten to reduce style to psychology. The dialectic between these two perspectives may make sonnet sequences the most interesting. Simultaneously a performance of skill and a reckoning with the failure of that skill to achieve its ends, sonnets challenge us to think about the place of poetry in a brazen world.

My job as a teacher is not to answer these questions. I doubt they can be answered. Rather, I want to pass them on as richly as possible, to allow these poems to become a site of resistance to narratives that move too easily from skill to grace. I close, therefore, with three strategies for deepening engagement with these texts while passing on to students the task of wrestling with the questions they pose. My focus here is on Shakespeare's Sonnets, as the sequence I most frequently teach.

\section{Read slowly, spreading the text over the whole semester ${ }^{11}$}

Covering the Sonnets in two or three class sessions necessitates a tremendous amount of explanation. Reading a handful of sonnets each day over the course of the semester, by contrast, allows you to treat them from a variety of perspectives. Early on, the Sonnets can help with the necessary skills for reading Shakespeare, offering occasions for self-contained lessons in close reading to complement the plays. As the semester ticks on, the dynamics of the sequence move to the fore: each poem rewrites and transforms those that come before it. Reading Shakespeare's lyrics becomes an ongoing exploration of the way one poem might shine in the light of another.

Classes, like sonnet sequences, are made up of the repetition of formally identical units. To distribute a text over the semester-particularly a narratively unsatisfying one like Shakespeare's Sonnets-is to ask your students to engage multiple timescales. They must respond both immediately, at the level of class session and poem, and slowly, as the resonances build up over time. 


\section{Write on the windows ${ }^{12}$}

I once shared an office that had huge glass windows overlooking campus. When meeting with students, I would hand them a marker and ask them to map out their ideas on the glass. We might piece together an outline, sketch out a scene, or just record a few thoughts. Standing up, side by side, with a large shared work surface, we found the dynamics of the meeting shifting, becoming more playful, collaborative, and expressive. As a young instructor, I also found that standing helped me pass control of the project over to the student without being frustrating or opaque.

The Sonnets respond well to letting students transform the spaces we inhabit: putting sticky notes on the wall, hanging up big pieces of paper, sharing documents through the web, and so on. A classroom projector makes an impromptu backdrop for a dramatic reading; most recently, with yarn and printed copies of the Sonnets, we traced connections, in the style of the investigative bulletin boards in crime TV shows. What all these methods share is that they invite students to take ownership over the physical space of the classroom, to replace postures designed for obedience with active and bodily engagement with each other's ideas. They ask students to represent thinking-in-progress, framing learning not as the banking of content but rather as putting tentative concepts into relation. Finally, they reduce the disciplinary effects of a teacher's desk or a position at the head of the table, as students clump, mingle, and maneuver.

\section{Engage a weird critical history}

In his New Variorum volume of the Sonnets, Hyder Rollins offers a sexist sniff at the tradition of rearranging Shakespeare's sonnets: "If our wives do not write novels and our daughters plays, they are likely on no provocation at all to malarrange Shakespeare's lyrics." ${ }^{13}$ The insult is targeted more at the (mostly) male arrangers to whom Rollins will turn his jaundiced eye in the rest of the appendix rather than to the wives and daughters it also mocks. Glib and dismissive sexism serves to denigrate the project of rearranging as romantic, amateur, speculative, and playful. The culturally inflected distinction between serious men and scribbling women becomes a metaphor for the separation of careful, scholarly study of Shakespeare and imaginative forms of engagement.

But our students need not inherit this distinction, at least not in the rigid form with which it came to us. There's a long history of inventive, transformative engagements with Shakespeare's Sonnets that has been marginalized within academia, from the "malarrangements" Rollins 
mocks to the computer-generated poems of Ross Goodwin, the erasure poems of Jen Bervin, and the anagram poems of K. Silem Mohammad. Alongside these, we might add amateur readings, parody, illustration, and the setting of Shakespeare to music. From miscellanies to mockeries, readers have always reshaped these poems.

Telling these stories diversifies our understanding of the reception of Shakespeare, even as it calls attention to the cultural work done by Shakespeare's name and reputation. It models both our extreme freedom to reckon with these poems and the larger structural forces that animate such engagement. To read is always both to remake and to be remade.

\section{Notes}

1. National Science Foundation, Human Resources Statistics Program, "Data Tables," 2015 Doctorate Recipients From U.S. Universities, n.d. <https:// www.nsf.gov/statistics/2017/nsf17306/data.cfm> (accessed February 25, 2019); Kevin Birmingham, "The Great Shame of Our Profession," Chronicle of Higher Education, February 12, 2017 <https://www.chronicle.com/ article/The-Great-Shame-of-Our/239148> (accessed February 25, 2019).

2. American Association of University Professors, "Trends in the Academic Labor Force 1975-2015,” March 2017 <https://www.aaup.org/our-work/ research $>$ (accessed February 25, 2019).

3. Edmund Spenser, The Shorter Poems (New Haven: Yale University Press, 1989), 654.

4. See Arthur Marotti, "'Love Is Not Love': Elizabethan Sonnet Sequence and the Social Order," English Literary History 49, no. 2 (summer 1982): 396428; Richard McCoy, Sir Philip Sidney: Rebellion in Arcadia (Ann Arbor: University of Michigan Press, 1979). See also Catherine Bates, Masculinity, Gender, and Identity in the English Renaissance Lyric (Cambridge: Cambridge University Press, 2007).

5. Philip Sidney, Poems, ed. William Ringler (Oxford: Clarendon Press, 1962), 165.

6. Stephen Greenblatt, "What Is the History of Literature?," Critical Inquiry 23, no. 3 (spring 1997): 463 <https://doi.org/10.1086/448838> (accessed February 25, 2019).

7. Precarious Workers Brigade, Training for Exploitation? Politicising Employability and Reclaiming Education (Los Angeles: Journal of Aesthetics and Protest Press, 2016), $9<$ http://joaap.org/press/pwb/PWB_Text_FINAL. pdf $>$ (accessed February 25, 2019).

8. Ibid., 8 .

9. Sidney, Poems, 181. 


\section{Matthew Harrison}

10. See Wayne Rebhorn, The Emperor of Men's Minds (Ithaca: Cornell University Press, 1995).

11. I owe this suggestion to Andrew Fleck.

12. I owe this idea to Sue Mendelsohn.

13. William Shakespeare, New Variorum Edition, Vol. 24: The Sonnets, ed. Hyder Rollins (Philadelphia: Lippincott, 1944), 86. 


\section{Confronting Bias and Identifying Facts: Teaching Resistance Through Shakespeare}

\section{Carla Della Gatta}

Recent terms such as "alternative facts," "fake news," and the more relaxed protocols of social media have changed the standards of spoken and written English. At the same time, technology has enabled widespread dissemination of both public and private information in the twenty-first century. But it has also brought forth a greater questioning of truth, as images and language can be easily manipulated or erased. Here I present a pedagogy that engages Shakespeare plays as key tools for teaching students how to recognize evidence that confuses facts, feelings, and opinions. In 2017, the political climate was marked by reading lessons from a breadth of people, including activist librarians, who ensured access to information by "hosting community discussions on fake news and sharing libguides to help people think critically about what they were reading," 1 and by scholars at the University of Washington who created a course "Calling Bullshit in the Age of Big Data" and posted the syllabus, tools, and case studies. ${ }^{2}$ How to conduct a close reading became a nearly national campaign.

Shakespeare studies has a lengthy, cross-cultural, and international history of determining, disputing, and reinterpreting facts. From the authorship controversy, where facts are reinterpreted to fit a pre-established model, to attribution studies, where new points of information disrupt longstanding certainties, the study of Shakespeare involves the negotiation of expertise. Shakespeare is cultural shorthand for an ongoing discovery modality operating adjacent to strongholds of theatrical and scholarly achievement. Understanding how knowledge is constructed shapes the baseline for resistance to false narratives. Likewise, the study of Shakespeare is largely dominated by a study of language, of linguistic shifts over the centuries, and of poetry. In contemporary universities and theaters, there is a long-held perception that mastery of Shakespearean language is tied to mastery of craft and of mind. 
Along with language study as a conduit for unpacking (mis)information, Shakespeare also serves as a platform for subverting dominant and oppressive structures because of the potential for diverse peoples in the classroom, audience, and onstage to interact with each other through the live art of storytelling. The history of color-blind, color-concept, and American-accented Shakespeare imbues the legacy of colonialist, essentialist, and elite Shakespeare with the democratic, inclusive, and accessible position he holds in curriculum and entertainment today.

The study of Shakespeare or any work with early modern verse is a ripe field for social justice pedagogies because, at the most basic level, teaching students how to read at an advanced level is a form of activism. Today's college students have grown up with numerous annual standardized tests that reinforce the idea that there is only one correct answer for any type of question, and oftentimes - as in the case of studying Shakespeare - they experience discomfort with the exploration of the text necessary to cultivating individual interpretation. Indisputable facts, scholarly analyses, general opinion, and outright lies all vie for space in similar (and sometimes the same) forums, requiring greater attention to be paid to close reading and the making of meaning as social justice practice.

In the last decade, much has been written on social justice pedagogies, but I use as a basis Paulo Freire's proposal in Pedagogy of the Oppressed that makes students co-creators of knowledge. ${ }^{3}$ With multiple levels of interpretation at every point in the process of studying Shakespeare, it is evident that students must make meaning and cannot simply memorize a dominant interpretation. Freire explains that in order to liberate the oppressed (here, students), "the requirement is seen not in terms of explaining to, but rather dialoguing with the people about their actions." "Shakespeare's plays serve as a model for collaboration in early modern theatrical and performance contexts today, but they also serve as a model for collaboration between students, educators, and all those who contribute to the printed texts. The following model is what I have formulated for a social justice pedagogy, and only one version of the possibilities for today's classrooms.

\section{Negotiating Expertise}

Before the 2012 U.S. presidential election, YouTube created a one-minute advertising video to show the breadth of the election coverage on its "Election Hub." 5 The one-minute video shows a floating balloon, and the narration begins, "A balloon. It usually means a celebration." The 
camera pans to different images of balloons in celebratory moments: a birthday, sailors' homecoming, and a grand opening. The narration continues, "But look at it differently and it could mean more jobs, if made in America . . . or fewer jobs if not." The video goes on to show images of balloons of drugs to be swallowed and transported, hot air balloons, a plastic balloon used in life-saving angioplasty, and more. The video clearly demonstrates how one word can signify so many different objects and points of view, and how each object and context can vary greatly.

I use this video in class to open a dialogue about bias and positionality. The recognition and consideration of bias is a necessary factor in the comparative and historical bibliography that determines the "text" of the plays. To study Shakespeare is to confront historical bias, but, unlike other editorial formats, Shakespeare editions are often transparent about these decisions, with notes on variants and emendations. I ask students to bring any edition of the play they might have, and I bring those that I have as well, including The Complete Oxford Shakespeare (1987), Folger (1992), The Riverside Shakespeare (1997), Arden (2003), Oxford (2000), Pelican (2000), New Cambridge First Quartos (2007), and The Norton Shakespeare (2016). A quick search in the university library has led me to older editions, such as those produced by Methuen \& Co. (1900), Ginn \& Co. (1902), Appleton-Century-Crafts, Inc. (1947), and others. Students look at one scene across editions to compare interpretations and analysis from different time periods and cultures. This exercise shatters any notion that Shakespearean texts are stable, that there is one "right" version.

For example, with Romeo and Juliet, I ask the students to describe the staging of the lovers' first encounter, beginning with Romeo's line, "If I profane with my unworthiest hand" (I, iv, 204). After a close reading and listening to their interpretations of the text, we discuss filmic and stage versions that may have informed and shaped their close readings. Then I show pages from the various editions. Oxford (1987) and the New Cambridge (2007) give the direction that Romeo will begin his lines "To Juliet, touching her hand" yet Folger's Romeo is a bit more aggressive, "taking Juliet's hand." Oxford (2000) offers no stage direction, and Riverside, Arden, and Pelican begin with a simple "To Juliet." Does he touch her hand, take her hand, or simply gesture toward it? Students understand quickly that editors and directors interpret the text differently, and they must confront how their own experience informs, or perhaps misinforms, their interpretation.

I ask students to describe the dramaturgy of this same scene. Oxford (1987) offers the direction "He kisses her" after "'Then move not while 
my prayer's effect I take'” (I, iv, 207) and "'Give me my sin again"” (I, iv, 221). Pelican writes it as "Kisses her," and Riverside writes it as "Kissing her." These are stylistic choices for the editors' stage directions, but the more contemporary No Fear Shakespeare (2003) for younger readers writes the direction "Kisses her" after "take" but changes the direction after "again" to "They kiss again." This caused one student who had read the play in that edition to question Juliet's agency and display of desire in that moment. Pablo Neruda's Spanish translation from 1964 includes direction for Romeo to kiss Juliet only once, "La besa," after twenty-one lines of dialogue (72-3). ${ }^{6}$ Although (and because) the sonnet's rhyme scheme and meter are not replicable in translation, students begin to apply their understanding of the scene from English to the Spanish translation; after discussing where the kiss should be placed when the stage directions of the sonnet form are absent, this dramaturgical choice maps back onto the scene in English in subsequent class conversations. Pelican offers a notably different direction: that he "Kisses her" after "purged" (rather than "take"). One student asked if this were an error, or just a less common perspective.

Through this exercise, the students see how cultural context, editorial biases, their own personal experiences, and their familiarity with filmic and other new media versions all inform their interpretation. After they have grappled with this, I then ask them, in groups, to write stage directions for this scene, and to determine where there are multiple possibilities and where there is no negotiation. When they share their work with the larger class, they demonstrate their ability to be makers of knowledge, and they gain confidence in their ability to question what was previously perceived as venerated authority or fact. Freire writes:

It is only when the oppressed find the oppressor out and become involved in the organized struggle for their liberation that they begin to believe in themselves. This discovery cannot be purely intellectual but must involve action; nor can it be limited to mere activism, but must include serious reflection: only then will it be a praxis. ${ }^{7}$

With multiple and sometimes conflicting authoritative statements on the same text, students must negotiate interpretation from "alternative fact." This process, the training of the discerning mind, is a necessary element of resistance to misinformation-and as counterpoint, also the foundation of civility toward diverse interpretations. As students must be trained to recognize truths from untruths, they will also be confronted with analyses and viewpoints that subvert dominant paradigms, and, for that reason, appear false. One part of identifying and refuting false 
information is examining how power structures reinforce conforming models; the other part involves welcoming perspectives that challenge these same paradigms.

\section{Language and Power}

While Shakespearean plots and language serve as a platform for learning to distinguish between fact and fiction, they also provide a necessary opportunity for discussing how characters know what they know. Words are used to manipulate, especially by those in positions of power. From Othello's "ocular proof" that falsely leads him to believe Desdemona is unfaithful, to Claudio's mistaken proof of Hero's infidelity, to Malvolio's confidence that the letter he finds is in Olivia's hand, Shakespeare points to the uncertainty of visual evidence. Similarly, Benedick and Beatrice overhear "the truth" about each other's feelings, and fall victims to a prank; Romeo hears and then sees the false news that Juliet is "dead," which drives him to suicide; and Shylock is misunderstood by those of a different cultural group and must clarify his meaning even though he speaks the same language. The consequences of misinformation vary from comedic to disastrous, but all are based on false truths or misreadings.

Resistance to "alternative facts" or "mis-truths" can be taught through analysis of characters who are swayed and confused by the rhetoric of others. For example, the opening of Henry $V$ illuminates how the Bishops of Canterbury and Ely will influence Harry to go to war with France. After Canterbury's confusing sixty-two-line explication of Salic law, even Harry, the king, needs to ask for clarification of whether he "with right and conscience [may] make this claim?" (I, ii, 96). Although Harry is king, he is still susceptible to manipulation by those in power such as the bishop and archbishop. Harry questions what he perceives to be true based on his own experience and education when he is confronted with the influential rhetoric of his elders, when they make a case for something that suits his (and their) self-interest.

For at least one class period per play, I devote a time slot to the question of what rhetoric drives a character to action, what language confuses characters, and what we know as readers versus as audience members. Twelfth Night offers an example of language that is meant to confuse for comedic and theatrical purposes. I instruct students to write down two or three notes or questions at the end of each scene or act, with the objective of tracing their knowledge of events clearly as the play progresses. In Twelfth Night, the students know after reading act 
I, scene $\mathrm{i}$ that Orsino is in love with someone named Olivia, who is in mourning for her deceased brother. At the outset of act I scene ii, they understand that Viola has been shipwrecked and her twin brother has died. But until the sea captain states that Orsino seeks "the love of fair Olivia" (I, ii, 33), the audience would think that this stranded woman, who quickly pronounces that her brother "is in Elysium" (I, ii, 4), is Olivia. Readers know that it is Viola for the first thirty lines because they can view the character's name in print. But the audience does not know that fact, and they will not hear Viola's name until Sebastian first speaks it at the end of the play (V, i, 231). The play's theme of identity confusion expands greatly with audiences unfamiliar with the story. What we know and what we assume (or think we know) after each scene are not one and the same. Distinguishing between exposition that includes information which all characters know and that which only some characters know highlights how language can be used to manipulate.

\section{Shakespeare for Everyone}

Creativity and out-of-the-box thinking are key components of social justice because they push forward the recognition and interplay of diverse groups. Beginning the study of a play with varied production clips offers performance as an educational heuristic. The idea of Shakespeare as a British import, English-language master playwright, and the figurehead of Western literary traditions comes into new focus when his works are performed by diverse peoples, internationally, interculturally, across languages, genres, and acting styles. For instance, the MIT Global Shakespeares webpage (globalshakespeares.mit.edu) offers free, accessible productions and clips from a breadth of nations and in different languages from around the world. While this disbands the hegemonic notion of universality, it also places divergent identities in conversation with each other to break down the myth of a homogenous U.S./U.K. Western tradition of Shakespeare.

When teaching Twelfth Night, for example, I use clips from an array of British and American films and productions to produce a new conception of national Shakespearean performance. ${ }^{8}$ From the U.K. I pull from Tim Supple's 2003 version staring Parminder Nagra and Chiwetel Ejiofor, Tim Carroll's famous all-male Globe production with Mark Rylance as Olivia, restaged in 2013, and Trevor Nunn's 1996 film with Imogen Stubbs, Helena Bonham-Carter, and Ben Kingsley. From the U.S., I contrast Nicholas Hytner's 1998 Lincoln Center production-turned-TV-movie with Helen Hunt and Kyra Sedgwick with 
Peter Novak's 2000 filmed staging of the play translated into American Sign Language. I prioritize the films that foreground people of color and people with disabilities, returning to them repeatedly so that students see both a demographic diversity with Western English-language Shakespearean performance and also a diversity of interpretations. This strategy puts the playwright and film director on equal par to negotiate characterization and staging; it further positions the student as a critic who engages with the play cross-culturally and cross-linguistically before approaching the written text.

The students in my theater-based critical studies classes engage in collaborative dramaturgical exercises with each other through assignments that are governed by rules of genre and structure and attempt to disrupt problematic hierarchies. For example, I have the students work in groups to outline how they would tell the story of Twelfth Night in the style of a ten-minute silent film. This exercise requires students to evaluate the structure of Shakespeare's play and transpose it into a condensed and different form, and one without language at all; this is a process which displaces the hegemony of English in Shakespearean performance. It also destabilizes the supremacy of contemporary acting methods, many of which have biases that favor particular demographics, as silent film acting does not cohere with modern conservatory-style training. I then show Eugene Mullin and Charles Kent's twelve-minute 1910 silent film, and we roundtable as a class to compare the arguments about the key components that constitute the story. While this exercise has much to do with plot, structure, and genre, it also removes language, accent, and actor training from shaping ideas about who Shakespeare is for and by. Once the plays are stripped of the hegemonic forms that often dominate their production, a more equitable Shakespeare emerges. This exercise serves as a model for dismantling ideas about tradition that are presented as fact and thinking outside of the dominant narrative toward a path of inclusion.

\section{Conclusion}

Teaching Shakespeare requires a confrontation with our own education and oppression, for I was one of the oppressed, too. The claims I revered as facts were not all as stated, and I experience the sadness of realizing that my scholarly inquiry at times leads to great conflict with those analyses that shaped my passion for this field. Freire writes of the "existential duality of the oppressed, who are at the same time themselves and the oppressor whose image they have internalized." As we strive as 
educators to advance conversations on age-old topics, to develop and apply theoretical lenses, to revisit histories for absences and oversights, we, too, are confronted with the discomfort of change.

The change may happen for us as researchers, as the demographics of Shakespearean scholars change, as the foci change. But the questions of what we know for certain versus what we can argue well will truly arise through teaching, through working with our students and getting them to do this work themselves. Freire notes, "It is only the oppressed who, by freeing themselves, can free their oppressors." ${ }^{10}$ As park rangers, librarians, and museum curators increasingly make public political statements alongside politicians, celebrities, and playwrights, students must be better prepared for resisting misleading or false information. Teaching Shakespeare provides a wealth of opportunities for engaging in this conversation, and his plots show the consequences of fictions mistaken as facts. Teaching social justice is a part of teaching Shakespeare.

\section{Notes}

1. Elizabeth Flock, "Why These Librarians Are Protesting Trump's Executive Orders," PBS NewsHour, February 13, 2017 < https://www.pbs.org/news hour/art/librarians-protesting-trumps-executive-orders $>$ (accessed February 25,2019$)$.

2. Carl T. Bergstrom and Jevin West, "Calling Bullshit in the Age of Big Data," 2017 < https://callingbullshit.org> (accessed February 25, 2019).

3. In line with Freire's seminal 1970 book, Heather W. Hackman's 2005 essay and Ayanna Thompson and Laura Turchi's 2016 book on contemporary pedagogies for Shakespeare at the university level advocate for student empowerment in the learning process both as a means to develop critical analysis skills but also as an essential tool for breaking down identity barriers and critiquing problematic historical interpretations that perpetuate stereotypes and colonial discourses. Paulo Freire, Pedagogy of the Oppressed, trans. Myra Bergman Ramos (New York: Continuum, 2000); Heather W. Hackman, "Five Essential Components for Social Justice Education," Equity and Excellence in Education 38 (2005): 103-9; Ayanna Thompson and Laura Turchi, Teaching Shakespeare with a Purpose: A Student-Centered Approach (London: Bloomsbury Arden Shakespeare, 2016).

4. Freire, Pedagogy of the Oppressed, 53.

5. "Introducing the YouTube U.S. Election Hub," YouTube, August 21, 2012 <https:/youtu.be/Ktkx1D0huTA> (accessed February 25, 2019).

6. William Shakespeare, Romeo y Julieta, trans. Pablo Neruda (Buenos Aires: Editorial Losada, 1964). 
7. Freire, Pedagogy of the Oppressed, 65.

8. This is in line with Homi K. Bhabha's idea of the "third space," "a performative site where national culture is not merely reflected, but actively produced." See Homi K. Bhabha, The Location of Culture (Abingdon: Routledge, 2004 [1994]); and George Richardson, "Singular Nation, Plural Possibilities: Reimagining Curriculum as Third Space," in Curriculum as Cultural Practice: Postcolonial Imaginations, ed. Yatta Kanu (Toronto: University of Toronto Press, 2016), 290.

9. Freire, Pedagogy of the Oppressed, 61.

10. Ibid., 56. 


\section{Literary Justice: The Participatory Ethics of Early Modern Possible Worlds}

\section{Debapriya Sarkar}

In an era that increasingly turned to empirical methods to understand the physical universe, early modern poets and dramatists reveled in the unseen, the intangible, and the unverifiable. This tendency repeatedly converges around the idea of possible worlds. As Philip Sidney declares in the Defence of Poetry (1595), the poet deals with what "may be and should be." Sidney's contemporary Edmund Spenser refines the formulation, claiming that The Faerie Queene depicts what "might best be" rather than prescribing what "should be." Several decades later, Margaret Cavendish deploys possibility to underscore an egalitarian principle of creation in The Blazing World (1666): anyone "may create worlds of their own." ${ }^{3}$ We could dismiss the pervasiveness of the language of possibility—what "may" or "might" be—as a wish to escape from reality, given that it lacks grounding in the material world and thereby seems dissociated from social concerns. William Shakespeare's Theseus adopts this stance in A Midsummer Night's Dream, mocking the poet who "gives to airy nothing / A local habitation and a name" $(\mathrm{V}, \mathrm{i}, 16-17) .^{4}$ Yet, in devaluing the insubstantiality of imaginative world-making, Theseus obfuscates — or misses — the ends to which early modern poiesis was often directed: as forms of engagement with what might or should exist that spark desires to reshape actuality.

Such discourses of possible worlds afford students and teachers distinct opportunities to excavate literature's potential for social justice. Early modern writers invite such examinations as they outline their creative goals. Sidney claims that poesie guides readers to praxis as well as gnosis; Spenser declares his allegory will "fashion a gentleman or noble person in vertuous and gentle discipline." ${ }^{5}$ Adapting the Horatian dictum to teach and delight, these authors model what I term a participatory readerly ethics, where imaginative projections motivate an engaged public life. This phrase captures the continual interplay of 
reading and writing that characterizes crucial aspects of early modern literary culture. Writers engage in acts of world-making with the tacit knowledge that their fictive worlds, incomplete and visionary, will be remade by various reading publics. Intended and unexpected readers accept these implicit invitations to modify the authorial worlds. I suggest we harness for pedagogical ends the ethical ethos underlying such acts of projection. Not all readers are in direct conversation with each other or with the authors of the original works. Nor are they all committed to a particular ethical stance or calls for social justice. But by collectively revising, reframing, and expanding the parameters of already fabricated worlds, they become co-creators of a culture in which reimagination, conversation, and participation become the norm. Often, marginalized voices find new avenues for expression, and propose radical approaches to social reform, within this participatory culture of readerly writing. Thus, these intertexts - which can extend across generations, nationalities, and languages-become repositories for profound rethinking on issues of class, race, gender, and privilege.

To underscore that participatory readerly ethics haunts much of early modern literature, I suggest we expose students to a wide range of literary genres-from prose utopias to Shakespearean drama to allegorical epic-romance-that seem particularly self-aware of or overtly dramatize imaginative projections; often, they provoke readers to redraw the parameters of fabricated worlds. The texts that I examine in this chapter serve as the blueprint of a syllabus that illustrates the ubiquity of participatory readerly ethics in Renaissance thought. Because of their direct or imagined interactions with readers across space and time, these works are ideally suited to highlighting how premodern literature can impact our public discourse.

Using the novel as her case study, Martha C. Nussbaum argues that "literature ... has the potential to make a distinctive contribution to our public life." She outlines "characteristics of the literary imagination as a public imagination, an imagination that will steer judges in their judging, legislators in their legislating, policy makers in measuring the quality of life of people near and far." A similar ethos undergirds early modern works that, without prescribing particular arenas of public life into which a "gentleman or noble person" must enter, nevertheless animate readers to inquire how imaginary "golden" worlds can affect the "brazen" world they inhabit. ${ }^{8}$ World-building activities grounded in possibility, that is, in the "may," "might," and "should," are particularly suited to broaching questions of ethics, since in using these terms authors are always making normative judgments. Their ruminations on creation are not only aesthetic representations, intellectual thought 
experiments, or defenses of fancy. They also reveal how imagining potential, uncharted, unmappable realms raises critical questions of social justice.

While the philosophical discourse of possible worlds might be alien to students, they are often well-versed in examples on the topic because of their experiences with online fan fiction or immersive video games. Thus, a study of early modern world-making provides them with new ways to consider long histories of what they already recognize to be the participatory spirit of many imaginative ventures. According to Nussbaum, "literary imagination" is "an essential ingredient of an ethical stance that asks us to concern ourselves with the good of other people whose lives are distant from our own." By linking early modern fiction-making to students' interests in participatory communities, we can help them inquire who has access to and authority over cultural production, and whether radical communities and unprecedented social organizations of fiction can mobilize audiences toward a just world. Through such investigations, students uncover the mechanics of early modern world-making and learn to apply these "distant" imaginative techniques in their own constructions of just futures.

To incorporate early modern culture's participatory readerly ethics into our pedagogy, I propose we cultivate instructional practices that invite students to identify with the reader who inhabits the role of constructing, maintaining, and furthering imaginative projections. Occupying the perspective of the participating reader, students grasp how possible worlds discourse is vital both to the processes and to the ends of fiction-making. Literature should "move men to take that goodness in hand," writers claim, or it should direct their "good endeuours." 10 Early modern literature thus offers particular historical and conceptual illustrations of the broader literary aim of activating readerly fancy, when in "their very mode of address to their imagined reader, [literary works] convey the sense that there are links of possibility, at least on a very general level, between the characters and the reader." ${ }^{11}$ Such "links" make the "reader's emotions and imagination" "highly active"; Nussbaum locates in this activity the "relevance for public thinking." 12

As teachers, we can cultivate tools, strategies, and practices that direct the "links of possibility" between text and reader toward specific goals. First, we should provide a broad array of case studies, making students think critically about exemplary textual instances that can help model our practices of social engagement. Next, we must develop activities that provoke students to bridge the gap between the theoretical effect of being moved when reading and the praxis that is supposed to follow from this experience. Indeed, this link between theory and practice 
is critical, and I model this translation in the intertextual examples I provide below. Finally, we must emphasize that early modern possible worlds are not only sites of infinite promise, but also cautionary tales: the imaginative tendencies that fueled the ambitions of "worldmakers"13 also summoned readers to participate in discovering and conquering distant realms. Since that which seems positively ethical could be negatively imperial, it is imperative that students recognize how poiesis is enmeshed with longings to rule, and that they develop interpretive practices that inculcate a desire to change the world without unilaterally imposing their will on it.

To establish the prevalence of participatory readerly ethics, we should introduce students to case studies that demonstrate how the discourse of possible worlds generates communities of readers who produce new, often unexpected, acts of world-making. I suggest we begin with the seminal Renaissance text of fictionality and community formation: Thomas More's Utopia (1516). The work's ontological crux centers on Utopia's unknown location (the fictional "no place" is presented as real), and the title's punning on eu-topos intimates its ideality. More's readers embrace their role of searching for this ideal through elaborate imaginative projections. We can highlight this activity by directing students to the words of humanist Peter Giles to Jerome de Busleyden. Giles explains that the "difficulties about locating the island" result from an "accident": as Raphael Hythloday was imparting this information, "one of More's servants came in to whisper something in his ear," distracting him at the very moment when another person in the audience "coughed so loudly that some of Raphael's words escaped me." ${ }^{14}$ Giles overcomes an impossibility-fictional islands cannot be located - by building a scene. In his expanded version, he introduces a new character (the servant) and a new situation-someone had caught a cold. Any lesson on Utopia must acknowledge such games of fictionality. But to foreground its participatory readerly ethics, we must also approach these games as examples of the creative power the text grants its readers.

Giles functions as a surrogate reader whose inability to find Utopia cements the ontological gap between existing and fabricated worlds. Instead of experiencing this indeterminacy as a problem, Giles discovers in it a discursive space for creation. Using this insight, students begin to recognize that Utopia's - and by extension fictional worlds'-distance from actuality is a necessary precondition to transform readers into co-creators. The aspiration to complete unfinished narratives makes participating readers forge communities. Students see such a community thriving in Utopia's paratexts, where humanists expound desires 
to access the eu-topos. The French humanist Guillaume Bude laments, "Hythloday has not yet told exactly where [the island of Utopia] is to be found." 15 The Dutch humanist Gerard Geldenhouwer declares that if readers seek both "pleasure" and "profit," they need only turn to Utopia, since "on this island, both will appear." ${ }^{16}$ Giles voices a universal yearning: the "Island of Utopia . . . should be known by everyone." ${ }^{17} \mathrm{Re}-$ constructing the contours of this ideal commonwealth, Utopia's readers refine what reality "should" be. Their approaches epitomize the "links of possibility" that activate readers' "emotions and imagination." Examining such "links," students begin to understand how indeterminacy in fiction galvanizes disparate individuals to propose perfected versions of actuality.

We could dismiss Utopia's exclusive collective of male humanists by emphasizing that communities often police themselves, allowing only certain members entry into a participatory culture. Yet, I suggest that we do not conclude our instruction by focusing on such exclusionary principles. Instead, we should stress that by assembling participants, the actions modeled in Utopia lay the foundation for one of the most audacious experiments of early modern world-building: a wide range of readers transform themselves into creators because unrealized worlds of fiction call out to be "perfected"-or completed. ${ }^{18}$ The instructor's task is to provide students with diverse instances of readers-turned-writers who embrace the logics of incomplete fictional worlds to assert their own voices. We can offer varied examples of participatory readerships: the continuation of possible worlds was explicit-see Anna Weamys's A Continuation of Sir Philip Sydney's Arcadia (1651)—and coded-as in Mary Wroth's Urania (1621), which rewrites episodes from Arcadia and Faerie Queene. The reimagination of imperfected worlds also operates through titular invocations-Delarivier Manley borrows Bacon's title for her political satire The New Atalantis (1709) — and by appending content-New Atlantis. Begun by the Lord Verulam, Viscount St. Albans: And Continued by R. H. Esquire (1660) offers a completed political structure of Bacon's technocratic state. Acts of reading move these readers to a distinct act: they remake the literary worlds of the original texts. In introductory classes it would be sufficient to expose students to the titles and short excerpts from these works so they comprehend the concept of participatory readerly ethics. However, a senior seminar on "Early Modern Possible Worlds" affords the chance to delve deeper into these issues by pairing Weamys's work, or Wroth's romance, with Arcadia.

Placing less familiar "perfections" alongside more canonical "original" texts in our syllabi, we ask students to grapple with an 
unconventional constellation of co-creators: How can marginalized groups lay claim to authorship? Who is licensed to define the parameters of a world? In environments where not all readers have equal power, can informal networks activated by fictional continuations generate new modes of authority and animate new publics? Modeling such questions is especially productive for courses on "Women Writers" or "Gender and Authorship." Often identified as ideal readers of ostensibly less serious works ${ }^{19}$ women flourished as readers-turned-creators: incomplete fictional worlds became their vehicles to exert their authorial personae and visions. Reading continuations by female writers - figures still treated as marginal in theorizing world-making - students encounter an expanded range of voices that comprise the era's literary corpus. They begin to confront the instability of the "canon" as they see how apparently exclusionary paradigms (of male humanist circles, or Shakespeare's individual genius) were added to and built upon by reader-authors who made other futures possible.

These continuations demonstrate that the impetus to create is transferable, from authors like More, to readers-turned-writers like Weamys, and thereby to students. The logical extension of this kind of instruction involves getting students to imitate readers who go on to form communities of creators. In other words, we must encourage students to become co-creators. I stress to them that they can re-create the participatory readerly ethics that animated early modern reader-authors. To this end, they undertake exercises in which they create fictional worlds to address questions of social justice, modeling the kind of "participatory culture" that Ayanna Thompson and Laura Turchi advocate. ${ }^{20}$ I compare such activities to structures of continuation, adaptation, and completion with which students might already be familiar (through user- and fan-generated media). This practical aspect has taken different forms in my classes. In "Global Shakespeare" and "Renaissance Drama" they script an "Unstaged Scene"- a scene that is mentioned, dreamt, or reported but that does not find "local habitation and a name"-from a play and stage it at a specific location on campus. This task makes them reflect on theater's collaborative practices; their search for an ideal staging-ground demands they cogitate about spaces-institutional, domestic, or public - that theater manifests. Through such collaborations, student-creators tap into the open-endedness at the heart of possible worlds discourse by exploring their own public engagements with past, present, and future.

Such examples and methods show students how possible worlds discourse can promote inclusive practices: the topic's capaciousness makes its capacities for invention and reconfiguring publics seem boundless. 
But to emphasize only its affirming aspects - the ways in which it facilitates the emergence of an equitable world-would give students an incomplete picture of the scope of early modern poiesis. Often, it is impossible to untangle imaginative projections from fantasies of power. The unjust desires that led to "terrible exploitations of people, nations, land, and resources" also sparked "efforts of the imagination to see and yearn past the bounds of the known and approved." 21 Thus, to gain a comprehensive understanding of the early modern imaginary, students must encounter its dark side, which thrives on tropes of racial othering, nationalistic pride, and colonialist ambitions. Sometimes, the gaps between history's "bare Was"22 and "what may be and should be," instead of furthering ethical practices, harbor seeds of injustice.

To foreground the tensions between world-making and injustice, I turn to The Tempest, which contends with these issues in powerful ways. Reading Shakespeare's play after studying inclusionary aspects of possible worlds discourse forces students to grapple with its imperialist ethos. Students witness this contradiction in Prospero, who controls events on the island-theater. He is world-maker par excellence. But, as I highlight, Prospero's power over stage direction is inseparable from his role as colonizer: he forces Ariel and Caliban-who have prior claim to the island-to do his bidding. To emphasize how the play's fantasies of sociopolitical ideals are corrupted by cravings for power, I make students turn to its most famous instance of imaginative projection. The courtier Gonzalo imagines a rulerless state: "I' the commonwealth I would by contraries / Execute all things." He conjures a perfect place of shared resources and authority, banishing trappings of power. This realm, he concludes, will have "No sovereignty." But Sebastian immediately counters Gonzalo- "Yet he would be king on't" (II, i, 144-51). ${ }^{23}$ Gonzalo's emphasis on his agency as the commonwealth's creator belies the egalitarian principle of his speech. This paradoxical moment can lead to productive conversations in the classroom: What is the responsibility of the individual to the collective? When absolute control is determined by one's imaginative reach, can one truly eliminate illusions of authority?

Gonzalo's model of an unidentifiable and uncharted society-a utopian desire, More's humanist friends would say - traffics in concrete questions that fascinated Shakespeare's contemporaries on Europe's relation to far-flung realms. To establish this porosity of fictional and nonfictional accounts, I share with students (many of whom are new to The Tempest) excerpts from writings that are accepted as the play's intertexts-from Montaigne's essay "Of Cannibals" (from which Shakespeare derives Gonzalo's speech) to William Strachey's True 
Reportory of the Wrack (1610), the account of a 1609 shipwreck from which Shakespeare might have drawn inspiration for the opening storm. Such connections underscore The Tempest's investment in contemporary travel and colonial ventures. Entering the play through Gonzalo's speech and encountering its intertexts, students confront the intertwinings of power and imagination. Ideally, this recognition makes them interrogate their own relations to power and inquire how their creative acts can become more equitable and just.

In advanced seminars, we can include additional readings to illuminate how writers deployed similar narrative strategies to blur lines between imagination and reality: thus the fictional Utopia became "the first piece of travel literature produced in England's Age of Discovery,"24 while travel writings including Thomas Harriot's A Briefe and True Report of the New Found Land of Virginia (1588) played on tropes of fictionality by "inser[ting] hypothetical goods and actions into its catalogues of American abundance." 25 The variety of texts-from Harriot's voyage narrative to Bacon's essay "Of Plantations"-underscores that possible worlds discourse was enmeshed in constructions of European identity: it helped demarcate inhabitants of non-European realms as nonhuman others one encountered in fiction, even as expansive forms of poiesis envisioned new ways to restructure these regions according to European norms.

Since creating a just world requires the dissociation of fancies from impulses to conquer, it is valuable to consider a limiting case: what does it mean when imagination becomes the foundation for discovery or colonization? To answer this question, students could turn to Spenser's epic-romance, whose narrator challenges naysayers dismissing Faerie Land as falsehood: "Sith none, that breatheth liuing aire, does know, / Where is that happy land of Faery." Instead, he argues, "daily"

Many great Regions were discouered, Which to late age were neuer mentioned.

Who euer heard of th'Indian Peru?

Or who in venturous vessell measured

The Amazons huge riuer now found trew?

Or fruitfullest Virginia who did euer vew?

Yet all these were when no man did them know,

Yet haue from wisest ages hidden beene

And later times thinges more vnknowne shall show. ${ }^{26}$

His argument is similar to those made by Utopia's readers, who championed the island's discoverability. Yet, instead of emphasizing Faerie 
Land's "no-placeness," Spenser's narrator situates it among recent discoveries. Unlike More's theoretical ideal, The Faerie Queene's list of known territories becomes a call to action. This description makes students confront the logical end-point of unbridled imagination, which aims to turn readers not into fiction-makers but into shapers of actuality who colonize "brazen" realms. The nationalist Protestant epic intertwines the ethical promise of readerly motivation with dark yearnings of conquest by challenging readers to imitate travelers. Here, students witness the grimmest aspect of early modern poetics: unleashing fancies, colonizing readers can ensure that a possible world of fiction today will become a mapped space that bends to the desires of European projectors.

Studying possible worlds emerging in an era of profound religious, political, and epistemological turmoil, students confront both the promise and the dangers of exceeding current conditions of existence. I have listed texts, problems, and assignments to incorporate in our instruction, but I would like to end on a more speculative note by envisioning exercises that might further orient this modality of learning toward issues of social justice. We could ask students to retell canonical accounts from the perspective of marginal characters: how would the "servant's" narration of Utopia differ from that of the humanist scholar? Such an account would allow students to examine the questions of status and class that do not immediately concern More's direct interlocutors. Moreover, since our students thrive by creating content across media, we could develop assignments that enable them to select excerpts from early modern works that seem ripe for social commentary and then re-present these selections in different formats (from chapbooks to online videos) that can be disseminated to wider publics. We could also emphasize the importance of creative components when introducing students to digital projects. For instance, we could use the recently launched Pulter Project, the latest example of how scholars are collaboratively recovering early modern women's voices. ${ }^{27}$ In their roles as participatory readers, students can construct narratives about Hester Pulter's formal education and her practical knowledge that are intimated by her poems - using her writing as the fragmentary evidence to fill out unknown components of her intellectual biography, we afford her work the same value women writers extended to male authors.

Such interactions with early modern literature's participatory culture can help students link matters of ethics-conceived to be the domain of the individual - to problems of communal, societal, and political import. By placing literary texts alongside philosophical works and historical documents, they conceptualize how our work in the classroom 
can reorient traditional topics of aesthetics, epistemology, and philosophy toward questions of social justice. Participatory readerly ethics ultimately exposes the radical potential of poiesis: our best engagements with imaginative writing should make us strive to form physical or virtual publics that can transform what actual futures might be.

\section{Notes}

1. Philip Sidney, A Defence of Poetry, ed. Jan Van Dorsten (Oxford: Oxford University Press, 1966), 26.

2. Edmund Spenser, "Letter to Raleigh," in The Faerie Queene, ed. A. C. Hamilton, Hiroshi Yamashita, and Toshiyuki Suzuki (Harlow: Longman, 2001), 716.

3. Margaret Cavendish, The Blazing World and Other Writing, ed. Kate Lilley (New York: Penguin, 1992), 225.

4. All Shakespeare quotations come from The Norton Shakespeare, 3rd edition, ed. Stephen Greenblatt et al. (New York: Norton, 2016), and will be cited parenthetically.

5. Sidney, A Defence of Poetry, 29; Spenser, "Letter to Raleigh," 714.

6. Martha C. Nussbaum, Poetic Justice: The Literary Imagination and Public Life (Boston: Beacon Press, 1995), 2.

7. Ibid., 3 .

8. Sidney, A Defence of Poetry, 24.

9. Nussbaum, Poetic Justice, xvi.

10. Sidney, A Defence of Poetry, 27; Spenser, The Faerie Queene, III, iii, 25.

11. Nussbaum, Poetic Justice, 5.

12. Ibid., 5 .

13. See Ayesha Ramachandran, The Worldmakers: Global Imagining in Early Modern Europe (Chicago: University of Chicago Press, 2015).

14. Thomas More, Utopia, ed. George M. Logan and Robert M. Adams (Cambridge: Cambridge University Press, 1989), 121.

15. Ibid., 116.

16. Ibid., 125 .

17. Ibid., 120.

18. See "perfected, adj.," OED Online (Oxford University Press) <https:// www.oed.com> (accessed September 1, 2017).

19. Sidney tells his sister, Mary Sidney, that his "idle work" was "done only for you, only to you." Philip Sidney, The Countess of Pembroke's Arcadia, ed. Maurice Evans (New York: Penguin Classics, 1977).

20. Ayanna Thompson and Laura Turchi, Teaching Shakespeare with a Purpose: A Student-Centered Approach (London: Bloomsbury Arden Shakespeare, 2016), 4. I expand their "informal learning communities" beyond the "Shakespeare classroom" and beyond dramatic texts. 
21. Mary B. Campbell, Wonder and Science: Imagining Worlds in Early Modern Europe (Ithaca: Cornell University Press, 1990), 1-2.

22. Sidney, A Defence of Poetry, 36.

23. William Shakespeare, The Tempest, ed. Stephen Greenblatt et al., The Norton Shakespeare (New York: Norton, 2016).

24. Mary B. Campbell, The Witness and the Other World: Exotic European Travel Writing, 400-1600 (Ithaca: Cornell University Press, 1988), 212.

25. Mary C. Fuller, Voyages in Print: English Travel to America, 1576-1624 (Cambridge: Cambridge University Press, 1995), 13.

26. Spenser, The Faerie Queene, II, Proem 1-3.

27. The Pulter Project: Poet in the Making, general editors Wendy Wall and Leah Knight <http://pulterproject.northwestern.edu> (accessed February 25, 2019). 
Shakespeare, Service, and Community 



\section{Shakespeare, Service Learning, and the Embattled Humanities}

Hillary Eklund

In a cultural landscape increasingly suspicious of higher education and of the utility of the humanities, the study of Shakespeare has been cast as - at best-a kind of benevolent excess. The head of Georgetown's Center on Education and the Workforce, for instance, recently advocated that students review their "employment and wage prospects" before choosing a major. "We don't want to take away Shakespeare," he said. "We're just talking about helping people make good decisions." And while Shakespeare's still-elevated status in the curriculum may protect our subject from the kind of targeted criticism lobbied at French, philosophy, and gender studies, professors of early modern literature would nonetheless do well to think about how we frame our subject's relevance to the wider world. ${ }^{2}$ Cultural debates about Shakespeare and the humanities afford an opportunity, in fact, to rethink a narrative of relevance that values direct application of course content to 'real world' scenarios, and which tends to privilege STEM fields accordingly.

Community engagement pedagogy provides one avenue for reshaping this narrative of relevance without recourse to defensive strategies that rely on a corporatist model of education (e.g. the marketability of hard skills like writing). In particular, service learning-a community-based learning experience that connects classroom topics to the real worldallows students to understand and address social problems, develop new ideas and attitudes about the world, and reflect on how those attitudes are formed and reformed through experience. In addition to teaching students about social justice, service learning can offer ways to answer the persistent question that dogs the humanities and, more specifically, literary studies: of what use is an English degree, or even literature itself, beyond the classroom? ${ }^{3}$

In this chapter I reflect on my experience with service learning and Shakespeare to explore the relationship between pedagogy, community 
engagement, and the relevance of the humanities in higher education and beyond. ${ }^{4}$ I argue that when we free ourselves from the burden of proving the relevance of Shakespeare in our world, and instead prioritize critical reflection on students' responses to their encounters with texts and with the community, we heighten both the intellectual and the civic stakes of our teaching. Both reading Shakespeare and serving in one's community help build frameworks for seeing how aspects of the social order are created and maintained. ${ }^{5}$ Comparing the structures of influence they find in their reading with those they witness in the community, students often find points of connection among them. Moreover, because these connections are more diffuse in a Shakespeare class than in some other academic settings, the process is often enriched by uncertainty. ${ }^{6}$ Ultimately, service learning affords a vocabulary for reframing higher education as an experience plotted in a particular environment and designed to enhance students' intellectual and civic identity within it. Below I outline how I have structured service learning in two Shakespeare courses and show, through my students' own writing, how they addressed the question of Shakespeare's relevance.

\section{Plotting Experience}

I teach at Loyola University New Orleans, a Jesuit university with a social justice mission. In this context, service learning is a key part of the school's educational mission, not a missionary activity on its own. It posits that service is best practiced and understood through the intellectual habits of critical thinking and reflection. Assuming that the benefits of service learning should be bilateral, the school builds partnerships with community agencies based on collaboration and reciprocity rather than on unidirectional models of service or volunteerism. Community partners and faculty collaborate in the Jesuit ideal of cura personalisthe education of the whole person. The aim is to engage students in intellectual formation through action and contemplation: exploring and interrupting the dynamics that create social problems, then reflecting on their evolving understanding of those problems. ${ }^{7}$ As students construct intellectual frameworks for the study of Shakespeare through reading and analyzing Shakespeare's works, they hone their ability to address social problems through service. Topical links between the two invite students to bring those frameworks to bear on one another. In this sense, service learning is oriented less specifically toward immediately measurable outcomes (for the agency, its clients, or the students) than around process and inquiry. 
Many students start out thinking of community engagement as a relatively straightforward way to "help people" and "be a good person." Yet service learning and other community engagement pedagogies present serious ethical challenges: How sustainable will students' engagement be after a semester's worth of service hours tied to academic credit? Do academic institutions support a culture of service or merely recognize good deeds? How closely connected are learning outcomes to students' experience in the community? Service activities directly tied to course material or discipline can carry heightened ethical risks because they affirm students' educational choices and existing knowledge. ${ }^{8}$ In a Shakespeare course, such activities might involve students as teachers (of literacy skills, language, or drama) or ambassadors of culture (expanding access to Shakespeare as cultural capital). As Matthew Hansen has written of his own Shakespeare students' "Shakespeare for Kids" program in an inner-city elementary school, "Improving access to Shakespeare does not challenge the perceived cultural capital associated with the playwright and his works." 9 Positioning students as the bearers of knowledge or competencies that others lack may prompt them to want to make others more like themselves. And though students may experience the disorientation of entering new contexts, the primacy of Shakespeare and Shakespeare's legitimizing effect on their service endeavors risk going unquestioned.

With this stew of educational goals, ethical commitments, and wariness of the "helper mentality" in mind, I organized my fall 2011 "Early Shakespeare" course around the theme of possession and dispossession; we explored the material, social, erotic, and political conditions that shape Shakespeare's characters, their relationships to one another, and their place in the wider world. In many respects, the course structure was traditional, with a blend of lecture and discussion, written analysis, and exams. For me, it was important to maintain the rigorous content and methods I had honed in my early career years. At the same time, I wanted to explore Shakespeare's wider reach in the context of Loyola's social justice mission and New Orleans' own vivid manifestations of possession and dispossession. Out of consideration for my own steep learning curve and the complicated schedules of my students, who juggle course work with jobs, commutes, family obligations, and rehearsals, I made service learning optional. Students who opted for service learning chose from a list of available placements working on issues ranging from immigration, substance abuse, and environmental degradation to disability and domestic violence. ${ }^{10}$ The service learners served twenty hours in their placements and wrote four blog posts responding to specific prompts about their experience: 
1. Discuss how/why you chose your placement and what you expect from it.

2. Describe your service learning experience thus far. What have you learned about the assumptions and expectations that you brought to this placement? Have those assumptions changed? What surprises, disappointments, successes, or challenges have you faced in your placement?

3. How do people in your placement react when you mention that you're there as part of a Shakespeare course? How do you explain the connection? How, if at all, has your work in the classroom informed your approach to service learning? What place does Shakespeare have in the "real world"?

4. What have you learned through your service learning placement? How, if at all, has your understanding of the issues that motivated you to choose this placement changed? How does your experience compare to the topics we have explored in Shakespeare's works?

Students who opted out of service learning chose a critical concept (such as desire, race, rank, or labor) to track through the semester's readings in a series of ten blog posts. Two days of class - one at mid-semester and one near the end-were devoted to discussions in which service learners and critical concepts bloggers collaboratively reflected on their work.

The main thing I learned from my 2011 experiment was that productive critical reflection takes considerable planning and time. Though I set aside discussion days with specific questions, I relied too much on students' readiness to unpack their assumptions and reflect on the intellectual frameworks they were building to toggle between the challenges of reading Shakespeare and the challenges of addressing critical social issues. The next time I taught the class, in fall 2014, I added more time for critical reflection and structured that reflection with readings and questions for students to prepare before discussion days.

In preparation for the first discussion day, I asked the entire class to $\mathrm{read} / \mathrm{watch} / \mathrm{listen}$ to three poems that articulate concerns about "helpers" and/or the "helper mentality" and to jot down some notes on one of them. ${ }^{11}$ I then asked all the students to review their early blog posts to explore what expectations and assumptions they brought to their placements or their concepts. In particular, I prompted service learners to think about the language they used to talk about their role in their placements and the people their agencies served. Among the students' most powerful tools for parsing their experience was the attention to language they were honing through their reading of Shakespeare. Training their critical eyes not on other people or even institutions but instead on their own forms of engagement with others allowed service 
learners to catch assumptions they made about the agencies and their clients, as well as to notice the oblique language they used for things that made them uncomfortable, like traveling into poor neighborhoods or struggling to connect with people across differences in age, race, and socioeconomic status. They used these insights to make their writing more specific and ultimately more honest. In addition, they began to think through the communication strategies that people employ for different purposes. Newly attentive to things like code switching, they saw how even our language is structured around the social constructs of race and class. Finally, I invited all the students to think about bridging this intellectual work with the Jesuit ideal of being people "for others." Did their experience and reflection show their lives to be bound up with those of the people they encountered in their placements? In what ways did the relationships they forged through service learning motivate them to transform the world? As they gathered in small groups, the students compared their responses to the prompts I had given them.

During the larger group discussion, we listed the benefits students identified from their work, and then spent some time finding points of commonality among their learning experiences so far. Many students mentioned shifting perspectives as one of the clearest benefits. Service learners compared their attempts to see the world from the perspective of the clients in their agencies to reading literature, which often draws us to a perspective other than our own. Critical concept bloggers described unexpected manifestations of their concepts that complicated how they understood them. Both groups claimed keener attention to the relations between individuals and societies and the forces that shape those relations. And both groups reported that, as they went along, they were learning how to get more out of their placements or their critical writing.

The second discussion day invited students to check in on the goals they had previously articulated for their service learning and critical concepts assignments. I asked them to select an event (for service learners) or a blog post (for critical concept bloggers) they found especially instructive or challenging, and prepare to discuss it. I also assigned an article from the New York Times about a performance of King Lear in a camp for Syrian refugees, and asked students to think about what claims the article made about the use of Shakespeare, what broader questions it raised about art, identity, performance, and suffering, and what benefits or drawbacks they saw in such a project. ${ }^{12}$ In small groups they talked about what helped or hindered them in meeting their goals, and they explored the insights and challenges, how they responded, and whether they would respond in the same way again. Most students admitted 
that if they had goals at the beginning of the semester, those goals had shifted. Their desires to "help others" and to "understand Shakespeare better" were shaken, especially for service learners, by a productive uncertainty about what either of those things entailed. However, no student expressed regret about their choice to serve or to blog, or their choice of placement.

From this place of shared but variable uncertainty we considered the performance of King Lear in the refugee camp. How, I asked, did the students' experience this semester shape their response to the article? Our conversation touched on questions of genre (can we call a civil war a "tragedy"?), Shakespeare's name recognition, and the implicit or explicit claims of cultural superiority it carries. The cultural encounter involved in that production of King Lear provided a platform for reconsidering the language of the Jesuit ideal of being people "for others": does it reinforce the self/other binary that students' reading, writing, and serving were breaking down? Or does it help us to reorient our "selves" around alterity? How successfully can we conscript Shakespeare as an instrument for such a reorientation?

\section{Recasting Relevance}

Both students and instructors involved in service learning can struggle to connect service experience with work in the classroom. While Mark Langseth describes a service learning project in which Shakespeare students who worked at a homeless shelter for men "suddenly could comprehend the lessons about power, physical decline, and redemption in the story of King Lear," few of us can expect such stark revelations. ${ }^{13}$ Laurie Grobman notes that the students in her multicultural literature courses tend to "mine the literature for answers and explanations" of social problems, as if there were a one-to-one correspondence between the theory of the text and a real-world application of it. ${ }^{14}$ There is a danger in assuming anything happens suddenly in service learning, or that any insights occur without guided reflection. The benefits of service learning do not map easily onto rubrics with measurable outcomes; instead, they evolve incrementally from a recurring loop of experience and reflection that seldom ends with final exams.

As both semesters progressed, my students adjusted what they were looking for and saw new connections. By the time I prompted them to initiate conversations in their placements about their service as part of a Shakespeare course, they had already reflected on the differences between what they expected and what they found in their placements. 
In some responses to this prompt, the label of Shakespeare catalyzed students' awareness of their privilege. Norah struck up a conversation with an attendee at the elder care center where she was serving and noted, "he nodded politely but was not very interested in pursuing a dialogue." To many of the elders, she supposed, Shakespeare had always been "reserved for the upper echelons, not something that has any real-world value for them." ${ }^{15}$ Norah's experience brought her face to face with her privilege as a student. Without a set framework for establishing the relevance of Shakespeare in her placements, she was able to look critically at the associations people have with the cultural institution of "Shakespeare" and the real and perceived ways that it can connect as well as divide.

Whereas connecting with individuals in their placements on the specific topic of Shakespeare proved difficult in some cases, several students saw connections in how they thought about the social problems they encountered in their reading and placements. At the legal aid agency where she served, Camille wondered at the motivations of employers who exploit their workers' labor. The clients, mostly undocumented low-wage workers, were especially vulnerable to being taken advantage of and often "have to conform to not being paid in fear of being deported." At first she attributed the employers' actions to sheer greed. But after exploring the motivations of characters like Shylock, Aaron the Moor, and even Richard II, she arrived at a different conclusion:

these questions are actually a lot harder to answer than they seem. Simply [saying] that people are "evil" and that it's all about greed is not good enough. The answer is a lot more complex and Shakespeare does a really good job of using different circumstances to describe a character's intentions.

For Camille, thinking carefully about Shakespeare's villains gave her a new way to think about questions of responsibility and blame in real-world contexts.

Even students in placements more directly tied to the study of language and literature dug deep to find less obvious thematic connections. Christine tutored two middle-school girls in a program that houses academically promising children from low-income families. When she first started out, she was surprised at the girls' positive attitude about being separated from their families:

Working with these girls, who have left their parents or family, may open a window into how separating from the past or from family in particular 
leads to a unique possession of the self and the future and what challenges come hand-in-hand with this growth ... [H] ow are Antipholus of Syracuse and Hermia's journeys different when we focus on the fact that they left behind their fathers and everything they knew to explore and discover pieces of themselves?

Rather than comparing actual people directly to characters in the plays, Christine considers the journeys her tutees have begun and the journeys undertaken by Antipholus and Hermia to better understand what is at stake in each. Each journey presents risk (to belonging, family stability, personal security) and reward (family reunification, love, academic achievement). Neither provides an interpretive key to the other, but each constructs a useful framework for addressing similar questions of displacement, belonging, and personal growth. Christine used the perspective she gained through service to rethink aspects of the plays she had read, and she did so without reducing the particularity of each situation.

As these examples suggest, students' attempts to locate the relevance of Shakespeare in the modern world led to some surprising conclusions. In relating their course work to their service learning experiences, they were free to explore the intellectual frameworks they encountered in and out of class as free-standing interpretive approaches to complicated social issues. This in turn allowed them to make thoughtful connections among those frameworks without identifying as ambassadors for Shakespeare or a particular kind of learning. It also, in some cases, spotlighted privileges that a more literally "relevant" service learning project might have concealed. Getting the most out of service learning in a literature course, as Grobman argues, requires exploring the space "between the literary text as a work of art and the literary text as a source of cultural or social truth." ${ }^{16}$ In other words, the interpretive practices that work best for processing service learning experiences have much in common with the interpretive practices we bring to literary works, but they do not bear tidy one-to-one correspondences. As The Taming of the Shrew's Christopher Sly learns that comedy "frame[s] your mind to mirth," so it goes with service learning: it is meant to frame students' minds to service, to reorient their intellectual selves toward serving others.

As my student Christine reflected,

We will never tie Shakespeare up nicely with a bow and say we understand it all now. My service learning experience is the same way ... I will be left with the question "What is the state of my community, and where do I fit in it?" 
That students linger with questions like this is one of the great benefits of service learning, and a model that decenters what we think of as the applicability or direct relevance of Shakespeare, I suggest, can go a long way toward helping students develop the critical imagination and comparative analytical skills so vital to the formation of engaged citizens. Quieting the treasure hunt for relevance also sheds light on the many other benefits of the humanities and liberal arts, including intellectual exploration, personal development, the fostering of an informed citizenry, and the promotion of civil discourse. Through study, service, and reflection, we reveal the embeddedness of humanist thought in unlikely arenas, moving from the local identification of relevance to the global practice of engagement. After all, Shakespeare's verse has feet-feet that are meant to move us to contemplation, to response, and to action.

\section{Notes}

1. Patricia Cohen, "A Rising Call to Promote STEM Education and Cut Liberal Arts Funding," New York Times, February 21, 2016, Business Day section <https:/www.nytimes.com/2016/02/22/business/a-rising-callto-promote-stem-education-and-cut-liberal-arts-funding.html> (accessed February 27, 2019).

2. Emphasis on workforce development in higher education, particularly where state funding for education is concerned, has been the focus of considerable debate in recent years. In a 2015 Republican Party primary debate, Senator Marco Rubio called for "more welders and less [sic] philosophers." Months later, Kentucky governor Matt Bevin proposed a plan to allocate state funding to higher education institutions based on the number of students they graduate in high-demand fields: in Bevin's words, "There will be more incentives to electrical engineers than French literature majors." Cohen, "A Rising Call."

3. Lesley Wheeler, "On Capstones, Service Learning, and Poetry," Profession 2010: 208.

4. For a review of the literature on service learning in literary studies and Shakespeare, see Matthew C. Hansen, “'O Brave New World': Service-Learning and Shakespeare," Pedagogy: Critical Approaches to Teaching Literature, Language, Composition, and Culture 11, no. 1 (winter 2011): 177-97.

5. Gregory Jay, "Service Learning, Multiculturalism, and the Pedagogies of Difference," Pedagogy: Critical Approaches to Teaching Literature, Language, Composition, and Culture 8, no. 2 (spring 2008): 258.

6. For more on productive uncertainty see Shari J. Stenberg and Darby Arant Whealy, "Chaos Is the Poetry: From Outcomes to Inquiry in 
Service-Learning Pedagogy," College Composition and Communication 60, no. 4 (June 2009): 683-706.

7. Peter-Hans Kolvenbach, "The Service of Faith and the Promotion of Justice in American Jesuit Higher Education," in A Jesuit Education Reader, ed. George Traub (Chicago: Loyola Press, 2008), 144-62.

8. Lesley Wheeler notes that "undergraduates find placements with young people incredibly rewarding, not least because this kind of community service affirms the value of their own educational choices" rather than challenging them to think in new ways. Wheeler, "On Capstones, Service Learning, and Poetry," 213.

9. Hansen, “'O Brave New World'," 181.

10. According to Marcy Schwartz, "Students who exercise agency in their community engagement adjust more smoothly and contribute more creatively to the partnership setting than do those who are assigned a placement." Marcy Schwartz, "Public Stakes, Public Stories: Service Learning in Literary Studies,” PMLA 127, no. 4 (October 2012): 990.

11. I am grateful to Kelly Brotzman for these suggestions: Building Changes, "My Name Is Not 'Those People,"” 2009 <https:/www.youtube.com/ watch?v=hQWbkVqZKeo>; Rachel Smith, "Hallelujah the Saviors Are Here," 2012 <https://www.wbez.org/shows/wbez-news/hallelujah-thesaviors-are-here/b7b4d9b1-39b6-4984-ae80-7440738601a8>; Gwendolyn Brooks, "The Lovers of the Poor," Poetry Foundation, October 6, 2017 <https://www.poetryfoundation.org/poems/43317/the-lovers-of-thepoor $>$ (all accessed February 27, 2019).

12. Ben Hubbard, "Behind Barbed Wire, Shakespeare Inspires a Cast of Young Syrians," New York Times, March 31, 2014, Middle East section <https:// www.nytimes.com/2014/04/01/world/middleeast/behind-barbed-wireshakespeare-inspires-a-cast-of-young-syrians.html> (accessed February 27, 2019).

13. Mark Langseth, "From Shakespeare to Chemistry: Service-Learning and Academic Pursuits," Thresholds in Education 22, no. 2 (May 1996): 22.

14. Laurie Grobman, "Is There a Place for Service Learning in Literary Studies?," Profession, 2005, 135.

15. All quotations from students' writing come from the public blog where they recorded their experience. To protect the students' identities and the agencies where they served, the blog is no longer public, and the students' names have been changed.

16. Grobman, “Is There a Place for Service Learning in Literary Studies?,” 136. 


\section{Teaching Shakespeare Inside Out: Creating a Dialogue Between Traditional and Incarcerated Students}

Jayme M. Yeo

A glance down any British literature survey syllabus yields an astonishing number of authors who spent time in prison: Thomas More, Thomas Wyatt, Robert Southwell, Christopher Marlowe, Thomas Dekker, Ben Jonson, John Milton, John Bunyan, Daniel Defoe. And yet, despite recent critical interest in early modern prison writing, ${ }^{1}$ issues of incarceration remain relatively removed from early modern literature classrooms. This elision seems strange, particularly given the recent surge of popular interest in prisons. The gritty glamour of media depictions of prison, however, perpetuates stereotypes about incarcerated people that underscore the injustices of the carceral system. Particularly troubling among these injustices is an epistemic silencing that limits the scope and authority of incarcerated voices, whose testimonial knowledge is undercut by their status as "inmates" or "criminals." This stereotyping not only limits inside voices, however: it also weakens our students' ability to approach issues of incarceration in early modern literature with sophistication. By creating opportunities in our classes for our outside students to dialogue about early modern literature with people on the inside - through face-to-face conversations, videoconferencing, correspondence, or critically analyzing inside art and writing-we might begin to redress this problem of testimonial oppression and challenge the stereotypes that contribute to it. In doing so, we might also create a community of readers among insiders and outsiders that more completely understands issues of incarceration, both in early modern literature and in the world today. Along the way, we may finally discover a pedagogy that transforms not only our students, but also ourselves. While the list of authors above suggests that this approach would be effective for a variety of British literature classes, I will use Shakespeare 
as a touchstone for this pedagogical approach. I suggest several possibilities for how educators might allow imprisoned readers to "speak" in their classrooms, and argue that doing so enables better understanding of issues of incarceration by enlivening questions of criminality and justice. I conclude with recommendations and cautions drawn from research on inside-out pedagogy and community literacy.

I first began teaching classes on "inside Shakespeare" several years ago. Taught to freshmen in the general education core, these classes are linked with an introductory course in sociology and feature assignments that utilize sociological theory to examine the motivations and responses to deviance in Shakespeare's work. As my investment in prison pedagogy has deepened, I have also begun developing a revised version of this course for upper-level students. This revised class draws in part on my experience teaching in prison, and I am collaborating with inside students to develop it. Unlike my freshman courses, this course facilitates direct correspondence between inside and outside students.

Focusing this classroom inquiry on Shakespeare makes good sense; the proliferation of prison Shakespeare programs worldwide has resulted in a collection of inside texts on Shakespeare that forms the basis for classroom engagement. ${ }^{2}$ As I use the term, "inside Shakespeare" refers both to staged productions and to writing by incarcerated thinkers, as well as the documentaries, books, and articles about Shakespeare's presence behind bars. Shakespeare's work also makes sense because it is deeply invested in the political imperative of speaking on one's own behalf. Indeed, the foundations of early modern drama rest on a courageous and dangerous self-publicizing, and Shakespeare bears witness to this fact in his work, where political subjectivity is inextricably linked with public speech. ${ }^{3}$ Witness, for instance, Paulina's insistence on using "that tongue [she] has" to counter the injustice of a mad king, or Caliban's subversive English that challenges the logic of colonialism. ${ }^{4}$ Both characters give critical testimony rooted in a subjugated knowledge of the failures of sovereignty, and both testimonies are largely suppressed. In other words, attending to incarcerated voices is an approach that resonates deeply with Shakespeare's own work, which itself expands the discursive space within which marginalized voices might be heard.

\section{Testimonial Oppression}

Incarceration subjects people to marginalizing forces amounting to social death: segregation and institutionalization, disenfranchisement, and stigmatizing/stereotyping. This death continues even after release, 
underwriting the well-documented challenges that formerly incarcerated people face when searching for jobs, housing, education, and in some states even the right to vote. ${ }^{5}$ These material conditions inform and are informed by the epistemic violence that accompanies the sign of "criminal," which precedes and marks incarcerated and formerly incarcerated subjects. While workshopping this chapter with a group of students at a facility for men in middle Tennessee, my conversations confirmed the lived experience of this epistemic oppression. One student, Frank, articulated it in stark terms: "Society's label never expires: outcast . . . because in our society 'guilty' is synonymous with 'irredeemable." 6

The social death of incarcerated subjects also robs them of epistemic agency, subjugating their knowledge and voices to the systemic injustice of testimonial oppression. ${ }^{7}$ Kristie Dotson argues that marginalized voices are functionally silenced when an audience "fails to identify a speaker as a knower" (termed "testimonial quieting") or when a speaker purposefully alters her own testimony to leave out material that might be perceived as unsafe or unintelligible by her audience (termed "testimonial smothering"). ${ }^{8}$ Translating these failures of communication to the context of prison, Anastazia Schmid notes that incarcerated thinkers have limited epistemic agency when, for instance, their testimony is rendered suspicious because of the label of "criminal," or when their grounds for knowing are posited on their status as "model prisoners" whose testimony validates the "rehabilitative" effects of prison. " Such is the double-bind for inside thinkers: they may speak, but only as carceral subjects whose speech is either quieted or smothered by an audience who mistrusts or anticipates their testimony. The students I spoke with were attuned to this fact, and noted that even in the growing opportunities for publication in venues such as PEN America or The Journal of Prisoners on Prisons, their authority as writers rests on their status as insiders. The problem was poignantly encapsulated in a rhetorical question that Adam posed to me: "Even if I do manage to get my ideas published, who is going to listen to a prisoner?" 10

Despite our best efforts, scholarship on inside Shakespeare is not exempt from this criticism. Notably, outside scholars almost exclusively direct the terms of this inquiry (this chapter is a case in point), while inside thinkers rarely contribute to our collective scholarly understanding of Shakespeare. ${ }^{11}$ With few exceptions such as the film Mickey B, a modernized adaptation of Macbeth written and acted by insiders at Maghaberry Prison in Northern Ireland, the inside work that we do receive is largely excerpted and disseminated to an audience through the arbitration of documentary editors, writers, and teachers, a form of testimonial quieting that mediates the knowledge of incarcerated 
thinkers and artists. Furthermore, there is an understandable but imbalanced emphasis on the psychological benefits of education and drama therapy, which frames inside knowledge of Shakespeare within a fixed arc of trauma and redemption, leading to testimonial smothering that filters out nontherapeutic engagements with Shakespeare. ${ }^{12}$ While we should certainly acknowledge and celebrate the transformative work of literature, we should also take care not to preclude other intellectual engagements with Shakespeare's work.

\section{Reframing Criminality and Justice}

The kind of class I propose addresses the effects of testimonial oppression by decentering criminality and positioning incarcerated people instead as readers, writers, actors, and artists. In my freshmen classes, we have analyzed work by Laura Bates and Amy Scott-Douglass, for instance, which features incarcerated writing about Shakespeare that galvanizes issues of social inequality, violence, and confinement. ${ }^{13}$ In addition, inside productions or adaptations of Shakespeare's work, including films such as Mickey B and Caesar Must Die, have provided rich ground for critical inquiry. Analyzing these works as part of a class accords the respect of serious academic consideration to artistic products that otherwise go undertheorized because of their status as therapeutic. ${ }^{14}$

This pedagogical approach reframes criminality and justice in Shakespeare, challenging simplistic or stereotypical assumptions. Early modern understandings of crime, for instance, resist the tendency to essentialize or pathologize criminality. As Thomas Freeman has recently argued, it wasn't until the sixteenth-century "houses of correction" that criminality first became linked to the discourse of normativity, with the "criminal" seen as "being outside of society and inherently different from its other members." ${ }^{15}$ In the early modern period, crime was more frequently associated with sin, a normative condition of possibility for humanity. This understanding illuminates the emotional complexity of Shakespeare's villains, as well as his characters' responses to deviance. In Measure for Measure, for instance, Isabella relies on this notion of crime as she pleads with Angelo on behalf of her brother Claudio:

If he had been as you, and you as he,

You would have slipp'd like him, but he like you

Would not have been so stern. ${ }^{16}$

Isabella appeals here to the universality of sin that enmires not only Claudio but also Angelo and herself. For her, deviance is marked not 
by her brother's minor crime of fornication, but rather by Angelo's unyielding judgment against it; inhuman behavior lies not in violating the law but rather in withholding a mercy that would rescue citizens from its excesses.

"Inside Shakespeare" also challenges punitive models of incarceration, which implicitly underwrite popular understandings of criminal justice. In my freshmen classes, we return multiple times to the question of how attitudes toward crime produce responses to deviance in Shakespeare's work and in the world today. This question invokes the tension in contemporary legal theory between retributive and restorative justice, where retributivism accounts for the punitive role of prisons in society while restorativism offers avenues for redress, often through meetings between the person who committed the crime and the victims. ${ }^{17}$ In this respect, restorative justice is concerned with what one inside student, Jacob, calls the "trauma to the narrative," the event that disrupts the apparent course of a life or society. ${ }^{18}$ Nascent forms of both models can be identified in early modern literature; retributivism is explicitly critiqued in works like Measure for Measure and The Merchant of Venice while restorative justice transcends the law, activated only by the generous mercy of the sovereign. The late romances in particular pit the retributive ends of tragedy against the restorative possibilities of comedy, calling for a justice that ultimately seeks to reinstate the humanity of its subjects.

\section{Creating a Dialogue}

While students in my freshmen classes produce work that demonstrates complex thinking about criminality and justice, and even occasionally ask me how to get involved with prison advocacy, I have come to realize that the fact that they do not dialogue directly with incarcerated people ultimately restricts the political efficacy of the course. One semester, for instance, when I asked students how the class had impacted (or not) their perception of incarceration, one student raised his hand: "I know that education and reform is important, but I wonder if it makes a difference. After all, people don't really change." Despite all evidence to the contrary, my student had not relinquished the same essentializing models of crime that he began the class with. Sadly, my experience is not unique. Tom Kerr also describes struggling with student apathy and even antipathy in a writing class grounded in critical resistance: "ethical and logical appeals ... did not win over hearts and minds. If the criminal justice system caused people to suffer, so much the better: that was the point, after all." 19 
An antidote to this political indifference comes in the form of a learning community facilitated through direct dialogue between insiders and outsiders. Kerr, for instance, invited his students to write letters that he forwarded to incarcerated people posing questions about the class material. He notes that students responded to the "human voices" of the replies, which often featured personal stories. As a result, his students developed greater sensitivity to injustices such as abuse, media misrepresentation, and lack of access to education..$^{20}$ When institutional structures permit, a more powerful possibility for dialogue is the inside-out model of teaching. Developed at Temple University, this approach features a blended population of incarcerated and non-incarcerated students in a single class, with the primary goal of learning together. The ethos of the inside-out model privileges learning over therapy or activism and fosters dialogue and equal participation among both populations. Research indicates that this approach yields positive social results, including increased activism and decreased stereotyping: several studies demonstrate that this pedagogical model helps all participants overcome preconceptions regarding out-groups-students from both populations as well as faculty. ${ }^{21}$

I have been encouraged by this research to begin planning an inside-out collaboration for an upper-division class on Shakespeare and justice, which I am developing in conjunction with a group of incarcerated students. Although combined face-to-face classes are logistically impossible, I will invite students from both populations to correspond with each other, and am investigating the possibility of videoconferencing for the classes. As I am discovering, a successful collaboration requires careful planning, including developing partnerships with local prison education organizations, protecting privacy (most inside-out programs recommend using first names for everyone), and navigating bias among all participants, myself included. ${ }^{22}$ Communicating ground rules and framing expectations are also essential, to help students understand the goals of the collaboration. To that end, my class includes a syllabus description that explains the academic objective of the collaboration in simple terms: "We aim to discover what Shakespeare says about justice by speaking with and listening to people who experience justice-and injustice—in a variety of ways.”

\section{Multivalence, or the Politics of Community Reading}

While I have hope that this collaboration will maximize the political effectiveness of the class, I temper this positivity with a caution from 
related research in community literacy, which notes that any endeavor to bring together a truly diverse population entails challenges. Although research in community literacy agrees that diverse reading communities foster mutual understanding, they also acknowledge that this understanding occurs only when participants agree "to openly acknowledge not only the difficulty of empathy and the history of failed conversations, but to purposefully examine the genuine conflicts, assumptions, and practices [they] bring to these new partnerships." ${ }^{23}$ In other words, a reading community should value not only common understanding but also misunderstanding, through the uncomfortable dissonances that occur when diverse populations interact.

This specter of discomfort should, paradoxically, put literature faculty at their ease, for multivalence and conflict accurately describe the work of literary interpretation itself, demonstrating that the primary social outcomes of this approach go hand in hand with its primary academic benefits. By teaching students to attend to testimony that is normally excluded from a college setting, we might also teach them to attend to interpretive possibilities that are also excluded. In doing so, we open the door simultaneously to academic and political learning precisely through the struggle to communicate. As Michael Bérubé et al. note, the work of reading in a diverse community is, simultaneously, the work of civil discourse: "making oneself listen to perspectives one doesn't agree with or even understand, struggling to figure out a ground on which give-and-take can occur, finding dialogue in discord ... these are skills that all social engagement with a various population requires." ${ }^{24}$ By foregrounding the value of this struggle for our students, we might help them realize that it is only by confronting their own preconceptions through productive disagreement-through hearing, understanding, assessing, and responding to new and challenging points of view-that they can sharpen their own rhetorical and analytical skills. Put another way, our best response to testimonial oppression may simply be developing the intellectual habit of listening well. Along the way, we might also uncover new readings of early modern literature and expand the discursive space of Shakespearean performance and interpretation in our world today.

\section{Notes}

My gratitude to the insiders who generously read and commented on drafts of this chapter: Adam, Claudell, Frank, Jacob, and Micah. Thanks also to Anastazia Schmid and Michelle Jones for their helpful thoughts. 
1. William Sherman and William Sheils, eds., "Prison Writings in Early Modern England," Huntington Library Quarterly 72, no. 2 (June 2009).

2. Sources might include documentaries and films such as Hank Rogerson, Shakespeare Behind Bars, DVD (Philomath Films, 2005); Jack Hitt, Act $V$, This American Life, n.d. <https:/www.thisamericanlife.org/218/act-v> (accessed February 26, 2019); Tom Magill, Mickey B, DVD (Educational Shakespeare Company, 2009); Paolo Taviani, Caesar Must Die, DVD (Homescreen, 2013); and texts such as Laura Bates, “To Know My Deed': Finding Salvation Through Shakespeare," in Performing New Lives: Prison Theatre, ed. Jonathan Shailor (London: Jessica Kingsley, 2011), 33-48; Herold Niels, "Movers and Losers: Shakespeare in Charge and Behind Bars," in Native Shakespeares: Indigenous Appropriations on a Global Stage, ed. Craig Dionne and Parmita Kaadia (London: Ashgate, 2008), 153-70; Rob Pensalfini, Prison Shakespeare (New York: Palgrave Macmillan, 2016); Jean Trounstine, Shakespeare Behind Bars: The Power of Drama in a Women's Prison (New York: St. Martin's Press, 2001); Jean Trounstine, "Beyond Prison Education," PMLA 123, no. 3 (May 2008): 674-7; Ramona Wray, "The Morals of Macbeth and Peace as Process: Adapting Shakespeare in Northern Ireland's Maximum Security Prison," Shakespeare Quarterly 62, no. 3 (2011): 340-63; Helen Zelon, “The Shakespeare Redemption: Inmates in a Kentucky Prison Grapple with the Truths of Human Existence," American Theater 18, no. 8 (October 2001): 32-5.

3. Julia Reinhard Lupton, "Public Women/Women of Valor," in Shakespeare in Our Time: A Shakespeare Association of America Collection, ed. Dympna Callaghan and Suzanne Gossett (London: Bloomsbury Arden Shakespeare, 2016), 287.

4. William Shakespeare, The Winter's Tale, ed. J. H. P. Pafford (London: Arden Shakespeare, 1963), II, ii, 51; William Shakespeare, The Tempest, ed. Virginia Mason Vaughan and Alden T. Vaughan (London: Arden Shakespeare, 1999), I, ii, 363-4.

5. See Christopher Uggen, Ryan Larson, and Sarah Shannon, "6 Million Lost Voters: State-Level Estimates of Felony Disenfranchisement, 2016,” The Sentencing Project, October 6, 2016 <http:/www.sentencingproject. org/publications/6-million-lost-voters-state-level-estimates-felonydisenfranchisement-2016> (accessed September 23, 2017); Bruce Western, "The Impact of Incarceration on Wage Mobility and Inequality," American Sociological Review 67, no. 4 (August 2002): 526-46.

6. Frank, personal interview with the author, October 24, 2016.

7. My appreciation to the inside thinkers (listed at the start of the notes section) who pointed me toward this idea.

8. Kristie Dotson, "Tracking Epistemic Violence, Tracking Practices of Silencing," Hypatia: A Journal of Feminist Philosophy 26, no. 2 (2011): 242-4.

9. Anastazia Schmid, "Can the Convict Race Speak?" Unpublished conference paper, National Conference on Higher Education in Prison, Belmont University, Nashville, TN (November 3-6, 2016). 
10. Adam, personal interview with the author, July 15, 2017.

11. See also Michelle Jones, "Incarcerated Scholars, Qualitative Inquiry, and Subjugated Knowledge: The Value of Incarcerated and Post-incarcerated Scholars in the Age of Mass Incarceration," Journal of Prisoners on Prisons 25, no. 2 (2016): 98-111.

12. Wray, "The Morals of Macbeth and Peace as Process," 341.

13. For instance Bates, "To Know My Deed': Finding Salvation Through Shakespeare" and Amy Scott-Douglass, Shakespeare Inside: The Bard Behind Bars (New York: Continuum, 2007).

14. Wray, "The Morals of Macbeth and Peace as Process," 346. See also Niels, "Movers and Losers," 164.

15. Thomas Freeman, "The Rise of Prison Literature," Huntington Library Quarterly 27, no. 2 (June 2009): 137.

16. William Shakespeare, Measure for Measure, ed. J. W. Lever (London: Arden Shakespeare, 1965), II, ii, 64-6.

17. See Howard Zehr, The Little Book of Restorative Justice (Intercourse, PA: Good Books, 2002).

18. Jacob, personal interview with the author, August 5, 2017.

19. Tom Kerr, "Between Ivy and Razor Wire: A Case of Correctional Correspondence," Reflections 4, no. 1 (2004): 66.

20. Ibid., 74 .

21. See Simone Weil Davis and Barbara Roswell, Turning Teaching Inside Out: A Pedagogy of Transformation for Community-Based Education (New York: Palgrave, 2013); Laura ("Lo") Mishne, Erica Warner, Brandon ("The B") Willis, and Robert ("Diesel”) Shomaker, "Breaking Down Barriers: Student Experiences of the Inside-Out Prison Exchange Program," Undergraduate Journal of Service-Learning and Community-Based Research 1 (2012); Carly M. Hilinsky-Rosick and Alicia N. Blackmer, "An Exploratory Examination of the Impact of the Inside-Out Prison Exchange Program," Journal of Criminal Justice Education 25, no. 3 (May 2014): 386-97; Norman Conti, Linda Morrison, and Katherine Pantaleo, "All the Wiser: Dialogic Space, Destigmatization, and Teacher-Activist Recruitment," Prison Journal 93, no. 2 (June 2013): 163-88.

22. Mishne et al., "Breaking Down Barriers"; Conti et al., "All the Wiser."

23. Wayne Campbell Peck, Linda Flower, and Lorraine Higgins, "Community Literacy," College Composition and Communication 46, no. 2 (May 1995): 205.

24. Michael Bérubé, Hester Blum, Christopher Castiglia, and Julia Spicher Kasdorf, "Community Reading and Social Imagination," PMLA 125, no. 2 (March 2010): 424. 


\section{"'Shakespeare' on his lips": Dreaming of the Shakespeare Center for Radical Thought and Transformative Action}

\section{Eric L. De Barros}

After Winston Smith, the protagonist of George Orwell's 1984 (1949), begins a diary, a "thoughtcrime" punishable by death, he continues the unearthing of a complex range of vague emotions and fragmented memories that "the Party" has systematically attempted to destroy. Eventually, those emotions and memories come together in the form of a dream that ends in a physical act of political rebellion:

The girl with dark hair was coming toward him across the field. With what seemed a single movement she tore off her clothes and flung them disdainfully aside ... What overwhelmed him in that instant was admiration for the gesture with which she had thrown her clothes aside. With its grace and carelessness it seemed to annihilate a whole culture, a whole system of thought, as though Big Brother and the Party and the Thought Police could all be swept into nothingness by a single splendid movement of the arm . . Winston woke up with the word "Shakespeare" on his lips. ${ }^{1}$

As I read 1984 for the first time in the midst of the urban despair that defined New York City in 1984, I was profoundly struck by the idea that Shakespeare could possibly function as a weapon of political resistance, let alone revolutionary change. For Orwell, almost identical to what structuralism would later teach me, reality is inextricable from the language we use to represent or construct it, and the surest way for an authoritarian society to control its people is by paring away the linguistic complexity that makes competing and potentially subversive "realities" possible. In the novel, Orwell explains this systematic process through the character Syme, one of an army of philologists "compiling the Eleventh Edition of the Newspeak dictionary." "Don't you see," he asks Winston, "that the whole aim of Newspeak is to narrow the range 
of thought? In the end we shall make thought-crime literally impossible, because there will be no words in which to express it." ${ }^{3}$ A few years earlier, Orwell also offered his seminal critique of "bad writing" in his 1946 essay "Politics and the English Language." In short, the consequence of bad writing - writing characterized by ready-made phrases, staleness of imagery, euphemisms, and a lack of precision-is that it "anaesthetizes a portion of one's brain," like "a packet of aspirins," from comprehending the consequences of an immoral political system. In that regard, the linguistic complexity of Shakespeare, if confronted as such, functions to wake us up, keep us alert, and potentially motivate our resistance to the crime of such language.

This understanding of Shakespeare has always been my central pedagogical goal. However, I have also never been able to achieve it for more than a small percentage of the students I have taught over a twenty-year period in two countries: the United States and Trinidad and Tobago. Unwilling to give in to elitist rationalizations about student underachievement, I began thinking seriously about why some four years ago. In what follows, I share how I have come to understand the problem specific to both countries as well as my ongoing efforts to imagine and test transformative solutions.

In the American context, there was the "fact" of my blackness in the majority-white college classroom. That is, with a decreasing number of black faculty and students at majority-white institutions, it is difficult for many students to accept instruction from high-achieving, politically responsive black faculty, particularly those in overwhelmingly white fields like Shakespeare studies. ${ }^{6}$ There is also the challenge of teaching a generation of students significantly, if not entirely, educated under a STEM-oriented focus on testing and assessment. ${ }^{7}$ And finally, perhaps even beyond Orwell's dystopian imagination, there is the frenetic pace of a social media culture working insidiously against the cultivation of critical consciousness.

Under these circumstances, the predominant "Shakespeare" is certainly not the personally inflected, politically responsive one on Winston's lips. Rather, it is one that sacrifices the potential for revolutionary expressive complexity in favor of an uncritical acceptance or rejection of those circumstances. In the "rejection" category, we find "Shakespeare, the individual genius" serving as a model of the "liberal humanist individualism" in terms of a confluence of social, political, and economic factors. Indeed, it was not uncommon for students to "Bardsplain" their love of Shakespeare in the process of complaining that my approach denied their self-evident right to an unselfconscious, impressionistic understanding 
of him and, by extension, themselves. In the "acceptance" category, we find the "cultural capital Shakespeare" and the "practical skills Shakespeare" reconciled to the corporatization of higher education: a decades-long transformation of higher education from "a public entitlement primarily offset by the state" to an increasingly prohibitively expensive "privatized service." ${ }^{10}$ Within this context, a context redefined by an expanding class of generously compensated administrators managing a shrinking class of modestly compensated tenured faculty and the expanding class of underpaid adjuncts replacing them, these "Shakespeares" anaesthetize students to the corporate-serving logic at the heart of it all.

If there is any hope for Orwell's "Shakespeare" in such a university enrolling such students, if there is any hope of his "Shakespeare" serving, as Ayanna Thompson describes, as a "catalyst or medium"11 for social justice, it will depend on engaging students in a pedagogical process that unapologetically weaponizes his "Shakespeare" against the others. Again, doing so has always been my goal. And in the spirit of the girl of Winston's dream, I had focused my efforts on the Shakespearean body as a key site from which to motivate revolutionary consciousness. However, this identification of the why of my limited success helped me realize that I had not been focusing enough on the specific activity that triggered Winston's identification of "Shakespeare": namely, diary or autobiographical writing. So, for my spring 2017 "Introduction to Shakespeare" course at Clark University, I began the semester with a discussion of Orwell's "Shakespeare" passage in terms of "a more personal historicism." 12 That is, drawing on William Pinar's curriculum theory and specifically its appropriation of the African-American autobiographical tradition, I encouraged students to reflect critically on the institutional structures and ideologies that shape them personally. As Pinar explains,

From slave narratives to contemporary writing, African-American autobiography has functioned as a powerful means of addressing and contesting social, political, and cultural realities in the United States ... In African-American autobiography, we discern not mindless egoism or asocial subjectivism . . . but rather first-person accounts composed by remarkable individuals whose subjective struggles were simultaneously collective ones. ${ }^{13}$

Winston's diary writing threatens a similar subversive function, and therefore the Party's control depends on discouraging it in the harshest possible terms. Of course, American society threatens nothing as direct as death for personal-political expression. However, I invited students 
to reflect on noncoercive methods of control, such the student-loan debt that many of them are forced to take on. As Jeffery Williams warns, "debt is ... a mode of pedagogy"14 that inculcates an anxious status-obsessed sensibility eventually "reinforced with . . . monthly [student-loan] payment[s] for the next fifteen years" 15 or more. I explained that much of our time would be spent reflecting on how these types of lessons shape our sense of what is right and possible.

Throughout the semester, I also modeled what such a method looks like by regularly illustrating how my own critical self-consciousness richly and legitimately informs the analysis of Shakespearean texts. For instance, in our discussion of 10 Things I Hate About You, the popular 1999 film adaptation of The Taming of the Shrew, I identified my position with that of the black English teacher (Mr. Morgan) in an effort to highlight the film's subtle exploration of the intersecting politics of race, gender, and class in American education. After drawing their attention to the parallel implications of a black man teaching Shakespeare, and specifically in an adaptation of the most difficult of his comedies to square with our ideals of gender equality, I shared with them my working-class black experience of that intersection and suggested that Mr. Morgan's abusive treatment of his students represents a misdirected fantasy release against the ongoing conditions of educational-institutional racism. While buffered by the near-farcical sexist banter that also characterizes Shakespeare's festive comedy, the seriousness of those conditions breaks through in Mr. Morgan's sarcastic response to Kat's feminist criticism of the curriculum:

And Kat, I want to thank you for your point of view. I know how difficult it must be for you to overcome all those years of upper-middle-class suburban oppression. Must be tough. But the next time you storm the PTA, crusading for better ... lunchmeat or whatever it is you white girls complain about, ask them why they can't buy a book written by a black man! ${ }^{16}$

Highlighted by the cartoonish portraits of white literary figures that come into view behind Mr. Morgan as the camera pans his approach to Kat, the political tensions revealed by his counter-criticism are immediately trivialized by the "That's right, mon!" ${ }^{17}$ exclamation of the two buffoonish white Rastas. That trivialization also significantly buffers the abusiveness that ends the scene, when Mr. Morgan arbitrarily kicks Kat out of class for "pissing [him] off." ${ }^{18}$ At this point, I invited students to join me in a self-critical process of imagining and working to actualize a more serious alternative outcome: one that sees social justice as part of an intersubjective process beyond rigidly defended identity positions. 
Generally, that process began with short daily passage analyses, for which I instructed students to avoid the simplifying tendencies of plot summary and focus instead, as I had been doing, on how their own ethical investments and/or expectations shaped or even prevented their understanding of the most pivotal textual instances. For the midterm and final papers, I similarly instructed students to draw on this self-critical process in the framing of their papers and specifically reserve the conclusion for the conceptualization of a practical strategy for raising awareness about or even solving the problem of a comparable present-day issues.

By semester's end, we had generated a rich store of potential connections: sexual violence and the complexities of consent in The Taming of the Shew, A Midsummer Night's Dream, and Romeo and Juliet; the racialization of beauty and colonization in A Dream and The Tempest; the pressures of cultural assimilation in The Merchant of Venice; gender and morality in Macbeth; education, social mobility, and the criminalization of racialized and non-elite characters in The Tempest. And while a majority of students struggled with the practical component of the process, a number of them developed promising possibilities: individual strategies for dealing with "mansplaining"; rewriting and staging Romeo and Juliet to raise awareness about sexual violence on college campuses; attacking misogyny and racism through comprehensive curricular reform; and advocating for more accessible quality education as essential to a democratic society.

Although it was at this point that I decided to change institutions, I was already in the process of making a case for translating those possibilities into extracurricular projects. Like an increasing number of institutions, Clark had restructured its curriculum around "real world" application, which it marketed as "Liberal Education and Effective Practice" (LEEP). ${ }^{19}$ As with the other "Shakespeares," my concern is that these initiatives tend to ignore or water down the social justice potentiality of the humanities. For instance, while all students were encouraged to apply for LEEP-project funding, most of the successful applications emphasized the "hands-on" practical and profitable over the transformative ethical. Also, of the small percentage that gestured at social justice, none reflected the potential of Orwell's "Shakespeare" or, for that matter, any other literary text or figure. My immediate plan was to address this absence. And then by continuing in that way to wake up with "Shakespeare" on my lips, I had high hopes of someday turning that dream of pedagogical success into the reality of "The Shakespeare Center for Radical Thought and Transformative Action."

In my next position at the University of the West Indies (UWI) at St. Augustine, Trinidad and Tobago, I worked with the same high hopes. 
As its strategic plan asserted, UWI's vision, mission, and key attributes of the ideal UWI graduate provided an exciting basis upon which to continue this work. ${ }^{20}$ In particular, reflecting a problem-solving urgency intensified by the 2008 global financial crisis, UWI determined that its ideal student must be: (1) a critical and creative thinker; (2) an effective communicator with good interpersonal skills; (3) IT-skilled and information literate; (4) innovative and entrepreneurial; (5) globally aware and well grounded in his/her regional identity; (6) socially, culturally, and environmentally responsible; and (7) guided by strong ethical values. Like the STEM bias in the U.S., many at UWI St. Augustine tended to think of Shakespeare in terms of a defensive and/or practical understanding of attributes 1 and 2. Therefore, I focused my 2018 "Shakespeare I" class on attributes 5 and 7 by engaging students in a personal historical process of reading themselves through Shakespearean expression.

The results were mixed. On the one hand, this approach facilitated some of the smartest and most stimulating discussions I have ever witnessed or been a part of. ${ }^{21}$ While I am still working through the reasons, my sense is that this success had much to do with the ability of my students to connect their culturally rooted sense of humor with Shakespeare's. ${ }^{22}$ On the other hand, the same brilliant students struggled mightily to translate those discussions into argumentative analyses. The reasons are, of course, complex. But my sense, again which I am still working through, is that they are rooted deeply in the politics of race and the institutionalized legacy of Trinidad's colonial history.

In this context, the "fact" of my blackness completely changed. Contrary to the majority-white U.S. classroom, it is not that my Trinbagonian students had any basic problems with my position as a black Shakespearean. Ironically, the only time they seemed to struggle with it was when I made it visible to them within the broader Anglo-American world. In other words, in the absence of a dominant, majority-white power structure, racism is not experienced or understood as an obvious and urgent problem. Of course, they know it exists, and that on some level it affects them; it's just that it has been rendered invisible and avoided within the colonial bureaucracies that have structured so much of their lives and education. Therefore, similar to the testing and assessment mandates in the U.S., education is not about critical thinking and creative argumentation; it's about rigidly enforced rules, regulations, and the memorization of authoritative knowledge.

The most disturbing articulation of these conditions came near the midpoint of the semester, when a frustrated Afro-Trinidadian student shared with me and the class that she was struggling to develop her own ideas through the direct analysis of text. Responding specifically 
to my highlighting of Titus Andronicus's Lavinia as an example of Shakespeare's Ovidian association of trauma with resourcefulness, ${ }^{23}$ she pushed back with:

I disagree with that, with trauma makes us resourceful ... To me, I find it makes us weak and timid ... I'll be honest, when I started this class-and maybe even now-I wasn't too sure about it or sure about you, because of some of the things you were saying. It was going against everything I had been taught ... Telling us to [develop] our own ideas and to forget about secondary sources. I was like, "what is he talking about?" ... Even now, it's still kind of hard because I guess I don't have that confidence in my own voice ... Trauma shames us ... When I was in secondary school, I had this idea and I had pitched it to my teacher. And she was like, "No. You can't use your own words or ideas. You are nobody. You have to say what people who are credited [have said]." That has always stuck with me.

"You are nobody." While an exceptionally crude statement, the traumatic lesson it delivered was variously received by many of my students over the course of their education. "You are nobody." And it's difficult for me not to hear in it and feel from it the ugly traumatic lesson of slavery and colonization refusing to shut up and die. "You are nobody." Indeed, it sticks with them. "You are nobody." And it sticks to them, as manifested in a lack of confidence preventing them from committing fully to a potentially empowering educational process.

So, if there is any hope for such an education in such a context, if there is any hope of combatting the fear, insecurity, and doubt instilled by such an authoritarian educational system, it will require first taking seriously the need to build student confidence. ${ }^{24}$ For this student, that meant telling her the truth about the lie that she is nobody. And that the strength it took her to share her story of traumatic weakness, timidity, and shame ironically revealed that she already knows deep down inside that she is somebody. But where does that strength come from? Perhaps the answer, as I suggested, is something close to Walter Benjamin's understanding that oppressed people hate their oppressors and sacrifice their own liberation not for the ideal of liberated grandchildren, but for the suffering of their enslaved ancestors. ${ }^{25}$ In other words, it's that inherited, deeply embodied knowledge of unjustifiable pain and suffering, no matter how repressed by bureaucratic structures or abusive comments, that potentially motivates us to "[sharpen our] wits" ${ }^{26}$ in the "resourceful" 27 pursuit of justice. That's what makes Trinidad one of the most interesting places in the world and UWI St. Augustine potentially one of the most interesting places to study. These students variously embody traumatic histories. So, in an effort to build confidence in 
what that could mean, I asked, "Who do you think is best positioned to creatively analyze Shakespearean expression, to breathe unpredictable and innovative new life into the Shakespearean past: you or the majority-white Anglo-American world perpetuating (in the academic books and journals it controls) the myth of its intellectual and cultural superiority?" That's not to endorse, as I continued, an anti-intellectual rejection of those texts and that world. We can't. It's to say, value first and foremost what you bring to the analytical process; value the histories that you embody; it is to say, honor those who suffered and endured so that you might transform their unjustifiable pain and suffering into something beautifully yours.

\section{Notes}

1. George Orwell, 1984 (New York: Signet Classics, 1977), 31.

2. Ibid., 48 .

3. Ibid., 52 .

4. George Orwell, "Politics and the English Language," in Major Modern Essayists, ed. Gilbert H. Muller and Alan F. Crooks (Englewood Cliffs: Prentice Hall, 1994), 78.

5. Ibid., 78.

6. See Andrew McGill, "The Missing Black Students at Elite American Universities," The Atlantic, November 23, 2015; and Ronald L. Jackson II and Rex Crawley, "White Student Confessions about a Black Male Professor: A Cultural Contracts Theory Approach to Intimate Conversations About Race and Worldview," Journal of Men's Studies 12, no. 1 (fall 2003), $25-41$.

7. See Scott L. Newstok, "How to Think Like Shakespeare," Chronicle of Higher Education, August 29, 2016.

8. Ron Strickland, "Teaching Shakespeare Against the Grain," n.d. <http:// pages.mtu.edu/ rlstrick/378/shakgran.htm> (accessed September 1, 2017).

9. Jeffrey J. Williams, "Debt Education: Bad for the Young, Bad for America." Dissent 53, no. 3 (2006), 54.

10. Ibid.

11. Ayanna Thompson, "Redefining Authenticity in Shakespeare Reform Programs," in Passing Strange: Shakespeare Race, and Contemporary America (London: Oxford University Press, 2011), 122.

12. Eric L. De Barros, "(Ig) Noble Lies: Personal Historicism and Richard Mulcaster's Positions Concerning the [Training] Up of Children (1581)," Changing English: Studies in Culture and Education 20, no. 3 (2013): 325.

13. William F. Pinar, "Autobiography: A Revolutionary Act," in What is Curriculum Theory? (Mahwah: Lawrence Erlbaum Associates, 2004), 42-7.

14. Williams, "Debt Education," 56. 
15. Ibid., 57.

16. 10 Things I Hate About You, directed by Gil Junger (Touchstone Pictures, 1999), 6:47-7:06.

17. Ibid., 7:06.

18. Ibid., $7: 15$.

19. See 'Liberal Education \& Effective Practice,' Clark University <http:// www2.clarku.edu/leep> (accessed September 1, 2017).

20. "UWI Triple A Strategic Plan: Revitalizing Caribbean Development," n.d. $<$ http://www.uwi.edu/uop/sites/uop/files/Full\%20plan.pdf> (accessed September 1, 2017).

21. I'd like to thank these students for their exceptional contribution: Demitri Bhagoutie, Deepak Deodath Basdeo, Collen Hector, Rashad Hosein, and Denise Matthews-Owen.

22. Suzanne Burke (UWI St. Augustine) usefully suggested that this ability likely reflects the inherited political sophistication of Calypso music.

23. Ovid, Metamorphoses, trans. David Raeburn (New York: Penguin, 2004), Book 6, 574-5. The specific instance is Ovid's transition from Philomela's confined mutilated condition to her tapestry-weaving solution with "But suffering sharpens the wits and misfortune makes / one resourceful."

24. I'd like to thank Adeltrude Bain and Roger Mc Farlane, of UWI St. Augustine, for identifying the lack of student confidence as a central problem.

25. Walter Benjamin, "Theses on the Philosophy of History: XII," in Illuminations, trans. Harry Zorn (London: Pimlico, 1999), 252.

26. Ovid, Metamorphoses, Book 6, 574.

27. Ibid., 575. 


\title{
From Pansophia to Public Humanities: Connecting Past and Present Through Community-Based Learning
}

\author{
Tania Boster
}

Taking a slight departure from this volume's emphasis on Shakespeare, this chapter explores a model of social justice pedagogy that brings historical methods of documentary analysis into a community-based learning (CBL) course. ${ }^{1}$ My approach to CBL is illustrated by a method of teaching first-year students to situate texts-historical and contemporary - into their contexts to support the critical evaluation of underlying structures that inform their creation and reception. This method could be applied in a variety of CBL classes, for instance to introduce students to historical contexts of Shakespeare's plays or their performance throughout time and place, or to support exploratory work on both universal and particular thematic issues. As my disciplinary background is in early modern European history, the model will be demonstrated in this instance through the primary and secondary literature that chronicles the activities of the mid-seventeenth-century "intelligencer" Samuel Hartlib and his circle in particular, who have much to teach us about teaching contemporary civic engagement for social justice.

I teach a first-year seminar called "Know Your Place: Civic Humanism, Community Engagement, and Public Humanities," which introduces students to methods and best practices of collaborating with communities to address pressing local, national, and global issues. Guided by principles of critical service learning, students are encouraged to pursue reciprocal relationships with community partners. ${ }^{2}$ The course also emphasizes the role of the humanities in civic engagement alongside an exploration of historical roots and models of civic humanism. Students learn directly from community members about select issues as they are being addressed locally, nationally, and internationally, 
and identify opportunities for engagement with these issues through co-curricular or curricular involvement, or through upper-level CBL courses in future semesters. The course title alone betrays a few things about my approach to CBL:

- "Know Your Place." In addition to the basics of learning about the geography and history of a community one is entering into, establishing our sense of place entails, among other considerations, acknowledgment of "town-gown" power dynamics and striving to not reinforce systems of inequality. At the same time, we recognize that formal institutions of education are not the only sites of knowledge production; knowledge is also held and generated in and by the community.

- Civic humanism. As a student of early modern history, I appreciate the remarkable degree to which humanism in its many historical manifestations (classical, religious, civic, etc.) has informed and even driven political and social change throughout time and place. Seventeenth-century European history offers examples of humanists such as John Milton, who deployed "paper bullets" and drew from a range of classical and moral philosophies to envision and go to battle to enact a better world. ${ }^{3}$

- Community engagement. Critical service-learning pedagogy informs the course. According to Tania Mitchell, "A critical service-learning pedagogy asks students to use what is happening in the classroomthe readings, discussion, writing assignments and other activities- to reflect on their service in the context of larger social issues." She goes on to quote Rhoads: "Such a vision is compatible with liberatory forms of pedagogy in which a goal of education is to challenge students to become knowledgeable of the social, political, and economic forces that have shaped their lives and the lives of others." ${ }^{4}$

- Public humanities. The utility of humanism is evident in the topics covered, which include: active listening and integrative communication; introduction to community-based research methods; documenting community-expressed needs and goals; ethics of community-based learning; writing as a process and rhetorical flexibility; oral history as social justice; political culture; poverty and systems of inequality; public history and public memory.

Community partners are the experts in their own experience and in the issue areas they and their communities are addressing. They are also co-educators in the course, as paid guest speakers or through site visits to their organizations. Their presentations are the primary "texts" 
for the class. Students put the presentations into context by consulting census records, public policy texts, historical documents, and a variety of other sources. I teach students a particular method of recording and interpreting community-identified needs and goals. The format is based on a medical model of triaging patients and documenting the findings of an examination known as "SOAP notes" (Subjective, Objective, Assessment, Plan). ${ }^{5}$ As they meet weekly with community partners they document their conversations in the following format:

- Subjective. What are your personal reflections on the discussion with the community partner?

- Objective. What did you learn about the issue area(s) the partner and their organization are addressing? This section should not include critique or interpretation; you are reporting what was shared in the presentation and discussion.

- Assessment. What are the broader issue areas the organization is trying to address, such as "poverty" or "access"? Identify and pursue answers to a research question that will illuminate or provide evidence about some aspect of what you learned by talking with the community partners.

- Plan. What opportunities for students to get involved did the community partner identify?

The learning goals of this assignment are to encourage first-year students to distinguish between the objective and personal aspects of their thinking, isolate a clear research question, identify credible source materials in pursuit of the answer to that question, and develop an argument based on their findings. Students engage deeply with a variety of community-defined challenges and goals that reveal the complexity behind a range of social issues, including conflicting interests and ideologies, and "big picture" problems such as structural inequality and external pressures related to funding and public policy. Ideally, the students will themselves make a commitment to being partners in these efforts during their time as members of this community, and then go on to be civically engaged in any community in which they eventually live and work, throughout their lives. For their final project, the class collaborates to compile a "Community Needs and Goals Assessment" documenting the testimonies and supplemental research they have collected over the semester. I frame this effort for the students as a snapshot of and reflection on their own learning. They are also asked to see it as a contribution to the community they have been learning from, in the form of a baseline report on the landscape of community issues at this 
point in time. The final assessment becomes an archival record in the form of a digital humanities project recording the particular struggles and aspirations of this place over the period of time designated by a semester. ${ }^{6}$

The difficult work of pursuing social justice is, and has throughout history been, complicated by factors such as self-interest and competing agendas. Students in my class gain subjective, candid insight into these challenges in their conversations with community partners. Historicizing community challenges such as poverty, hunger, and racism is a feature of my course, and the community-based research methods I teach draw on many of the same critical thinking skills used in historical analysis. I have been exploring a historical method that would bring into the course lessons from the early modern period about competing views of social justice, radicalism, patronage, network analyses, structure, and agency, and the practical application of the liberal arts. Self-knowledge, or at least the willingness to pursue it, is a necessary condition for social justice. As the historian Jonathan Scott puts it, "History is ... the study, and imaginative recreation, of experience other than our own," to enhance self-knowledge, "not by examination of the self-let alone of an imaginary self elaborated into the past-but by that engagement with the world outside the self which is the only context for genuine self-understanding."

In this spirit, the "Great Intelligencer" Samuel Hartlib (c. 1600-62) and his associates provide insight into historical civic humanism relative to present-day struggles, and draw attention to the timeless complexities and contradictions inherent in efforts at creating a better world. The Hartlib Papers are a window into creative early modern problem solving by people who drew on natural philosophy, metaphysics, rhetoric, translation, and the many other multipurpose tools in a humanist's toolkit. Through the Papers we gain insight into how early modern humanists attempted not just to envision and implement a better world, but also to achieve universal spiritual and material transformation: the "Great Instauration." ${ }^{8}$ Their ambitious vision and the mechanics of the circle's inner workings have been documented through the Hartlib Papers digitization project at the University of Sheffield, which is now freely available online. ${ }^{9}$ This collection of manuscripts, presented in conversation with associated archival and printed sources collected in the Early English Books Online (EEBO) digital archive, offers easily accessible primary sources for studying civic humanism in the early modern world. As humanists reading these texts, we become privy to the inherent messiness of pursuing social transformation; good intentions do not always produce beneficial results for the target population. 
Hartlib, responding from London to the troubles of Europe's seventeenth-century Reformation/Counter-reformation, established a pan-European network of scholars to facilitate the exchange of ideas in the hope of ending decades of violence (the Thirty Years War and English Civil War, in particular) and permanently settling religious differences. ${ }^{10}$ The network exchanged ideas for a variety of humanistic and experimental projects designed to improve humanity's moral condition and prevent future upheaval. Projects included agricultural and medical research, urban planning, schemes to employ the poor, the translation of documents into common languages (Latin and English, depending upon the intended audience), and the complete restructuring of educational philosophy and pedagogy. They published utopian tracts, which were submitted to Parliament and broadly circulated as a means of influencing policy. John Milton, Henry Neville, Marchamont Nedham, and other prominent English republicans were among the ranks of Hartlib's collaborators, and the circle came under the official patronage of the Long Parliament and subsequent republic. ${ }^{11}$

One of the leading figures in the circle was the Moravian philosopher, educator, and religious refugee John Amos Comenius (né Komensky, 1592-1670), whose Pansophia diatopsis, or Patterne of universall knowledge, became a guiding methodological text for the group's ventures. Comenius maintained that pansophy, or universal wisdom, was the key to achieving that coveted peace:

Since wisdom therefore the Governesse of things, deserts men; what wonder need it be to us to see all things done immoderately, and by way of tumult ... It must necessarily redound them to the health and welfare of mankind, to place so clearly in the sight and view of all men, the true discover'd ends of things ... And this is that very thing which PANSOPHY seeks after and hopes for, through its waies of full Universailty, Truth, and Facility. ${ }^{12}$

Accordingly, Comenius informed efforts by English republicans eager to move education away from the scholasticism and rote instruction associated with monarchy and inherited intellectual traditions. Comenius's philosophy of education and pansophia prescribed a humanist pedagogy of substance to spark moral reforms that republicans believed better suited to a commonwealth. The preconditions for peace and productivity relied upon universal education, based on a clear and true logic that would not allow fallacies and doctrinal disputes to obstruct the pursuit of "godliness":

As for the darknesse of errors, it would flee amaine from the face of so cleare a light: and men, being busied onely about solidities, and bending through 
assured and certaine wayes unto serious ends, would easier leave off those dissentions, strifes, and warres, where with the world is now consumed. ${ }^{13}$

This was the ideal, the utopian vision. But, in practice, Hartlib, Comenius, and friends lived in a deeply divided society coping with all of the socioeconomic challenges that accompany war. Take, for instance, the timeless issue of poverty. In a pamphlet titled "An Act . . . For the Relief, and Imployment of the Poor," a member of the circle responds to the demands on society posed by an influx of refugees into London. He proposes forming a corporation charged with and given legal authority to detain "any Rogues, Vagrants, Sturdy Beggers, idle, and disorderly persons" and force them into labor. Those found guilty of past offenses are subject to corporal punishment and may be banished back to their "places of birth, or last abode, as the case, according to the Laws and Statutes in that case provided shall require." 14 This would have presented formidable challenges to those escaping religious persecution. The author goes on to prescribe labor and education "to preuent misery $\&$ wickednes in the tyme of this Reformation. That workehouses \& Bridwells may be set vp in and about the Citty, the workehouse to trayne vp Childeren in Trades \& to imploy the honest \& laborious." Under the influence of "honest Schoolmasters \& Mechannick Arts Masters," children in these workhouses would be reformed from "Idlenes \& other wickednes, as Sweareing Sabboth brakeing \& such like," all of which would be a great service to ministers and magistrates. ${ }^{15}$

The process of analyzing this archival source alongside Comenius's prescription for pansophia begins with asking students to reconcile Comenius's idealistic call for universal education, irrespective of class or creed, with the punitive impetus that emerges in legislation proposed by the associate of the Hartlib circle who authored this "Act." Students conduct a discourse analysis of the content, form, and purpose of the archival documents to try to determine the values and priorities of the author and the author's patron(s), and analyze the text purely for what is being said, suspending judgment and interpretation.

Once the contents of the primary source have been analyzed on their own terms, the next step is contextualization, looking to social and intellectual history to fill in some of the gaps. What structural inequities account for the poverty identified in these documents? Who were these displaced people? What conditions contributed to their hardship? What were the intellectual and moral traditions informing the author's analysis of the problem and his prescribed solution? With the benefit of historical hindsight and the labor of generations of historians who have poured through the archives and public record offices, we may be able to 
come to some rather sophisticated conclusions. Historical phenomena and themes could include but are most certainly not limited to: the draining of the Fens ${ }^{16}$ destruction of the commons, ${ }^{17}$ religious war, ${ }^{18}$ state formation/building, ${ }^{19}$ and the dilemmas inherent to designing utopias and ideal societies. ${ }^{20}$

Parallel to the historical documentary analysis, I invite students to consider present-day prescriptions for addressing poverty, homelessness, and other familiar features of a society and political culture that do not prioritize that society's most vulnerable members. What we learn from members of the community, supplemented by demographic, policy, historical, and other research into root causes and barriers to inclusion, serves a function similar to the historical secondary literature we use to contextualize the Hartlib circle's pursuits. We may marvel at the contradictions that surface when the lofty ideals of pansophia espoused in a philosophical treatise by Comenius are put into practice by conscripting child labor. Rather than attributing such practices to the delusions of a pre-modern society, I invite students to look more closely at how-even with the best intentions-poverty is moralized and criminalized here and now. The lone social service organization in our small college town has seen sharp increases in demand year after year, with no end in sight. Yet with its small staff it has chosen to adopt a more time-consuming and labor-intensive model of working with clients that prioritizes building trust and community within the walls of the agency, creating a warm, welcoming environment in which the food pantry is set up like a grocery store rather than a distribution point to destigmatize accessing services, even when this approach does not align with the priorities dictated by state and federal funding. I dare say that this empathic approach is not replicated throughout our society, as is evident in debates about the moral necessity of cutting "entitlements" to discourage the "undeserving poor" from exploiting the system. ${ }^{21}$

The Hartlib circle, with its readily available, publicly accessible electronic archive of manuscript and printed sources, is a model for parallel historical analysis within a community-based learning course. The method translates readily to a variety of historical contexts and manuscript collections. In a similar vein, one could study perceptions of Shakespeare's plays during the English Civil War and commonwealth, when public theaters were closed by puritans and did not open again until the restoration of the monarchy in 1660 . We might gain insight into social control by guiding students through a comparative analysis of arts censorship in contemporary contexts. Moreover, the method complements critical service-learning pedagogy, which "fosters a critical consciousness, allowing students to combine action and reflection in 
classroom and community to examine both the historical precedents of the social problems addressed in their service placements and the impact of their personal action/inaction in maintaining and transforming those problems." ${ }^{22}$ As critical service learning pushes us to explore structures of inequality and the systems and private interests that keep these in place, the early modern period, with the robust social, literary, and intellectual history that we have access to on the heels of many generations of scholars, offers relatively distant yet resonant historical connections. For instructors interested in the pedagogies of justice, Hartlib and his circle offer a deep well of resources for developing students' capacity to identify structure and agency, as well as the nuances and often painful implications of a given society's competing moral philosophies. ${ }^{23}$

\section{Notes}

1. I use the terms community-based learning (CBL) and service learning interchangeably in this chapter, as it is known by both in the field. At my institution we define CBL as "a pedagogy in which faculty collaborate with community partners to identify community needs and goals and integrate these, through community-based research or class projects, into the academic goals of a course for the mutual benefit of the partner and student learning."

2. Tania D. Mitchell, "Traditional vs. Critical Service-Learning: Engaging the Literature to Differentiate Two Models," Michigan Journal of Community Learning 14, no. 2 (spring 2008): 50-65.

3. Joad Raymond, Pamphlets and Pamphleteering in Early Modern Britain (Cambridge: Cambridge University Press, 2003).

4. Mitchell, "Traditional vs. Critical Service-Learning," 55.

5. The practice of diagnosing a social or political problem metaphorically as a medical issue also has classical humanist roots, and examples abound in early modern sources. See for example Nathaniel Joceline, Parliament Physick for a Sin-Sick Nation. Or, An Ordinance of Parliament Explained, and Applyed to These Diseased Times... (London, 1644).

6. In theory and practice, the students become part of the long humanist tradition of chronicling. See Sharon Dale, Alison Williams Lewin, and Duane J. Osheim, eds., Chronicling History: Chroniclers and Historians in Medieval and Renaissance Italy (University Park: Pennsylvania State University Press, 2007).

7. Jonathan Scott, England's Troubles: Seventeenth-Century English Political Instability in European Context (Cambridge: Cambridge University Press, 2000), 18.

8. The "Great Instauration" refers to the significant millenarian strand in the Hartlib circle's thought. Charles Webster, Samuel Hartlib and the 
Advancement of Learning (Cambridge: Cambridge University Press, 1970).

9. Mark Greengrass, Michael Leslie, and Michael Hannon, eds. The Hartlib Papers (Sheffield: Humanities Research Institute, 2013) <https://www.dhi. ac.uk/hartlib/context> (accessed February 26, 2019). Hereafter referred to as $H P$.

10. The Hartlib circle's history has been documented in a robust body of secondary literature which constitutes a historiography of its own. See H. R. Trevor-Roper, Three Foreigners: The Philosophers of the Puritan Revolution (London: Macmillan, 1967); Webster, Samuel Hartlib and the Advancement of Learning; Mark Greengrass, Michael Leslie, and Timothy Ralor, eds., Samuel Hartlib and Universal Reformation: Studies in Intellectual Communication (Cambridge: Cambridge University Press, 1994). On the English Civil War as it relates to the Thirty Years War, see Scott, England's Troubles.

11. Jonathan Scott, Commonwealth Principles: Republican Writing of the English Revolution (Cambridge: Cambridge University Press, 2004), 90.

12. Johann A. Comenius, A Patterne of Universall Knowledge ...., trans. Jeremy Collier (London, 1651), 12-13. Comenius originally wrote the text in Latin around 1643, and it was translated into English and published at Hartlib's behest.

13. Johann A. Comenius, "A Reformation of Schooles Designed in Two Excellent Treatises ...," trans. Samuel Hartlib, 1642. Readers may be familiar with a related treatise: John Milton's "Of Education".

14. Printed tract, "An Act ... For the Relief, and Imployment of the Poor ...," $H P[57 / 4 / 12 / 5 B]$.

15. "Proposal For Employment Of Poor Immigrants To The City," $H P$ [53/13/1A, 1B].

16. Eric H. Ash, The Draining of the Fens: Projectors, Popular Politics, and State Building in Early Modern England (Baltimore: Johns Hopkins University Press, 2017).

17. Peter Linebaugh and Marcus Rediker, The Many-Headed Hydra: The Hidden History of the Revolutionary Atlantic (London: Verso Books, 2012).

18. Scott, England's Troubles.

19. Michael J. Braddick, State Formation in Early Modern England, c. 15501700 (Cambridge: Cambridge University Press, 2000).

20. J. C. Davis, Utopia and the Ideal Society: A Study of English Utopian Writing, 1516-1700 (Cambridge: Cambridge University Press, 1981).

21. For example: "There are the deserving poor and the undeserving poor. It used to be that way, and it became politically incorrect. We are returning to some of the old values that served people very effectively until the welfare reforms of the 1960s." Bob Woodson quoted in Charles M. Blow, "Paul Ryan and His Poverty Prophet," New York Times, July 23, 2014, Opinion section < https://www.nytimes.com/2014/07/24/opinion/ 
224 Tania Boster

charles-blow-paul-ryan-and-his-poverty-prophet.html> (accessed February 26, 2019).

22. Mitchell, "Traditional vs. Critical Service-Learning," 54.

23. See John D. Staines, "The Age of Shakespeare Versus the Age of Milton: Reopening the Noisy Theaters," Modern Language Quarterly 78, no. 3 (2017): 395-419. 


\title{
Cultivating Critical Content Knowledge: Early Modern Literature, Pre-service Teachers, and New Methodologies for Social Justice
}

\author{
Todd Butler and Ashley Boyd
}

For college and university faculty in literary studies, there is perhaps no greater-or more neglected-opportunity to support social justice and change than by working with those students who, as pre-service teachers preparing for careers in secondary education, represent the next generation of educators. Especially in large state universities, students with a focus in English education frequently comprise the majority of English majors, and in an era when the curriculum of many English departments has become increasingly attentive to the diversity of national and world literatures, courses of study for English education majors still at least expect, if not require, the study of Shakespeare as a vital element of their pre-professional preparation. Indeed, even with the significant changes presented by the recent introduction in the United States of state-level Common Core State Standards (CCSS), ${ }^{1}$ the study of Shakespeare retains its primacy within the secondary English curriculum. Shakespeare's work appears across the CCSS's contentious Exemplar Text List, ${ }^{2}$ and his plays are often used to teach many of the key skills emphasized by the CCSS, including close reading and deep content knowledge. The continuing presence of Shakespeare in grades 9-12, however, has become increasingly controversial, with local challenges to the relevance of Shakespeare's works to contemporary, multicultural classrooms escalating into not only local but also national disputes that are themselves reflective of much deeper American divides. In 2015, for example, the Washington Post sparked predictable outrage from cultural critics and internet pundits when it published a guest column by Dana Dusbiber, a teacher working at a high school in Sacramento, California, with a majority low-income and minority student population, in which she argued for the teaching of world and 
contemporary literatures that might better speak to her ethnically and socially diverse classroom. Dusbiber detailed her worry that "as long as we continue to cling to ONE (white) MAN'S view of life as he lived it so long ago, we (perhaps unwittingly) promote the notion that other cultural perspectives are less important." Perhaps, as she wrote, "It might now be appropriate for us to acknowledge him as chronicler of life as he saw it 450 years ago and leave it at that."

Especially in such an environment, preparing pre-service teachers to understand, navigate, and critically analyze the intersections between literature and contemporary questions of race, gender, class, and sexuality must itself be a key objective of the early modern classroom. Just as important, however, college and university faculty need to become more attuned to-and directly engaged with-the challenges that face our nation's high school teachers, many of whom have become not just educators but "first responders" to a range of concerns-student self-harm, abuse, and various forms of insecurity and poverty. Preparing our students (and ourselves) to meet these challenges requires that post-secondary faculty in literary studies attend to recent trends in teacher education emphasizing more inclusive approaches to teaching. Of particular importance in this regard are newly developed methodologies, themselves grounded in social justice pedagogies, for fostering in teacher candidates a greater capacity to recognize and work effectively with the varying subject positions of their students. In juxtaposing these new theories with examples drawn from William Shakespeare's A Midsummer Night's Dream and John Milton's Paradise Lost, this chapter demonstrates how faculty teaching early modern texts can pursue questions regarding social justice within a theoretically sophisticated pedagogical framework, one that will help pre-service teachers find a place-especially within more traditional school districts or curriculato examine matters of social justice. In addition, rethinking our own teaching to model a diverse range of approaches and assignments helps transform the learning experience of non-English education majors as well. Ultimately, we contend, by enabling all students to become better teachers, we can extend our pedagogy beyond the classroom to effect truly long-lasting change in both our students and the society they seek to serve.

\section{Social Justice Pedagogical and Content Knowledge}

In 1986, Lee Shulman's theory of pedagogical content knowledge (PCK) ${ }^{4}$ forever altered the landscape of teacher education. Shulman posited 
that, in addition to possessing both general pedagogical knowledge and knowledge about a subject, successful teachers also possess a specific acumen for translating subject knowledge for students in ways that cater to their learning needs and interests. Skilled educators also anticipate the difficulties students may encounter when broaching new material and therefore design ways to ensure students overcome those potential roadblocks. Such ingenuity, Shulman theorized, requires a depth of content knowledge, or "the variety of ways in which the basic concepts and principles of the discipline are organized to incorporate its facts," as well as "the set of rules for determining what is legitimate to say in a disciplinary domain." ${ }^{5}$ It also necessitates a range of pedagogical maneuvers, those skills in classroom management and organization that "transcend subject matter." The combination of both resulted in successful student learning.?

While Shulman's theory highlights the professionalized knowledge of the teacher and therefore helped to solidify the importance of teacher education, it largely ignores issues of student diversity and, even more important in our contemporary society, of social equity. Jeanne Dyches and Ashley Boyd, ${ }^{8}$ the latter of whom is a co-author here, therefore more recently reconceptualized Shulman's framework to account for such topics, theorizing a social justice pedagogical and content knowledge (SJPACK) framework for teacher education. Building upon a teacher's expertise in the concepts and terms that traditionally define a field, SJPACK integrates equity theories, current events, and political ideologies to enable teachers to translate their subject matter in ways that simultaneously respond to students' positionalities and raise their sociopolitical awareness. The result is a pedagogy that not only theorizes the nature of instruction within the classroom but also provides specific techniques whereby presumptively traditional content such as Shakespeare can help us resolve questions of cultural relevance and heighten the consciousness of social justice issues among our students. Teaching in this fashion helps turn the very canonicity of early modern texts-emblematized in the continuing presence of Shakespeare at the secondary level - into a vital entry into discussions that might otherwise be regarded as merely the product of a politicized and ideologically charged present.

The framework for SJPACK proffers three domains of knowledge with which a socially conscious teacher should engage: social justice knowledge, social justice pedagogical knowledge, and social justice content knowledge. Social justice knowledge, as the base of the paradigm, encompasses the ideas of discourse, theory, history, and agency needed to maintain a critical outlook on the world and to understand the social 
injustices that pervade our society. Social justice pedagogical knowledge refers to those approaches to teaching that utilize students' backgrounds as the basis for learning, such as culturally responsive ${ }^{9}$ and relevant ${ }^{10}$ teaching, critical pedagogies that teach students to question and critique society, ${ }^{11}$ and action-inciting methods that prompt students to organize and act on their critical consciousness. ${ }^{12}$ Finally, social justice content knowledge includes a depth of knowledge of both traditional content, "the academic vocabulary and particulars of the content area," ${ }^{13}$ such as a common interpretation of a play, and critical content, which critiques traditional content for its dominant ideological constructions and includes an alternative curriculum that can be paired for study with traditional content to draw parallels to current events and topics.

As even this necessarily brief summary suggests, pursuing a social justice pedagogy of the sort modeled by SJPACK asks teachers not to abandon what they already know but to expand beyond it. Critical content knowledge, for example, relies heavily on a strong grasp of traditional content knowledge. ${ }^{14}$ For example, a teacher still must possess a thorough understanding of The Tempest, and subsequent scholarly criticism of its colonialist and imperialist implications, to be able to draw parallels for students to contemporary controversies. SJPACK instead offers teachers a framework for pursuing more deliberately questions of social justice within their classroom teaching. In addition, it also challenges early modern faculty to engage with both the theories that many of their English education majors are learning in their education methods courses, and the professional colleagues who teach them. For example, early modernists might supplement their reading in field-specific journals (such as Shakespeare Quarterly, ELR, and Renaissance Quarterly) with reading in journals such as English Education and Research in the Teaching of English that concentrate specifically on theoretically informed and classroom-tested methods of teaching. ${ }^{15}$ As exemplified in the recent Arden volume Teaching Shakespeare with a Purpose: A Student-Centered Approach, co-authored by Ayanna Thompson (a literary and performance scholar) and Laura Turchi (a scholar of education), such connections can substantially enhance not only our teaching but also our own learning. ${ }^{16}$

There are, of course, often significant institutional barriers that hinder faculty from growing professionally in this fashion. Most immediately, while graduate programs in English may include pedagogical training in the teaching of first-year writing, rarely do they include, much less institutionalize through coursework, sustained training in literary pedagogy. Expectations of scholarly productivity often magnify this problem, as does the increasing reliance of institutions upon 
temporary faculty. Non-tenure-track faculty in particular may find that the very contingency of their positions directs them away from attempting the potentially controversial work of pursuing questions of social justice in their teaching. Improving the ability of all faculty to address more substantially the interests and needs of the large percentage of pre-service teachers in our classrooms is also frequently made more difficult by the comparative lack of interdisciplinary engagement with departments and colleges of education. Surmounting such obstacles can be difficult but, as evidenced by the establishment of the Modern Language Association's Working Group on K-16 Alliances, collaboration between secondary and post-secondary teachers is becoming increasing vital to attaining positive educational outcomes.

\section{SJPACK and the Early Modern Classroom}

In many instances, this work may best be begun by simply talking to local teachers and education faculty, pursuing collaborative teaching and grant opportunities, or even (as in the case of the present chapter) writing together. In the remainder of this chapter we thus discuss two examples of how faculty might use the frameworks suggested by new educational theories to shape the teaching of early modern literature. Both examples explore a matter of particular importance to contemporary students and faculty, namely the growing awareness of the prevalence of sexual assault and sexual harassment. In detailing these examples, drawn from two successive semesters of undergraduate teaching experienced by the early modernist co-author of this piece (Butler), we take a developmental approach, examining first an instance of what we might term intuitive or spontaneous social justice teaching, and then an example of how a more thorough attention to course and assignment design can encourage more impactful and longer-lasting experiences for both pre-service teachers and their fellow classmates.

The first example comes from a large-scale, sophomore-level "Introduction to Shakespeare" course designed for both prospective majors and other students seeking to fulfill general education requirements. Taught in the fall semester to approximately seventy-five students, the course by its nature was largely instructor-driven and reliant upon lecture and more traditional methods of assessment, such as exams and papers. Butler's assignment to the course in fall 2015 came on the heels of a campus screening the previous semester of The Hunting Ground, an influential and controversial documentary film on campus sexual assault, as well as an ongoing series of Title IX investigations of 
the university by the U.S. Department of Education. Sensitive to both the continuing campus conversation and the disproportionate incidence of sexual assault during the so-called "red zone" of August through November, Butler steered the class's early engagement with A Midsummer Night's Dream, and in particular the discussion of events in the forest, to questions of intoxication, sexual attraction, and consent. ${ }^{17}$ Drawing on this discussion, Butler concluded the class's week-long study of Midsummer, which happened to occur on a Friday, with an exhortation to the students to be careful over that weekend, and in particular to look out for each other during the various social events that could, for at least some of them, involve similarly fraught situations.

Such teaching reflects how many faculty initially pursue a more socially conscious and engaged classroom. Drawing upon their own traditional content knowledge, and informed by their own awareness of larger issues, faculty may employ the most foundational element of social justice knowledge-maintaining a critical outlook-to identify moments in texts and discussion particularly suitable for introducing more critical and contemporary content. Doing so often means being attentive to the immediate conversations of the moment and using those as occasions to shift one's teaching. Such moments can be powerful learning opportunities. Even four months later, for example, this discussion regarding sexual assault stuck with students, many of whom commented in their end-of-course evaluations that it had been important to them (and unexpected) to have a Shakespeare teacher forthrightly address such issues. In the absence of any advance planning, however, the breakneck demands of a survey course inevitably meant that attention to these and similar issues was necessarily episodic and at times in competition with the perceived demand for coverage, or what Thompson and Turchi call teaching "every word of every play." 18 Perhaps more importantly, the course still relied largely on forms of assessment-IDs and short-essay exams, the final essay-that by their very nature tended to reinforce the centrality of traditional content knowledge.

In fall 2016, by contrast, Butler sought from the outset to use ideas drawn from SJPACK and other theories of active, socially engaged learning to structure a course on the poetry and prose of John Milton. Questions of gender-based violence became a matter of regular discussion, starting with the early Maske at Ludlow, in which a young girl is held captive by a deceitful sorcerer, and continuing on through the divorce tracts of the 1640s and Milton's epic Paradise Lost. In the latter, Butler first focused discussion on Satan's encounter with Sin in Book 2. Conceived (in both senses) by Satan's rebellion, Sin's participation in incest with her creator and her subsequent rape by their joint progeny 
Death presents a particularly complex instance of sexual assault and violence. In discussing these issues, Butler again abandoned coverage to focus on a passage that has gone largely unremarked upon by literary critics. Relating to Satan her assault by Death, Sin explains: "I fled, but he pursu'd (though more, it seems, / Inflam'd with lust than rage) and swifter far, / Mee overtook his mother all dismaid" (Book 2, 790-2). Here the intrusion of the explanatory parenthetical, which goes unglossed in all major editions of the poem, evokes the complicated aftermath of sexual trauma and the tendency to explain away assault as a matter of desire rather than violence- "lust" rather than "rage." Bereft of any editorial guidance-an absence that students also later critiqued - the class struggled together with the origin of this parenthetical and thus by extension its meaning. Was it an interjection of the poem's narrative voice, suggestive thereby of the disregard encountered by assault victims? Or was it an internalization of that disregard by the victim herself? Such discussions continued to inform students' later work on the poem. Having become increasingly aware of how Milton handles questions of gender hierarchy and sexual violence, for example, students independently insisted on spending considerable time with Eve's recollection to Adam that when "thy gentle hand / Seisd mine, I yielded," expressing uncertainty that Eve is recalling a moment of necessarily positive and mutual consent (Book 4, 488-9).

When given the opportunity to think with Milton's texts in creative ways, students took them in surprising directions. In lieu of a formal analysis or response paper, for example, Butler assigned a "remix" of Paradise Lost, which asked students to take elements from the poem, combine them with other visual or audile material, and then present the resulting reading to the class. In response, one English education major designed for her fellow students a public service announcement on the dangers of sexual assault that featured an image of a young woman holding an apple, Eve's recollection of "Seisd" / "yielded," and contact information for local sexual assault and violence resources and support groups. Another English education major, taking advantage of a similar opportunity to design a teaching unit rather than a more traditional literary analysis paper, developed a syllabus, lesson plans, and assignments for using Milton to explore questions of sexual assault her own grade 9-12 students might encounter.

Compared with the first example of teaching A Midsummer Night's Dream, this second example of teaching Paradise Lost meets more fully the challenge posed to traditional teaching by SJPACK and similar theories. The more sustained attention to issues of violence and assault in the course extended the use of social justice knowledge beyond a 
single or limited series of class meetings, making it a more defining structure for the course and its content. By combining traditional disciplinary practice - in this instance, close reading - with more critical content, students were encouraged to see how the juxtaposition of texts can reveal ideological formations that might otherwise go unnoticed. They were also empowered to relate their reading to their present contexts and to situations currently prevalent in public conversations. At the same time, by enabling students to pursue projects specifically directed toward an outside audience (such as a public service announcement or teaching unit), the course's assignment sequence deliberately emphasized social justice pedagogical knowledge's link with analysis, reflection, and action. Students' learning styles and individual interests were met, and they were given the opportunity to respond to the social issue they chose through the medium that most appealed to them. Energizing the classroom in this fashion often means not only giving over discussion to students but also substantially widening the range of possible assignments in which students can apply their ideas. Indeed, the most vital moments of learning in the class, such as the public service announcement, came in giving students the initiative. More strikingly, they came from English education majors, students who are generally more ready than literary studies majors to explore how textual material might be explained to multiple audiences.

These latter examples demonstrate that one important way to advance social justice issues in the early modern classroom lies in self-consciously placing the teaching of literature at a course's center. Doing so does not necessarily require an ambitious course redesign, for, as our first classroom example suggests, even individual discussions can enable faculty and students to think more openly about how to communicate contemporary concerns through early modern texts. Simply modeling for students the ways critical content knowledge can be employed in a classroom, through critiques of traditional content as well as through current events and social issues, will likely have a vast impact on their practice. Research has shown ${ }^{19}$ again and again that teachers often teach the way they were taught, ${ }^{20}$ and this is especially relevant regarding content, ${ }^{21}$ such as Shakespeare's plays. Teaching that incorporates SJPACK thus helps English education students discern new possibilities for their own future practice, thereby extending our own classrooms to generations of students we might not otherwise encounter. Importantly, these benefits extend to other students as well. In all his courses, for example, Butler allows both education majors and non-education students (or even non-English majors) the option of designing lesson plans or teaching units for their final projects. Doing 
so not only validates English education majors as expert resources for their classmates but also encourages all students toward a more active engagement in the broader sociocultural sphere. Most importantly, for all its engagement with the immediate concerns of its students, SJPACK holds that socially conscious and effective teaching is defined not by the use of a contemporary text but by a sustained focus on combining content with reflection and action, a combination that can make the early modern classroom a lively place indeed.

\section{Notes}

1. "English Language Arts Standards," Core Standards, October 16, 2015 $<$ http://www.corestandards.org/ELA-Literacy> (accessed February 26, 2019).

2. "Appendix B: Text Exemplars and Sample Performance Tasks," Core Standards, October 16, 2015 <http://www.corestandards.org/assets/ Appendix_B.pdf $>$ (accessed February 26, 2019).

3. Dana Dusbiber in Valerie Strauss, "Teacher: Why I Don't Want to Assign Shakespeare Anymore (Even Though He's in the Common Core)," Washington Post, June 13, $2015<$ https://www.washingtonpost.com/ news/answer-sheet/wp/2015/06/13/teacher-why-i-dont-want-to-assignshakespeare-anymore-even-though-hes-in-the-common-core> (accessed February 26, 2019). Dusbiber's column prompted rejoinders from both current and future teachers, as well as responses from across the political spectrum.

4. Lee Shulman, "Those Who Understand: Knowledge Growth in Teaching," Educational Researcher 15, no. 2 (1986): 4-14.

5. Ibid., 9 .

6. Lee Shulman, "Knowledge and Teaching: Foundations of the New Reform," Harvard Educational Reviews 57, no. 1 (1987): 8.

7. Almost immediately, Shulman's conclusions were applied to studies of secondary English teachers, often with Shakespeare playing a significant role. See for example Pamela Grossman, "A Study in Contrast: Sources of Pedagogical Content Knowledge for Secondary English," Journal of Teacher Education 40, no. 5 (1989): 24-31.

8. Jeanne Dyches and Ashley Boyd, "Foregrounding Equity in Teacher Education: Toward a Model of Social Justice Pedagogical and Content Knowledge," Journal of Teacher Education, 68, no. 5 (2017): 476-90.

9. Geneva Gay, Culturally Responsive Teaching: Theory, Research, and Practice, 2nd edition (New York: Teachers College Press, 2010).

10. Gloria Ladson-Billings, "'Yes, But How Do We Do It?' Practicing Culturally Relevant Pedagogy," in White Teachers/Diverse Classrooms: A Guide to Building Inclusive Schools, Promoting High Expectations, and 
Eliminating Racism, ed. Chance W. Lewis and Julie Landsman (Herndon: Stylus Publishing, 2006), 29-42.

11. Peter McLaren, Life in Schools: An Introduction to Critical Pedagogy in the Foundations of Education, 4th edition (Boston: Pearson Education, 2003).

12. Ashley Boyd, Social Justice Literacies in the English Classroom: Teaching Practice in Action (New York: Teachers College Press, 2017).

13. Dyches and Boyd, "Foregrounding Equity in Teacher Education," 485.

14. Ibid.

15. Carlin Borsheim-Black, Michael Macaluso, and Robert Petrone, "Critical Literature Pedagogy: Teaching Canonical Literature for Critical Literacy,” Journal of Adolescent and Adult Literary 58, no. 2 (2014): 127.

16. Ayanna Thompson and Laura Turchi, Teaching Shakespeare with a Purpose: A Student-Centered Approach (London: Bloomsbury Arden Shakespeare, 2016).

17. Matthew Kimble, Andrada D. Neacsiu, William F. Flack Jr., and Jessica Horner, "Risk of Unwanted Sex for College Women: Evidence for a Red Zone," Journal of American College Health 57, no. 3 (2008): 331-7.

18. Thompson and Turchi, Teaching Shakespeare with a Purpose, 14.

19. Dan Lortie, Schoolteacher: A Sociological Study (Chicago: University of Chicago Press, 1975).

20. Pamela Grossman, "Overcoming the Apprenticeship of Observation in Teacher Education Coursework," Teaching and Teacher Education 7, no. 4 (1991): 345-57.

21. Denise S. Mewborn and Andrew M. Tyminski, “Lortie's Apprenticeship of Observation Revisited," For the Learning of Mathematics 26, no. 3 (2006): 30-2. 


\title{
An Afterword About Self/ Communal Care
}

\author{
Ayanna Thompson
}

It is interesting to note that the terms "Shakespeare" and "social justice" are neither assumed to be synonymous nor necessarily "relevant" to each other. I find this particularly ironic because as a black, female Shakespeare scholar, I have come to think of Shakespeare as my great secret weapon. I frequently wield him in the service of dialogues about equality, justice, and progress as a hidden dagger that slices to the heart of the matter. As a graduate student, I specifically chose not to specialize in African-American literature and culture because I thought (naively and mistakenly) that I would not get a large enough set of interlocutors; many who are resistant to pedagogies/scholarship of justice simply opt not to engage with (i.e. ignore all together) African-American literature, culture, and scholarship. Shakespeare, on the other hand, has been so thoroughly adopted as both the epitome of high culture and as quintessentially American (regardless of the pesky fact of his birth in Stratford-upon-Avon) that many come to his works on the page, the stage, and in the classroom with their defenses down. They are more open and available to complex social issues when they encounter them in Shakespeare's works. My students regularly comment that they come to my classes to study Shakespeare but leave having learned so much more about our contemporary world. I know that many of you will have heard similar comments.

What this collection demonstrates so palpably and practically, however, is the fact that framing discussions of Shakespeare through a social justice lens is beneficial not only politically and socially, but also intellectually. Many of the chapters show how creating innovative social justice pedagogy also renders more complex readings of Shakespeare's plays and, by extension, all texts. For instance, Carla Della Gatta's work aims to help students "gain confidence in their ability to question what was previously perceived as venerated authority 
or fact," a transferable skill set that enables more complex readings of Shakespeare, rhetoric, and literary and nonliterary texts as a whole. Likewise, Debapriya Sarkar's focus on utopias encourages students to think constitutively about the possibilities for world-making in their own lives and Shakespeare's deployment of genre. And Sawyer Kemp's excellent chapter about a trans approach to Shakespeare not only does justice by our trans students, but also does justice by Hamlet. In other words, this collection reveals that while Shakespeare can be a secret weapon used to get to social justice issues, social justice lenses provide deeper, more sophisticated, and potentially more complex understandings of Shakespeare. Shakespeare needs social justice pedagogies as much as social justice pedagogies benefit from Shakespeare.

My relationship with Shakespeare as a tool for social justice has been a fairly smooth one to date. While my work has been greeted with some overt skepticism (my favorite rejection letter came from Shakespeare Quarterly, informing me that my research on race did not live up to the import of a flagship journal!), the overwhelming technique for resistance to my work has been non-engagement, a willful neglect of not only my work but also the growing body of work that has been produced in early modern race studies. But I have had a few face-to-face encounters with white supremacists who have attended my public lectures, and those moments have made it clear that we need to have a larger discussion about self-care.

Teaching social justice through Shakespeare must be placed in productive dialogue on both theoretical and practical terms, as this collection makes abundantly clear, but I want to raise the specter of self-care, which is not usually a part of our Shakespeare discourse. We might need to learn from critical race theorists and social activists about exactly how to protect ourselves when the dialogues move beyond the relatively safe confines of the classroom. I had the good fortune to participate in the 2018 Shakespeare and Race festival organized by Farah Karim-Cooper at Shakespeare's Globe in London, and the critical race theorists who attended and presented, Kimberlé Crenshaw, Luke Harris, and Devon Carbado, were much more attentive to issues of care. While they presented their work in a traditional conference fashion, they did not approach the dialogues in the conference in a traditional fashion: they asked climate questions about the field in general; they asked debriefing questions about people's emotional states at key moments; and they asked what could have been communicated differently to ease some of the tensions that arose. I watched in awe as these legal and critical race scholars modeled how to attend to both the intellectual content presented and the individual emotions experienced. 
One of the things I took away from the Shakespeare and Race festival was the sense that the scholars who have been attempting to put Shakespeare and pedagogies of justice into productive dialogue do not often reveal how emotionally taxing that work can be. We only ever reveal the emotional labor in quiet, safe spaces. Those spaces are important, and I have relied on them heavily throughout my career (hello, Negresses!), but they do render the extraordinary emotional labor invisible to those not invited into the safe spaces. We have been so focused on justifying the need for this kind of work-it is incredibly pressing "now, now, very now" - that we do not often feel safe admitting what might be perceived as a weakness.

But once again, I look to this collection because it offers essays that are amazingly forthright. Eric L. De Barros's chapter articulates so clearly the mental tax Shakespeareans of color face in predominantly white institutions of higher education; we have to work exceptionally hard to be seen as an authority. And Allison P. Hobgood discovers a "feminist disability pedagogy of disorientation" when teaching Shakespeare in Japan. Revealing both her cultural disorientation and debilitating migraines, Hobgood shows the potential benefits of abandoning a need for mastery, and exploring instead "an immersive, deeply affective, real-time experiential learning." Likewise, Ruben Espinosa's chapter explains how he allows his Latinx students to explore their at times tenuous relationship with the United States through creative retellings of Shakespeare. For them, Shakespeare becomes a place in which fragility and vulnerability can be explored. These essays represent a refreshingly new turn in Shakespeare studies, a turn that admits the labor and toll that social justice work can require. Unlike many older models of scholarship, they admit vulnerability, weakness, and fatigue, and they show the intellectual benefits of reading Shakespeare from that position.

Teaching social justice through Shakespeare is important; it is moving our cultural and intellectual dials in significant ways. Nonetheless, this work is incredibly hard and it requires more than intellectual vivacity and originality; it requires emotional resilience and fortitude. How can we get ourselves as individuals and communities into shape? I would love to read some companion essays about strategies for self-care when exploring teaching social justice. I can imagine some strategies like working collaboratively so that one can spread and share the emotional intensity. I am not at all surprised that this volume is co-edited, for example. Wendy Beth Hyman and Hillary Eklund's partnership in editing this volume provides one model for creating a community of care. The two co-authored pieces in this collection also model strategies for sharing the emotional weight this work can require. Rebecca 
Laroche and Jennifer Munroe explain how we can stretch the bounds of the "classroom," and they also implicitly pattern new ways to imagine our interconnectedness. Likewise, Todd Butler and Ashley Boyd's co-authored chapter demonstrates how colleagues can push one another toward a social justice focus that "helps English education students discern new possibilities for their own future practice, thereby extending our own classrooms to generations of students we might not otherwise encounter."

How else can we creatively address structural issues so as to render self-care less of an individual necessity? What needs to be understood at the unit level, the college level, and the institutional level to render this invisible work visible? What structural changes can we suggest and explore? Are there networks we can build outside of our institutions to foster communal care? What about in our professional organizations? Is there something the Shakespeare Association of America (SAA) or the Renaissance Society of America (RSA) could and should do? How can we build alliances with others doing this kind of work: medievalists, critical race scholars, education specialists, theater practitioners, and so on? If we manage to build these alliances, how can we sustain them? And how can we get our extra-institutional research centers-like the Folger Shakespeare Library, Huntington, Newberry, and Getty-to support this kind of work?

I realize that answering these questions requires more labor and time by the very group of people who may already be intellectually and emotionally overburdened, but many of us are already having these discussions quietly and unsystematically. Now it is time to have them out loud, openly, and systematically. If we argue that teaching social justice through Shakespeare benefits us all socially, politically, and intellectually, then we must also argue that caring for the individuals and communities who do this type of work benefits society as a whole as well. 


\section{Bibliography}

Adams, Joseph Quincy. "The Folger Shakespeare Memorial Dedicated April 23, 1932: Shakespeare and American Culture." Spinning Wheel, July 1932: 212-15, 229-31.

Adams, Maurianne. "Pedagogical Frameworks for Social Justice Education." In Teaching for Diversity and Social Justice, 2nd edition, ed. Maurianne Adams, Lee Anne Bell, and Pat Griffin, 15-33. New York: Routledge, 2007.

Ahmed, Sara. "Melancholic Migrants." In The Promise of Happiness, 121-59. Durham, NC: Duke University Press, 2010.

Alaimo, Stacy. Bodily Natures: Science, Environment, and the Material Self. Bloomington: Indiana University Press, 2010.

Al-Bassam, Sulayman. The Al-Hamlet Summit: Original Playscript in English and Arabic with an Introduction by Graham Holderness. Hatfield: University of Hertfordshire Press, 2006.

Alcantar, Ricky. "What I Learned About Teaching from Listening to Serial." Medium: The Synapse, December 17, 2014. <https://medium.com/synapse/ what-i-learned-about-teaching-from-listening-to-serial-f91a5b4304e1>.

American Association of University Professors. "Trends in the Academic Labor Force 1975-2015,” March 2017. <https://www.aaup.org/our-work/ research> (accessed February 25, 2019).

Anzaldúa, Gloria. Borderlands/La Frontera: The New Mestiza, 4th edition. San Francisco: Aunt Lute Books, 1987.

"Appendix B: Text Exemplars and Sample Performance Tasks." Core Standards, October 16, 2015. <http://www.corestandards.org/assets/Appendix_B. pdf $>$ (accessed February 26, 2019).

Appignanesi, Richard. Macbeth. Manga Shakespeare Series. New York: Abrams, 2008.

Aristotle. On Poetics. Trans. Seth Benardete and Michael Davis. South Bend: St. Augustine's Press, 2002.

- The Nicomachean Ethics. Trans. Martin Ostwald. New York: Macmillan, 1962.

- The Poetics. In Critical Theory Since Plato, ed. Hazard Adams and Leroy Searle, 52-68. Boston: Wadsworth, 2005. 
Ash, Eric H. The Draining of the Fens: Projectors, Popular Politics, and State Building in Early Modern England. Baltimore: Johns Hopkins University Press, 2017.

Attridge, Derek. The Singularity of Literature. New York: Routledge, 2004.

Baber, Ceola R. "From Liberal Teacher to Liberated Teacher Educator." In Critical Race Theory and Perspectives on the Social Studies: The Profession, Policies, and Curriculum, ed. Gloria Ladson-Billings, 45-69. Charlotte: Information Age, 2003.

Baldwin, Davarian L. Chicago's New Negroes: Modernity, the Great Migration, and Black Urban Life. Chapel Hill: University of North Carolina Press, 2009.

Baldwin, James. "Why I Stopped Hating Shakespeare." In The Cross of Redemption: Uncollected Writings, ed. Randall Kenan, 65-9. New York: Vintage International, 2011.

Barad, Karen. Meeting the Universe Halfway: Quantum Physics and the Entanglement of Matter and Meaning. Durham, NC: Duke University Press, 2007.

Barker, Howard. Arguments for a Theatre. London: John Caldor Press, 1989.

Bates, Catherine. Masculinity, Gender, and Identity in the English Renaissance Lyric. Cambridge: Cambridge University Press, 2007.

Bates, Laura. “'To Know My Deed': Finding Salvation Through Shakespeare.” In Performing New Lives: Prison Theatre, ed. Jonathan Shailor, 33-48. London: Jessica Kingsley, 2011.

Bearden, Elizabeth B. "Before Normal, There Was Natural: John Bulwer, Disability, and Natural Singing in Early Modern England and Beyond." PMLA 132, no. 1 (January 2017): 33-50.

Beckett, Samuel. Waiting for Godot: A Tragicomedy in Two Acts. New York: Grove Atlantic, 2011.

Benjamin, Walter. Illuminations. Trans. Harry Zorn. London: Pimlico, 1999.

Bergstrom, Carl T., and Jevin West. "Calling Bullshit in the Age of Big Data." 2017. <https://callingbullshit.org> (accessed February 14, 2017).

Bernstein, J. M. “Tragedy." In The Oxford Handbook of Philosophy and Literature, ed. Richard Eldridge, 71-3. New York: Oxford University Press, 2009. Bertram, Corrine C., and Sue Crowley. "Teaching About Sexual Violence in Higher Education: Moving from Concern to Conscious Resistance." Journal of Women Studies 33, no. 1 (January 2012): 63-82.

Bérubé, Michael, Hester Blum, Christopher Castiglia, and Julia Spicher Kasdorf. "Community Reading and Social Imagination." PMLA 125, no. 2 (March 2010): 418-25.

Bhabha, Homi K. The Location of Culture. Abingdon: Routledge, [1994] 2004. Bhardwaj, Vishal. Omkara. Eros International; Shemaroo Entertainment Limited, 2006.

Biggers, Jeff. “The 'Madness' of the Tucson Book Ban: Interview with Mexican American Studies Teacher Curtis Acosta on The Tempest." HuffPost, 
January 17, 2012. <https://www.huffingtonpost.com/jeff-biggers/tucsonethnic-studies-_b_1210393.html> (accessed February 21, 2019).

Birmingham, Kevin. "The Great Shame of Our Profession." Chronicle of Higher Education, February 12, 2017. <https://www.chronicle.com/article/ The-Great-Shame-of-Our/239148> (accessed February 25, 2019).

Bland, Shelia Rose. "How I Would Direct Othello." In Othello: New Essays by Black Writers, ed. Mythili Kaul, 29-41. Washington, DC: Howard University Press, 1997.

Block, Joshua. "A Court Ruling in Gavin Grimm's Case Is a Very Big Deal." American Civil Liberties Union, May 23, 2018. <https://www.aclu.org/ blog/lgbt-rights/transgender-rights/court-ruling-gavin-grimms-case-verybig-deal $>$ (accessed February 21, 2019).

Bloom, Harold. Shakespeare: The Invention of the Human. New York: Riverhead Books, 1998.

Blow, Charles M. "Paul Ryan and His Poverty Prophet." New York Times, July 23, 2014. Opinion section. <https://www.nytimes.com/2014/07/24/ opinion/charles-blow-paul-ryan-and-his-poverty-prophet.html> (accessed February 26, 2019).

Borsheim-Black, Carlin, Michael Macaluso, and Robert Petrone. "Critical Literature Pedagogy: Teaching Canonical Literature for Critical Literacy." Journal of Adolescent and Adult Literary 58, no. 2 (2014): 123-33.

Bourdieu, Pierre. Language and Symbolic Power. Ed. John Thompson. Trans. Gino Raymond and Matthew Adamson. Cambridge, MA: Harvard University Press, 1982.

Boyd, Ashley. Social Justice Literacies in the English Classroom: Teaching Practice in Action. New York: Teachers College Press, 2017.

Braddick, Michael J. State Formation in Early Modern England, c. 1550-1700. Cambridge: Cambridge University Press, 2000.

Brady, Jeff. "When a Transgender Person Uses a Public Bathroom, Who Is At Risk?" NPR.org, May 15, 2016. <https://www.npr. org/2016/05/15/477954537/when-a-transgender-person-uses-a-publicbathroom-who-is-at-risk> (accessed February 21, 2019).

Brame, Cynthia J. "Flipping the Classroom." Vanderbilt University: Center for Teaching, 2013. <https://cft.vanderbilt.edu/guides-sub-pages/flipping-theclassroom > (accessed February 22, 2019).

Brammall, Kathryn, and Whitney Leeson. "Feminist Forum at the SCSC: Teaching and Activism in a Transformed Landscape." Sixteenth Century Journal 48, no. 4 (winter 2017): 879-83.

Brecht, Bertolt. Brecht on Theatre: The Development of an Aesthetic. Ed. and trans. John Willet. London: Methuen, 1964.

Bristol, Michael D. Shakespeare's America, America's Shakespeare. New York: Routledge, 1990.

Brooks, Gwendolyn. "The Lovers of the Poor.” Poetry Foundation, October 6, 2017. <https://www.poetryfoundation.org/poems/43317/the-lovers-of-thepoor $>$ (accessed February 27, 2019). 
Brown, David Sterling. "(Early) Modern Literature: Crossing the Color-Line.” Radical Teacher 105 (summer 2016). <http://radicalteacher.library.pitt. edu/ojs/index.php/radicalteacher/article/download/255/190> (accessed June 23, 2019).

Brown, Carlyle. The African Company Presents Richard III. New York: Dramatists Play Service, 1998.

Bruce, John Edward. "A Speech to Ye Friends of Shakespeare" (1916). John Edward Bruce Papers, Schomburg Center for Black Culture.

- The Selected Writings of John Edward Bruce: Militant Black Journalist. Ed. Peter Gilbert. New York: Arno Press, 1971.

Building Changes. "My Name Is Not 'Those People," 2009. <https:/www. youtube.com/watch?v $=$ hQWbkVqZKeo $>$ (accessed February 27, 2019).

Butler, Judith. Bodies That Matter: On the Discursive Limits of "Sex". New York: Routledge, 1993.

Caddoo, Cara. "The Birth of a Nation, Police Brutality, and Black Protest." Journal of the Gilded Age and Progressive Era 14, no. 4 (October 2015): 608-11.

Campana, Joseph. "Epilogue: H Is for Humanism." In Renaissance Posthumanism, ed. Scott Maisano and Joseph Campana, 283-316. New York: Fordham University Press, 2016.

Campbell, Mary B. The Witness and the Other World: Exotic European Travel Writing, 400-1600. Ithaca: Cornell University Press, 1988.

-. Wonder and Science: Imagining Worlds in Early Modern Europe. Ithaca: Cornell University Press, 1990.

Carbone, Courtney. Macbeth \#killingit. OMG Shakespeare Series. New York: Penguin Random House, 2016.

"Care Home Massacre Probed as Mercy Killing." Japan Times Online, July 27, 2016. <https:/www.japantimes.co.jp/news/2016/07/27/national/crimelegal/suspect-sagamihara-care-facility-mass-murder-says-no-remorse $>$ (accessed February 21, 2019).

Carlson, Jen. "Flashback: Growing Manhattan, 1916." Gothamist. <http:// gothamist.com/2011/01/11/flashback_manhattan_1916.php> (accessed July 1, 2017).

Carter, Angela M. “Teaching with Trauma: Trigger Warnings, Feminism, and Disability Pedagogy.” Disability Studies Quarterly 35, no. 2 (July 2015): 9-19.

Cave, Damien. “Officer Darren Wilson's Grand Jury Testimony in Ferguson, Mo., Shooting." New York Times, November 25, 2014, U.S. section. <https://www.nytimes.com/interactive/2014/11/25/us/darren-wilsontestimony-ferguson-shooting.html $>$ (accessed February 20, 2019).

Cavendish, Margaret. The Blazing World and Other Writing. Ed. Kate Lilley. New York: Penguin, 1992.

Chappelle, Aleta. Romeo and Juliet in Harlem. DVD. Library Video Company, 2015. 
Chavez, Leo R. The Latino Threat: Constructing Citizens, Immigrants, and the Nation, 2nd edition. Stanford: Stanford University Press, 2008.

Chen, Mel. "The Race for Cripistemology." Journal of Literary and Cultural Disability Studies 8, no. 2 (January 2014): 172-82.

Childress, Alice. "A Candle in a Gale Wind.” In Black Women Writers (19501980): A Critical Evaluation, ed. Mari Evans, 111-16. New York: Anchor Books, 1984.

Cohen, Patricia. "A Rising Call to Promote STEM Education and Cut Liberal Arts Funding." New York Times, February 21, 2016, Business Day section. $<$ https://www.nytimes.com/2016/02/22/business/a-rising-call-to-promotestem-education-and-cut-liberal-arts-funding.html> (accessed February 27, 2019).

Cole, Rick, and Beth Kramer. "Podcasts and the Twenty-First Century College Classroom." Impact: The Journal of the Center for Interdisciplinary Teaching and Learning, summer 2017. <http://sites.bu.edu/impact/ previous-issues/impact-summer-2017/podcasts-and-the-twenty-firstcentury-college-classroom > (accessed February 22, 2019).

Collette, Matt. “To Download or Not to Download," Slate Magazine, November 20, 2014. http://www.slate.com/blogs/schooled/2014/11/20/serial_replaces_ shakespeare_in_one_california_english_class.html> (accessed February 22, 2019).

Comenius, Johann A. A Patterne of Universall Knowledge . . Trans. Jeremy Collier. London, 1651.

-. "A Reformation of Schooles Designed in Two Excellent Treatises . . ." Trans. Samuel Hartlib, 1642.

Committee A on Academic Freedom and Tenure. "On Trigger Warnings." AAUP, August 2014. <http://www.aaup.org/report/trigger- warnings>.

Conti, Norman, Linda Morrison, and Katherine Pantaleo. "All the Wiser: Dialogic Space, Destigmatization, and Teacher-Activist Recruitment.” Prison Journal 93, no. 2 (June 2013): 163-88.

“Conway: Press Secretary Gave 'Alternative Facts'." NBC News, January 22, 2017. <https:/www.nbcnews.com/meet-the-press/video/conway-presssecretary-gave-alternative-facts-860142147643> (accessed February 15, 2019).

Corredera, Vanessa. “'Not a Moor Exactly': Shakespeare, Serial, and Modern Constructions of Race." Shakespeare Quarterly 67, no. 1 (2016): 30-50.

Costa, Arthur L., and Bena Kallick, eds. Learning and Leading With Habits of Mind. Alexandria, VA: Association for Supervision and Curriculum Development, 2009.

Coyne, Jerry A. "Life Is 'Triggering.' The Best Literature Should Be, Too.” New Republic, May 14, 2015. <https://newrepublic.com/article/121790/lifetriggering-best-literature-should-be-too $>$ (accessed February 15, 2019).

Dale, Sharon, Alison Williams Lewin, and Duane J. Osheim, eds. Chronicling History: Chroniclers and Historians in Medieval and Renaissance Italy. University Park: Pennsylvania State University Press, 2007. 
Davis, J. C. Utopia and the Ideal Society: A Study of English Utopian Writing, 1516-1700. Cambridge: Cambridge University Press, 1981.

Davis, Simone Weil, and Barbara Roswell. Turning Teaching Inside Out: A Pedagogy of Transformation for Community-Based Education. New York: Palgrave, 2013.

De Barros, Eric L. "(Ig)Noble Lies: Personal Historicism and Richard Mulcaster's Positions Concerning the [Training] Up of Children (1581).” Changing English: Studies in Culture and Education 20, no. 3 (2013): 317-26.

Derrida, Jacques. "Aphorism Countertime." In Acts of Literature, ed. Derek Attridge, trans. Nicholas Royle, 414-33. New York: Routledge, 1992.

Donaldson, Peter S. "About MIT Global Shakespeares," 2010. <http:// globalshakespeares.mit.edu/about> (accessed February 15, 2019).

Dotson, Kristie. "Tracking Epistemic Violence, Tracking Practices of Silencing." Hypatia: A Journal of Feminist Philosophy 26, no. 2 (2011): 236-57.

Dyches, Jeanne, and Ashley Boyd. "Foregrounding Equity in Teacher Education: Toward a Model of Social Justice Pedagogical and Content Knowledge." Journal of Teacher Education, 68, no. 5 (2017): 476-90.

"English Language Arts Standards." Core Standards, October 16, 2015. < http:// www.corestandards.org/ELA-Literacy> (accessed February 26, 2019).

Enterline, Lynn. Shakespeare's Schoolroom: Rhetoric, Discipline, Emotion. Philadelphia: University of Pennsylvania Press, 2012.

Escolme, Bridget. "Costume, Disguise and Self-Display." In Shakespeare's Theatres and the Effects of Performance, ed. Farah Karim-Cooper and Tiffany Stern, 118-40. London: Bloomsbury, 2013.

Espinosa, Ruben. "Beyond The Tempest: Language, Legitimacy, and La Frontera." In The Shakespeare User: Critical and Creative Appropriations in a Networked Culture, ed. Valerie M. Fazel and Louise Geddes, 41-62. New York: Palgrave Macmillan, 2017.

Essig, Laurie. “Trigger Warnings Trigger Me.” Chronicle of Higher Education Blogs: The Conversation, March 10, 2014. <https://www.chronicle.com/ blogs/conversation/2014/03/10/trigger-warnings-trigger-me> (accessed February 22,2019$)$.

Euripedes. Alcestis, Medea, Hippolytus. Ed. Diane Arnson Svelien. Indianapolis: Hackett, 2007.

Faulkner, William. Requiem for a Nun. New York: Random House, 1951.

Flaherty, Colleen. “Trigger Unhappy.” Inside Higher Ed, April 14, 2014. < https:// www.insidehighered.com/news/2014/04/14/oberlin-backs-down-triggerwarnings-professors-who-teach-sensitive-material> (accessed February 22, 2019).

Flanagan, Linda. "What Teens Are Learning From 'Serial' and Other Podcasts." KQED: News, March 11, 2015. <https://www.kqed.org/mindshift/39461/ what-teens-are-learning-from-serial-and-other-podcasts $>$ (accessed February 22, 2019). 
Flock, Elizabeth. "Why These Librarians Are Protesting Trump's Executive Orders.” PBS NewsHour, February 13, 2017. <https://www.pbs.org/news hour/art/librarians-protesting-trumps-executive-orders $>$ (accessed February 25, 2019).

Ford, Derek R. Politics and Pedagogy in the "Post-Truth" Era: Insurgent Philosophy and Praxis. New York: Bloomsbury, 2018.

Freebody, Kelly, and Michael Finneran. "Introduction." In Drama and Social Justice: Theory, Research and Practice in International Contexts, ed. Kelly Freebody and Michael Finneran, 1-5. New York: Routledge, 2015.

Freeman, Thomas. "The Rise of Prison Literature." Huntington Library Quarterly 27, no. 2 (June 2009): 133-46.

Freire, Paulo. Education for Critical Consciousness. New York: Bloomsbury Academic, 2013.

-. Pedagogy of Hope: Reliving Pedagogy of the Oppressed. Trans. Robert R. Barr. New York: Bloomsbury Academic, 2014.

- Pedagogy of the Oppressed. Trans. Myra Bergman Ramos. New York: Penguin Books, 1996.

-. Pedagogy of the Oppressed. Trans. Myra Bergman Ramos. New York: Continuum, 2000.

"Frequently Asked Questions About Transgender People." National Center for Transgender Equality, July 9, 2016. <https://transequality.org/issues/ resources/frequently-asked-questions-about-transgender-people> (accessed February 21, 2019).

Friedman, Sarah. "Vanderbilt Students Get Added to Racist GroupMe Chat." Vanderbilt Hustler blog, November 14, 2016. <http://vanderbilthustler. $\mathrm{com} /$ featured/vanderbilt-students-get-added-to-racist-groupme-chat. html> (accessed February 22, 2019).

Fuller, Mary C. Voyages in Print: English Travel to America, 1576-1624. Cambridge: Cambridge University Press, 1995.

Gafney, Julie L. “Teaching Serial at the Criminal Justice College: Discomforting Ethics and Interdisciplinary Methods for Critical Thinking." Impact: The Journal of the Center for Interdisciplinary Teaching and Learning, summer 2017. <http://sites.bu.edu/impact/previous-issues/impact-summer-2017/ teaching-serial-at-the-criminal-justice-college-discomforting-ethics-andinterdisciplinary-methods-for-critical-thinking> (accessed February 22, 2019).

Gamerman, Ellen. "'Serial' Podcast Catches Fire." Wall Street Journal, November 13, 2014. <https://www.wsj.com/articles/serial-podcast-catchesfire-1415921853> (accessed February 22, 2019).

Gay, Geneva. Culturally Responsive Teaching: Theory, Research, and Practice, 2nd edition. New York: Teachers College Press, 2010.

"G.G. v. Gloucester County School Board." American Civil Liberties Union, March 6, 2017. <https://www.aclu.org/cases/gg-v-gloucester-countyschool-board $>$ (accessed February 21, 2019).

Giroux, Henry A. On Critical Pedagogy. New York: Continuum, 2011. 
Godsey, Michael. "The Value of Using Podcasts in Class.” The Atlantic, March 17, 2016. <https://www.theatlantic.com/education/archive/2016/03/thebenefits-of-podcasts-in-class/473925> (accessed February 22, 2019).

Goodey, C. F. A History of Intelligence and "Intellectual Disability": The Shaping of Psychology in Early Modern Europe. Burlington: Ashgate, 2011.

Grafton, Anthony, and Lisa Jardine. From Humanism to the Humanities: Education and the Liberal Arts in Fifteenth-and Sixteenth-Century Europe. Cambridge, MA: Harvard University Press, 1986.

Green, William A. "Caliban by the Yellow Sands: Percy MacKaye's Adaptation of The Tempest." Maske und Kothurn 31, no. 1 (1989): 59-66.

Greenblatt, Stephen. "Shakespeare Explains the 2016 Election." New York Times, October 8, 2016. <https:/www.nytimes.com/2016/10/09/opinion/ sunday/shakespeare-explains-the-2016-election.html> (accessed February 20, 2019).

-. "What Is the History of Literature?" Critical Inquiry 23, no. 3 (spring 1997): 460-81. <https://doi.org/10.1086/448838> (accessed February 25, 2019).

Greengrass, Mark, Michael Leslie, and Michael Hannon. The Hartlib Papers. Sheffield: Humanities Research Institute, 2013. < https:/www.dhi.ac.uk/ hartlib/context> (accessed February 26, 2019).

Greengrass, Mark, Michael Leslie, and Timothy Ralor, eds. Samuel Hartlib and Universal Reformation: Studies in Intellectual Communication. Cambridge: Cambridge University Press, 1994.

Grobman, Laurie. "Is There a Place for Service Learning in Literary Studies?" Profession, 2005: 129-40.

Grossman, Pamela. "A Study in Contrast: Sources of Pedagogical Content Knowledge for Secondary English." Journal of Teacher Education 40, no. 5 (1989): 24-31.

-. "Overcoming the Apprenticeship of Observation in Teacher Education Coursework." Teaching and Teacher Education 7, no. 4 (1991): 345-57.

H. R. The New Atlantis. Begun by the Lord Verulam, Viscount St. Albans: And Continued by R. H. Esquire. Wherin Is Set Forth a Platform of Mechanical Government, Etc. London, 1660.

Hackman, Heather W. "Five Essential Components for Social Justice Education." Equity and Excellence in Education 38 (2005): 103-9.

Halberstam, Jack. In a Queer Time and Place: Transgender Bodies, Subcultural Lives. New York: New York University Press, 2005.

-. "You Are Triggering Me! The Neo-liberal Rhetoric of Harm, Danger and Trauma.” Bully Bloggers, July 5, 2014. < https://bullybloggers.wordpress. com/2014/07/05/you-are-triggering-me-the-neo-liberal-rhetoric-of-harmdanger-and-trauma $>$ (accessed February 22, 2019).

Hall, Kim F. “'These Bastard Signs of Fair': Literary Whiteness in Shakespeare's Sonnets.” In Post-colonial Shakespeares, ed. Ania Loomba and Martin Orkin, 64-83. New York: Routledge, 1998. 
- Things of Darkness: Economies of Race and Gender in Early Modern England. Ithaca: Cornell University Press, 1995.

Hansen, Matthew C. “'O Brave New World': Service-Learning and Shakespeare." Pedagogy 11, no. 1 (winter 2011): 177-97.

Haraway, Donna. When Species Meet. Minneapolis: University of Minneapolis Press, 2008.

Hartley, L. P. The Go-Between. London: Hamish Hamilton, 1953.

Heyer, Katharina. Rights Enabled: The Disability Revolution from the US, to Germany and Japan, to the United Nations. Ann Arbor: University of Michigan Press, 2015.

Hilinsky-Rosick, Carly M., and Alicia N. Blackmer. "An Exploratory Examination of the Impact of the Inside-Out Prison Exchange Program." Journal of Criminal Justice Education 25, no. 3 (May 2014): 386-97.

Hitt, Jack. Act V. This American Life, n.d. <https://www.thisamericanlife. org/218/act-v> (accessed February 26, 2019).

Hobgood, Allison P. “Teeth Before Eyes: Illness and Invisibility in Shakespeare's Richard III." In Disability, Health, and Happiness in Shakespeare, ed. Sujata Iyengar, 24-38. New York: Routledge, 2015.

Hobgood, Allison P., and David Houston Wood. "Disabled Shakespeares." Disability Studies Quarterly 29, no. 4 (2009). <http://dsq-sds.org/article/ view/991/1183> (accessed February 21, 2019).

— and - Recovering Disability in Early Modern England. Columbus: Ohio State University Press, 2013.

Holland, Peter. "Shakespeare, Humanity Indicators, and the Seven Deadly Sins." Borrowers and Lenders: The Journal of Shakespeare and Appropriation 7, no. 1 (2012). <http://www.borrowers.uga.edu/783091/show> (accessed February 21, 2019).

Hollins, Caprice, and Ilsa Govan. Diversity, Equity, and Inclusion: Strategies for Facilitating Conversations on Race. New York: Rowman and Littlefield, 2015.

hooks, bell. "Loving Blackness as Political Resistance.” In Killing Rage: Ending Racism, 146-62. New York: Henry Holt, 1995.

- Teaching Community: A Pedagogy of Hope. New York: Routledge, 2003.

Hornstein, Gail A. "Why I Dread the Accommodations Talk." Chronicle of Higher Education, March 26, 2017. <https:/www.chronicle.com/article/ Why-I-Dread-the-Accommodations/239571> (accessed February 22, 2019).

Hubbard, Ben. "Behind Barbed Wire, Shakespeare Inspires a Cast of Young Syrians.” New York Times, March 31, 2014, Middle East section. <https:// www.nytimes.com/2014/04/01/world/middleeast/behind-barbed-wireshakespeare-inspires-a-cast-of-young-syrians.html> (accessed February 27, 2019).

Hume, David. "Of the Influencing Motives of the Will." In A Treatise on Human Nature, ed. Ernest G. Mossner, 153-61. London: Penguin Books, 1985. 
Hutson, Lorna. The Invention of Suspicion: Law and Mimesis in Shakespeare and Renaissance Drama. Oxford: Oxford University Press, 2007.

Hyman, Wendy Beth. Impossible Desire and the Limits of Knowledge in Renaissance Poetry. Oxford: Oxford University Press, 2019.

"Introducing the YouTube U.S. Election Hub." YouTube, August 21, 2012. $<$ https:/youtu.be/Ktkx1D0huTA> (accessed February 25, 2019).

Irving, Simon, and Jenny Helin. "A World for Sale: An Ecofeminist Reading of the Sustainable Development Discourse." Gender, Work and Organization 25, no. 3 (May 2018): 264-78.

Islas, Arturo. La Mollie and the King of Tears. Albuquerque: University of New Mexico Press, 1996.

"Issues: Housing and Homelessness." National Center for Transgender Equality, 2015. <http://www.transequality.org/issues/housing-homelessness> (accessed February 21, 2019).

Jackson II, Ronald L., and Rex Crawley. "White Student Confessions About a Black Male Professor: A Cultural Contracts Theory Approach to Intimate Conversations About Race and Worldview.” Journal of Men's Studies 12, no. 1 (fall 2003): 25-41.

Jaschik, Scott. "Kentucky's Governor vs. French Literature," Inside Higher Ed, February 1, 2016. <https://www.insidehighered.com/quicktakes/ 2016/02/01/kentuckys-governor-vs-french-literature> (accessed February 22, 2019).

- "Making a Point by Moving Shakespeare's Portrait," Inside Higher Ed, December 14, 2016. <https:/www.insidehighered.com/news/2016/12/14/ students-penn-remove-portrait-shakespeare > (accessed February 20, 2019).

Jay, Gregory. "Service Learning, Multiculturalism, and the Pedagogies of Difference." Pedagogy: Critical Approaches to Teaching Literature, Language, Composition, and Culture 8, no. 2 (spring 2008): 255-81.

Joceline, Nathaniel. Parliament Physick for a Sin-Sick Nation. Or, An Ordinance of Parliament Explained, and Applyed to These Diseased Times . . . London, 1644.

Johnson, James Weldon. Black Manhattan. New York: Arno Press, 1968.

Jones, Ann Rosalind, and Peter Stallybrass. "Transvestism and the 'Body Beneath': Speculating on the Boy Actor." In Renaissance Clothing and the Materials of Memory, 207-19. Cambridge: Cambridge University Press, 2000.

Jones, Michelle. "Incarcerated Scholars, Qualitative Inquiry, and Subjugated Knowledge: The Value of Incarcerated and Post-incarcerated Scholars in the Age of Mass Incarceration." Journal of Prisoners on Prisons 25, no. 2 (2016): 98-111.

Junger, Gil. 10 Things I Hate About You. Burbank: Touchstone Pictures, 1999. Kafer, Alison. "Un/Safe Disclosures: Scenes of Disability and Trauma.” Journal of Literary and Cultural Disability Studies 10, no. 1 (2016): 1-20.

Kant, Immanuel. "Transition from the Ordinary Rational Knowledge of Morality to the Philosophical." In Grounding for the Metaphysics of 
Morals, trans. James W. Ellington, 7-17. Cambridge, MA: Hackett Publishing, 1991.

Keenan, Jillian. Sex with Shakespeare. New York: William Morrow, 2016.

Kennedy, Dennis, and Li Lan Yong. Shakespeare in Asia: Contemporary Performance. Cambridge: Cambridge University Press, 2010.

Kerr, Tom. "Between Ivy and Razor Wire: A Case of Correctional Correspondence." Reflections 4, no. 1 (2004): 62-75.

Kiefer, Michael. "Arizona Law Outlawing Mexican-American Studies Ruled Unconstitutional." azcentral, August 23, 2017. <https://www. azcentral.com/story/news/local/arizona-education/2017/08/23/ arizona-law-outlawing-mexican-american-studies-tucson-schools-ruledunconstitutional/592446001> (accessed February 21, 2019).

Kimble, Matthew, Andrada D. Neacsiu, William F. Flack Jr., and Jessica Horner. "Risk of Unwanted Sex for College Women: Evidence for a Red Zone." Journal of American College Health 57, no. 3 (2008): 331-7.

King, Helen. The One-Sex Body on Trial: The Classical and Early Modern Evidence. New York: Routledge, 2013.

King, Joyce E. "Unfinished Business: Black Student Alienation and Black Teachers' Pedagogy." In Qualitative Investigations into Schools and Schooling: Volume 11, Readings on Equal Education, ed. Michele Foster. New York: AMS Press, 1991.

Kishi, Tetsuo, and Graham Bradshaw. Shakespeare in Japan. London: Continuum International, 2005.

Kittredge, George Lyman. Shakspere. An Address. Delivered on April 23, 1916, in Sanders Theatre at the Request of the President and Fellows of Harvard College. Cambridge, MA: Harvard University Press, 1926. <http://hdl. handle.net/2027/uiug.30112113376450> (accessed February 22, 2019).

Knox, Emily J. M. “On Trigger Warnings." In Trigger Warnings: History, Theory, Context, ed. Emily J. M. Knox, xiii-xxi. Lanham: Rowman and Littlefield, 2017.

Koenig, Sarah. "Rumors." Serial, Season One: Episode 11 (n.d.). <https:// serialpodcast.org/season-one> (accessed February 22, 2019).

—. "The Alibi." Serial, Season One: Episode 1 (n.d.). <https://serialpodcast. org/season-one> (accessed February 22, 2019).

—. "The Best Defense Is a Good Defense." Serial, Season One: Episode 10 (n.d.). <https://serialpodcast.org/season-one> (accessed February 22, 2019).

—. "The Breakup." Serial, Season One: Episode 2 (n.d.). <https://serialpodcast. org/season-one> (accessed February 22, 2019).

-. "The Case Against Adnan Syed." Serial, Season One: Episode 6 (n.d.). $<$ https://serialpodcast.org/season-one> (accessed February 22, 2019).

Kolvenbach, Peter-Hans. "The Service of Faith and the Promotion of Justice in American Jesuit Higher Education.” In A Jesuit Education Reader, ed. George Traub, 144-62. Chicago: Loyola Press, 2008.

Kozintsev, Grigori. Hamlet [Gamlet]. Lenfilm, 1964. 
Kurita, Yoshihiro. Hamlet. Ryutopia Noh Theatre, Niigata, Japan, 2007.

Lacey, Marc. "Rift in Arizona as Latino Class Is Found Illegal." New York

Times, January 7, 2011, U.S. section. <https://www.nytimes.com/2011/ 01/08/us/08ethnic.html> (accessed February 21, 2019).

Ladson-Billings, Gloria. "'Yes, But How Do We Do It?' Practicing Culturally Relevant Pedagogy." In White Teachers/Diverse Classrooms: A Guide to Building Inclusive Schools, Promoting High Expectations, and Eliminating Racism, ed. Chance W. Lewis and Julie Landsman, 29-42. Herndon: Stylus Publishing, 2006.

Langseth, Mark. "From Shakespeare to Chemistry: Service-Learning and Academic Pursuits." Thresholds in Education 22, no. 2 (May 1996): 22-4.

Laqueur, Thomas. Making Sex: Body and Gender from the Greeks to Freud. Cambridge, MA: Harvard University Press, 1990.

Laroche, Rebecca. "Ophelia's Plants and the Death of Violets." In Ecocritical Shakespeare, ed. Lynne Bruckner and Daniel Brayton, 211-22. Burlington: Ashgate, 2011.

-. "Roses in Winter: Recipe Ecologies and Shakespeare's Sonnets." In Ecological Approaches to Early Modern English Texts, ed. Jennifer Munroe, Edward J. Geisweidt, and Lynne Bruckner, 51-60. Burlington: Ashgate, 2015.

- and Jennifer Munroe. Shakespeare and Ecofeminist Theory. London: Bloomsbury Academic, 2017.

Lei, Bi-qi Beatrice, Judy Celine A. Ick, and Poonam Trivedi. Shakespeare's Asian Journeys: Critical Encounters, Cultural Geographies, and the Politics of Travel. New York: Routledge, 2017.

Lewis, Bradley. "A Mad Fight: Psychiatry and Disability Activism." In The Disability Studies Reader, 5th edition, ed. Lennard J. Davis, 102-18. New York: Routledge, 2006.

“Liberal Education \& Effective Practice." Clark University. <http://www2. clarku.edu/leep> (accessed September 1, 2017).

Linebaugh, Peter, and Marcus Rediker. The Many-Headed Hydra: The Hidden History of the Revolutionary Atlantic. London: Verso Books, 2012.

Little, Arthur. Shakespeare's Jungle Fever: National-Imperial, Re-visions of Race, Rape, and Sacrifice. Stanford: Stanford University Press, 2000.

Loomba, Ania. Shakespeare, Race, and Colonialism. Oxford: Oxford University Press, 2002.

Lorde, Audre. "Power." In The Collected Poems of Audre Lorde (New York: W. W. Norton \& Company, Inc., 1997), 215-16.

Lortie, Dan. Schoolteacher: A Sociological Study. Chicago: University of Chicago Press, 1975.

Love, Heather. Feeling Backward: Loss and the Politics of Queer History. Cambridge, MA: Harvard University Press, 2009.

Luhrmann, Baz. Romeo + Juliet. DVD. Twentieth Century Fox, 1996. 
Lupton, Julia Reinhard. "Public Women/Women of Valor." In Shakespeare Association of America Collection, ed. Dympna Callaghan and Suzanne Gossett, 285-8. London: Bloomsbury Arden Shakespeare, 2016.

Lyth, Ragnar. Den Tragiska Historien on Hamlet-Prins Av Danmark. Sweden, 1984.

MacDonald, Michael J. The Oxford Handbook of Rhetorical Studies. Oxford: Oxford University Press, 2017.

Magill, Tom. Mickey B. DVD. Educational Shakespeare Company, 2009.

Manley, Delarivier. The New Atalantis, 1709.

Marotti, Arthur. "Love Is Not Love': Elizabethan Sonnet Sequence and the Social Order." English Literary History 49, no. 2 (summer 1982): 396-428.

Matz, Robert. "Slander, Renaissance Discourses of Sodomy, and Othello." English Literary History 66 (1999): 261-76.

Maus, Katharine Eisaman. Inwardness and Theatre in the English Renaissance. Chicago: University of Chicago Press, 1995.

McCoy, Richard. Sir Philip Sidney: Rebellion in Arcadia. Ann Arbor: University of Michigan Press, 1979.

McCurry, Justin. "Japan Knife Attack: Stabbing at Care Centre Leaves 19 Dead.” The Guardian, July 26, 2016. <https://www.theguardian.com/ world/2016/jul/25/tokyo-knife-attack-stabbing-sagamihara $>$ (accessed February 21,2019 ).

McFarland, Jami. "On Privilege, Authority, and Abuses of Professional Power." In Trigger Warnings: History, Theory, Context, ed. Emily J. M. Knox, 165-78. Lanham: Rowman and Littlefield, 2017.

McGill, Andrew. "The Missing Black Students at Elite American Universities." The Atlantic, November 23, 2015.

McGuin, Tristan. "Foalefoote: Defining Ingredients Contextually," EMROC, June 2017. <https://emroc.hypotheses.org/1380> (accessed February 22, 2019).

McLaren, Peter. Life in Schools: An Introduction to Critical Pedagogy in the Foundations of Education, 4th edition. Boston: Pearson Education, 2003.

Mentz, Steve. "Coriolanus in Trumpland (Red Bull @ Barrow St, 11/17/16)." The Bookfish Thalassology, Shakespeare, and Swimming blog, November 20, 2016. <http://stevementz.com/coriolanus-in-trumpland-red-bullbarrow-st-111716> (accessed February 22, 2019).

-. "He Must See Ghosts: Richard III, Trump, and the Future." Hypocrite Reader, no. 70 (December 2016). <http:/hypocritereader.com/70/mustsee-ghosts $>$ (accessed February 22, 2019).

—. "Kings of War: 11/4/16@BAM.” The Bookfish Thalassology, Shakespeare, and Swimming blog, November 6, 2016. <http://stevementz.com/kings-ofwar-11416-bam> (accessed February 22, 2019).

—. "NYSX's 'Lucrece.” The Bookfish Thalassology, Shakespeare, and Swimming blog, October 16, 2016. <http://stevementz.com/nysxs-lucrece> (accessed February 22, 2019). 
Metzger, Mary Janell. Shakespeare Without Fear: Teaching for Understanding. Portsmouth, NH: Heinemann, 2004.

Mewborn, Denise S., and Andrew M. Tyminski. "Lortie's Apprenticeship of Observation Revisited." For the Learning of Mathematics 26, no. 3 (2006): $30-2$.

Migala, Jessica. "5 Things Everyone Gets Wrong About Transgender People." Health, May 1, 2017. <https://www.health.com/mind-body/transgendermyths $>$ (accessed January 26, 2019).

Minami, Ryita, Ian Carruthes, and John Gillies. Performing Shakespeare in Japan. Cambridge: Cambridge University Press, 2001.

Mishne, Laura (“Lo"), Erica Warner, Brandon (“The B”) Willis, and Robert ("Diesel”) Shomaker. "Breaking Down Barriers: Student Experiences of the Inside-Out Prison Exchange Program.” Undergraduate Journal of Service-Learning and Community-Based Research 1 (2012).

Mitchell, Tania D. "Traditional vs. Critical Service-Learning: Engaging the Literature to Differentiate Two Models." Michigan Journal of Community Learning 14, no. 2 (spring 2008): 50-65.

Moran, Caitlyn Keefe. “'Yet I'll Speak': Othello's Emilia, A Rebuke to Female Silence,” April 13, 2016. <http://the-toast.net/2016/04/13/yet-ill-speakothellos-emilia> (accessed February 20, 2019).

More, Thomas. Utopia. Ed. George M. Logan and Robert M. Adams. Cambridge: Cambridge University Press, 1989.

Morrison, Toni. Desdemona. London: Oberon Books, 2012.

Munroe, Jennifer. "Harvesting Earth: Where Sustainability and Recipes Meet." The Recipes Project blog. <https://recipes.hypotheses.org/6390> (accessed September 8, 2017).

-. "Is It Really Ecocritical If It Isn't Feminist? The Dangers of 'Speaking for' in Ecological Studies and Shakespeare's Titus Andronicus." In Ecological Approaches to Renaissance Texts: A Field Guide to Reading and Teaching, 37-47. Burlington: Ashgate, 2015.

Murray, Daisy. "Laverne Cox On Why Not All Trans Women Experienced Male Privilege Pre-Transition.” Elle, March 13, 2017. <http://www.elleuk.com/ life-and-culture/culture/news/a34593/laverne-cox-writes-about-why-notall-trans-women-experienced-male-privilege-pre-transition>.

Nakamura, Karen. A Disability of the Soul: An Ethnography of Schizophrenia and Mental Illness in Contemporary Japan. Ithaca: Cornell University Press, 2013.

-. Bethel: Community and Schizophrenia in Northern Japan. DVD. Manic Productions, 2010.

National Science Foundation, Human Resources Statistics Program. "Data Tables.” 2015 Doctorate Recipients From U.S. Universities, n.d. <https:// www.nsf.gov/statistics/2017/nsf17306/data.cfm> (accessed February 25, 2019).

Neutill, Rani. “My Trigger-Warning Disaster: '9 1/2 Weeks,' 'The Wire' and How Coddled Young Radicals Got Discomfort All Wrong." Salon, October 28, 
2015. <https://www.salon.com/2015/10/28/i_wanted_to_be_a_supporter_ of_survivors_on_campus_and_a_good_teacher_i_didnt_realize_just_how_ impossible_this_would_be>.

"New Literary Society Organized in New York. Known as Friends of Shakespeare-C. M. Moloney Elected President." Afro-American, May 22, 1915.

Newstok, Scott L. "How to Think Like Shakespeare." Chronicle of Higher Education, August 29, 2016.

Niels, Herold. "Movers and Losers: Shakespeare in Charge and Behind Bars." In Native Shakespeares: Indigenous Appropriations on a Global Stage, ed. Craig Dionne and Parmita Kaadia, 153-70. London: Ashgate, 2008.

Nixon, Rob. Slow Violence and the Environmentalism of the Poor. Cambridge, MA: Harvard University Press, 2011.

Nunn, Hillary. "Household Water: Porous Pages and Early Modern Manuscript Recipe Books." Conference Paper for Shakespeare Association of America. Atlanta, April 2017.

Nussbaum, Martha C. Not for Profit: Why Democracy Needs the Humanities. Princeton: Princeton University Press, 2010.

-. Poetic Justice: The Literary Imagination and Public Life. Boston: Beacon Press, 1995.

—. "Rational Emotions." In Poetic Justice: The Literary Imagination and Public Life, 53-78. Boston: Beacon Press, 1995.

O'Dair, Sharon. "Is It Shakespearean Ecocriticism If It Isn't Presentist?" In Ecocritical Shakespeare, ed. Lynne Bruckner and Daniel Brayton, 71-85. Burlington: Ashgate, 2011.

OED Online. Oxford University Press. <http://www.oed.com> (accessed September 27, 2017).

Olivier, Laurence. Hamlet. Universal Pictures, 1948.

Orwell, George. 1984. New York: Signet, 1977 [1949].

-. "Politics and the English Language" [1946]. In Major Modern Essayists, ed. George H. Muller and Alan F. Crooks. Englewood Cliffs: Prentice Hall, 1994.

Ovid. Metamorphoses. Trans. David Raeburn. New York: Penguin, 2004.

Parsons, Elaine Frantz. "Revisiting The Birth of a Nation at 100 Years." Journal of the Gilded Age and Progressive Era 14, no. 4 (October 2015): 596-8.

Peck, Wayne Campbell, Linda Flower, and Lorraine Higgins. "Community Literacy." College Composition and Communication 46, no. 2 (May 1995): 199-222.

Penn, Irvine Garland. The Afro-American Press and Its Editors. Springfield: Willey \& Co., 1891.

Pensalfini, Rob. Prison Shakespeare. New York: Palgrave Macmillan, 2016.

Perry, David. "Should Shakespeare Come with a Warning Label?" CNN, May 20, 2014. <http://www.cnn.com/2014/05/20/opinion/perry-triggerwarning-label-for-shakespeare/index.html> (accessed February 22, 2019). 
Phipen, Weston J. "How One Law Banning Ethnic Studies Led To Its Rise." The Atlantic, July 19, 2015. <https://www.theatlantic.com/education/ archive/2015/07/how-one-law-banning-ethnic-studies-led-to-rise/398885> (accessed February 21, 2019).

Pinar, William F. What Is Curriculum Theory? Mahwah: Lawrence Erlbaum Associates, 2004.

Plumwood, Val. "Nature in the Active Voice." Australian Humanities Review, no. 46 (2009): 113-29.

Precarious Workers Brigade. Training for Exploitation? Politicising Employability and Reclaiming Education. Los Angeles: Journal of Aesthetics and Protest Press, 2016. <http://joaap.org/press/pwb/PWB_Text_FINAL.pdf> (accessed February 25, 2019).

Price, Margaret, and Lennard J. Davis. "Defining Mental Disability." In The Disability Studies Reader, 5th edition, ed. Lennard J. Davis, 333-42. New York: Routledge, 2006.

Quinn, Paul, and Dwain A. Perry. H4. Unreleased, 2013.

Ramachandran, Ayesha. The Worldmakers: Global Imagining in Early Modern Europe. Chicago: University of Chicago Press, 2015.

Raymond, Joad. Pamphlets and Pamphleteering in Early Modern Britain. Cambridge: Cambridge University Press, 2003.

Rebhorn, Wayne. The Emperor of Men's Minds. Ithaca: Cornell University Press, 1995.

Rensin, Emmett. “The Smug Style in American Liberalism.” Vox, April 21, 2016. <https://www.vox.com/2016/4/21/11451378/smug-american-liberalism> (accessed February 20, 2019).

Richardson, George. "Singular Nation, Plural Possibilities: Reimagining Curriculum as Third Space." In Curriculum as Cultural Practice: Postcolonial Imaginations, ed. Yatta Kanu, 283-301. Toronto: University of Toronto Press, 2016.

Roervik, Solveig. "What Constitutes a Diet Drink?” EMROC: Early Modern Recipes Online Collective blog, May 30, 2017. <https://emroc.hypotheses. org/1358> (accessed February 22, 2019).

Rogerson, Hank. Shakespeare Behind Bars. DVD. Philomath Films, 2005.

Row-Heyveld, Lindsey. "Disability and Masculine Commerce in The Fair Maid of the Exchange." Allegorica: Traditions and Influences in Medieval and Early Modern Literature 29 (2013): 88-105.

Saunders, Ben. "Iago's Clyster: Purgation, Anality, and the Civilizing Process." Shakespeare Quarterly 55, no. 2 (2004): 148-76.

Sax, Geoffrey. Othello. BBC, London, 2001.

Schaberg, Christopher. The Work of Literature in an Age of Post-Truth. New York: Bloomsbury, 2018.

Schmid, Anastazia. "Can the Convict Race Speak?" Unpublished conference paper, National Conference on Higher Education in Prison, Belmont University, Nashville, TN (November 3-6, 2016). 
Scholars, students, staff, and alumni of the University of Aberdeen. "Reclaiming Our University.” <https://reclaimingouruniversity.wordpress.com> (accessed April 14, 2018).

Schwartz, Marcy. "Public Stakes, Public Stories: Service Learning in Literary Studies.” PMLA 127, no. 4 (October 2012): 987-93.

Scott, Jonathan. Commonwealth Principles: Republican Writing of the English Revolution. Cambridge: Cambridge University Press, 2004.

-. England's Troubles: Seventeenth-Century English Political Instability in European Context. Cambridge: Cambridge University Press, 2000.

Scott-Douglass, Amy. Shakespeare Inside: The Bard Behind Bars. New York: Continuum, 2007.

Sears, Djanet. Harlem Duet. Winnipeg: J. Gordon Shillingford Publishing, 1998.

Seraile, William. Bruce Grit: The Black Nationalist Writings of John Edward Bruce. Knoxville: University of Tennessee Press, 2003.

Shakespeare, William. King Lear: A Conflated Text. The Norton Shakespeare. Ed. Stephen Greenblatt. New York: Norton, 1997.

- Macbeth. Manga Shakespeare Series. New York: Amulet Books, 2008.

- Measure for Measure. Ed. J. W. Lever. London: Arden Shakespeare, 1965.

- New Variorum Edition, Vol. 24: The Sonnets. Ed. Hyder Rollins. Philadelphia: Lippincott, 1944.

-. No Fear Shakespeare: Romeo and Juliet. New York: Spark Publishing, 2013.

- Othello. The Norton Shakespeare. Ed. Stephen Greenblatt. New York: Norton, 1997.

- Romeo y Julieta. Trans. Pablo Neruda. Buenos Aires: Editorial Losada, 1964.

—. Shakespeare's Plays. Ed. Barbara Mowat et al. Folger Digital Texts (Washington: Folger Shakespeare Library). <https:/www.folgerdigitaltexts.org> (accessed December 4, 2017).

- The Arden Shakespeare Complete Works, 2nd edition. Ed. Ann Thompson, David Scott Kastan, and Richard Proudfoot. London: Arden Shakespeare, 2011.

- The Complete Oxford Shakespeare. Ed. Stanley Wells and Gary Taylor. Oxford: Oxford University Press, 1987.

- The Complete Pelican Shakespeare, 2nd edition. Ed. Stephen Orgel and A. R. Braunmuller. Penguin Classics, 2002.

-. The First Quarto of Romeo and Juliet. Ed. Lukas Erne. The New Cambridge Shakespeare: The Early Quartos. Cambridge: Cambridge University Press, 2007.

- The Norton Shakespeare. Ed. Stephen Greenblatt, Walter Cohen, Jean E. Howard, Katharine Eisaman Maus. New York: Norton, 1997.

- The Norton Shakespeare, 3rd edition. Ed. Stephen Greenblatt, Walter Cohen, Jean E. Howard, Katharine Eisaman Maus, Gordon McMullan, and Suzanne Gossett. New York: Norton, 2015. 
- The Norton Shakespeare, 3rd edition. Ed. Stephen Greenblatt, Walter Cohen, Jean E. Howard, Katharine Eisaman Maus, Gordon McMullan, and Suzanne Gossett. New York: Norton, 2016.

-. The Oxford Shakespeare: The Complete Works, 2nd edition. Ed. Stanley Wells, Gary Taylor, John Jowett, and William Montgomery. Oxford: Oxford University Press, 2005.

-. The Riverside Shakespeare, 2nd edition. Ed. G. Blakemore Evans. New York: Houghton Mifflin, 1997.

- The Tempest. Ed. Virginia Mason Vaughan and Alden T. Vaughan. London: Arden Shakespeare, 1999.

- The Tempest. Ed. Stephen Greenblatt, Walter Cohen, Jean E. Howard, Katharine Eisaman Maus, Gordon McMullan, and Suzanne Gossett. The Norton Shakespeare. New York: Norton, 2016.

—. The Winter's Tale. Ed. J. H. P. Pafford. London: Arden Shakespeare, 1963.

"Shakespeare and Race Across Borders: A Scholarly Symposium." < http:// www.shakespearesglobe.com/whats-on-2018/shakespeare-and-race> (accessed January 25, 2019).

Sherman, William, and William Sheils, eds. "Prison Writings in Early Modern England." Huntington Library Quarterly 72, no. 2 (June 2009).

Shiva, Vandana. Earth Democracy: Justice, Sustainability, and Peace. Cambridge, MA: South End Press, 2005.

Showalter, Elaine. "Representing Ophelia: Women, Madness, and the Responsibilities of Female Criticism." In Shakespeare and the Question of Theory, ed. Patricia Barker and Geoffrey Hartman, 77-94. London: Methuen, 1985.

Shulman, Lee. "Knowledge and Teaching: Foundations of the New Reform." Harvard Educational Reviews 57, no. 1 (1987): 8.

-. "Those Who Understand: Knowledge Growth in Teaching." Educational Researcher 15, no. 2 (1986): 4-14.

Sidney, Philip. A Defence of Poetry. Ed. Jan Van Dorsten. Oxford: Oxford University Press, 1966.

—. "A Defence of Poetry (1595)." In Miscellaneous Prose of Sir Philip Sidney, ed. Katherine Duncan-Jones and Jan van Dorsten, 59-122. Oxford: Clarendon Press, 1973.

—. Poems. Ed. William Ringler. Oxford: Clarendon Press, 1962.

- The Countess of Pembroke's Arcadia. Ed. Maurice Evans. New York: Penguin Classics, 1977.

Sieg, Linda, and Kwiyeon Ha. "Japan Confronts Disability Stigma After Silence Over Murder Victims' Names.” Reuters, September 16, 2016. <https:// www.reuters.com/article/us-japan-disabled/japan-confronts-disabilitystigma-after-silence-over-murder-victims-names-idUSKCN11M0AM> (accessed February 21, 2019).

Skrebels, Paul, and Sieta van der Hoeven. For All Time? Critical Issues in Teaching Shakespeare. Cambridge, MA: Wakefield Press, 2002. 
Smith, Rachel. "Hallelujah the Saviors Are Here," 2012. <https://www.wbez. org/shows/wbez-news/hallelujah-the-saviors-are-here/b7b4d9b1-39b64984-ae80-7440738601a8> (accessed February 27, 2019).

Solnit, Rebecca. Men Explain Things To Me. Chicago: Haymarket Books, 2014.

Sophocles. The Three Theban Plays: Antigone; Oedipus the King; Oedipus at Colonus. Trans. Robert Fagles. New York: Penguin, 2000.

Spenser, Edmund. "Letter to Raleigh." In The Faerie Queene, ed. A. C. Hamilton, Hiroshi Yamashita, and Toshiyuki Suzuki, 713-18. Harlow: Longman, 2001.

-. The Faerie Queene. Ed. A. C. Hamilton, Hiroshi Yamashita, and Toshiyuki Suzuki. Harlow: Longman, 2001.

—. The Shorter Poems. New Haven: Yale University Press, 1989.

Staines, John D. "The Age of Shakespeare Versus the Age of Milton: Reopening the Noisy Theaters." Modern Language Quarterly 78, no. 3 (2017): 395-419.

"Statement by Press Secretary Sean Spicer." Press Briefings, January 21, 2017. $<$ https://www. whitehouse.gov/briefings-statements/statement-presssecretary-sean-spicer> (accessed February 15, 2019).

Stenberg, Shari J., and Darby Arant Whealy. "Chaos Is the Poetry: From Outcomes to Inquiry in Service-Learning Pedagogy." College Composition and Communication 60, no. 4 (June 2009): 683-706.

Stevens, Carolyn S. Disability in Japan. New York: Routledge, 2013.

Strachey, William. A True Reportory of the Wracke, and Redemption of Sir Thomas Gates Knight; upon and from the Llands of the Bermudas: His Coming to Virginia, and the Estate of That Colonie Then, and after, under the Government of the Lord La Warre, July 15. 1610, 1610.

Strauss, Valerie. "Teacher: Why I Don't Want to Assign Shakespeare Anymore (Even Though He's in the Common Core)." Washington Post, June 13，2015. <https://www.washingtonpost.com/news/answer-sheet/ wp/2015/06/13/teacher-why-i-dont-want-to-assign-shakespeare-anymoreeven-though-hes-in-the-common-core> (accessed February 26, 2019).

Strickland, Ron. "Teaching Shakespeare Against the Grain.” n.d. < http://pages. mtu.edu/ rlstrick/378/shakgran.htm> (accessed September 1, 2017.

"Study Plan for Lear Is Here." Global Shakespeares Modules. <https:// globalshakespeares.mit.edu/modules/module/lear-is-here> (accessed January 26,2019$)$.

Sturgess, Kim C. Shakespeare and the American Nation. Cambridge: Cambridge University Press, 2004.

Summit, Jennifer. "Renaissance Humanism and the Future of the Humanities." Literature Compass 9, no. 10 (October 2012): 665-78.

Taviani, Paolo. Caesar Must Die. DVD. Homescreen, 2013.

Taylor, Holly. "Accessibility on Campus: Posttraumatic Stress Disorder, Duty to Accommodate, and Trigger Warnings." In Trigger Warnings: History, 
Theory, Context, ed. Emily J. M. Knox, 22-36. Lanham: Rowman and Littlefield, 2017.

“The Art of Transliness Guide to Being Read as Male.” The Art of Transliness. $<$ http://theartoftransliness.com/post/19575647114/the-art-of-translinessguide-to-being-read-as-male> (accessed January 26, 2019).

"The FTM's Complete Illustrated Guide to Looking Like a (Hot) Dude." <http://ftmguide.rassaku.net> (accessed January 26, 2019).

"The Pulter Project: Poet in the Making." http://pulterproject.northwestern. edu (accessed February 25, 2019).

Thompson, Ayanna. Passing Strange: Shakespeare, Race, and Contemporary America. London: Oxford University Press, 2011.

-. "Unmooring the Moor: Researching and Teaching on YouTube." Shakespeare Quarterly 61, no. 3 (2010): 337-56.

-, and Laura Turchi. Teaching Shakespeare with a Purpose: A StudentCentered Approach. London: Bloomsbury Arden Shakespeare, 2016.

Tolmer, Elizabeth. "Adapting Trigger Warnings in the Introduction to Women's Studies Course: A Case Study." In Trigger Warnings: History, Theory, Context, ed. Emily J. M. Knox, 200-7. Lanham: Rowman and Littlefield, 2017.

Tosh, Will. "What You Will.” Tumblr post, May 11, $2017<$ https://blog. shakespearesglobe.com/post/160546033578/gender-in-twelfth-night> (accessed February 21, 2019).

“Transgender People: 10 Common Myths.” Vox, March 21, 2017. <https:// www.vox.com/identities/2016/5/13/17938088/transgender-people-rightsmyths $>$ (accessed February 21, 2019).

"Transgender Rates of Violence: Victim Service Provider's Fact Sheet 6." FORGE, October 2012. <http://forge-forward.org/wp-content/docs/FAQ10-2012-rates-of-violence.pdf $>$.

Trevor-Roper, H. R. Three Foreigners: The Philosophers of the Puritan Revolution. London: Macmillan, 1967.

Trivedi, Poonam, and Ryuta Minami. Re-playing Shakespeare in Asia. New York: Routledge, 2010.

Trounstine, Jean. "Beyond Prison Education.” PMLA 123, no. 3 (May 2008): 674-7.

- Shakespeare Behind Bars: The Power of Drama in a Women's Prison. New York: St. Martin's Press, 2001.

Trudell, Scott. "The Meditation of Poesie: Ophelia's Orphic Song." Shakespeare Quarterly 63, no. 1 (2012): 46-76.

Turner, David M., and Kevin Stagg. Social Histories of Disability and Deformity. New York: Routledge, 2006.

Uggen, Christopher, Ryan Larson, and Sarah Shannon. "6 Million Lost Voters: State-Level Estimates of Felony Disenfranchisement, 2016.” The Sentencing Project, October 6, 2016. <http:/www.sentencingproject. org/publications/6-million-lost-voters-state-level-estimates-felonydisenfranchisement-2016> (accessed September 23, 2017). 
"Update to April 8, 2016 article, 'Don't major in history, Lt. Gov. tells students." Louisville Courier Journal, April 11, 2016.

"UWI Triple A Strategic Plan: Revitalizing Caribbean Development," n.d. $<$ http://www.uwi.edu/uop/sites/uop/files/Full\%20plan.pdf > (accessed September 1, 2017).

Veeser, Harold Aram. The New Historicism. New York: Routledge, 1989.

Wallace, David F. "Some Remarks on Kafka's Funniness." In Consider the Lobster and Other Essays, 60-5. Boston: Little, Brown, 2006.

Washick, Bonnie. "An 'App' for That: The Case against the 'Equal Access' Argument for Trigger Warnings." In Trigger Warnings: History, Theory, Context, ed. Emily J. M. Knox, 88-122. Lanham: Rowman and Littlefield, 2017.

Weamys, Anna. A Continuation of Sir Philip Sidney's Arcadia, 1651.

Webster, Charles. Samuel Hartlib and the Advancement of Learning. Cambridge: Cambridge University Press, 1970.

Western, Bruce. "The Impact of Incarceration on Wage Mobility and Inequality." American Sociological Review 67, no. 4 (August 2002): 526-46.

Wheeler, Lesley. “On Capstones, Service Learning, and Poetry." Profession, 2010, 207-19.

“Why You Don't Pass. Part I." Man 101: The Brutally Honest FTM Guide. <http://man101.tumblr.com/post/4634418160/why-you-dont-pass-part-i> (accessed January 26, 2019).

Williams, Jeffrey J. "Debt Education: Bad for the Young, Bad for America." Dissent 53, no. 3 (2006): 53-9.

Williams, Katherine Schapp. "'More Legs Than Nature Gave Thee': Performing the Cripple in The Fair Maid of the Exchange." ELH 82, no. 2 (summer 2015): 491-519.

—. "Performing Disability and Theorizing Deformity." English Studies 94, no. 7 (2013): 757-72.

Williams, Patricia J. “The Obliging Shell.” In The Alchemy of Race and Rights, 98-130. Boston: Harvard University Press, 1991.

Wilson, August. The Ground on Which I Stand. New York: Theatre Communications Group, 2000.

Wilson, Doni. "9 Trigger Warnings for Hamlet." The Federalist, May 27, 2014. <http://thefederalist.com/2014/05/27/9-trigger-warnings-for-hamlet> (accessed February 22, 2019).

Witmore, Michael. "Opening Remarks for Plenary Panel on 'The Color of Membership.'” Presented at the annual meeting of the Shakespeare Association of America, Atlanta, April 17, 2017.

WKMS. "Governor Bevin on Higher Ed Funding," March 20, 2019. <https:// wkms.org> (accessed February 22, 2019).

Wood, David Houston. "New Directions: 'Some Tardy Cripple: Timing Disability in Richard III."' In Richard III: A Critical Reader, ed. Annaliese Connolly, 129-54 (London: Bloomsbury, 2013). 
—. "Shakespeare and Variant Embodiment." In Shakespeare in Our Time: A Shakespeare Association of America Collection, ed. Dympna Callaghan and Suzanne Gossett, 189-94. London: Bloomsbury Arden Shakespeare, 2016.

Wray, Ramona. "The Morals of Macbeth and Peace as Process: Adapting Shakespeare in Northern Ireland's Maximum Security Prison.” Shakespeare Quarterly 62, no. 3 (2011): 340-63.

Wroth, Mary. Urania. London, 1621.

Xiaogang, Feng. The Banquet [Yè Yàn]. Huayi Brothers, China, 2006.

Yang, Jung-Un. A Midsummer Night's Dream. Yohangza Company, 2006.

Yōda, Hiroe. "New Views on Disabilities and the Challenge to Social Welfare in Japan." Social Science Japan Journal 5, no. 1 (2002): 7-8.

Yoshino, Kenji. A Thousand Times More Fair: What Shakespeare's Plays Teach Us About Justice. New York: HarperCollins, 2011.

Zehr, Howard. The Little Book of Restorative Justice. Intercourse, PA: Good Books, 2002.

Zelon, Helen. "The Shakespeare Redemption: Inmates in a Kentucky Prison Grapple with the Truths of Human Existence." American Theater 18, no. 8 (October 2001): 32-5. 


\section{Index}

academic precarity, 155, 159, 229

Acosta, Curtis, 76-7

Adams, Joseph Quincy, 69-70

Adams, Maurianne, 4

Adichie, Chimamanda Ngozi, 45n13

African-American culture, 71-4, 90-1, 235

early twentieth-century radicalism, 85-9, 90

see also Baldwin, James; hooks, bell; Lorde, Audre

African Americans see African-American culture; blackness; race and racism

Akala, 90

Al-Hamlet Summit, The, 58, 61

Aldridge, Ira, 90

“alternative facts," 1, 2, 165, 168-9

ambiguity

$v$ s. authority, 28, 29, 34

embraced through "riffing," 32-4

see also disorientation and getting lost

Amoretti (Spenser), 156

"An Act ... For the Relief, and

Imployment of the Poor"

(pamphlet), 220

Anzaldúa, Gloria, 77-8, 79-80, 81, 91

"Aphorism Countertime" (Derrida), 111

aporia, 107-9, 112

Appignanesi, Richard: Macbeth

(Manga Shakespeare series), 50-1

Arcadia (Sidney), 178, 183n19
Aristotle, 108, 109

Nicomachean Ethics, 109-10, 118-19

Poetics, 109, 116-17

on rhetorical strategies, 149

Arizona: anti-immigrant policies, 76

Art of Transliness blog, 40, 44n6

As You Like It

close-reading prompt exercise, 33-4

and transgender experiences, 38 , $39-40$

"Asides for a Tragic Theatre"

(Barker), 111

Astrophil and Stella (Sidney), 156, 157, 160

authority $v s$. ambiguity, 28, 29, 34

Baber, Ceola Ross, 90

Bailey, Lucy: Titus Andronicus

(Shakespeare's Globe, 2014), 98

Baldwin, James, 113

"Why I Stopped Hating

Shakespeare," 27-8

Banquet, The (Feng), 61

Barad, Karen, 125, 127

"bardsplaining," 207

Barker, Harold: "Asides for a Tragic Theatre," 111

Barth, John: "Lost in the Funhouse," 112

Al-Bassam, Sulayman: The Al-Hamlet Summit, 58, 61

Beckett, Samuel: Waiting for Godot, 110 
Benjamin, Walter, 212

Bernstein, J. M., 115-16

Bertram, Corrine C., 104n12

Bérubé, Michael, 203

Bevin, Matt, 106, 113-14n2, 195n2

Bhabha, Homi K., 173n8

Bhardwaj, Vishal: Omkara, 57, 60

Birth of a Nation, The (Griffith), 85, 89

black nationalism, 85-9

blackness

casting representation, 70, 171

educator experience of, 207, 209, 211, 235, 237

in Othello, 57, 71-2, 121-2

see also African-American culture; race and racism

Bland, Sheila Rose: "How I Would

Direct Othello," 71-2

Blazing World, The (Cavendish), 174

blogging, student

in critical service learning, 189-90, 191-2

and cross-campus collaboration, $127,128,130$

Bloom, Harold, 80

body dysphoria, 42

Bollywood, 60

Bornstein, Kate: Hidden: A Gender, 39

Bourdieu, Pierre, 79

Boyd, Ashley, 227

Brammall, Kathryn, 5

Brewer, Kevin: The Rape of Lucrece

(NYSX, 2016), 137-8

Bristol, Michael, 88

Bruce, John Edward, 85-90

\section{Caliban by the Yellow Sands}

(MacKaye), 86, 88

"Calling Bullshit in the Age of Big

Data" (University of Washington), 165

Campana, Joseph: "H is for Humanism," 140

"Candle in a Gale Wind" (Childress), 91

Carbado, Devon, 236
Carbone, Courtney: Macbeth

\#killingit, 50-1

Cautery, Jessica, 137-8

Cavendish, Margaret: The Blazing World, 174

Chavez, Leo, 80

Chen, Mel, 49-50

Chicanxs, 76-82

Childress, Alice: "Candle in a Gale Wind," 91

climate change, 124

Clinton, Hillary, 136

close reading, 31-3, 42, 130, 225, 232 editorial influence on, 167

and evaluation of (mis)information, 165-166

and related literary skills, 158

cognitive differences, 49-50

Cole, Rick, 147

collaborative and collective work creative exercises and assignments, 32-4, 33-4, 57-8, 80-1, 171, 179 cross-campus, $127,128-9$ diversity of perspective in, 74, 203 in ideology of The Friends of Shakespeare, 87

importance in social justice pedagogy, 166

with incarcerated and non-incarcerated students, 202-3

in research and scholarship, 125-8, $182,237-8$

between secondary and post-secondary educators, 229

in service learning, 188, 215, 217-18

and student motivation, 89-90

colonization

and the early modern imagination, 177, 180-2

and race in Trinidad, 211-13

Comenius, John Amos, 219-20

Common Core State Standards (CCSS), 225

community-based learning see service learning

community literacy, 203

Continuation of Philip Sydney's Arcadia, A (Weamys), 178 
Conway, Kellyanne, 1

Coriolanus

2016 Red Bull Theater production, 139-40

suggested text pairing, 119

Corredera, Vanessa, 147-8

Cox, Laverne, 45n13

Crenshaw, Kimberlé, 236

criminality and criminal justice, 197, 198-201

and poverty, 220, 221

cross-dressing, 37-41

Crowley, Sue, 104n12

Cullen, Countee: "A Song of Praise," 90

Cymbeline, 39-40

Davis, Henrietta Vinton, 90

Davis, Michael, 109

debt, 209

Defence of Poetry, A (Sidney), 160, 174

Demeter, Jason, 8

democracy, 139-40

democratization of learning see collaborative and collective work; student empowerment

Derrida, Jacques: "Aphorism

Countertime," 111

Desai, Adhaar Noor, 8

digital pedagogy

collaborative "riffing" assignment, 33-4

distance collaboration, 127, 128-9, 130,202

reflective blogging, 189-90, 191-2

use of podcasts, 147

video projects, $57-8,62,80-2$

see also online projects and resources

"Dim Lady" (Mullen), 90

disability, 46-52; see also mental disability and mental illness discomfort, embracing, 57, 118, 171-2, 203; see also trigger warnings

disorientation and getting lost historical, 7

political, 136-7, 140 productive, 49-50, 52, 107-9, 112

in service learning, 189, 192

tragic, $110-12$

see also ambiguity

Dotson, Kristie, 199

drag performance, $43-4 \mathrm{n} 2$

drama as social medium, 8

Dugan, Margaret Garcia, 76

"dumbing down," 51

Dunbar, Paul Laurence, 90

Dusbiber, Dana, 225-6

Dyches, Jeanna, 227

Early English Books Online (EEBO), 218

early modern literature (general/nonShakespearean)

civic humanism, 216, 218-21

disability in, 47, 51

foreignness and defamiliarization, 7 ideas of justice, 145, 200-1

and language skills, 166

participatory culture, 174-80, 182-3

prison writing, 197

relevance of, 4-5, 20, 187, 195

SJPACK teaching approach, 228, 230-3

sonnet sequences, 155-61

travel writing, 181-2

violence in, 99-100, 230-1

Early Modern Recipes Online

Collective (EMROC), 126,

127-8, 129

Earth Democracy, 125

ecofeminism, 125, 127-8, 130-1

economic and employment precarity, 155, 158-60, 193, 229; see also poverty

editorial bias, $167-8$

EEBO (Early English Books Online), 218

employability, 106-7, 159-60, 187; see also academic precarity

EMROC (Early Modern Recipes

Online Collective), 126, 127-8, 129

environment, early modern and present, 129-32 
Escolme, Bridget, 40-1

ethics

of community engagement, 189

and imaginative world-building, 174-80, 182-3

and tragedy, 109, 115-19

tragic text pairings, 118-22

Euripides: Medea, 110

European culture, 2, 7-8, 69-70

and colonialism, 177, 181-2

Faerie Queene, The (Spenser), 174, 181-2

Faulkner, William, 7

Feinberg, Leslie: Stone Butch Blues, 39

feminism, 5

ecofeminism, 125, 127-8, 130-1

readings of Hamlet, 60-2

Feng Xiaogang: The Banquet, 61

Finneran, Michael, 8

"flipping the classroom," 147; see also student empowerment

Folger Shakespeare Library, 7, 69 recipe collection of Mrs. Corlyon, 129

Ford, Derek R.: Politics and Pedagogy in the "Post-Truth" Era, 3-4, $22 \mathrm{n} 30$

forgiveness, 31

Freebody, Kelly, 8

Freeman, Thomas, 200

Freire, Paolo, 4, 28

Education for Critical Consciousness, 23n32

Pedagogy of the Oppressed, 83n9, 108-9, 166, 168, 171-2

Friends of Shakespeare, The ("The Friends”), 85-7, 90

Garvey, Marcus, 86

gender

and agency, 60-2

and credibility, 150

and engagement with the Sonnets, 162-3

see also feminism; sexual violence; transgender identity

Gill, Allison, 40
Giroux, Henry, 9

Global Shakespeares (MIT), 55, 59, 170

Globe theater, London see Shakespeare's Globe

Godsey, Michael, 146, 147

Great Migration, 85, 89

Greenblatt, Stephen, 29, 160

Griffith, D. W.: The Birth of a Nation, 85,89

Grit, Bruce see Bruce, John Edward

Grobman, Laurie, 192, 194

"H is for Humanism" (Campana), 140

Hackman, Heather W., 172n3

Halberstam, Jack, 99

Hall, Kim, 80

hamartia, 108, 109

Hamlet

and female agency, 60-2

global productions, 56-7, 58

interiority and transgender identity, $41,42-3$

interpretive tradition, 55-6

Hamlet (Kozintsev film, 1964), 56-7

Hampton, Jenean M. (Lieutenant

Governor of Kentucky), 106

Hansen, Matthew C., 189

"Harlem Dancer, The" (McKay), 90

Harris, Luke, 236

Hartley, L. P., 7

Hartlib, Samuel, 215, 218, 219, 222

Hartlib Papers project, 218

Helin, Jenny, 124

Henry V, 169

Hidden: A Gender (Bornstein), 39

higher education contemporary cultural context, 2-3, 106-7, 208

and debt, 209

employee experience, 155, 159, 229

institutions and the community,

216 (see also service learning)

pedagogical practices, 10-11

"real world" application initiatives, 210

see also humanities education

hip hop, 90 
historical study

and conservatism, 4-5

as context to Shakespeare, $87-8$,

129-30, 131

and foreignness, 7

and understanding community

challenges, 218

Hoeven, Sieta van der, 22n22

Holland, Peter, 78

hooks, bell, 4, 72

Horne, Tom, 76

Hornstein, Gail A., 104n10

Huerta, Dolores, 76

humanism, historical, 140, 216

Hartlib circle, 218-21

see also Utopia

humanities education

aims of, 10

political and financial pressure on, 106-7, 109-10

value of, 3-7, 187-8, 195, 216

Hume, David: "Of the Influencing

Motives of the Will," 119

Hyman, Wendy Beth, 22n24

immigrants, attitudes to

in Singapore, 57

in the U.S., 76, 82

Impressions, The: "Woman's Got

Soul," 90

incarceration, 197-203

Irving, Simon, 124

Islas, Arturo: La Mollie and the King of Tears, 78-9

\section{Japan}

attitudes to disability, 46, 48, 50, 52 attitudes to Shakespeare, 48, 49, $53-4 \mathrm{n} 11$

Jesuit educational ideals, 188, 191, 192 Julius Caesar, 135, 136, 137, 140

Shakespeare in the Park production (2017), 7

justice, 8, 9-10, 112

Aristotelian, 109-10

dramatic resolution and, 139

retributive $v s$. restorative, 201

see also criminality and criminal justice
Kafer, Alison, 104n9

Kafka, Franz: Metamorphosis, 108

Kant, Immanuel, 109

"Transition from the Ordinary

Rational Knowledge of Morality to the Philosophical," 119

Keenan, Jillian: Sex with

Shakespeare, 29

Kent, Charles: Twelfth Night (1910), 171

Kentucky: higher-education funding, 106-7

Kerr, Tom, 201, 202

Kestig, Hans, 134-5

King, Joyce E., 89-90

King Lear

refugee-camp performance, 191-2

suggested text pairing, 119

and tragic "getting lost," 110

see also La Mollie and the King of

Tears; Lear Is Here

Kings of War (Toneelgroep Amsterdam), 134-5

Kittredge, George Lyman, 86, 88

Koenig, Sarah see Serial

Kozintsev, Grigori: Hamlet (1964), 56-7

Kramer, Beth, 147

Kurita, Yoshihiro: Nob-inspired Hamlet, 61-2

Kurosawa, Akira: Throne of Blood, 50

\section{La Mollie and the King of Tears} (Islas), 78-9

Langseth, Mark, 192

language

as challenge or barrier, 7, 49, 50,

51, 68, 80-1

critical sensitivity to, 90, 91, 190-1

emphasized in Shakespeare studies, 165

and identity, 79-80, 81

and political control, 206-7

silent film and, 171

see also rhetoric

Laroche, Rebecca: Shakespeare and

Ecofeminist Theory, 126-7

Latinxs see Chicanxs 
law

anti-immigrant legislation, 76

and equity, 109-10, 120

process, rhetoric and proof, 148-51

see also criminality and criminal justice

Lear Is Here (Wu), 59

Leeson, Whitney, 5

Lei, Bi-qi Beatrice, $54 \mathrm{n} 11$

librarian activism, 165

"Little Brown Baby" (Dunbar), 90

Lorde, Audre

portrait controversy at University of Pennsylvania, 27, 73

"Power," 29-31

lost, being see disorientation and getting lost

"Lost in the Funhouse" (Barth), 112

Love's Labor's Lost, 31

"Loving Blackness as Political Resistance" (hooks), 72

Luhrmann, Baz: Romeo + Juliet, $83 \mathrm{n} 16$

Lundy, Cristina, 137-8

Macbeth

and attitudes to mental disability, $50,51-2$

collaborative close-reading exercise, 32-3

and tragic "getting lost," 110

see also Mickey B

Macbeth (Appignanesi) (Manga

Shakespeare), 50-1

Macbeth \#killingit (Carbone), 50-1

MacKaye, Percy: Caliban by the

Yellow Sands, 86, 88

McKay, Claude: "The Harlem

Dancer," 90

Manga Shakespeare Series, 50-1

Manley, Delarivier: The New

Atalantis, 178

"mansplaining," 31

marriage

contemporary and early modern attitudes, 151-2

same-sex, 60

Maske Presented at Ludlow Castle, A (Milton), 230
Matz, Robert, 63n8

Maus, Katharine Eisaman, 41

meaning, 31

Measure for Measure, 150-1, 200-1

Medea (Euripides), 110

Meno (Plato), 107, 108-9

mental disability and mental illness

body dysphoria, 42

"brain fog" and disorientation, 49-50

in Hamlet, 60-1

Japanese attitudes, 48, 52

in Macbeth, 50, 51-2

post-traumatic stress disorder, 97, 99-102

Merchant of Venice, The

law and justice in, 201

text pairings, 31

and transgender experience, 39-40

Merry Wives of Windsor, The, 42

Mexican-Americans, 76-82

Mickey B (Magill), 199

"micro-aggressions," 30

Midsummer Night's Dream, A, 174, 230

Milton, John, 197, 216, 219, 230-1

Of Education, 223n13

Maske at Ludlow, 230

Paradise Lost, 145, 230-1

MIT Global Shakespeare Project, 55, 59,170

Mitchell, Tania (quoted), 216, 221-2

Mock, Janet: Redefining Realness, 39

Montaigne, Michel de: "Of Cannibals," 180-1

More, Thomas: Utopia, 177-8, 181, 182

Mullen, Harryette, 90

Mullin, Eugene, and Charles Kent: Twelfth Night (1910), 171

Munroe, Jennifer, 127-8, 133n18 Shakespeare and Ecofeminist Theory, 126-7

"myth"-busting, transgender, 41, $45 \mathrm{n} 14$

Nakamura, Karen, 52

Neruda, Pablo (trans.): Romeo y Julieta, 168 
New Atalantis, The (Manley), 178

New York City, 85, 206

2016 Shakespeare productions, 134-5, 137-40

The Friends of Shakespeare, 85-7, 90

New York Shakespeare Exchange

(NYSX): The Rape of Lucrece, 137-9

1984 (Orwell), 206-7, 208-9

Nixon, Rob, 124, 125

Noh-influenced versions, 50, 61-2

Nussbaum, Martha, 106, 175, 176

"Rational Emotions," 119

"Obliging Shell, The" (Williams), 119, 120-1, 122

O'Dair, Sharon, 133n18

Oedipus the King (Sophocles), 110

"Of Cannibals" (Montaigne), 180-1

OMG Shakespeare series, 51

Omkara (Bhardwaj), 57, 60

online projects and resources

Calling Bullshit in the Age of Big Data (University of Washington), 165

Early English Books Online (EEBO), 218

Early Modern Recipes Online Collective (EMROC), 126, $127-8,129$

Global Shakespeares (MIT), 55, 59,170

Hartlib Papers (University of Sheffield), 218

Pulter Project, 182

on trans issues, 40,41

YouTube, 81

Orwell, George

1984, 206-7, 208-9

"Politics and the English Language," 207

\section{Othello}

and non-Western views of race, 57 rhetoric and proof in, 148-50, 169 and sexual identity, 60, 63n8 text pairings, 29-31, 71-2, 119, 120-2, 149-50 and tragic "getting lost," 111
pan-Africanism, 87

Pansophia diatopsis (Comenius), 219

participatory readerly ethics, 174-80, 182-3

pedagogical content knowledge (PCK), 226-7

Pedagogy of the Oppressed (Freire), 83n9, 108-9, 166, 168, 171-2

performances and productions

audience $v$ s. reader knowledge, 169-70

casting and minority visibility, 37 , $70,80,166,170-1$

election-year (2016) resonance, 134-5, 137-40

experienced prior to written text, 59,171

global Hamlets, 56-7, 58, 60-2

global Othellos, 57, 60

refugee-camp King Lear, 191-2

Perry, David, 105n14

Pinar, William, 208

Plato, 115

Meno, 107, 108-9

Politics and Pedagogy in the "PostTruth" Era (Ford), 3-4

"Politics and the English Language" (Orwell), 207

"Portrait in Georgia" (Toomer), 90

"post-truth," 3-4; see also "alternative facts"

post-traumatic stress disorder (PTSD), 97, 99-102; see also trauma

poverty

early modern and contemporary, 220-1, 223n21

and rural opportunity, 106-7

see also economic and employment precarity

pre-service teachers see teacher education

Precarious Workers Brigade, 159

prisons, 197-203

Pulter Project, 182

race and racism, 29-31, 80, 120-2, 147-8

Chicanx experience, 76-82 
Shakespeare and Race festival

(Globe theater), 5, 236-7

Singaporean attitudes, 57

Trinbagonian experience, 211-13

see also black nationalism; black-

ness; white supremacy

Rape of Lucrece, The, 102

2016 New York Shakespeare

Exchange adaptation, 137-9

suggested text pairing, 118-19

"Rational Emotions" (Nussbaum), 119

Red Bull Theater: Coriolanus (2016), 139-40

Redefining Realness (Mock), 39

relatability, 160-1

religious identity, 58

retributive $v s$. restorative justice, 201

rhetoric, 145-6, 148-52, 169-70

Richard III see Kings of War

"riffing," 28, 32-4

Rollins, Hyder, 162

Romeo and Juliet

editorial decisions, 167-8

false knowledge in, 169

name and identity in, 111

suggested text pairing, 119

teaching with Serial, 145, 149, 151-2

Romeo + Juliet (Luhrmann), 83n16

Rubio, Marco, 195n2

safe spaces, 237; see also trigger warnings

Sagamihara massacre, 46-7, 48, 50, 52

same-sex marriage, 60

Saunders, Ben, 63n8

Sax, Geoffrey: Othello (2001), 59-60

Schaberg, Christopher: The Work of Literature in an Age of PostTruth, 3

Schmid, Anastazia, 199

Schwartz, Marcy, 196n10

Scott, Jonathan, 218

self-care, 236-7

Serial podcast (Koenig)

and rhetoric, 145, 148-52

social justice issues in, 147-8 student engagement with, 145 , 146-7

service learning/community-based learning (CBL), 187, 215-18

aims, 187, 188-9, 217

and critical reflection, 189-92, 195, 216, 221-2

and study of Hartlib circle texts, 215, 218-22

and study of Shakespeare, 189, 192-5

terminology, 222n1

sexual identity, 59-60

sexual violence, 102-3, 137-9, 229-31

Shakespeare

anti-revolutionary models of, 207-8

Chandos portrait, 78

and Chicanx identity, 78-82

history and culture of study, 165-6

Japanese attitudes to, 48, 49, $53-4 n 11$

place in U.S. education, 68-9, 70-1, 73-4, 187, 225-6, 235

prison programs, 198, 200

Singaporean attitudes to, 55, 56

in social context of service learning, 189, 192-3, 194

as symbol of white culture, 2, 8, 67-70

works (see titles of individual works)

Shakespeare and Ecofeminist Theory (LaRoche and Munroe), 126-7

Shakespeare Association of America, $7-8,238$

Shakespeare's Globe (theater)

Shakespeare and Race festival, 5, 236-7

Titus Andronicus (2014), 98

Twelfth Night (2012-13), 170

Twelfth Night (2017), 36, 43-4n2

Shiva, Vandana, 125

Showalter, Elaine, 60

Shulman, Lee, 226-7

Sidney, Philip

Arcadia , 178, 183n19

Astrophil and Stella, 156, 157, 160

A Defence of Poetry, 160, 174 
silent film, 171

Singapore

attitudes to race, 57

attitudes to Shakespeare, 55, 56

religious identity and sensitivity, 58,62

Sixteenth Century Society, 2017 Conference, 5

SJPACK (social justice pedagogical and content knowledge) framework, 227-8

implementation, 230-3

Skrebels, Paul, 22n22

slow violence, $124-5$

SOAP notes, 217

social justice education

emotional labor of, 237-8

intellectual benefits of, 235-6

intuitive $v s$. structured, 229-33

key features of, 4, 166

SJPACK framework, 227-8, 232-3

structural disincentives to, 210, 228-9

trend towards, 20

Socratic method, 107-8

Solnit, Rebecca: "Men Explain Things To Me," 31, 34

"Song of Praise, A" (Cullen), 90

sonnets, 155-61

Shakespeare's, 90, 161-3

Sophocles: Oedipus the King, 110

Spenser, Edmund, 47

Amoretti, 156

The Faerie Queene, 174, 181-2

Spicer, Sean, 1

stage directions, $167-8$

Stone Butch Blues (Feinberg), 39

Strachey, William: True Reportory of the Wrack, 180-1

student debt, 209

student empowerment, 10, 59-62, 232

co-creation of knowledge, 28, 166, 168

"flipping the classroom," 147

oppression as barrier to, 212-13

through democratizing classroom space, 162 through trigger warnings, 99-100, 101

see also collaborative and collective work

Summit, Jennifer, 6

Taming of the Shrew, The see 10

Things I Hate About You

Taylor, Holly, 104n10

teacher education, 225-9, 232-3

literature response assignments, 231, 232

Tempest, The , 76-7, 80, 180-1, 210; see also Caliban by the Yellow

Sands

Temple University: inside-out pedagogy, 202

10 Things I Hate About You, 209

testimonial oppression, 197, 198-200

text pairings, $31,72-4,118-19$

with "cross-dressing" comedies, 39,40

with Hamlet, 42-3

with Measure for Measure, 150-1

with More's Utopia, 181

with Othello, 29-31, 71-2, 119,

120-2, 149-50

with Romeo and Juliet, 151-2

with Sidney's Arcadia, 178

with Sonnets, 90

with The Tempest, 180-1

Thompson, Ayanna, 80, 81-2, 208

Teaching Shakespeare with a

Purpose (with Turchi), 5, 7, 8, 147, 172n3, 179, 228

Throne of Blood (Kurosawa), 50

Titus Andronicus, 98

Toomer, Jean: "Portrait in Georgia," 90

Tosh, Will, 36

tragedy

and Aristotle, 109-10, 116-17

establishing norms for engagement,

117-18 (see also trigger warnings)

as form of knowledge, 115-16

and getting lost (aporia), 108,

110-12

philosophical text pairings, 118-22 
transgender identity

and body dysphoria, 42

casting representation, 37

cross-dressing heroines and, 36-41

Hamlet and, 41, 42-3

trauma, 212; see also post-traumatic stress disorder

trigger warnings, 97-103

Trinidad and Tobago, 210-13

Trudell, Scott, 61

True Reportory of the Wrack (Strachey), 180-1

Trump, Donald

election victory, 134, 135, 136

inauguration crowd, 1

racial rhetoric, 82

sexual assault allegations, 137, 138

Tucson High School: Mexican-

American Studies (MAS)

program, 76-7, 78

Turchi, Laura (with Thompson):

Teaching Shakespeare with a

Purpose, 5, 7, 8, 147, 172n3, 179, 228

Twelfth Night

audience knowledge $v s$. reader

knowledge, 169-70

diverse interpretations, 170-1

and transgender experience, 36 , 39,40

uncertainty see ambiguity; disorientation and getting lost

"universality" of Shakespeare, 7-8, 55-6, 70, 73, 120-1

and white supremacy, 90, 91

universities see higher education

University of Pennsylvania:

Shakespeare portrait protest, 27,73

"Unstaged Scenes," 179

Urania (Wroth), 178

Utopia (More), 177-8

Vanderbilt University rape trial, 102-3

"Variation on a Theme Park"

(Mullen), 90 violence

in The Merry Wives of Windsor, 42

in Othello, 30-1, 121-2

in Trumpian politics, 136-7, 140-1

slow (environmental), 124-5

white supremacist, 85,89

see also Sagamihara massacre; sexual violence; trigger warnings

Wallace, David Foster, 108

Washick, Bonnie, 104n11

Weamys, Anna: A Continuation of

Sir Philip Sydney's Arcadia, 178

Wheeler, Lesley, 196n8

white supremacy, 2

early twentieth-century, 85,89

emotional challenge of, 98, 236

and loving blackness, 72

Shakespeare as icon of, 2, 7-8, 68-71

"Why I Stopped Hating Shakespeare" (Baldwin), 27-8

Williams, Jeffery, 209

Williams, Patricia J.: "The Obliging Shell," 119, 120-1, 122

Wilson, Woodrow, 89

Winter's Tale, The , 31, 34

Witmore, Michael, 7-8

"Woman's Got Soul" (The Impressions), 90

women

agency of, 60-2, 168

and legal neutrality, 120

and politics of sexual assault, 137-9

as reader-authors, 178-9

see also feminism

Woodson, Bob, 223n21

Work of Literature in an Age of PostTruth, The (Schaberg), 3

worker exploitation, 193

world-building, 174

and colonialism, 177, 180-2

digital collaboration, 182

diversity of participation, 178-9, 182

and ethics, 174-7, 182-3

Utopia, 177-8 
Wroth, Mary: Urania, 178

Wu Hsing-kuo: Lear Is Here, 59

Yōda, Hiroe, 48

Yoshino, Kenji, 8
YouTube

creative assignment using, 80 as resource, 81

U.S. Election Hub video (2012), 166-7 
